\title{
Bulk and surface property characterization of novel solid oxide fuel cell cathode materials
}

\author{
A Dissertation \\ Presented to \\ the faculty of the School of Engineering and Applied Science \\ University of Virginia \\ in partial fulfillment \\ of the requirements for the Degree \\ Doctor of Philosophy \\ in Chemical Engineering \\ by \\ Rosemary Ann Cox-Galhotra
}

May

2012 


\section{APPROVAL SHEET}

The dissertation

is submitted in partial fulfillment of the requirements

for the degree of

Doctor of Philosophy

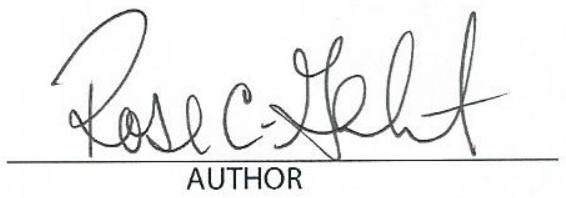

The dissertation has been read and approved by the examining committee:

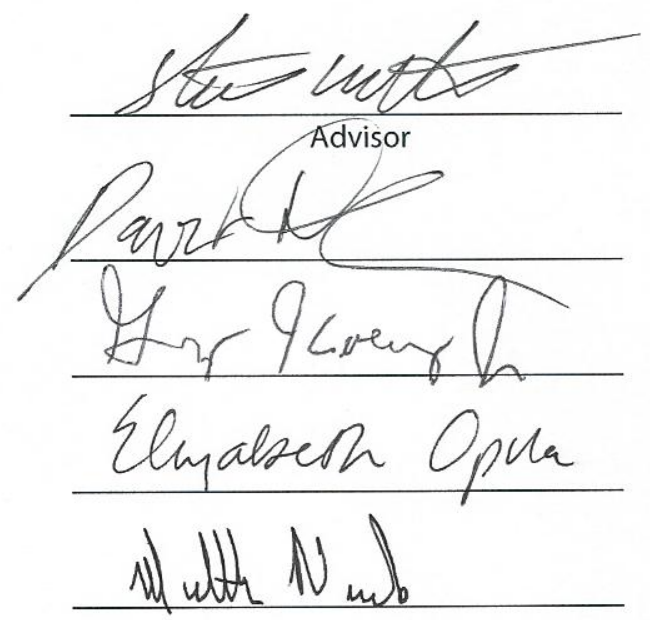

Accepted for the School of Engineering and Applied Science:

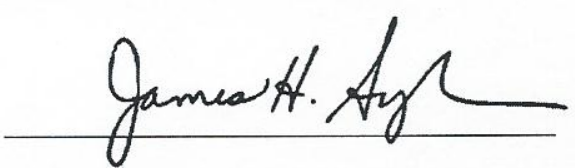

Dean, School of Engineering and Applied Science

May

2012 


\section{Acknowledgements}

First, I would like to thank my advisor, Prof. Steven Mclntosh, for his commitment to excellence and many helpful discussions. I would also like to thank Prof. Tor Grande at NTNU in Trondheim, Norway, for kindly allowing me to join his research group during the fall 2010 semester. I am grateful for his many insights into the preparation of solid oxide fuel cell materials, as well as Norwegian customs and culture. I would also like to thank Prof. Beth Opila at UVA for her many helpful discussions, and my former lab-mates, Maria Azimova, Michael van den Bossche and M. Ali Haider, for their help and encouragement. Last, but certainly not least, I would like to thank my husband, Lucas, for his unwavering patience, support, motivation and love.

Financial support from the National Science Foundation Graduate Research Fellowship was provided from May 2009 - May 2012, and has made the work in each chapter possible.

The research in Chapters 4 and 5 at Oak Ridge National Laboratory's Spallation Neutron Source was funded by the Scientific User Facilities Division, Office of Basic Energy Sciences, U.S. Department of Energy, and were done in collaboration with Ashfia Huq and Jason Hodges at ORNL.

The Research Council of Norway and the U.S. National Science Foundation provided funding through the Nordic Research Opportunity for the 5-month collaboration in Trondheim, Norway, at the Norwegian University of Science and Technology (NTNU) with Prof. Tor Grande, which resulted in Chapter 6. 


\section{Abstract}

The development of intermediate temperature solid oxide fuel cells (IT-SOFCs) with operating temperatures in the $500-700{ }^{\circ} \mathrm{C}$ range would provide cost savings, and thus commercial viability over traditional high temperature $\left(800-1000^{\circ} \mathrm{C}\right)$ SOFCs. However, at intermediate temperatures, the electrochemical processes within the cell become significantly slower due to high activation energies for ion transport and reactions at the electrodes, leading to decreased power output. A fundamental understanding of cathode processes, such as oxygen transport, and detailed structural information for bulk cathode materials are necessary for the development of IT-SOFCs.

Electrical conductivity relaxation (ECR) was utilized to determine the oxygen surface exchange coefficient, $k_{\text {chem, }}$ and bulk diffusion coefficient, $D_{\text {chem }}$, for $\mathrm{La}_{0.6} \mathrm{Sr}_{0.4} \mathrm{Co}_{0.2} \mathrm{Fe}_{0.8} \mathrm{O}_{3-\delta}(\mathrm{LSCF} 6428)$ materials at $1073 \mathrm{~K}\left(800{ }^{\circ} \mathrm{C}\right)$ in the 100 to $3.3 \% \mathrm{pO}_{2}$ range. The value of $k_{\text {chem }}$ varies by almost one order of magnitude depending on the number of terms chosen in the data fit. However, a precise determination of $k_{\text {chem }}$ can be accomplished by performing ECR with dense thin film model cathodes, allowing $D_{\text {chem }}$ to be eliminated from the analysis. LSCF 6428 samples were also individually surfacedoped with La, Sr, Co, and Fe, as well as with LSCF 6428 nanoparticles $(25-50 \mathrm{~nm})$ to investigate trends in $k_{\text {chem }}$ and $D_{\text {chem }}$. Fe surface doping caused a decrease in $k_{\text {chem }}$, while La, Sr, Co and nanoparticle doping did not affect the oxygen surface exchange or bulk diffusion coefficients.

$\mathrm{PrBaCO}_{2} \mathrm{O}_{5+\delta}(\mathrm{PBCO})$ layered perovskite polycrystalline thin films were deposited onto a polished polycrystalline $\mathrm{SrTiO}_{3}$ substrate using a spray pyrolysis technique. ECR was utilized to determine $k_{\text {chem }}$ in the $650-850 \mathrm{~K}\left(377-577^{\circ} \mathrm{C}\right)$ temperature range and $100 \%$ to $0.05 \% \mathrm{pO}_{2}$ range. The resulting values are higher than the values reported for some traditional single perovskite materials at intermediate temperature. 
Layered perovskites $\mathrm{NdBaCO}_{2} \mathrm{O}_{5+\delta}$ (NBCO) and $\mathrm{PrBaCo}_{2} \mathrm{O}_{5+\delta}$ (PBCO) were characterized using neutron powder diffraction under in-situ conditions: $550-825^{\circ} \mathrm{C}$ and $10^{-1}-10^{-4}$ atm oxygen. The tetragonal $(P 4 / \mathrm{mmm})$ space group provided the best fit for the data. Transport of oxygen through both materials via the vacancy hopping mechanism likely involves the nearest-neighbor oxygen sites in the Co-layer, in addition to the more vacant oxygen sites in the $\mathrm{Nd} / \mathrm{Pr}$ layer. Total oxygen stoichiometry values ranged from $5.51-5.11$ and $5.57-5.17$ for $\mathrm{NBCO}$ and $\mathrm{PBCO}$, respectively. The tetragonal lattice parameters for both materials showed crystal expansion with temperature. However, the crystal shortened in the $c$-direction with decreasing $\mathrm{pO}_{2}$ as all sites shifted toward the increasingly vacant $\mathrm{Nd} / \mathrm{Pr}-\mathrm{O}$ layer.

Finally, formation of $\mathrm{La}_{0.6} \mathrm{Sr}_{0.4} \mathrm{CoO}_{3}$ (LSC64) nanorods was attempted via direct hydrothermal synthesis, calcination of hydrothermal synthesis products and topochemical conversion of $\mathrm{La}(\mathrm{OH})_{3}$ nanorod templates. LSC64 nanorods were not formed during hydrothermal synthesis as reported previously. LSC was produced by calcination and topochemical conversion, but the rod structure was lost due to coarsening at temperatures as low as $500{ }^{\circ} \mathrm{C}$. These findings are discussed in terms of the kinetics and thermodynamics of the hydrothermal synthesis reaction, pointing to the thermodynamic instability of $\mathrm{LaCoO}_{3}$ at reaction conditions. 


\section{Table of Contents}

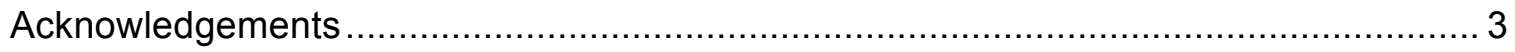

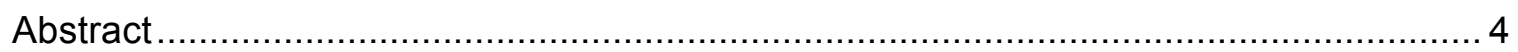

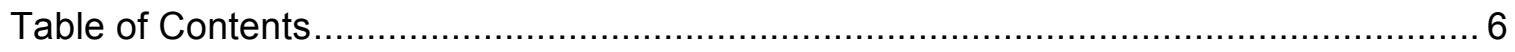

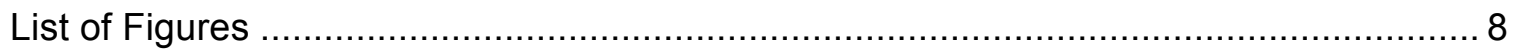

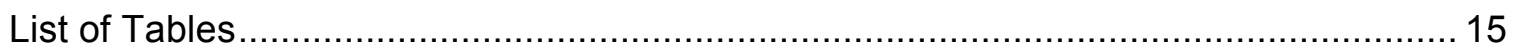

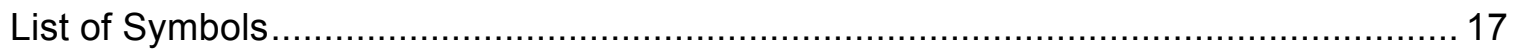

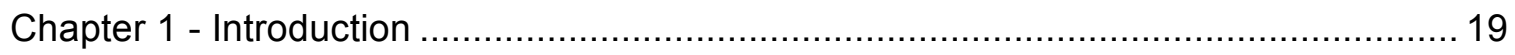

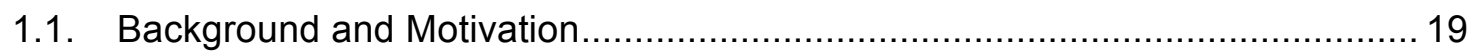

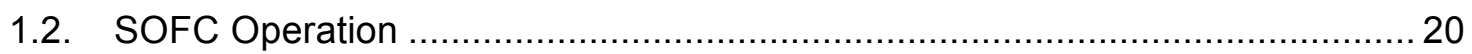

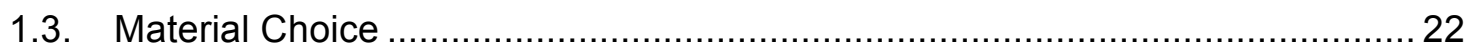

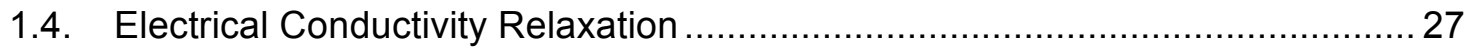

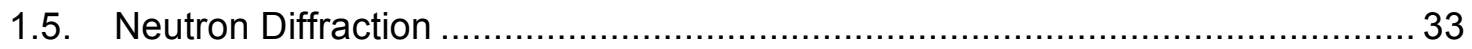

Chapter 2 - Unreliability of the Electrical Conductivity Relaxation Technique for a

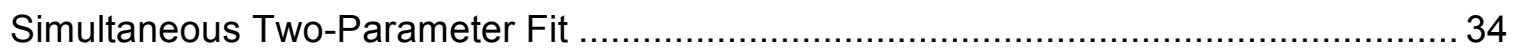

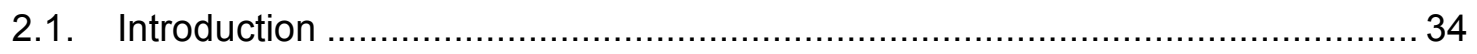

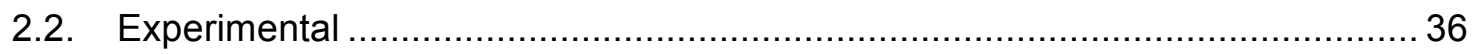

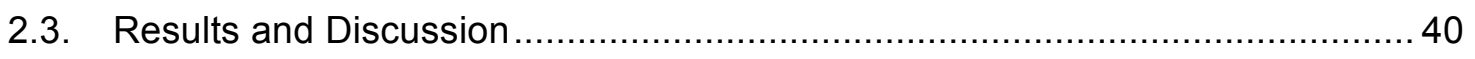

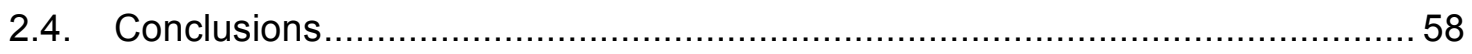

Chapter 3 - Electrical Conductivity Relaxation of Layered Perovskite Thin Films

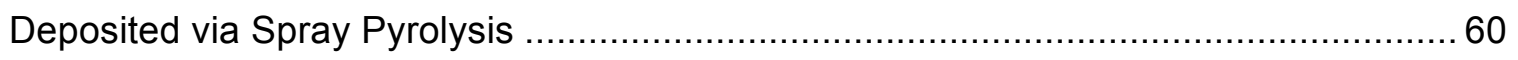

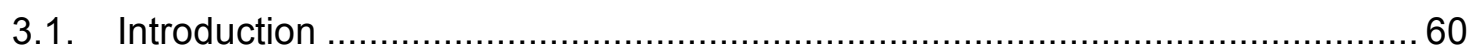




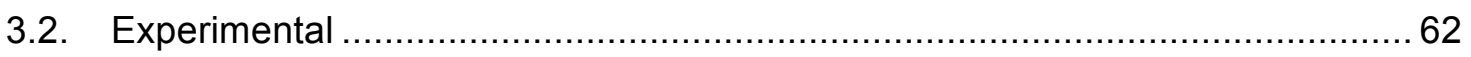

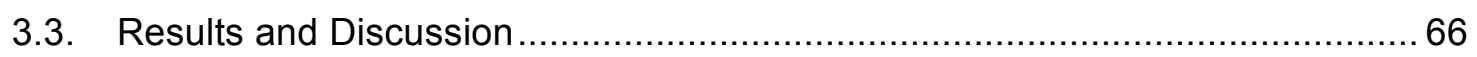

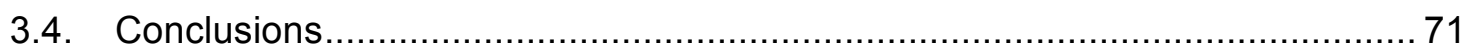

Chapter 4 - Neutron Diffraction of $\mathrm{NdBaCO}_{2} \mathrm{O}_{5+\delta}$ at in-situ SOFC Conditions ................ 72

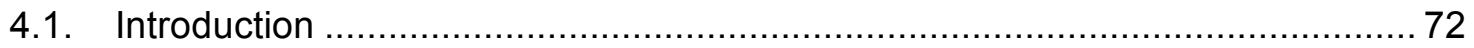

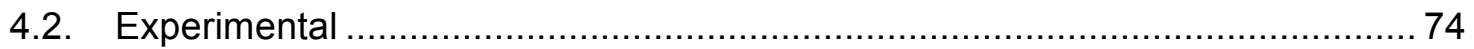

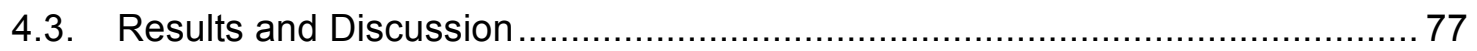

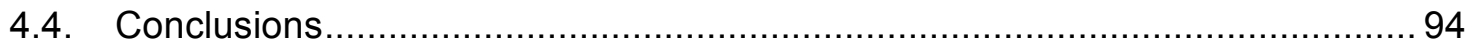

Chapter 5 - Neutron Diffraction of $\mathrm{PrBaCO}_{2} \mathrm{O}_{5+\delta}$ at in-situ SOFC Conditions ................96

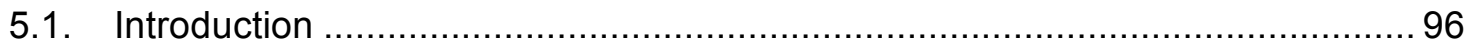

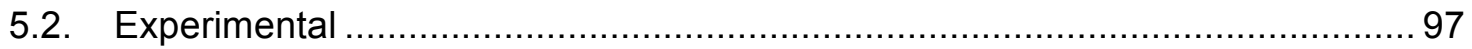

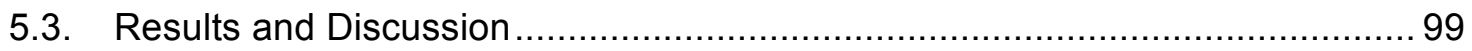

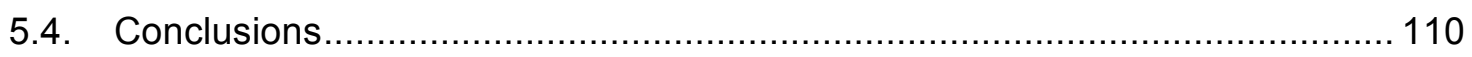

Chapter 6 - Attempts to Synthesize Perovskite Nanorods ................................. 111

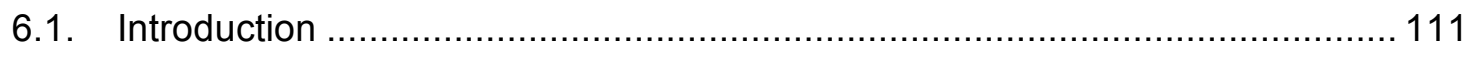

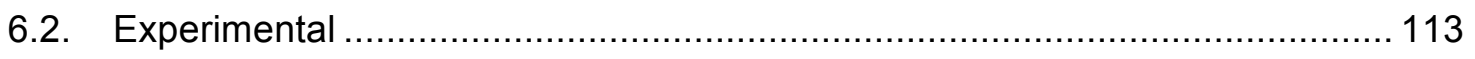

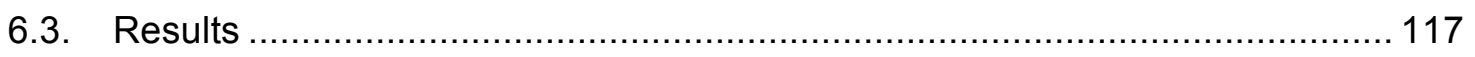

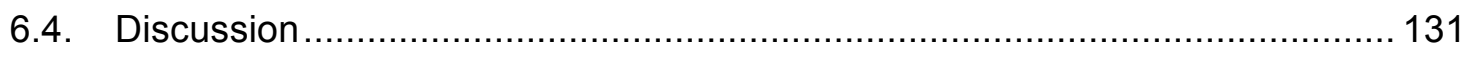

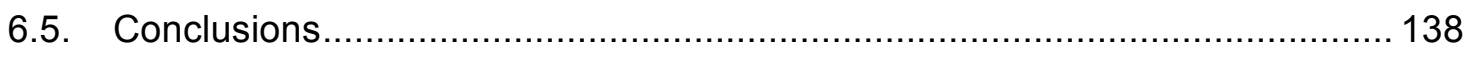

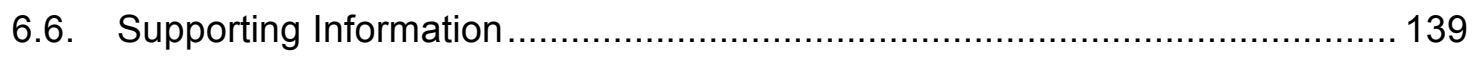

Summary and Recommendations for Future Work ....................................... 142

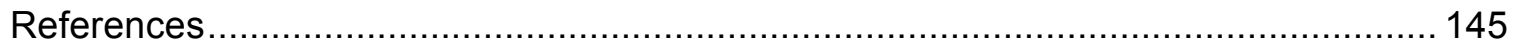




\section{List of Figures}

Figure 1. Diagram of an SOFC during operation.

21

Figure 2. Oxygen vacancy formation in a generalized perovskite crystal. 23

Figure 3. Double perovskite (A site ordering) shown with partial oxygen deficiency in the AO plane. 25

Figure 4. Oxygen transport in an MIEC cathode: (1) incorporation of gaseous oxygen at the surface (described by $k_{c h e m}$ ), (2) reduction to form an oxygen anion, and (3) diffusion through the bulk to the electrolyte (described by $D_{\text {chem }}$ ). 27

Figure 5. Electrical conductivity relaxation experimental setup. 29

Figure 6. X-Ray Diffraction pattern of crushed LSCF 6428 sample sintered in air at 1523 $\mathrm{K}\left(1250^{\circ} \mathrm{C}\right)$ for 12 hours. Perovskite peaks are indexed as $(\nabla)$. 41

Figure 7. SEM image showing top view of the surface grain structure of an unpolished LSCF 6428 sample sintered in air at $1523 \mathrm{~K}\left(1250{ }^{\circ} \mathrm{C}\right)$ for 12 hours, and then heated to $1073 \mathrm{~K}\left(800^{\circ} \mathrm{C}\right)$ for 140 hours in air.

Figure 8. Strontium binding energy peaks obtained with XPS for an as-synthesized LSCF 6428 sample and one heated to $1073 \mathrm{~K}\left(800^{\circ} \mathrm{C}\right)$ for over 150 hours in the $100 \%$ to $3.3 \% \mathrm{pO}_{2}$ range. $\mathrm{N}(\mathrm{E})$ refers to number of electrons counted at each binding energy.

Figure 9. Unmodified polished LSCF 6428 sample tested four consecutive times over the entire $100 \%$ to $3.3 \% \mathrm{pO}_{2}$ range at $1073 \mathrm{~K}\left(800{ }^{\circ} \mathrm{C}\right)$. Oxidation switches are plotted as a function of $\log \left[\mathrm{pO}_{2} / \mathrm{atm}\right]:(\mathrm{a}) \log \left[k_{c h e m} / \mathrm{cm} \mathrm{s}^{-1}\right]$; (b) $\log \left[D_{c h e m} / \mathrm{cm}^{2} \mathrm{~s}^{-1}\right]$. 44 
Figure 10. Normalized conductivity data from Trial 2 in Fig 4 (unmodified polished LSCF 6428 sample) plotted as a function of time over the $\mathrm{pO}_{2}$ switches from $29.3 \%$ to $16.0 \%$ and $16.0 \%$ to $29.3 \%$ : (a) $0-500 \mathrm{~s}$; (b) $50-150 \mathrm{~s}$. 45

Figure 11. Double-log plot of conductivity as a function of $\mathrm{pO}_{2}$ for unmodified polished LSCF 6428 sample (Trial 2 in Fig 4) compared with data from Ref [9, 45]. 46

Figure 12. Number of roots of $\beta, \gamma$, and $\phi$ in Eq. (4) were varied for an unmodified polished LSCF 6428 sample (Trial 2 in Fig 4) for the $100 \%$ to $54.7 \% p_{2}$ switch: (a) Log $\left[k_{\text {chem }} / \mathrm{cm} \mathrm{s}^{-1}\right]$; (b) Log $\left[D_{\text {chem }} / \mathrm{cm}^{2} \mathrm{~s}^{-1}\right]$. Both $k_{\text {chem }}$ and $D_{\text {chem }}$ are plotted with the residual square error, $S_{R}[$ Eqn. (21)] of the data fit. 50

Figure 13. Reduction switches are plotted as a function of $\log \mathrm{pO}_{2}$ for LSCF 6428 samples at $1073 \mathrm{~K}\left(800^{\circ} \mathrm{C}\right)$ with and without surface doping: (a) $\log \left[k_{\text {chem }} / \mathrm{cm} \mathrm{s}^{-1}\right]$; (b) $\log \left[D_{c h e m} / \mathrm{cm}^{2} \mathrm{~s}^{-1}\right]$.

Figure 14. TEM image of LSCF 6428 nanoparticles (25-50 nm diameter). 53

Figure 15. XRD of LSCF 6428 nanoparticles sintered in air at $1073 \mathrm{~K}\left(800{ }^{\circ} \mathrm{C}\right)$; unavoidable impurity phases are present and indexed as $(\diamond)$. 54

Figure 16. AFM images of sample with one addition of nanoparticles sintered to the surface before testing: (a) several particle clusters, height $\sim 30 \mathrm{~nm}$; (b) single nanoparticle cluster, height $\sim 43 \mathrm{~nm}$, width $\sim 350 \mathrm{~nm}$. 55

Figure 17. AFM images of sample after second addition of nanoparticles sintered to the surface and after more than 20 hours of testing at $1073 \mathrm{~K}\left(800^{\circ} \mathrm{C}\right)$ : (a) several particle clusters, height $\sim 25 \mathrm{~nm}$; (b) single nanoparticle cluster, height $\sim 28 \mathrm{~nm}$, width $\sim 400 \mathrm{~nm}$. 
Figure 18. Three samples tested at $1073 \mathrm{~K}\left(800{ }^{\circ} \mathrm{C}\right):(1)$ unmodified polished surface, (2) nanoparticles added, and (3) double amount of nanoparticles added: (a) Log [ $k_{\text {chem }}$ I $\left.\mathrm{cm} \mathrm{s}^{-1}\right]$ for reduction switches with lines denoting the average between the oxidation and reduction switches; (b) $\log \left[D_{c h e m} / \mathrm{cm}^{2} \mathrm{~s}^{-1}\right]$.... 57

Figure 19. Experimental setup for spray pyrolysis thin film deposition. 63

Figure 20. SEM images of as-synthesized PBCO thin films: (a) surface morphology; (b) cross-section with film and substrate labeled. 66

Figure 21. XRD of PBCO thin film. Peaks are indexed as marked: $-\mathrm{PBCO}$ $\mathrm{SrTiO}_{3} ; \square-\mathrm{Pr} ; \bullet-\mathrm{Co}$ 67

Figure 22. Normalized conductivity data and model fit for PBCO thin film at $427^{\circ} \mathrm{C}(700$ K) during the $\mathrm{pO}_{2}$ switch from $10 \%$ to $2 \%$ oxygen. For clarity, only a fraction of the collected raw data points are shown. 68

Figure 23. PBCO thin film: $k_{\text {chem }}$ as a function of temperature, $650-850 \mathrm{~K}(377-577$ $\left.{ }^{\circ} \mathrm{C}\right)$, for the step change from $10 \%$ to $2 \%$ oxygen. 70

Figure 24. PBCO thin film: $\log k_{\text {chem }}$ as a function of log pO2 (100\% to $0.05 \%$ oxygen) at $700-850 \mathrm{~K}\left(427-577^{\circ} \mathrm{C}\right)$. 70

Figure 25. Schematic of neutron diffraction experimental setup. Note that the basket is hanging from the end of a sealed quartz tube of similar diameter (not depicted). 75

Figure 26. Semi-logarithmic plot of effluent gas oxygen content for inlet mixtures of $10^{-1}$ atm oxygen at $550{ }^{\circ} \mathrm{C}$ and $650{ }^{\circ} \mathrm{C}$ (left side), and $10^{-4}$ oxygen at $750{ }^{\circ} \mathrm{C}$ and $825^{\circ} \mathrm{C}$ (right side). 
Figure 27. Lattice parameters $(P 4 / \mathrm{mmm})$ for NBCO at: (a) $10^{-1}$ atm oxygen at $550{ }^{\circ} \mathrm{C}$ and (b) $10^{-4} \mathrm{~atm}$ oxygen at $825^{\circ} \mathrm{C}$ during the equilibration prior to recording the neutron diffraction pattern at these conditions. Error bars are smaller than the data symbols. ...79

Figure 28. NBCO Model $1(P 4 / \mathrm{mmm}): 10^{-1} \mathrm{~atm}$ oxygen at $550{ }^{\circ} \mathrm{C}$. The entire pattern is shown in (a). Patterns consist of observed (circles), calculated (top line), and difference (bottom line) data. Theoretical Bragg reflection positions are marked with vertical lines. A detailed view of the boxed area indicated in the top figure is shown in (b) with Bragg reflections marked for (i) $P 4 / \mathrm{mmm}$ and (ii) Pmmm space groups. 85

Figure 29. Crystal structure of $\mathrm{NdBaCo}_{2} \mathrm{O}_{5+\delta}$ in the $P 4 / \mathrm{mmm}$ space group: (a) Model 1 with $\mathrm{O} 3$ site vacancies shown; (b) Model 2, split $\mathrm{Nd}$ and $\mathrm{O} 2$ sites, with $1 / 4$ of the unit cell shown. $50 \%$ probability thermal ellipsoids are illustrated for all sites, but $\mathrm{Nd}, \mathrm{O} 3, \mathrm{O} 2 \mathrm{a}$, and $\mathrm{O} 2 \mathrm{~b}$ sites in (b) have isotropic thermal parameters and are thus spherical. 87

Figure 30. Oxygen stoichiometry with temperature for $P 4 / \mathrm{mmm}$ Models 1 and 2 with $p \mathrm{O}_{2}$ values: (a) $10^{-1} \mathrm{~atm}$; (b) $10^{-2} \mathrm{~atm}$; (c) $10^{-3} \mathrm{~atm}$; (d) $10^{-4} \mathrm{~atm}$. 88

Figure 31. $P 4 / \mathrm{mmm}$ Model 1 change in $\mathrm{O} 1-\mathrm{Co}-\mathrm{O} 2$ bond angle with fractional $\mathrm{O} 3$ site occupancy as a function of temperature and $\mathrm{pO}_{2}$. Error bars are smaller than the data symbols. 90

Figure 32. $\mathrm{P} 4 / \mathrm{mmm}$ Model 1 : change in (a) Co-O1 bond length and (b) Co-O3 bond length with fractional $\mathrm{O} 3$ site occupancy as a function of temperature and $\mathrm{pO}_{2}$. Error bars for fractional $\mathrm{O} 3$ site occupancy are smaller than the data symbols. 91

Figure 33. Tetragonal $(P 4 / \mathrm{mmm})$ lattice parameters for each $\mathrm{pO}_{2}$ range. Error bars are smaller than the symbols used in the figure. All tetragonal models yielded identical lattice parameters to within three decimal places. 92 
Figure 34. P4/mmm Model 2: (a) fractional position of $\mathrm{Nd}(x, y)$ and (b) O2a-O2b site distance, both plotted with fractional $\mathrm{O} 3$ site occupancy for the Temperature and $\mathrm{pO}_{2}$ range studied. Error bars for $\mathrm{O} 3$ occupancy and $\mathrm{O} 2 \mathrm{a}-\mathrm{O} 2 \mathrm{~b}$ distance are smaller than the data symbols .94

Figure 35. Lattice parameters for $\mathrm{PBCO}$ during equilibration prior to recording the neutron diffraction pattern at (a)10-1 atm oxygen at $550{ }^{\circ} \mathrm{C}$ and (b) $10^{-4}$ atm oxygen at $825^{\circ} \mathrm{C}$. 100

Figure 36. Crystal structure of $\mathrm{PrBaCO}_{2} \mathrm{O}_{5+\delta}$ in the $P 4 / m m m$ space group with thermal ellipsoids (50\% probability) for the $10^{-1}$ atm oxygen at $825^{\circ} \mathrm{C}$ data set. 102

Figure 37. Rietveld fit of neutron diffraction pattern for PBCO $(P 4 / \mathrm{mmm}) 10^{-1} \mathrm{~atm}$ oxygen at $825{ }^{\circ} \mathrm{C}$. The entire pattern is shown in (a) and consist of observed (circles), calculated (top line), and difference (bottom line) data. Theoretical Bragg reflection positions are marked with vertical lines. A detailed view of the boxed area indicated in the top figure is shown in (b) with Bragg reflections marked for (i) $\mathrm{CoO}(\mathrm{Fm} 3 \mathrm{~m})$ secondary phase, and (ii) PBCO $(P 4 / \mathrm{mmm})$ phase. 105

Figure 38. Oxygen stoichiometry of PBCO with temperature and $\mathrm{pO}_{2}$ 106

Figure 39. Change in $\mathrm{O} 1-\mathrm{Co}-\mathrm{O} 2$ bond angle with fractional $\mathrm{O} 3$ site occupancy as a function of temperature and $\mathrm{pO}_{2}$. Error bars are smaller than the data symbols 107

Figure 40. (a) Co-O1 bond length and (b) $\mathrm{Co}-\mathrm{O} 3$ bond length with fractional $\mathrm{O} 3$ site occupancy as a function of temperature and $\mathrm{pO}_{2}$. Error bars for $\mathrm{O} 3$ site occupancy are smaller than the data symbols and are not plotted. 108 
Figure 41. Tetragonal $(P 4 / \mathrm{mmm})$ lattice parameters for each $\mathrm{pO}_{2}$ range. Error bars are smaller than the symbols used in the figure. 109

Figure 42. (a) XRD of washed hydrothermal synthesis product. Phases are labeled as: * $\mathrm{La}(\mathrm{OH})_{3}$ (ICDD PDF\# 01-083-2034) $\square-\mathrm{Co}_{3} \mathrm{O}_{4}$ (PDF\# 01-076-1802), O-CoO (PDF\# 01-078-0431). Miller indices are added for the largest $\mathrm{La}(\mathrm{OH})_{3}$ peaks. (b) FEG-SEM image of same material. Examples of structures other than nanorods are circled. 118

Figure 43. TEM images of nanorods present in washed synthesis product. 119

Figure 44. TEM images of nanorods and other hydrothermal synthesis product structures. EDS analysis is provided for the indicated areas. 120

Figure 45. FEG-SEM images of washed synthesis products calcined at (a) $400{ }^{\circ} \mathrm{C}$ for 2 $\mathrm{h}+650{ }^{\circ} \mathrm{C}$ for $2 \mathrm{~h},(\mathrm{~b}) 800^{\circ} \mathrm{C}$ for $2 \mathrm{~h}$, and (c) $900{ }^{\circ} \mathrm{C}$ for $2 \mathrm{~h}$. 124

Figure 46. TG / DSC of washed, uncalcined hydrothermal synthesis product during heating from $180{ }^{\circ} \mathrm{C}$ to $1000{ }^{\circ} \mathrm{C}$. Dashed line refers to TG; solid line refers to DSC... 125

Figure 47. XRD spectrum of (i) phase pure $\mathrm{La}(\mathrm{OH})_{3}$ (IDCC PDF\# 04-005-8587) via mild hydrothermal synthesis, and (ii) this material after calcination at $400{ }^{\circ} \mathrm{C} 2 \mathrm{~h}+650{ }^{\circ} \mathrm{C} 2 \mathrm{~h}$. Labeled phases: - $\mathrm{La}_{2} \mathrm{O}_{3}$ (PDF\# 00-005-0602), •-La $\mathrm{CO}_{5}(\mathrm{PDF}$ 00-023-0320) ....... 126

Figure 48. SEM images of $\mathrm{La}(\mathrm{OH})_{3}$ nanorods (a) as synthesized, and (b) after calcination at $400^{\circ} \mathrm{C} 2 \mathrm{~h}+650^{\circ} \mathrm{C} 2 \mathrm{~h}$. 127

Figure 49. XRD spectra of two-step synthesis products after calcination at (i) $800^{\circ} \mathrm{C}, 2 \mathrm{~h}$, (ii) $400{ }^{\circ} \mathrm{C} 2 \mathrm{~h}+, 650{ }^{\circ} \mathrm{C} 2 \mathrm{~h}$, (iii) $500^{\circ} \mathrm{C}$, 8h. Labeled phases: $\diamond-\mathrm{La}_{1-\mathrm{x}} \mathrm{Sr}_{\mathrm{x}} \mathrm{CoO}_{3}, \square-$-unknown, - $-\mathrm{SrCO}_{3}($ ICDD PDF\# 00-005-0418). 128 
Figure 50. SEM images of two-step synthesis products after calcination at (a) $800{ }^{\circ} \mathrm{C}$, $2 \mathrm{~h},(\mathrm{~b}) 400{ }^{\circ} \mathrm{C} 2 \mathrm{~h}+, 650{ }^{\circ} \mathrm{C} 2 \mathrm{~h},(\mathrm{c}) 500^{\circ} \mathrm{C}, 8 \mathrm{~h}$. 129

Figure 51. XRD spectra of (i) Phase pure untreated $\mathrm{La}_{0.6} \mathrm{Sr}_{0.4} \mathrm{CoO}_{3}$ powder (ii) product after LSC64 powder was subjected to mild hydrothermal conditions, (iii) product after LSC64 powder was annealed in $\mathrm{N}_{2}$ and then subjected to mild hydrothermal conditions. Labeled phases: $\bullet-\mathrm{La}_{0.6} \mathrm{Sr}_{0.4} \mathrm{CoO}_{3}\left(\mathrm{ICDD}\right.$ PDF\# 00-048-0121), $-\mathrm{La}(\mathrm{OH})_{3}($ ICCD PDF\# 00-036-1481), $\mathbf{\square}-\mathrm{SrCO}_{3}($ ICDD PDF\# 01-017-0213). ........................................ 130 


\section{List of Tables}

Table 1. Approximate bulk total conductivity $(\sigma)$ values for selected perovskite materials in air. Asterisk indicates double perovskites. 26

Table 2. Average outlet $\mathrm{pO}_{2}(\mathrm{~atm})$ at equilibrium for each temperature and inlet gas mixture. 79

Table 3. Rietveld fit parameters for NBCO orthorhombic $(P m m m)$ model at $550^{\circ} \mathrm{C}$ and a $\mathrm{pO}_{2}$ of $10^{-1} \mathrm{~atm}$ with sites: $\mathrm{Nd} 2 p(0.5$ y 0.5$)$; $\mathrm{Ba} 20(0.5$ y 0$)$; Co1 $2 r(00.5 \mathrm{z})$; Co2 $2 q(0$

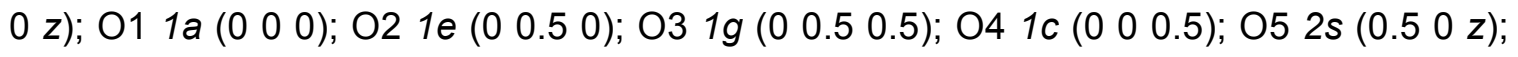
O6 $2 t(0.50 .5 z) ; 074 u(0 y z)$ 81

Table 4. Tetragonal $(P 4 / \mathrm{mmm})$ Rietveld fit parameters for $\mathrm{NBCO}$ at $550^{\circ} \mathrm{C}$ and a $\mathrm{pO}_{2}$ of $10^{-1} \mathrm{~atm}$ refined using: (a) Model 1, with sites: Nd 1c (0.5 0.5 0); Ba $1 d$ (0.5 0.5 0.5); Co $2 g(0 \quad 0$ z); O1 1b (0 0 0.5); O2 4i (0 0.5 z); O3 1a (0 0 0); (b) Model 2, with same Ba, Co, O1, $\mathrm{O} 3$ sites as Model 1, but $\mathrm{Nd} 4 j(x$ y 0$)$ and $\mathrm{O} 2 \mathrm{a} / \mathrm{b} 4 i\left(\begin{array}{lll}0 & 0.5 z\end{array}\right)$ 84

Table 5. Average outlet $\mathrm{pO}_{2}(\mathrm{~atm})$ at equilibrium for each temperature and inlet gas mixture. 101

Table 6. Rietveld fit parameters for $\mathrm{PBCO}$ at $825^{\circ} \mathrm{C}$ and $p \mathrm{O}_{2}$ of $10^{-1}$ atm refined using a tetragonal $(P 4 / \mathrm{mmm})$ model, with sites: $\operatorname{Pr} 1 c(0.50 .50)$; Ba $1 d(0.50 .50 .5)$; Co $2 g(00$ z); O1 1b (0 0 0.5); O2 4i (0 0.5 z); O3 1a ( $\left.\begin{array}{llll}0 & 0 & 0\end{array}\right)$ 104

Table 7. Conditions and phases observed in washed hydrothermal synthesis products. Average width, length and aspect ratio of nanorods present are included. 121

Table 8. Calcination of washed hydrothermal synthesis product: conditions and observed phases. 123 
Table 9. Thermodynamic properties of species involved in the formation of $\mathrm{LaCoO}_{3} . .134$

Table 10. Solubility product constant and concentration of cation in solution for $\mathrm{Sr}^{2+}$, $\mathrm{Co}^{2+}$, and $\mathrm{La}^{3+}$ in three different solution environments. 


\section{List of Symbols}

$\begin{array}{ll}D_{\text {chem }} & \text { bulk oxygen diffusion coefficient }\left(\mathrm{cm}^{2} / \mathrm{s}\right) \\ \mathrm{E}_{0} & \text { reversible potential }(\mathrm{V}) \\ \mathrm{F} & \text { Faraday's constant }(96485 \mathrm{C} / \mathrm{mol}) \\ \mathrm{I} & \text { current }(\mathrm{A}) \\ \mathrm{L} & \text { film thickness }(\mathrm{cm}) \\ \mathrm{R} & \text { gas constant }(8.314 \mathrm{~J} / \mathrm{mol}-\mathrm{K}) \\ \mathrm{S} & \text { surface area }\left(\mathrm{cm}^{2}\right) \\ \mathrm{T} & \text { temperature }\left(\mathrm{K} \mathrm{or}^{\circ} \mathrm{C}\right)\end{array}$

a, b, c lattice parameters for a crystal structure $(\AA)$

d interplanar crystal lattice spacing $(\AA)$

$k_{\text {chem }} \quad$ oxygen surface exchange coefficient $(\mathrm{cm} / \mathrm{s})$

I film thickness $(\mathrm{cm})$

$m \quad$ mass $(\mathrm{kg})$

$n \quad$ number of electrons transferred

$\mathrm{pO}_{2} \quad$ partial pressure of oxygen

$\mathrm{pX} \quad$ partial pressure of component $\mathrm{X}$

$t \quad$ time (s)

$v \quad$ volume $\left(\mathrm{cm}^{3}\right)$

$w, x, y, z \quad$ dimensions of a rectangular bar sample $(\mathrm{cm})$

$\beta_{\mathrm{m}} \quad$ positive, non-zero root of Eqn. (11)

$\gamma_{n} \quad$ positive, non-zero root of Eqn. (11)

$\delta \quad$ oxygen non-stoichiometry 
$\phi_{\mathrm{p}}$

$\theta$

$\sigma$ positive, non-zero root of Eqn. (11)

angle (degrees)

conductivity $(\mathrm{S} / \mathrm{cm})$

positive charge relative to the lattice in Kröger-Vink notation negative charge relative to the lattice in Kröger-Vink notation no net charge relative to the lattice in Kröger-Vink notation 


\section{Chapter 1 - Introduction}

\subsection{Background and Motivation}

The rising cost of crude oil and the need to lower $\mathrm{CO}_{2}$ emissions have resulted in the demand for more efficient use of fossil fuel resources, as well as the ability to utilize bio-derived hydrocarbon fuels. Solid oxide fuel cells (SOFCs) are a promising technology that provides direct, efficient conversion of chemical energy stored in fuel to electrical energy. Operating temperatures of $800-1000{ }^{\circ} \mathrm{C}$ are necessary to ensure high power density, affording advantages over low temperature fuel cells, such as fuel flexibility (fossil as well as bio-derived hydrocarbons), higher tolerance for traditional catalyst poisons like sulfur, and the production of a pure $\mathrm{CO}_{2}$ stream that can be easily sequestered [1, 2]. However, this operating temperature also limits the commercial viability of the technology due to increased cost of materials, accelerated thermal degradation, and complicated system start-up and shut-down [1, 3].

There are significant efforts within the SOFC community toward the development of intermediate temperature fuel cells (IT-SOFCs), which operate in the $500-700{ }^{\circ} \mathrm{C}$ range, offering reduced costs (increased durability/lifetime) and less difficult use/maintenance, leading to increased commercial viability over high temperature SOFCs. However, decreased operating temperatures lead to increased overpotentials (voltage losses) due to higher activation energies for ion transport in the electrolyte and for the electrode reactions $[1,2]$. The cathode is the subject of much study because of the relatively high activation energy for oxygen reduction, which leads to significantly slower kinetics at lower temperatures [1, 3]. A fundamental understanding of the processes occurring in the cathode, such as oxygen transport, and detailed structural information on bulk cathode materials are necessary for the development of materials tailored for use in IT-SOFCs. 


\subsection{SOFC Operation}

Like all electrochemical cells, solid oxide fuel cells (SOFCs) consist of three main components: an anode, a cathode, and an electrolyte. A schematic of an oxygen anion conducting SOFC is shown in Figure 1. During operation, fuel (in this case, hydrogen) is supplied to the anode and is oxidized to form $\mathrm{H}_{2} \mathrm{O}$ :

$\mathrm{H}_{2(g)}+\mathrm{O}^{2-} \rightarrow \mathrm{H}_{2} \mathrm{O}_{(g)}+2 e^{-}$

Two electrons are produced per mole of $\mathrm{H}_{2}$ that reacts, and they flow to the cathode through an external circuit. In the cathode, oxygen (typically from air) is reduced to form oxygen anions using these electrons:

$1 / 2 \mathrm{O}_{2(g)}+2 e-\rightarrow \mathrm{O}^{2-}$

Oxygen anions migrate through the dense ceramic electrolyte to reach the anode and react with hydrogen to complete the energy generation circuit. [1, 2] 


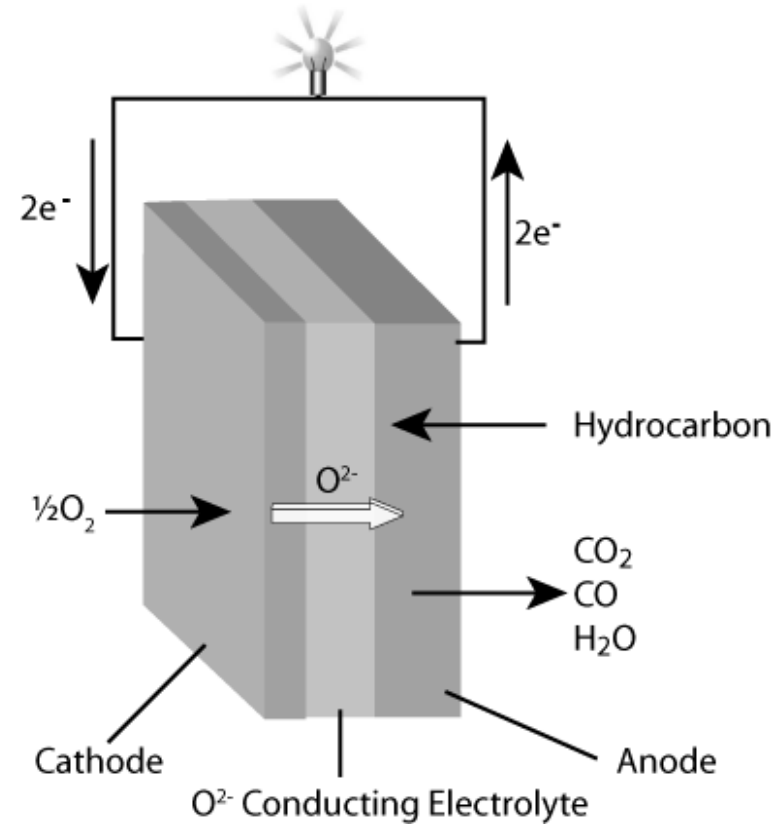

Figure 1. Diagram of an SOFC during operation.

The thermodynamic driving force for cell operation is the difference in the electrochemical potential of oxygen across the cell. The maximum theoretical cell potential occurs at open circuit potential (OCP). The Nernst equation describes the maximum theoretical cell potential under the conditions that the cell is in electrochemical equilibrium and only oxygen anions are conducted through the electrolyte. For the example of $\mathrm{H}_{2}$ fuel the Nernst equation becomes [2]:

$E=\frac{R T}{2 F} \ln \left(\frac{p O_{2, \text { cathode }}^{0.5}}{p O_{2, \text { anode }}^{0.5}}\right)=E_{0}-\frac{R T}{2 F} \ln \left(\frac{p H_{2, \text { anode }} p O_{2, \text { cathode }}^{0.5}}{p H_{2} O_{\text {anode }}}\right)$

where $E$ is the open circuit potential, $E_{0}$ is the reversible potential, $R$ is the gas constant, T is temperature, $\mathrm{F}$ is Faraday's constant, $\mathrm{pO}_{2}, \mathrm{pH}_{2}, \mathrm{pH}_{2} \mathrm{O}$ are partial pressures, and 2 is the number of electrons transferred. The partial pressure of oxygen at the anode in 
Equation 3 was calculated using partial pressures of the products and reactants of the overall fuel cell equation [4]:

$\mathrm{H}_{2(g)}+1 / 2 \mathrm{O}_{2(g)} \rightarrow \mathrm{H}_{2} \mathrm{O}_{(g)}$

\subsection{Material Choice}

In general, the cathode must have: (1) high electrocatalytic activity to ensure rapid oxygen reduction kinetics, (2) high electronic conductivity to ensure that electrons are readily available for consumption during oxygen reduction, (3) high ionic conductivity to extend the reduction reaction into the electrode and ensure rapid oxygen anion delivery to the electrolyte, (4) chemical and structural stability at high temperature to prevent physical damage during operation, and (5) compatibility with the electrolyte, often yttria-stabilized zirconia (YSZ), to prevent the formation of deleterious secondary phases at the interface [1, 4-6]. For the reasons outlined above, mixed ion and electron conductors (MIEC) are typically used as cathode materials [3].

Perovskite-structured oxides have the general formula $A B O_{3-\delta}$ where $\delta$ refers to the oxygen non-stoichiometry, which is the oxygen deficiency in the crystal lattice. Figure 2 shows the structure of a cubic perovskite. For SOFC cathode materials, the A site cation is typically La, Sr, Ba or Ca, while the B site is a transition metal such as Fe, Co or Mn [4]. Perovskites are commonly used in SOFC applications because of their ability to accommodate high concentrations of A and B site dopants and oxygen vacancies. Dopants provide enhanced electronic conductivity and catalytic activity, while oxygen vacancies provide enhanced ionic conductivity [2-4]. Ion conductivity occurs through a mechanism in which oxygen vacancies hop between energetically equivalent oxygen anion lattice sites [7]. 


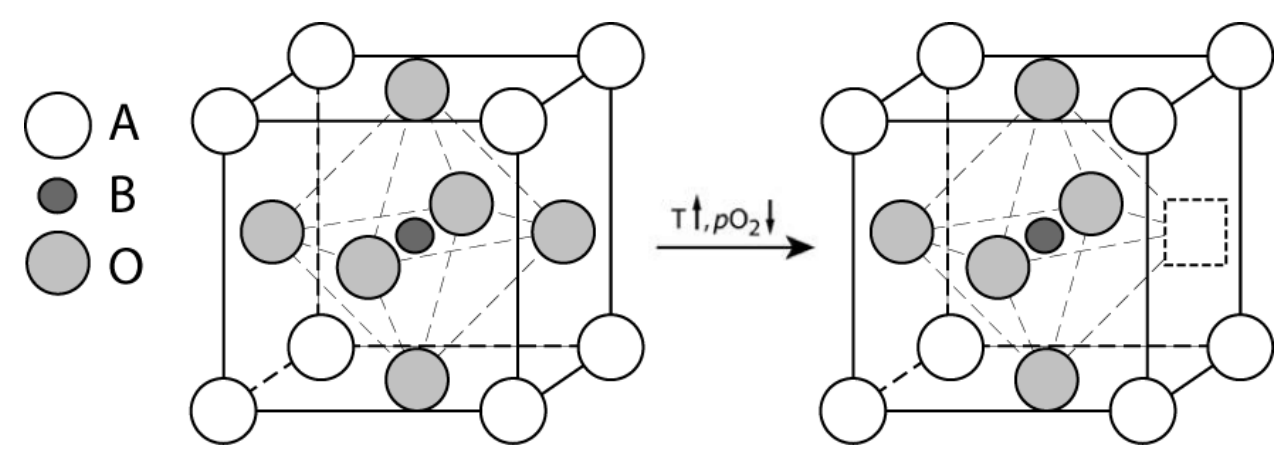

Figure 2. Oxygen vacancy formation in a generalized perovskite crystal.

Oxygen vacancies $(\delta>0)$ are produced in the lattice by altering the environment of the material through increased temperature and/or decreased $\mathrm{pO}_{2}$, and electroneutrality is maintained through reduction of the B-site cation [5, 7]. Aliovalent doping of the A site leads to charge compensation through either oxidation of the B site or formation of oxygen vacancies [5, 7]. Kröger-Vink notation[8] is used to illustrate point defects in the crystal lattice. Neutral, positive, and negative charges relative to the base lattice are represented as $\mathrm{X},(\cdot)$, and ('), respectively. For example, when $\mathrm{Sr}^{2+}$ is added to the A-site of $\mathrm{LaFeO}_{3}$ to obtain $\mathrm{La}_{1-\mathrm{x}} \mathrm{Sr}_{x} \mathrm{FeO}_{3}$, electroneutrality is maintained by iron adopting a net one positive charge $\left(\mathrm{Fe}^{4+}\right)$ relative to its base lattice site $\left(\mathrm{Fe}^{3+}\right)[5,9]$ :

$$
\mathrm{SrFeO}_{3} \stackrel{\mathrm{LaFeO}_{3}}{\longrightarrow} \mathrm{Sr}_{\mathrm{La}}^{\prime}+\mathrm{Fe}_{\mathrm{Fe}}^{\cdot}+3 \mathrm{O}_{\mathrm{O}}^{X}
$$

where $\mathrm{Sr}_{\mathrm{La}}^{\prime}$ is $\mathrm{Sr}^{2+}$ on a lanthanum lattice site, resulting in a net negative charge relative to the base lattice, and $F e_{F e}^{\cdot}$ is iron on its lattice site with a positive charge relative to the base lattice. $\mathrm{Fe}_{\mathrm{Fe}}^{\cdot}$ serves as a $p$-type charge carrier (electron hole) resulting in electronic conduction $[5,9]$. However, it may be reduced to form an oxygen vacancy: 
$2 F e_{F e}^{\cdot}+O_{O}^{X} \leftrightarrow 2 F e_{F e}^{X}+V_{O}^{* \bullet}+1 / 2 O_{2(\mathrm{~g})}$

These electronic (Eqn. 5) and ionic (Eqn. 6) charge compensation mechanisms are competitive and dependent on temperature, as well as $\mathrm{pO}_{2}$ conditions. At high $p \mathrm{O}_{2}$, electronic compensation dominates as Eqn. 6 shifts to the left. As $\mathrm{pO}_{2}$ decreases, the electronic conductivity decreases though conversion of charge carriers into oxygen vacancies, shifting Eqn. 6 to the right (ionic compensation) [5, 9]. Under SOFC operating conditions the electronic conductivity of the cathode material is typically orders of magnitude higher than ionic conductivity due to the high $\mathrm{pO}_{2}[9,10]$. The mixed oxidation states of the transition metal B sites allow for transport of electrons for $n$-type conduction (i.e. $F e_{F e}^{\prime}$ ) or holes for $p$-type conduction (i.e. $F \vec{e}_{F e}$ ), though the latter most commonly occurs in oxygen anion conducting SOFC cathodes due to the high operating $p \mathrm{O}_{2}[11]$.

Perovskite materials of the form $\mathrm{La}_{1-x} \mathrm{Sr}_{\mathrm{x}} \mathrm{Co}_{1-y} \mathrm{Fe}_{y} \mathrm{O}_{3-\delta}$ have been chosen for portions of the work presented due to their high performance as MIEC cathode materials $[1,9,11-13]$. As previously discussed, the addition of $\mathrm{Sr}^{2+}$ to the $\mathrm{A}$ site results in the formation of oxygen vacancies and/or increased electronic conductivity. On the B site, $\mathrm{Fe}^{3+}$ and $\mathrm{Co}^{2+}$ both act as catalysts for the reduction of oxygen under cathode conditions. However, $\mathrm{Co}^{2+}$ provides increased electronic and ionic conductivity, but decreased structural stability due to thermal and chemical expansion [14], while $\mathrm{Fe}^{3+}$ provides added structural stability at the expense of ion conductivity. [4, 11]

Double perovskites are layered perovskites with the general structure $A A^{\prime} B_{2} O_{6}$ (Figure 3) and are comprised of two single perovskite unit cells. The B atoms have 6-fold oxygen coordination, residing inside $\mathrm{BO}_{6}$ octahedra, while $A$ or $A^{\prime}$ atoms have 12 -fold oxygen coordination and are located inside the cavity outlined by $8 \mathrm{BO}_{6}$ octahedra. Double perovskites include alternating $A$ and $A^{\prime}$ atoms in the $\left(\begin{array}{lll}0 & 0 & 1\end{array}\right)$ direction $[4,15]$. If $A^{\prime}$ 
has a lower valence than $A$, the structure becomes oxygen-deficient relative to the fully stoichiometric material and the crystal becomes $\mathrm{AA}^{\prime} \mathrm{B}_{2} \mathrm{O}_{5+\delta} .[4,16,17]$

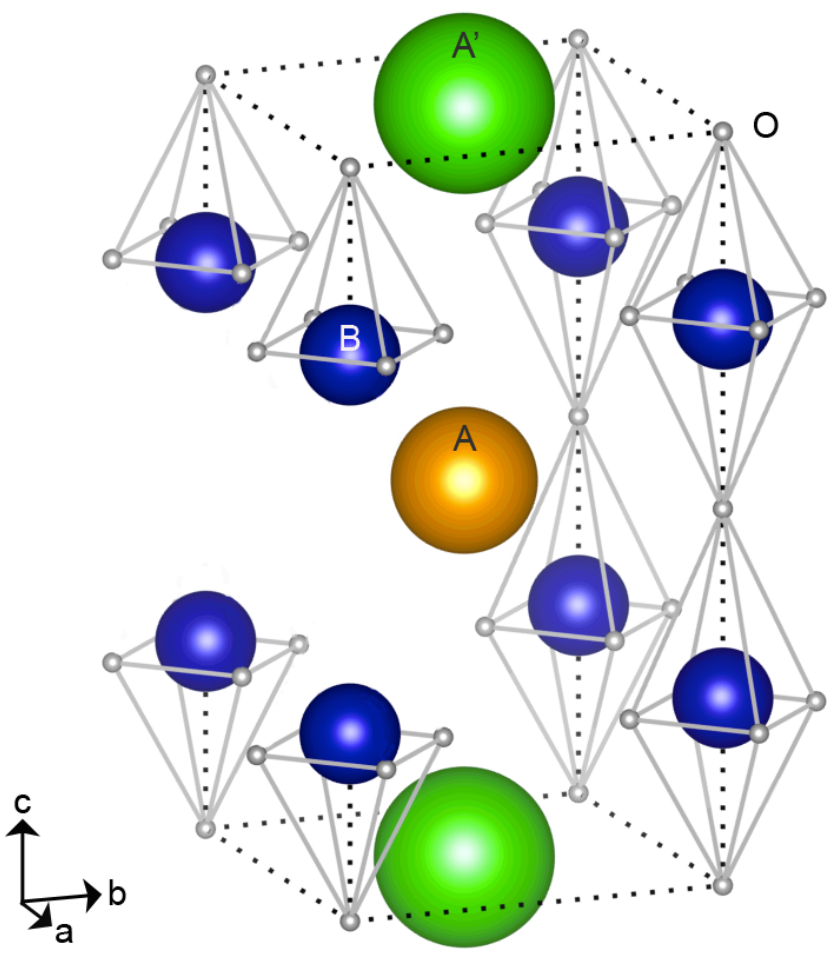

Figure 3. Double perovskite (A site ordering) shown with partial oxygen deficiency in the AO plane.

Double perovskites of the series $\mathrm{LnBaCO}_{2} \mathrm{O}_{5+\delta}$ (where $\mathrm{Ln}=\mathrm{La}, \mathrm{Pr}, \mathrm{Nd}, \mathrm{Sm}, \mathrm{Gd}$ ) have oxygen vacancies primarily located in the $\mathrm{LnO}_{\delta}$ layers.[17] When all O-sites are fully occupied, the Co-sites are octahedrally coordinated as $\mathrm{CoO}_{6}$. Oxygen vacancies in the $\mathrm{LnO}_{\delta}$ layer result in square pyramidal Co-site coordination as $\mathrm{CoO}_{5}$. Therefore, $\mathrm{LnBaCO}_{2} \mathrm{O}_{5+\delta}$ materials contain a mixture of Co-sites in octahedral and square pyramidal configurations with varying degrees of ordering based on oxygen stoichiometry and temperature.[18-21] This ordering phenomenon is thought to account for observations of enhanced oxygen surface exchange kinetics and lower activation energies at reduced 
temperatures, compared with traditional $\mathrm{ABO}_{3}$ perovskites, making them potentially promising candidates for IT-SOFC cathodes.[22-25] Table 1 provides a comparison of bulk conductivity values. However, this hypothesis has not been structurally verified at cathode operating conditions $\left(>500{ }^{\circ} \mathrm{C}, \mathrm{pO}_{2} 1-10^{-5} \mathrm{~atm}\right)$. These materials have been well characterized at low temperatures $\left(T<500{ }^{\circ} \mathrm{C}\right)$, and studies have been devoted to investigating their catalytic properties at cathode operating temperatures and at varying $\mathrm{pO}_{2}$ environments $[18,22,23,25-35]$, but their structural properties have not been investigated in such conditions. It is necessary to characterize the structural properties of these materials at in-situ SOFC conditions, including determination of the crystal symmetry, lattice parameters, oxygen stoichiometry, and degree of cation and vacancy ordering, to understand the structure-property relationships in this class of materials.

Table 1. Approximate bulk total conductivity $(\sigma)$ values for selected perovskite materials in air. Asterisk indicates double perovskites.

\begin{tabular}{|l|c|l|}
\hline Material & $\begin{array}{c}\sigma(\mathrm{S} / \mathrm{cm}) \\
\mathrm{T}=500-750{ }^{\circ} \mathrm{C}\end{array}$ & Reference \\
\hline $\mathrm{La}_{0.8} \mathrm{Sr}_{0.2} \mathrm{MnO}_{3-\delta}$ & $120-130$ & {$[36,37]$} \\
\hline $\mathrm{La}_{0.5} \mathrm{Sr}_{0.5} \mathrm{Co}_{3-\delta}$ & $1300-1800$ & {$[36,37]$} \\
\hline $\mathrm{La}_{0.6} \mathrm{Sr}_{0.4} \mathrm{Co}_{0.2} \mathrm{Fe}_{0.8} \mathrm{O}_{3-\delta}$ & $275-310$ & {$[38]$} \\
\hline $\mathrm{Ba}_{0.5} \mathrm{Sr}_{0.5} \mathrm{Co}_{0.8} \mathrm{Fe}_{0.2} \mathrm{O}_{3-\delta}$ & $10-55$ & {$[39,40]$} \\
\hline${ }^{*} \mathrm{GdBaCo}_{2} \mathrm{O}_{5+\delta}$ & $80-125$ & {$[41]$} \\
\hline${ }^{*} \mathrm{PrBaCo}_{2} \mathrm{O}_{5+\delta}$ & $140-190$ & {$[41]$} \\
\hline${ }^{*} \mathrm{NdBaCo} \mathrm{O}_{5+\delta}$ & $160-190$ & {$[41]$} \\
\hline
\end{tabular}




\subsection{Electrical Conductivity Relaxation}

For MIEC cathodes, oxygen transport occurs through exchange at the surface followed by diffusion through the bulk to the electrolyte, illustrated in Figure 4 [10, 37].

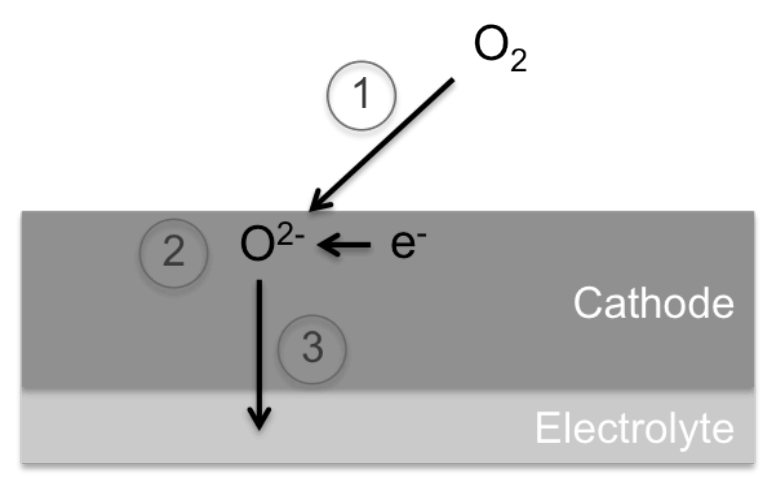

Figure 4. Oxygen transport in an MIEC cathode: (1) incorporation of gaseous oxygen at the surface (described by $k_{c h e m}$ ), (2) reduction to form an oxygen anion, and (3) diffusion through the bulk to the electrolyte (described by $D_{c h e m}$ )

Information regarding the surface incorporation and bulk diffusion steps can be quantified in terms of the oxygen surface exchange coefficient, $k_{c h e m}$, and the bulk oxygen diffusion coefficient, $D_{\text {chem }}$. Physically, $k_{\text {chem }}$ describes the exchange of oxygen on the cathode surface at high $\mathrm{pO}_{2}$, which can be expressed in Kröger-Vink notation[8] as:

$1 / 2 O_{2}+V_{O}^{\bullet \bullet} \leftrightarrow O_{O}^{X}+2 h^{\bullet}$

Gaseous oxygen combines with an oxygen vacancy to form oxygen on its lattice site and two electron holes, which serve as charge carriers for ( $p$-type) cathode materials [5]. After oxygen has been exchanged, an oxygen vacancy gradient exists between the 
surface and the bulk of the material. The direction of this gradient depends on whether oxygen was released from or incorporated into the surface. $D_{c h e m}$ measures the diffusion of these oxygen vacancies through the bulk material in order to re-establish equilibrium [42]. The accurate determination of these parameters for cathode materials at a variety of temperatures and $\mathrm{pO}_{2}$ ranges is necessary for a fundamental understanding of their oxygen transport properties, and thus their performance under operating conditions in an SOFC $[1,3,4,14]$.

Electrical conductivity relaxation $(E C R)$ is a technique commonly used to determine the oxygen surface exchange coefficient, $k_{\text {chem }}$, and bulk diffusion coefficient, $D_{\text {chem }}$ of mixed oxygen anion and electronic conductors $[9,11,42-50]$. In the ECR technique, the total conductivity of a dense, rectangular bar of cathode material (thickness $\sim 0.05 \mathrm{~cm}$ ) is measured during an instantaneous step change in $\mathrm{pO}_{2}$ at constant temperature. The change in electronic conductivity is directly related to $\mathrm{pO}_{2}$ through a proportional change in the concentration of charge carriers [51] through $\sigma=\mu F[h]$, where $\sigma$ is electrical conductivity, $\mu$ is hole mobility (assumed constant), $\mathrm{F}$ is Faraday's constant, and $[\mathrm{h}]$ is hole concentration. For $p$-type conductors, the concentration of electron holes decreases directly with decreasing $\mathrm{pO}_{2}$ (Eqn. 7 shifts to the left), resulting in decreased electronic conductivity as the bulk oxygen nonstoichiometry increases. As such, the rate of change in electronic conductivity may be directly correlated with the rate of change in oxygen stoichiometry of the material, and thus to the rates of the surface reaction and bulk diffusion steps.

A schematic of the ECR equipment can be found in Figure 5. The gas $\mathrm{pO}_{2}$ was varied by diluting the oxygen stream with nitrogen. Two gas pathways were included in the system, each with one oxygen stream and one nitrogen stream, such that two different $\mathrm{pO}_{2}$ values could be simultaneously achieved. Only one gas pathway was able 
to flow through the furnace at any time. A computer-controlled pneumatic 4-way-valve was utilized to rapidly switch between gas pathways and achieve instantaneous step changes in $\mathrm{pO}_{2}$.

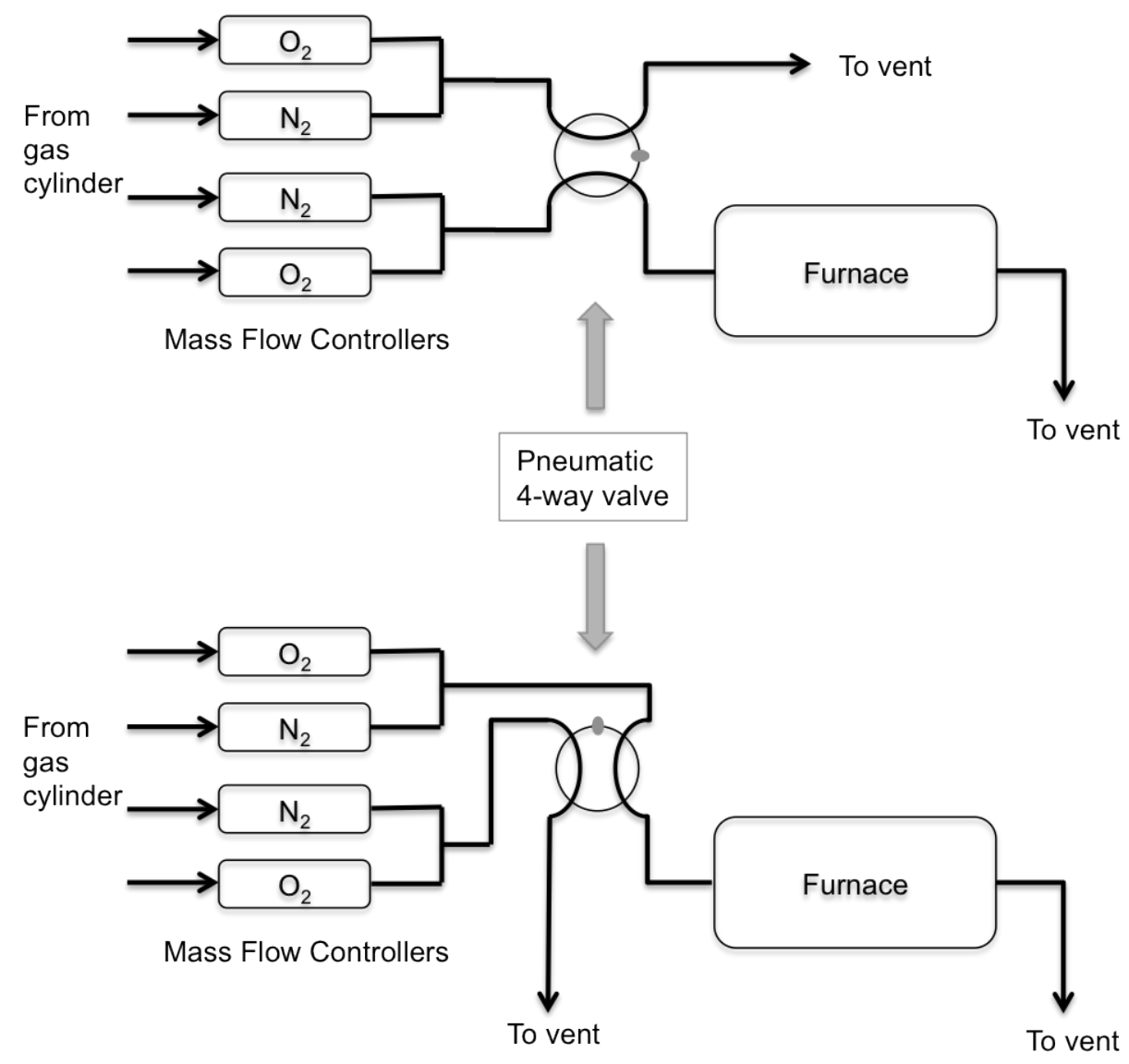

Figure 5. Electrical conductivity relaxation experimental setup.

The equations used to extract $k_{\text {chem }}$ and $D_{c h e m}$ from conductivity relaxation data can be derived starting with Fick's Second law [52]:

$\frac{\partial c}{\partial t}=D_{\text {chem }} \frac{\partial^{2} c}{\partial w^{2}}$ 
where $c$ is the concentration of oxygen, $t$ is time, $D_{\text {chem }}$ is the bulk oxygen diffusion coefficient, and $w$ is a sample dimension. If we consider a thin, flat sheet with thickness $2 a$, and assume thermodynamic equilibrium is established at $t<0$, and at $t=0$ a step change in $\mathrm{pO}_{2}$ occurs leading to a new equilibrium oxygen concentration, $\mathrm{c}_{\infty}$. The boundary conditions for Eqn. (8) are:

$-\left.D_{\text {chem }} \frac{\partial c}{\partial w}\right|_{x=a}=k_{\text {chem }}\left[c(a)-c_{\infty}\right]$

and

$-\left.D_{\text {chem }} \frac{\partial c}{\partial w}\right|_{x=-a}=k_{\text {chem }}\left[c(-a)-c_{\infty}\right]$

where $k_{\text {chem }}$ is the oxygen surface exchange coefficient. The initial condition for $c(w, t)$ is:

$c(w, 0)=c_{0}$

Eqn (8) can be solved using separation of variables, resulting in a Sturm-Liousville equation [53]. The general solution is given by Crank [54]:

$\frac{c(w, t)-c_{0}}{c_{\infty}-c_{0}}=1=\sum_{n=1}^{\infty} \frac{2 L \cos \left(\beta_{n} w / a\right) \exp \left(-\beta_{n}^{2} D_{c h e m} t / a^{2}\right)}{\left(\beta_{n}^{2}+L^{2}+L\right) \cos \left(\beta_{n}\right)}$

where the eigenvalues are obtained from:

$\beta_{m} \tan \beta_{m}=L_{\beta}=\frac{a k_{\text {chem }}}{D_{\text {chem }}}$ 
Assuming that conductivity is linearly related to oxygen vacancy concentration though a proportional change in the concentration of charge carriers (valid for small $\mathrm{pO}_{2}$ changes), a solution as a function of time can be obtained by integrating with respect to $w$ between $+a$ and $-a$ :

$\frac{\sigma_{t}-\sigma_{0}}{\sigma_{\infty}-\sigma_{0}}=1-\sum_{m=1}^{\infty} \frac{2 L_{\beta}^{2} \exp \left(\frac{-\beta_{m}^{2} D_{c h e m} t}{a^{2}}\right)}{\beta_{m}^{2}\left(\beta_{m}^{2}+L_{\beta}^{2}+L_{\beta}\right)}$

Eqn. (13) - (14) are expanded for a solid with the dimensions $2 x, 2 y, 2 z$ to obtain [45]:

$\sigma_{n}=\frac{\sigma_{t}-\sigma_{0}}{\sigma_{\infty}-\sigma_{0}}$

$\sigma_{n}=1-\sum_{m=1}^{\infty} \sum_{n=1}^{\infty} \sum_{p=1}^{\infty} \frac{2 L_{\beta}^{2} \exp \left(\frac{-\beta_{m}^{2} D_{\text {chem }} t}{x^{2}}\right)}{\beta_{m}^{2}\left(\beta_{m}^{2}+L_{\beta}^{2}+L_{\beta}\right)} \times \frac{2 L_{\gamma}^{2} \exp \left(\frac{-\gamma_{n}^{2} D_{\text {chem }} t}{y^{2}}\right)}{\gamma_{n}^{2}\left(\gamma_{n}^{2}+L_{\gamma}^{2}+L_{\gamma}\right)} \times \frac{2 L_{\phi}^{2} \exp \left(\frac{-\phi_{p}^{2} D_{\text {chem }} t}{z^{2}}\right)}{\phi_{p}^{2}\left(\phi_{p}^{2}+L_{\phi}^{2}+L_{\phi}\right)}$

$L_{\beta}=x \frac{k_{\text {chem }}}{D_{\text {chem }}} ; L_{\gamma}=y \frac{k_{\text {chem }}}{D_{\text {chem }}} ; L_{\phi}=z \frac{k_{\text {chem }}}{D_{\text {chem }}}$

$\beta_{m} \tan \beta_{m}=L_{\beta} ; \gamma_{n} \tan \gamma_{n}=L_{\gamma} ; \phi_{p} \tan \phi_{p}=L_{\phi}$ 
where $t$ is time in seconds; $\sigma_{n}$ is normalized conductivity, $\sigma_{t}$ is instantaneous conductivity at time $t, \sigma_{0}$ is initial conductivity and $\sigma_{\infty}$ is conductivity at equilibrium for a given $p \mathrm{O}_{2} ; x$, $y, z$, are dimensions of the sample in centimeters, and $\beta_{m}, \gamma_{n}, \phi_{p}$ are the positive, nonzero roots of Eqn. (18). The conductivity is normalized for each $\mathrm{pO}_{2}$ switch according to Eqn. (15). The normalized conductivity curves are then fit to Eqns. (16) - (18)] [45, 54], where the adjustable parameters are the surface exchange coefficient, $k_{\text {chem }}$, measured in $\mathrm{cm} / \mathrm{s}$, and the bulk diffusion coefficient, $D_{c h e m}$, measured in $\mathrm{cm}^{2} / \mathrm{s}$.

The use of dense thin film samples, in which the surface of the film is maximized with respect to its thickness, allow $D_{\text {chem }}$ to be eliminated from the analysis, because we can assume there is no oxygen concentration gradient through the film (again, valid for small $\mathrm{pO}_{2}$ changes) and surface exchange is the dominant process [55]. Thus, the relationship between $k_{\text {chem }}$ and conductivity is obtained by the conservation of mass at the surface [55]:

$\frac{d c(t)}{d t}=\frac{S}{\mathrm{v}} k_{c h e m}[c(t)-c(\infty)]$

where $c(t)$ is the concentration of oxygen ions at time $t, c_{\infty}$ is the concentration of oxygen ions at the new $\mathrm{pO}_{2}$ equilibrium, $S$ is the surface area of the film, and $v$ is the volume of the film. Integrating with the boundary condition at $t=0, c(t)=c_{0}$ provides:

$$
\left(\frac{\sigma(t)-\sigma_{0}}{\sigma_{\infty}-\sigma_{0}}\right) \approx\left(\frac{c(t)-c_{0}}{c_{\infty}-c_{0}}\right)=1-\exp \left(\frac{l t}{k_{\text {chem }}}\right)
$$

where $t$ is time in seconds; I is the film thickness; $\sigma(\mathrm{t})$ is the instantaneous conductivity at time $t, \sigma_{0}$ is initial conductivity and $\sigma_{\infty}$ is conductivity at equilibrium for a given $p \mathrm{O}_{2}$. A 
similar lattice parameter and thermal expansion coefficient between film and substrate is desirous to avoid cracks in the film due to lattice strain or heating and cooling cycles.

\subsection{Neutron Diffraction}

Neutron powder diffraction (NPD) may be used to determine material properties of perovskites. In contrast to x-ray diffraction (XRD), incident neutrons interact with the nucleus of atoms in the material, rather than the surrounding electron cloud. This provides three critical advantages over XRD: (1) lighter elements, such as oxygen and hydrogen, are detected, (2) the diffracted signal is able to detect very large and very small crystal lattice $d$-spacing values, which allows for more precise structural information, and (3) neutron scattering lengths vary such that elements of similar atomic number may be distinguished. Space group models are then fit to the diffraction peaks using Rietveld refinements. This process yields information such as lattice parameters, bond lengths, oxygen stoichiometry and placement of atoms in the lattice. $[56,57]$ 


\section{Chapter 2 - Unreliability of the Electrical Conductivity}

\section{Relaxation Technique for a Simultaneous Two-Parameter Fit}

\subsection{Introduction}

Perovskite structured oxides of the form $\mathrm{La}_{x} \mathrm{Sr}_{1-x} \mathrm{Co}_{y} \mathrm{Fe}_{1-\mathrm{y}} \mathrm{O}_{3-\delta}$ (LSCF) are mixed oxygen ion-electron conductors widely used as solid oxide fuel cell (SOFC) cathode materials [1, 58-60]. LSCF serves as an electrocatalyst for oxygen reduction and provides high electrode performance by facilitating a bulk pathway for oxygen anion transport [1]. Efforts to reduce operating temperatures below $973 \mathrm{~K}$ are hampered by the high activation energy barriers for ion transport and electrocatalytic reactions at the electrodes that lead to increased overpotentials [1,2]. The cathode is of particular interest as there are a number of competing theories regarding the oxygen incorporation mechanism and kinetic parameters for the oxygen reduction reaction (ORR) [1].

Previous work with $\mathrm{L}_{1-\mathrm{x}} \mathrm{Sr}_{\mathrm{x}} \mathrm{MnO}_{3}$ (LSM) cathodes has demonstrated enhanced catalytic activity after cathodic polarization, yet the reason for this increase in activity is not well understood [61-63]. Shao-Horn and co-workers have determined that the LSM surface becomes significantly La-enriched during annealing, but after cathodic polarization the decrease in electrochemical resistance (measured via impedance spectroscopy) is accompanied by a decrease in surface La and an increase in surface Sr and Mn [61]. They hypothesize that the post-annealing LSM surface is covered with lanthanum oxides, blocking the surface exchange of oxygen. Cathodic polarization reduces the La species and frees the surface for oxygen exchange, which significantly enhances catalytic activity [61]. Baumann et al. have similarly investigated the surface of $\mathrm{La}_{0.6} \mathrm{Sr}_{0.4} \mathrm{Co}_{0.8} \mathrm{Fe}_{0.2} \mathrm{O}_{3-\delta}$ (LSCF 6482) before and after cathodic polarization using X-ray photoelectron spectroscopy (XPS). Their results indicate that the surface becomes $\mathrm{Sr}$ 
enriched and La depleted after cathodic polarization, which is accompanied by a significant decrease in electrochemical resistance via impedance spectroscopy [64].

Surface doping of SOFC cathodes with nanoparticles is also an area of growing interest. There is evidence to suggest that nanostructured electrodes provide enhanced performance over bulk materials, specifically for nanoparticles applied at high densities $[65,66]$. However, it is not currently known if these enhancements are due to an increase in surface area or an increase in electrocatalytic activity upon nanostructuring.

Electrical conductivity relaxation $(E C R)$ is a technique commonly used to determine the oxygen surface exchange coefficient, $k_{c h e m}$, and bulk diffusion coefficient, $D_{\text {chem, }}$ of mixed oxygen anion and electronic conductors $[9,11,42-50]$. In the ECR technique, the total conductivity of a sample is measured during an instantaneous step change in $\mathrm{pO}_{2}$ at constant temperature. The change in electronic conductivity is directly related to $\mathrm{pO}_{2}$ through a proportional change in the concentration of charge carriers. For p-type conductors, the concentration of electron holes decreases directly with $\mathrm{pO}_{2}$, resulting in decreased electronic conductivity as the bulk oxygen non-stoichiometry increases. As such, the change in electronic conductivity may be directly correlated with the change in oxygen stoichiometry of the material. The ECR data is thus fit to an appropriate solution of Fick's second law where $k_{c h e m}$ and $D_{c h e m}$ are adjustable parameters.

$\mathrm{La}_{0.6} \mathrm{Sr}_{0.4} \mathrm{Co}_{0.2} \mathrm{Fe}_{0.8} \mathrm{O}_{3-\delta}$ (LSCF 6428), a p-type conductor, is a common cathode material and has been the subject of previous ECR studies [9, 11, 44]; however, reported values for $k_{\text {chem }}$ vary by approximately one order of magnitude. For example at $\log \left(\mathrm{pO}_{2} / \mathrm{atm}\right)$ of -1.0 , Kilner and co-workers report $k_{\text {chem }}$ as $\sim 1 \times 10^{-4} \mathrm{~cm} / \mathrm{s}[9,44]$, while Bouwmeester and co-workers report $\sim 1 \times 10^{-3} \mathrm{~cm} / \mathrm{s}$ [11]. $D_{\text {chem }}$ at $\log -p \mathrm{O}_{2}$ of -1.0 is consistently reported as $\sim 5.6 \times 10^{-6}[9,11,44]$. The availability of comparative data makes it a logical material from which to study the influence of surface doping upon $k_{c h e m}$. The 
work presented here seeks to characterize the oxygen surface exchange coefficient, $k_{\text {chem }}$, and bulk diffusion coefficient, $D_{\text {chem }}$, for LSCF 6428-based cathodes: polished, La, Sr, Co, and Fe surface-doped, and nanoparticle doped. We discuss the efficacy of the ECR technique and how this influences the ability to successfully determine changes in $k_{\text {chem }}$ and $D_{\text {chem. }}$

\subsection{Experimental}

a. Sample preparation

The $\mathrm{La}_{0.6} \mathrm{Sr}_{0.4} \mathrm{Co}_{0.2} \mathrm{Fe}_{0.8} \mathrm{O}_{3-\delta}$ (LSCF 6428) material was synthesized using a modified Pechini procedure [67]. The precursors were $\mathrm{La}\left(\mathrm{NO}_{3}\right)_{3} \cdot 6 \mathrm{H}_{2} \mathrm{O}, \operatorname{Sr}\left(\mathrm{NO}_{3}\right)_{2}[\mathrm{~min}$ 99\%, Alfa Aesar, Ward Hill, MA, USA], $\mathrm{Co}\left(\mathrm{NO}_{3}\right)_{2} \cdot 6 \mathrm{H}_{2} \mathrm{O}$, and $\mathrm{Fe}\left(\mathrm{NO}_{3}\right)_{3} \cdot 9 \mathrm{H}_{2} \mathrm{O}$ [min $99 \%$, Acros Organics, Morris Plains, NJ, USA]. Nitrate solutions were prepared by dissolving the salts in de-ionized water with the final metal concentration determined by complexometric titrations with ethylenediaminetetraacetic acid (EDTA) [68]. These solutions were mixed in the appropriate ratios to form the desired composition, then complexed with EDTA [min 99\%, Acros Organics, Morris Plains, NJ, USA] in the presence of ammonium hydroxide. The resulting mixture was evaporated to a gel-like state and pyrolized in an oven at $573 \mathrm{~K}\left(300^{\circ} \mathrm{C}\right)$. The combustion product was ground and calcined at $1298 \mathrm{~K}\left(1025^{\circ} \mathrm{C}\right)$ for 2 hours and the resulting powder ball-milled for 24 hours in ethanol to achieve a homogeneous particle size. The material was then sieved through $212 \mu \mathrm{m}$ mesh prior to uniaxial pressing at 8000 psi to form disks. The disks were sintered in air at $1523 \mathrm{~K}\left(1250{ }^{\circ} \mathrm{C}\right)$ for 12 hours ( 3 degree/min heating and cooling rates) to obtain $>95 \%$ theoretical density, determined by measuring their mass and volume. The disks were progressively polished on both sides using P400 and P4000 silicon carbide polishing pads [Buehler, Lake Bluff, IL, USA] followed by a $0.05 \mu \mathrm{m}$ alumina 
suspension [MasterPrep Polishing Suspension, Buehler, Lake Bluff, IL, USA]. At least $0.03 \mathrm{~cm}$ was removed from the thickness of each disk as a consequence of this polishing regimen. Rectangular bar samples were cut from the polished discs to approximate dimensions of $1.2 \mathrm{~cm} \times 0.5 \mathrm{~cm} \times(0.06-0.08) \mathrm{cm}$ and were cleaned by immersion in ethanol prior to use.

A four-point configuration was utilized to collect DC conductivity data. Gold electrode wires [Alfa Aesar, Ward Hill, MA, USA] were attached to each end of the bar sample using gold ink [Engelhard, Newark, NJ, USA], which was further added to completely cover both ends. Two additional contacts, placed 0.2-0.4 cm from each end of the bar, were made by wrapping gold wire around the bar and applying gold ink to ensure good electrical contact. The sample was then heated to $423 \mathrm{~K}\left(150{ }^{\circ} \mathrm{C}\right)$ in air to allow the ink to dry.

LSCF 6428 bar samples were individually surface-doped with La, Sr, Co, and Fe. The sample was heated to $478 \mathrm{~K}\left(205^{\circ} \mathrm{C}\right)$ on a homemade resistive-heater plate and a $0.3 \mathrm{M}$ nitrate salt aqueous solution of the dopant was added to the surface via spray deposition [Air Brush Model 175-7, Badger Air-Brush Co., Franklin Park, IL, USA] with air at 4.5 psi as the carrier gas. Both sides of the sample were doped and then it was heated to $573 \mathrm{~K}\left(300^{\circ} \mathrm{C}\right)$ for 1 hour. Finally, the sample was calcined at $1073 \mathrm{~K}\left(800^{\circ} \mathrm{C}\right)$ in oxygen gas [99.999\% purity, GTS-Welco, Allentown, PA, USA] flowing at $200 \mathrm{~mL} / \mathrm{min}$ for 1 hour before testing to ensure removal of carbonaceous residues.

LSCF 6428 nanoparticles of $25-50 \mathrm{~nm}$ in diameter were synthesized using a reverse micelle process and were subsequently washed and sintered at $1073 \mathrm{~K}$ (800 $\left.{ }^{\circ} \mathrm{C}\right)$. Full synthesis details are available elsewhere [69]. The nanoparticles were dispersed in an ethanol-water solution containing a small quantity of Triton-X-100 surfactant [Sigma-Aldrich, St. Louis, MO, USA] and were added to both sides of the 
rectangular LSCF 6428 bar samples via spray deposition at room temperature with air carrier gas at $31.0 \mathrm{kPa}(4.5 \mathrm{psi})$. The samples were immediately sintered at $823 \mathrm{~K}$ (550 ${ }^{\circ} \mathrm{C}$ ) in air for 1 hour to ensure nanoparticle adherence and surfactant burn-off.

\section{b. Electrical conductivity relaxation (ECR)}

The sample was placed inside a quartz tube with oxygen [99.994\% purity, GTSWelco, Allentown, PA, USA] flowing at $200 \mathrm{~mL} / \mathrm{min}$. The sample was then heated to $1073 \mathrm{~K}\left(80{ }^{\circ} \mathrm{C}\right)$ and allowed to equilibrate for at least $30 \mathrm{~min}$. The gas $\mathrm{pO}_{2}$ was varied by diluting the oxygen stream with nitrogen [99.999\% purity, Praxair, Danbury, CT, USA]. Two gas pathways were included in the system, each with one oxygen stream and one nitrogen stream, such that two different $\mathrm{pO}_{2}$ values could be simultaneously achieved. Only one gas pathway was able to flow through the quartz tube at any time. A computer-controlled 4-way-valve [Swagelok, Dibert Valve \& Fitting Co, Inc., Richmond, VA, USA] was utilized to rapidly switch between gas pathways and achieve instantaneous step changes in $p \mathrm{O}_{2}$. The gas flow rates for each $p \mathrm{O}_{2}$ stream were set with computerized mass flow controllers [Omega, Stamford, CT, USA]. The total flowrate was fixed at $200 \mathrm{~mL} / \mathrm{min}$ with $\mathrm{pO}_{2}$ ranging from $100 \%$ to $3.3 \%$ in steps that are close-toequally spaced when viewed on a log-scale. Each $\mathrm{pO}_{2}$ switch was measured twice, as the $\mathrm{pO}_{2}$ was decreased from $100 \%$ to $54.7 \%$ to $29.3 \%$ to $16.0 \%$ to $8.7 \%$ to $4.7 \%$ to $3.3 \%$ (six steps), then increased to $100 \%$ (six steps).

Changes in conductivity resulting from the $\mathrm{pO}_{2}$ switches were measured using the four-point electrode arrangement described above with data recorded at a constant frequency of $80 \mathrm{~Hz}$ [Gamry Instruments Reference 600, Gamry Instruments, Malvern, PA, USA]. The conductivity was normalized for each $\mathrm{pO}_{2}$ switch according to Eqn. (15) and was fit to a solution of Fick's Second Law [Eqns. (16) - (18)] [45, 54]. The variable 
parameters in the fit are the surface exchange coefficient, $k_{c h e m}$, measured in $\mathrm{cm} / \mathrm{s}$, and the bulk diffusion coefficient, $D_{\text {chem }}$, measured in $\mathrm{cm}^{2} / \mathrm{s}$.

$$
\sigma_{n}=\frac{\sigma_{t}-\sigma_{0}}{\sigma_{\infty}-\sigma_{0}}
$$

$\sigma_{n}=1-\sum_{m=1}^{\infty} \sum_{n=1}^{\infty} \sum_{p=1}^{\infty} \frac{2 L_{\beta}^{2} \exp \left(\frac{-\beta_{m}^{2} D_{\text {chem }} t}{x^{2}}\right)}{\beta_{m}^{2}\left(\beta_{m}^{2}+L_{\beta}^{2}+L_{\beta}\right)} \times \frac{2 L_{\gamma}^{2} \exp \left(\frac{-\gamma_{n}^{2} D_{\text {chem }} t}{y^{2}}\right)}{\gamma_{n}^{2}\left(\gamma_{n}^{2}+L_{\gamma}^{2}+L_{\gamma}\right)} \times \frac{2 L_{\phi}^{2} \exp \left(\frac{-\phi_{p}^{2} D_{\text {chem }} t}{z^{2}}\right)}{\phi_{p}^{2}\left(\phi_{p}^{2}+L_{\phi}^{2}+L_{\phi}\right)}$

$L_{\beta}=x \frac{k_{\text {chem }}}{D_{\text {chem }}} ; L_{\gamma}=y \frac{k_{\text {chem }}}{D_{\text {chem }}} ; L_{\phi}=z \frac{k_{\text {chem }}}{D_{\text {chem }}}$

$\beta_{m} \tan \beta_{m}=L_{\beta} ; \gamma_{n} \tan \gamma_{n}=L_{\gamma} ; \phi_{p} \tan \phi_{p}=L_{\phi}$

where $t$ is time in seconds; $\sigma_{n}$ is normalized conductivity, $\sigma_{t}$ is instantaneous conductivity at time $t, \sigma_{0}$ is initial conductivity and $\sigma_{\infty}$ is conductivity at equilibrium for a given $p \mathrm{O}_{2} ; x$, $y, z$, are dimensions of the sample in centimeters, and $\beta_{m}, \gamma_{n}, \phi_{p}$ are the positive, nonzero roots of Eqn. (18).

\section{c. Sample Characterization}

Powder X-ray diffraction patterns [Scintag X-Ray Diffraction, XDS 2000, Cupertino, CA, USA] with Cu-Ka radiation source and fixed slit width were collected on 
unmodified LSCF 6428 samples prepared as above and then crushed to a powder. The patterns were obtained in the range of $20-65^{\circ}$ with a $0.02^{\circ}$ step size and a counting time of $1.0 \mathrm{~min} /$ degree. Grain structure was determined using a field emission scanning electron microscope (SEM) [JEOL JSM 6700, Tokyo, Japan]. Prior to SEM imaging, the LSCF 6428 sample was sintered as above, polished, and tested at $1073 \mathrm{~K}\left(800{ }^{\circ} \mathrm{C}\right)$ for over 150 hours in the $100 \%$ to $3.3 \% \mathrm{pO}_{2}$ range. Nanoparticle size and morphology was determined via Transmission Electron Microscopy (TEM) [JEOL 2000FX, LEOL Ltd. Tokyo, Japan]. A slow scan charge-coupled device (CCD) camera was used to acquire images, which were analyzed with the Gatan Digital Micrograph software package [Gatan Inc, Pleasanton, CA, USA]. Atomic Force Microscopy (AFM) [SOLVER PRO-M, NT-MDT, Moscow, Russia] was performed in contact mode. X-Ray Photoelectron Spectroscopy (XPS) [Physical Electronics 5400, Chanhassen, MN, USA] was performed at Virginia Polytechnic Institute and State University in Blacksburg, VA, USA.

\subsection{Results and Discussion}

a. Sample characterization

The XRD pattern obtained from a crushed, polished disc, shown in Figure 6 has the perovskite structure (perovskite peaks indicated), and is consistent with previous work [12]. An unpolished sample heated at $1073 \mathrm{~K}\left(800^{\circ} \mathrm{C}\right)$ in air for 140 hours was imaged via SEM to determine grain size and distribution, shown in Figure 7 . The grain size has a wide variation from approximately $0.5-5 \mu \mathrm{m}$. 


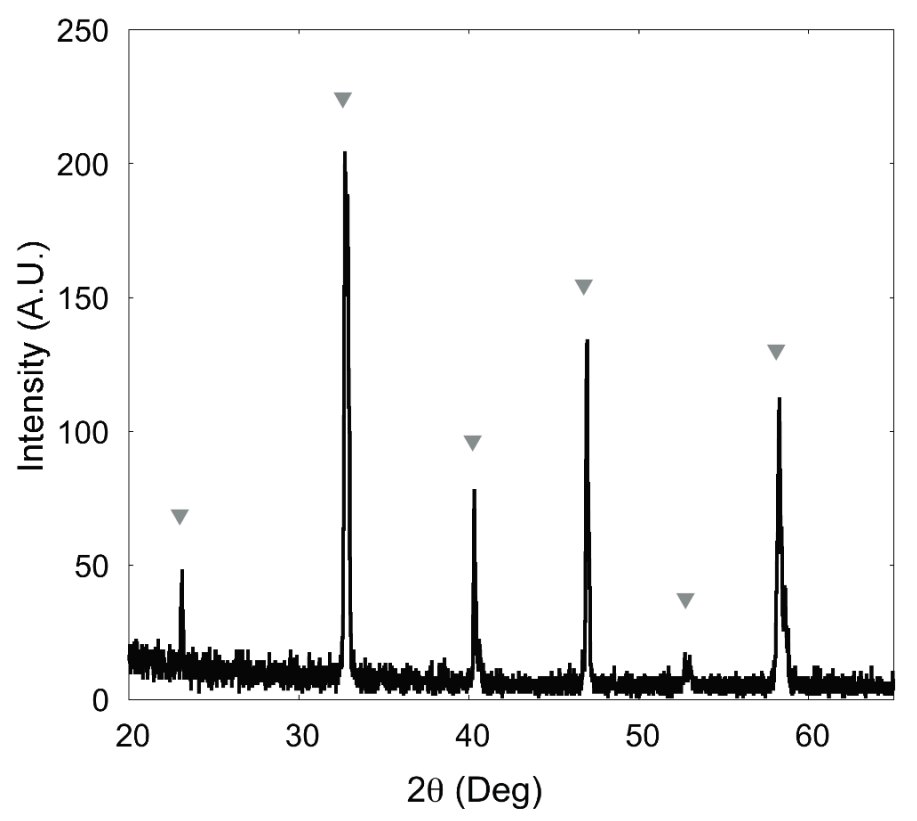

Figure 6. X-Ray Diffraction pattern of crushed LSCF 6428 sample sintered in air at 1523 $\mathrm{K}\left(1250^{\circ} \mathrm{C}\right)$ for 12 hours. Perovskite peaks are indexed as $(\nabla)$.

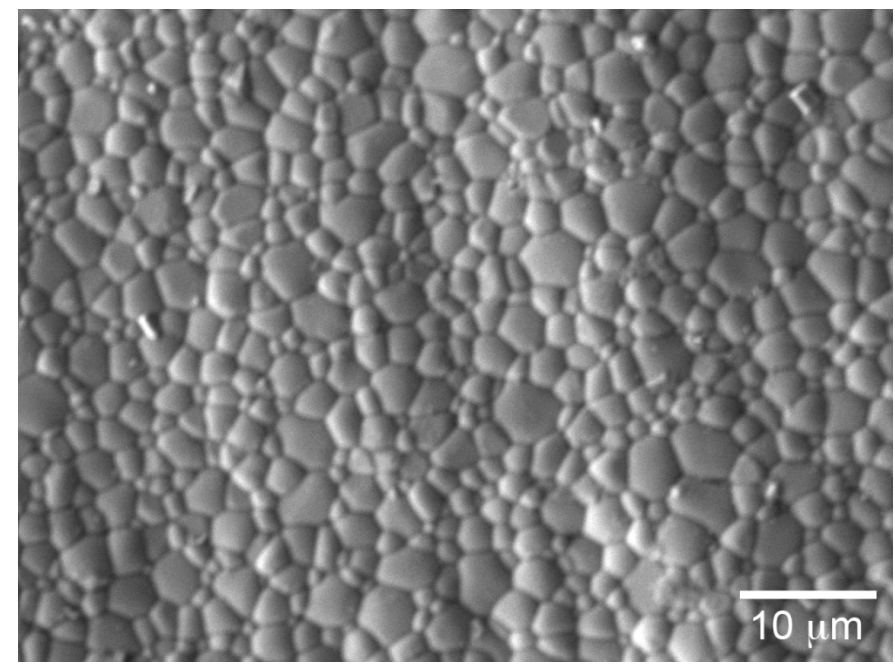

Figure 7. SEM image showing top view of the surface grain structure of an unpolished LSCF 6428 sample sintered in air at $1523 \mathrm{~K}\left(1250{ }^{\circ} \mathrm{C}\right)$ for 12 hours, and then heated to $1073 \mathrm{~K}\left(800^{\circ} \mathrm{C}\right)$ for 140 hours in air. 


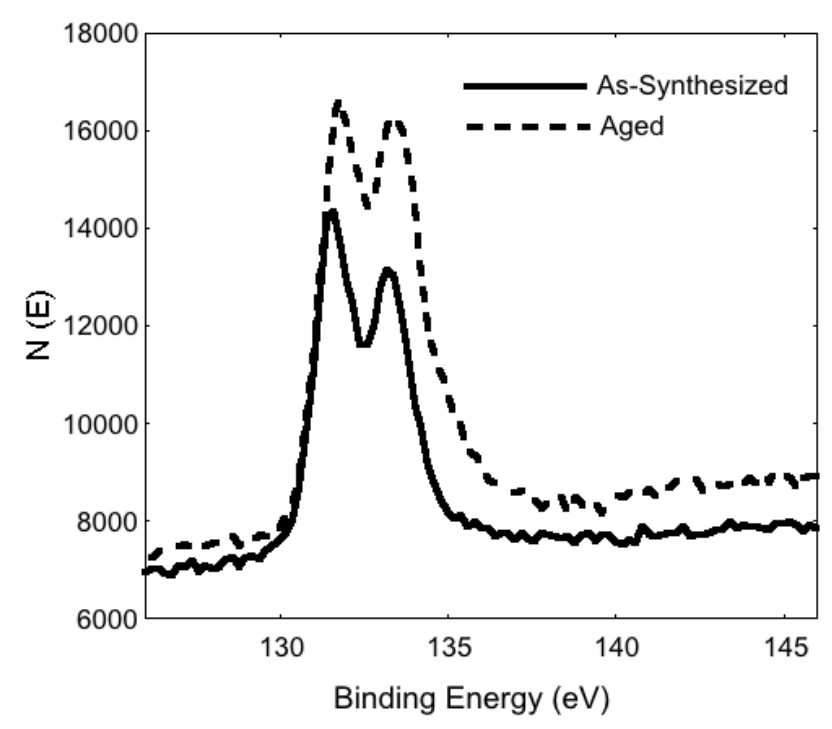

Figure 8. Strontium binding energy peaks obtained with XPS for an as-synthesized LSCF 6428 sample and one heated to $1073 \mathrm{~K}\left(800{ }^{\circ} \mathrm{C}\right)$ for over 150 hours in the $100 \%$ to $3.3 \% \mathrm{pO}_{2}$ range. $\mathrm{N}(\mathrm{E})$ refers to number of electrons counted at each binding energy.

XPS was performed on a polished, as-synthesized LSCF 6428 sample and on a polished LSCF 6428 sample tested in the ECR system for over 150 hours at $1073 \mathrm{~K}$ $\left(800{ }^{\circ} \mathrm{C}\right)$ in the $100 \%$ to $3.3 \% \mathrm{pO}_{2}$ range. The data indicate the surface of the sample became strontium enriched, as evidenced by the larger peak for the aged sample at the Sr binding energy, shown in Figure 8. The XPS analysis of the aged sample also registered a trace amount of bismuth with unknown origin. The quartz tube and sample holder for the ECR system have never been exposed to bismuth, nor - to the authors' knowledge - is $\mathrm{Bi}$ a component in any material or surface that has come in contact with the sample.

b. Validity of numerical values extracted from data fit

Electrical conductivity relaxation (ECR) was used to determine the oxygen surface exchange coefficient, $k_{\text {chem }}$, and the bulk oxygen diffusion coefficient, $D_{c h e m}$. 
Conductivity data for a polished LSCF 6428 sample was recorded for the $100 \%$ to $3.3 \%$ $\mathrm{pO}_{2}$ range four consecutive times over a period of 80 hours (20 hours per experiment) and the data from each $\mathrm{pO}_{2}$ step was fit to Eqs. (15)-(18). The values of $k_{\text {chem }}$ and $D_{\text {chem }}$ extracted from the oxidation (increasing $\mathrm{pO}_{2}$ ) steps of each repetition are shown on a double-log scale in Figure 9. There was no significant variation in the values of $k_{\text {chem }}$ and $D_{\text {chem }}$ at each $\mathrm{pO}_{2}$ over the experiment period, indicating the experimental and data analysis procedures are reproducible, and that the sample is stable under prolonged testing. Within each repetition, $D_{c h e m}$ did not change significantly with $\mathrm{pO}_{2}$ at $(2.5-5.0)$ $\times 10^{-5} \mathrm{~cm}^{2} / \mathrm{s}$, while $k_{\text {chem }}$ varied between $1.5 \times 10^{-2} \mathrm{~cm} / \mathrm{s}$ and $2.0 \times 10^{-3} \mathrm{~cm} / \mathrm{s}$. The decrease in $k_{\text {chem }}$ with $\mathrm{pO}_{2}$ is consistent with published accounts $[9,11,44]$ and is most likely due to the reduction of oxygen concentration above the sample. Due to the uncertainty associated with this technique (discussed fully below), no conclusion can be drawn from the possible change in slope of $k_{\text {chem }}$ at a $\mathrm{pO}_{2}$ of 0.8 atm. Figure 10 shows normalized conductivity data and curve fits for the reduction and oxidation steps in the $16.0 \%$ to $29.3 \% \mathrm{pO}_{2}$ range taken from Figure 9 Trial 2 . The normalized conductivity curves overlapped almost entirely in Figure 10a, and the curve fits traced the behavior of the normalized conductivity data, shown in Figure 10b, a close-up between 50 and 150 seconds. The behavior illustrated in Figure 10 is representative of all switches within the $\mathrm{pO}_{2}$ range studied. 

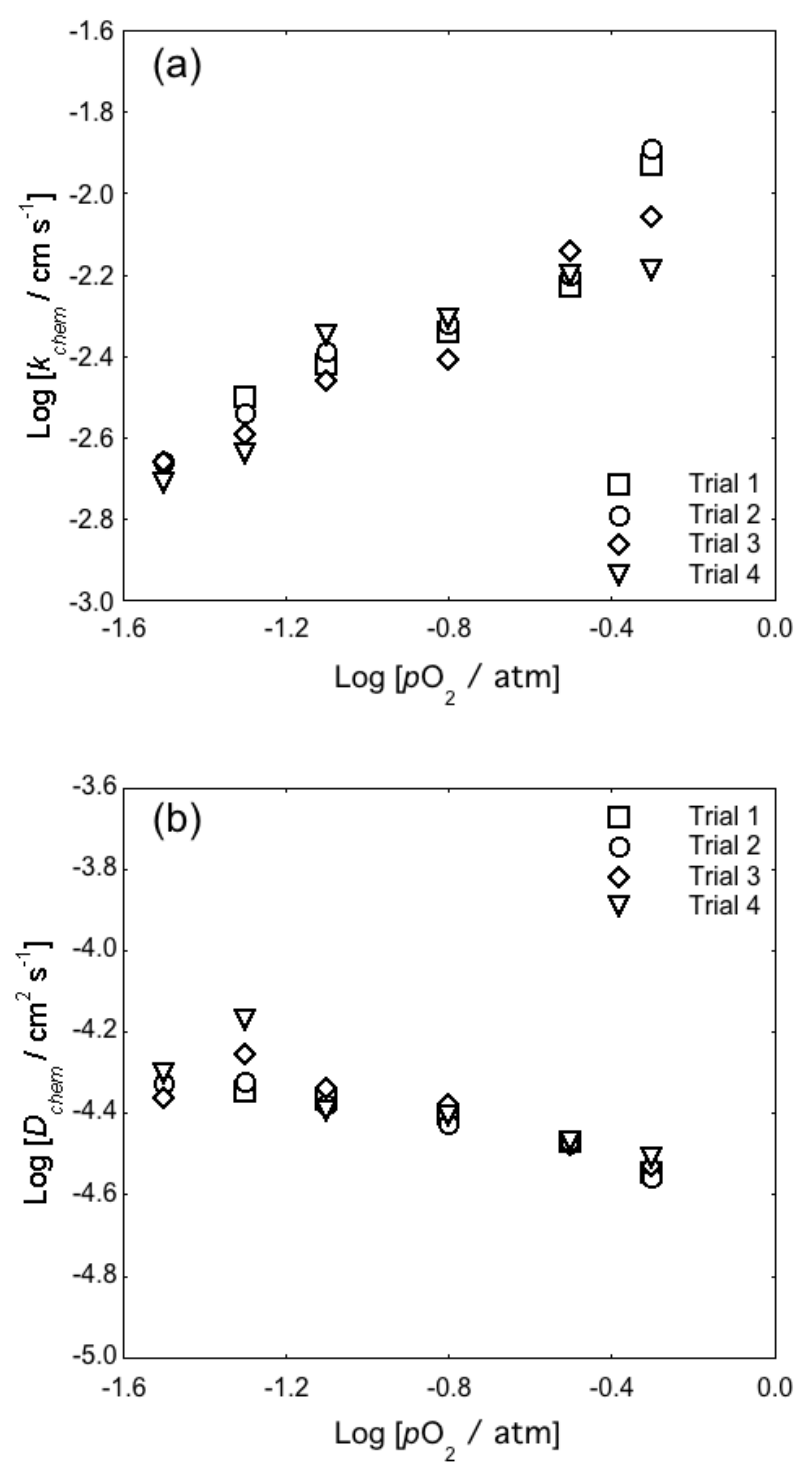

Figure 9. Unmodified polished LSCF 6428 sample tested four consecutive times over the entire $100 \%$ to $3.3 \% \mathrm{pO}_{2}$ range at $1073 \mathrm{~K}\left(800{ }^{\circ} \mathrm{C}\right)$. Oxidation switches are plotted as a function of $\log \left[p \mathrm{O}_{2} / \mathrm{atm}\right]:$ (a) $\log \left[k_{\text {chem }} / \mathrm{cm} \mathrm{s}^{-1}\right]$; (b) $\log \left[D_{c h e m} / \mathrm{cm}^{2} \mathrm{~s}^{-1}\right]$. 

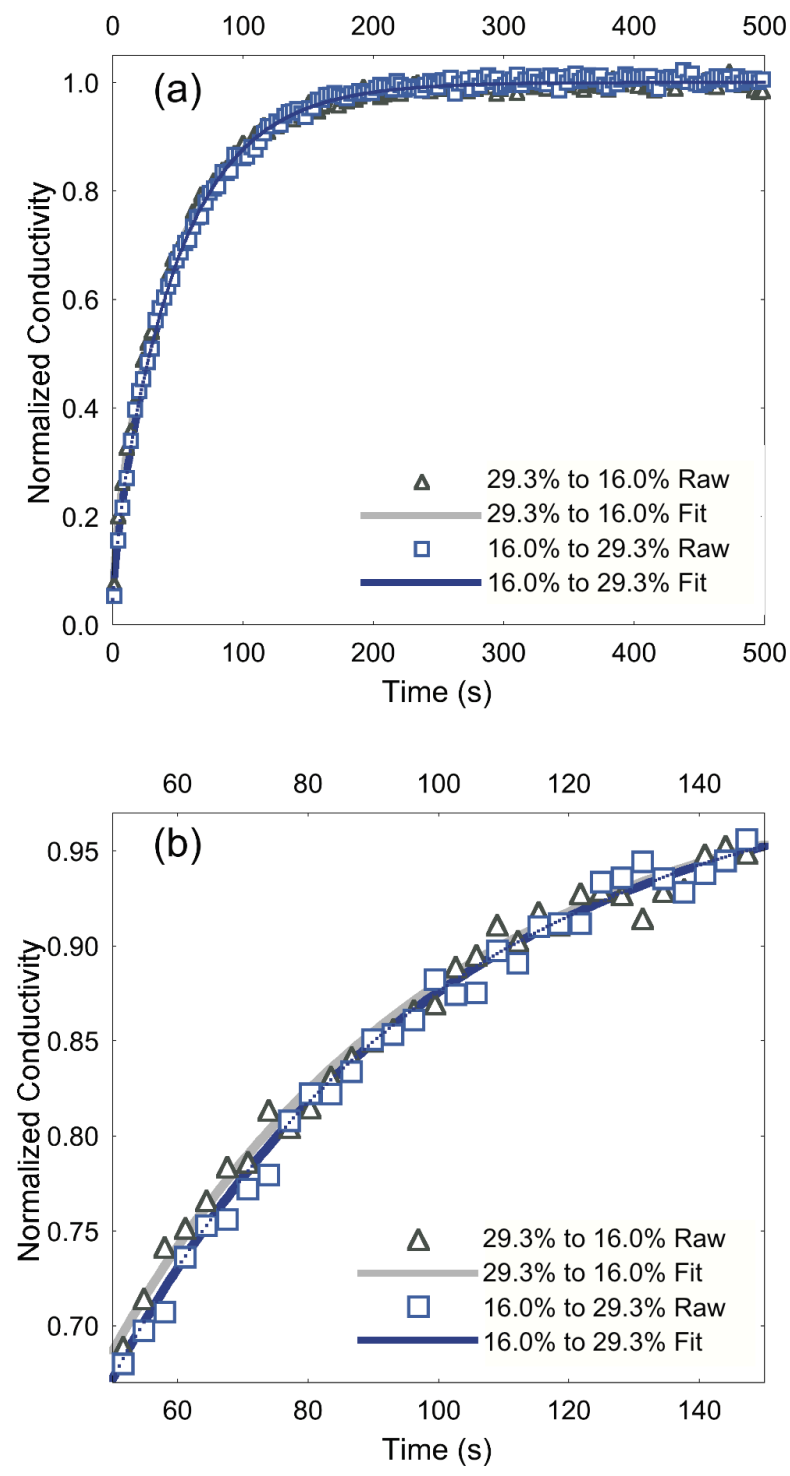

Figure 10. Normalized conductivity data from Trial 2 in Fig 4 (unmodified polished LSCF 6428 sample) plotted as a function of time over the $\mathrm{pO}_{2}$ switches from $29.3 \%$ to $16.0 \%$ and $16.0 \%$ to $29.3 \%$ : (a) $0-500 \mathrm{~s}$; (b) $50-150 \mathrm{~s}$.

Values of $k_{\text {chem }}$ and $D_{c h e m}$ extracted from the polished sample in Figure 9 were higher than previously published data. Kilner and co-workers reported $[9,44]$ lower $D_{c h e m}$ values, although within one order of magnitude of our results in Figure 9, and between one and two orders of magnitude lower than $k_{\text {chem }}$ values in this work. Bouwmeester and 
co-workers [11] also reported lower values for $k_{\text {chem }}$ and $D_{\text {chem }}$, although both were within one order of magnitude of values shown in Figure 9.

The simplest explanation for these inconsistencies is variation between samples from different laboratories. To investigate this possibility, we compared the conductivity from Figure 9 Trial 2 as a function of $\mathrm{pO}_{2}$ with that published by Kilner and co-workers [9, $44]$ in the 0 to $-1.3 \log -p \mathrm{O}_{2}$ range, Figure 11 . The two data sets are nearly identical, suggesting that the bulk samples have similar properties, and that variation between laboratories is not likely a factor. Significant variation in grain structure between samples may affect the values of $k_{c h e m}$ and $D_{c h e m}$, as rates of ionic and electronic transport (and thus electronic conductivity) differ between bulk sample and grain boundaries [70]. Figure 7 provides the grain size and distribution for an unpolished LSCF 6428 sample to serve as a reference point for comparison to future work.

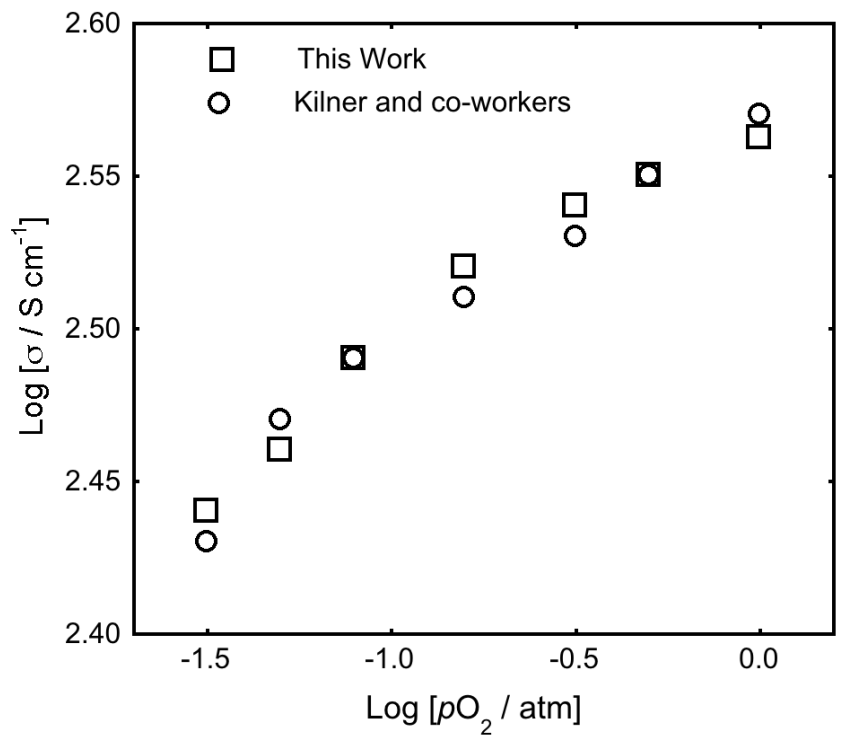

Figure 11. Double-log plot of conductivity as a function of $\mathrm{pO}_{2}$ for unmodified polished LSCF 6428 sample (Trial 2 in Fig 4) compared with data from Ref [9, 44]. 
Variations in sample preparation, especially degree of polishing, may also (to a lesser extent) be responsible for the difference in values of $k_{\text {chem }}$ and $D_{\text {chem }}$ measured in this work and reported elsewhere [9, 11, 44]. Kilner and co-workers do not discuss polishing or surface preparation of their ECR samples, while the Bouwmeester group reports polishing their samples prior to ECR with 1000 mesh SiC, though the amount of material removed is unknown. All LSCF 6428 samples used in this work were first polished to a mirror-finish with at least $0.3 \mathrm{~mm}$ of the original $1.3-1.1 \mathrm{~mm}$ sample thickness removed, surface modification was then performed (if necessary) prior to ECR testing. A higher degree of polishing would decrease the surface roughness and provide less surface area for oxygen exchange, which should decrease $k_{\text {chem }}$, as $k_{\text {chem }}$ is calculated from sample area, not actual surface area. However, if polishing were a significant factor, the values of $k_{\text {chem }}$ measured in this work would be lower, not higher, than those reported elsewhere. Removal of greater than $300 \mu \mathrm{m}$ of material from both surfaces may eliminate post-sintering surface contaminants such as Si [71], and expose the LSCF 6428 surface to provide more accurate measurements.

Finally, the ECR experiments were repeated on two polished bar samples, resulting in nearly identical $k_{c h e m}$ and $D_{c h e m}$ values. The average scatter on a log-scale was $\sim 0.1$ at each $\mathrm{pO}_{2}$ for both parameters. Thus, if the samples are assumed to be nominally identical, we must next inspect the experimental method.

The gas residence time above the sample in our reactor is $0.01 \mathrm{~s}$ with the abrupt change in $\mathrm{pO}_{2}$ occurring within $0.05 \mathrm{~s}$ as measured utilizing a mass spectrometer [OmniStar, Pfeiffer Vacuum, Nashua, NH, USA] at the outlet of the reactor tube. The experimental design appears to be satisfactory given the rapid change in gas composition and short residence time. Without any apparent problem with the sample or experimental setup, we turn to the data fitting procedure and application of Eqs. (15) (18). 
A precise determination of the roots of $\beta, \gamma$ and $\phi$ in Eqn. (18) is necessary to avoid significant error in the numerical values of $k_{\text {chem }}$ and $D_{c h e m}$ [53]. In the work presented here, the roots of $\beta, \gamma$ and $\phi$ are calculated to 13 decimal places, so error is not a likely factor in the discrepancy; however, the number of roots employed in the curve fit calculation significantly affects the results. Figure 12 shows $k_{\text {chem }}$ and $D_{\text {chem }}$ as a function of the number of roots in Eqn. 18 (also number of terms in sums of Eqn 16).

The value of $k_{\text {chem }}$ varies between $1.95 \times 10^{-3} \mathrm{~cm} / \mathrm{s}$ for 2 roots and $1.30 \times 10^{-2} \mathrm{~cm} / \mathrm{s}$ for 30 roots, nearly a full order of magnitude difference. The value of $D_{c h e m}$ decreases from 5.8 x $10^{-5} \mathrm{~cm}^{2} / \mathrm{s}$ at 2 roots to approximately $3 \times 10^{-5} \mathrm{~cm}^{2} / \mathrm{s}$ for $6-30$ roots. The ratio of $k_{\text {chem }} / D_{\text {chem }}$ also varies by more than one order of magnitude across the range of 2 to 30 roots. The quality of the fit for each number of roots was investigated by calculating the sum of the square residual, $S_{R}$, Eqn. (21), which is the difference between the raw normalized conductivity and the normalized conductivity generated by the fitting routine at each period:

$S_{R}=\sum_{t=1}^{n}\left(c_{t, \text { measured }}-c_{t, \text { fit }}\right)^{2}$

where $n$ is the number of data points and $c$ is normalized conductivity. $S_{R}$ remained virtually constant throughout the analysis at a value of $\sim 0.8$, indicated by the data overlaid on Figure 12. A multitude of solutions to the curve fit exist providing different values of $k_{\text {chem }}$ that fit the data equally well. While it appears that both $k_{\text {chem }}$ and $D_{\text {chem }}$ are converging as the number of roots increases, it should be noted that as more roots are added, the additional terms in Eqn. (16) contribute less to the magnitude of the sum. Furthermore, the quality of fit parameter, $S_{R}$, does not increase with increased number of roots. Therefore, our confidence in the determined values does not necessarily increase 
with increasing roots. We conclude that numerical values of $k_{\text {chem }}$ and $D_{\text {chem }}$ resulting from the simultaneous fit of both parameters are unreliable. To obtain numerical values of $k_{\text {chem }}$ and $D_{\text {chem }}$ for accurate comparison between laboratories, the sample thickness must be varied significantly such that analysis occurs completely in the $k_{\text {chem }}$ regime (thin film) or $D_{\text {chem }}$ regime (thick sample) and the number of adjustable parameters collapses to one. 

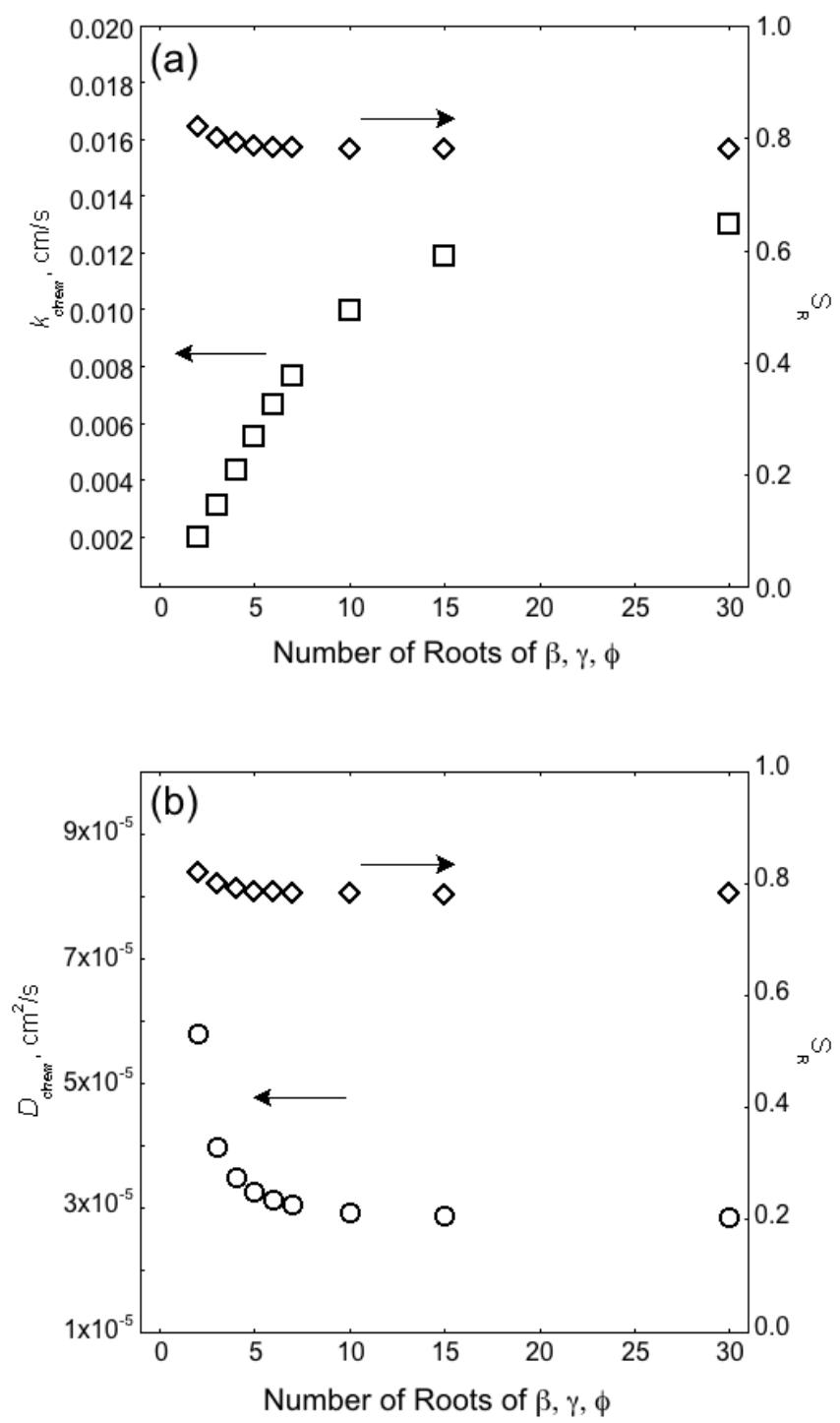

Figure 12. Number of roots of $\beta, \gamma$, and $\phi$ in Eq. (4) were varied for an unmodified polished LSCF 6428 sample (Trial 2 in Fig 4) for the $100 \%$ to $54.7 \% \mathrm{pO}_{2}$ switch: (a) Log $\left[k_{\text {chem }} / \mathrm{cm} \mathrm{s}^{-1}\right]$; (b) Log $\left[D_{c h e m} / \mathrm{cm}^{2} \mathrm{~s}^{-1}\right]$. Both $k_{\text {chem }}$ and $D_{\text {chem }}$ are plotted with the residual square error, $S_{R}[$ Eqn. (21)] of the data fit. 


\section{c. Measured data trends}

While we suggest that the absolute values of $k_{\text {chem }}$ and $D_{\text {chem }}$ extracted from simultaneous fitting are unreliable, trends in measured data for a fixed fitting procedure may be useful. XPS analysis of polished LSCF 6428 samples (Figure 8) indicates that the surface becomes strontium enriched when tested at $1073 \mathrm{~K}\left(800{ }^{\circ} \mathrm{C}\right)$ for over 150 hours, compared with an untested sample; however, Figure 9a shows no significant change in $k_{\text {chem }}$ over the course of four consecutive ECR trials $(80 \mathrm{hrs})$ at $1073 \mathrm{~K}(800$ $\left.{ }^{\circ} \mathrm{C}\right)$. A series of experiments were performed to further investigate whether surface enrichment of LSCF 6428 with its individual constituent elements would lead changes in oxygen surface exchange, as measured by an increase in the value of $k_{\text {chem }}$. Previous work with LSM cathodes has shown that surface enrichment of La is linked to decreased catalytic activity via high electrochemical resistance, presumably due to the formation of La-based oxides that hinder oxygen surface exchange [61, 62]. Work with LSCF 6482 cathodes indicate that after cathodic polarization the surface becomes highly Sr enriched and La depleted [64], thus one might expect an La-doped LSCF 6428 sample to yield lower $k_{\text {chem }}$ values. However, the results in Figure 13 indicate that enrichment of La, Sr, and Co did not significantly affect the values of $k_{\text {chem }}$ or $D_{\text {chem }}$ at any $\mathrm{pO}_{2}$ compared with a non-doped sample; however, Fe enrichment of the surface appeared to hinder oxygen exchange, resulting in a lowered $k_{\text {chem }}$ for the entire $\mathrm{pO}_{2}$ range, while $D_{\text {chem }}$ was not affected by the surface dopants. The decrease in $k_{\text {chem }}$ for the Fe-doped sample may be due to a passivation effect. 

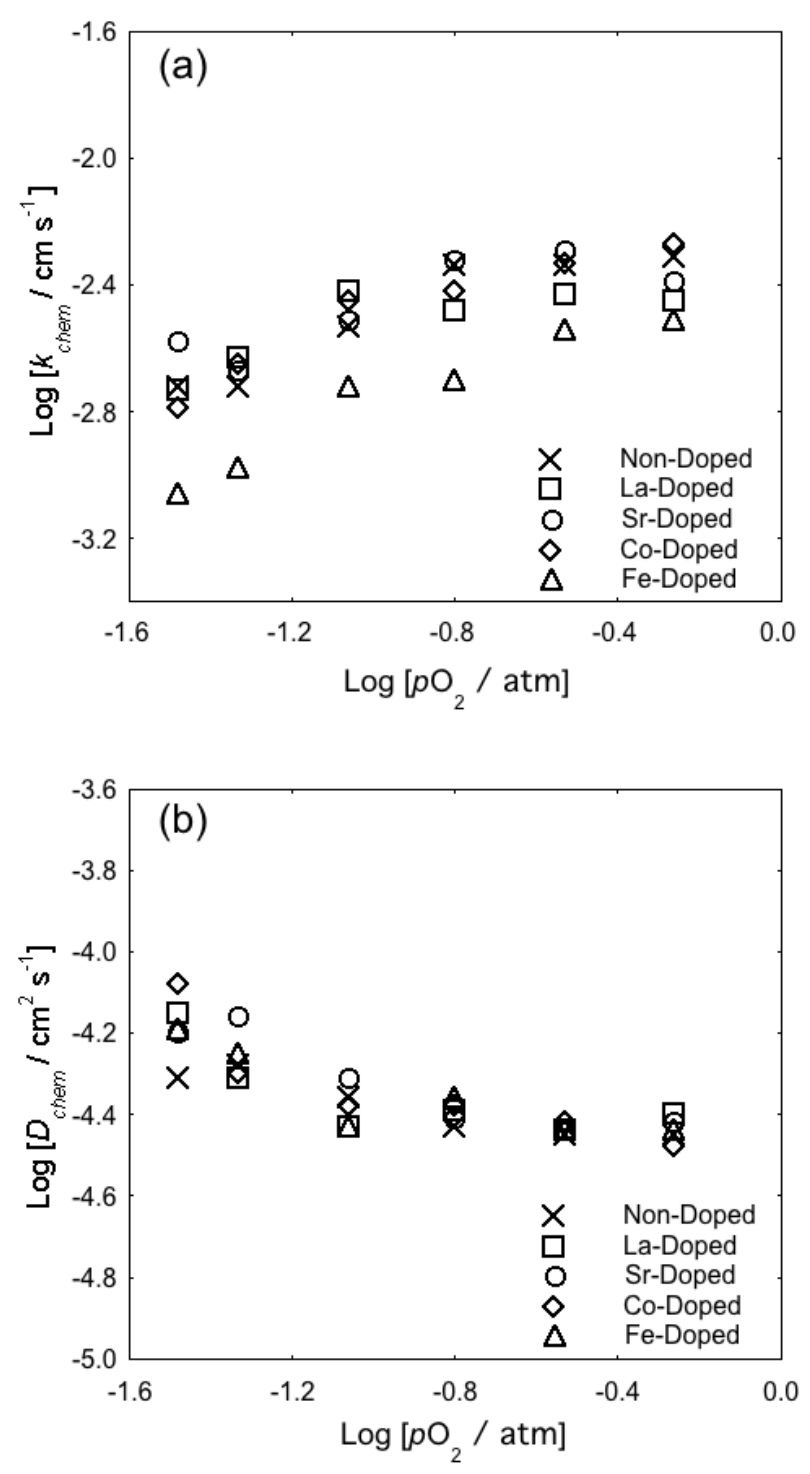

Figure 13. Reduction switches are plotted as a function of Log $\mathrm{pO}_{2}$ for LSCF 6428 samples at $1073 \mathrm{~K}\left(800^{\circ} \mathrm{C}\right)$ with and without surface doping: (a) Log $\left[k_{\text {chem }} / \mathrm{cm} \mathrm{s}^{-1}\right]$; (b) $\log \left[D_{\text {chem }} / \mathrm{cm}^{2} \mathrm{~s}^{-1}\right]$.

Nanoparticles (30-50nm in diameter), TEM shown in Figure 14, were also deposited onto a polished LSCF 6428 surface to investigate their effect on $k_{\text {chem }}$ and $D_{c h e m}$. There is evidence to suggest that nanostructured electrodes provide enhanced performance over bulk materials [65, 66]. XRD shown in Figure 15 confirms the 
presence of small phase impurities consistent with segregation; however, literature accounts indicate these impurities are currently unavoidable for reverse-micelle synthesis $[69,72,73]$. Cobalt oxide secondary phases are most likely responsible for the impurities (indicated in Figure 15) [69, 74-76].

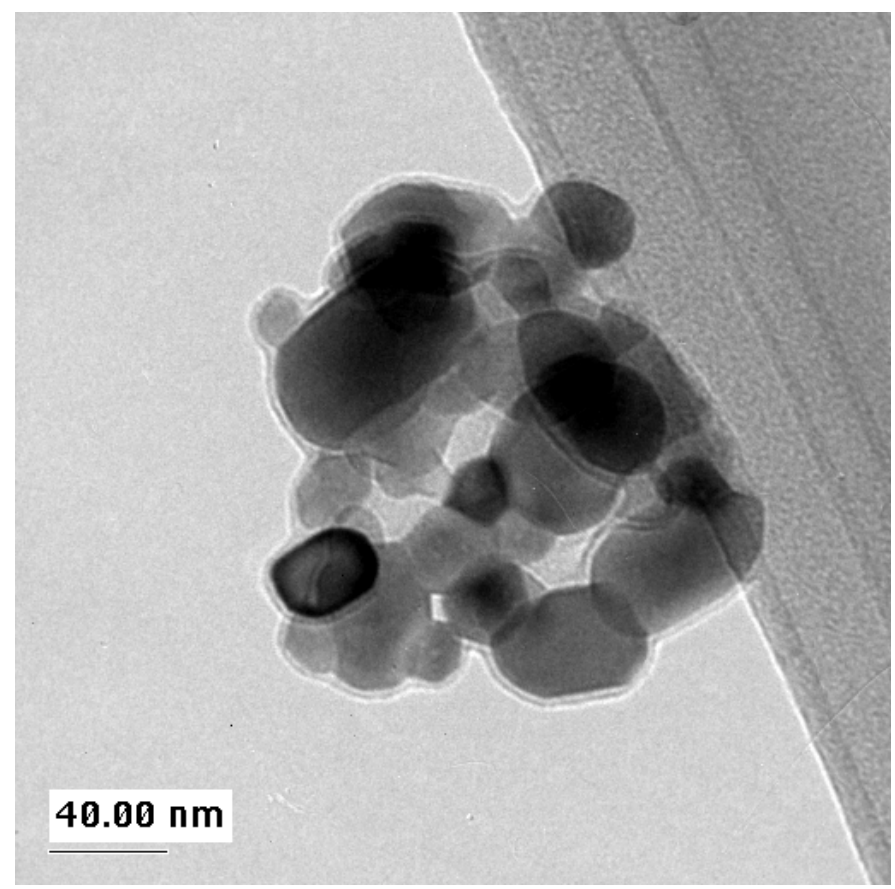

Figure 14. TEM image of LSCF 6428 nanoparticles (25-50 nm diameter). 


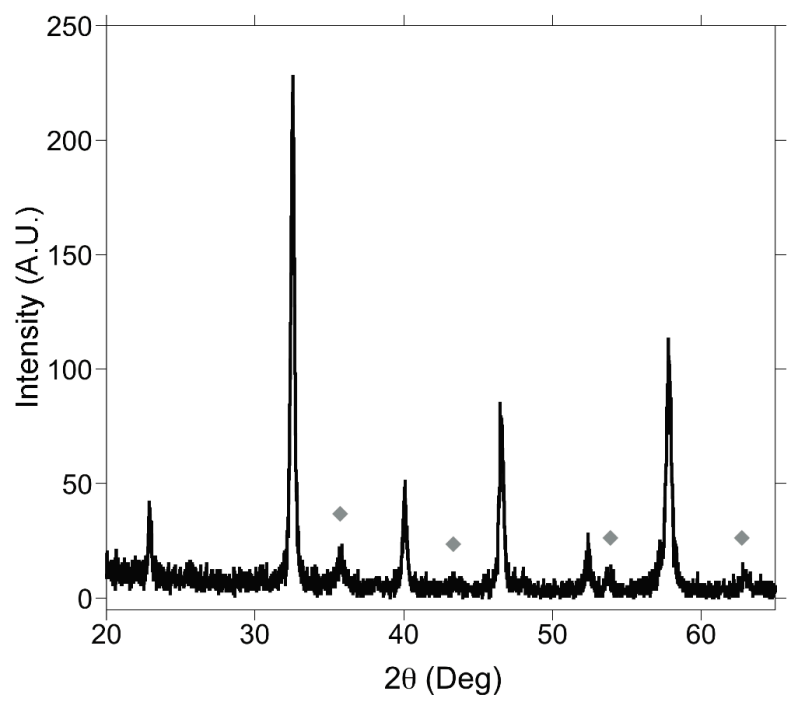

Figure 15. XRD of LSCF 6428 nanoparticles sintered in air at $1073 \mathrm{~K}\left(800{ }^{\circ} \mathrm{C}\right)$; unavoidable impurity phases are present and indexed as $(\diamond)$.

AFM images of the particles were taken after deposition but before ECR testing. Note that the particles were originally $30-50 \mathrm{~nm}$ spheres, but had agglomerated on the LSCF 6428 surface after sintering at $823 \mathrm{~K}\left(550^{\circ} \mathrm{C}\right)$ in air for 1 hour, forming features 30 $-45 \mathrm{~nm}$ in height and $\sim 350 \mathrm{~nm}$ in width. Figure 16a shows several such agglomerated features, while Figure $16 \mathrm{~b}$ provides a closer view of one feature. Conductivity relaxation was performed on the sample, nanoparticles were added again such that approximately twice as many agglomerated features were present, and then ECR was repeated. AFM was performed again after the second conductivity relaxation measurements. The particle clusters appeared to have lost height and gained width, as shown in Figure 17. The post-testing height of these features was $25-30 \mathrm{~nm}$, while the width increased to $\sim 400 \mathrm{~nm}$ in the area imaged, indicating they may have incorporated into the surface. 
(a)

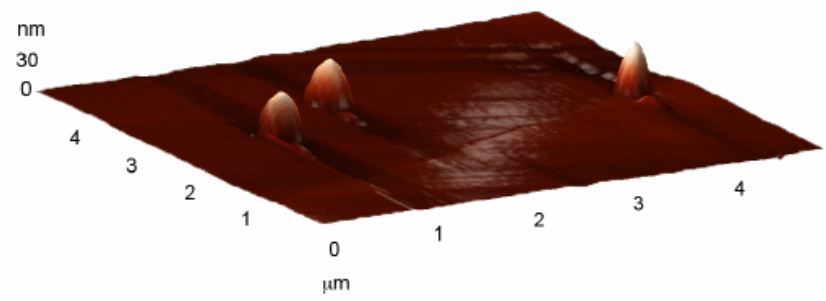

(b)

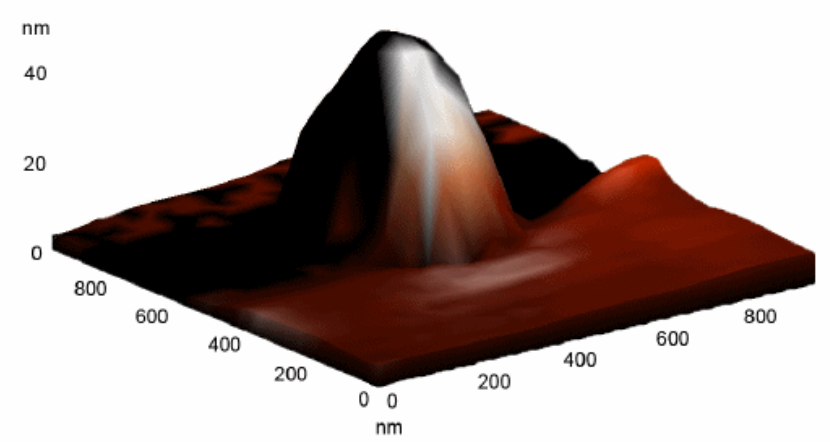

Figure 16. AFM images of sample with one addition of nanoparticles sintered to the surface before testing: (a) several particle clusters, height $\sim 30 \mathrm{~nm}$; (b) single nanoparticle cluster, height $\sim 43 \mathrm{~nm}$, width $\sim 350 \mathrm{~nm}$. 
(a)

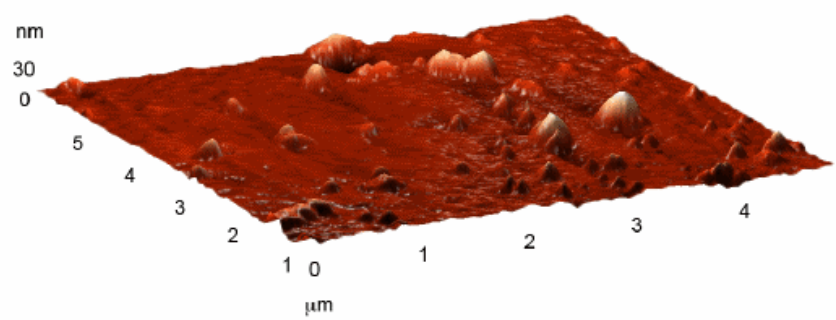

(b)

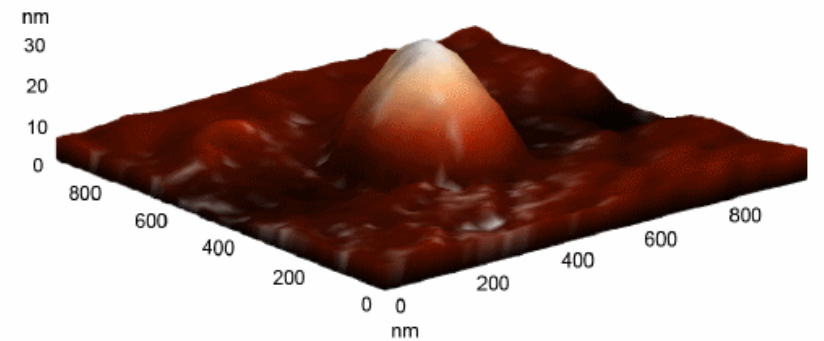

Figure 17. AFM images of sample after second addition of nanoparticles sintered to the surface and after more than 20 hours of testing at $1073 \mathrm{~K}\left(800^{\circ} \mathrm{C}\right)$ : (a) several particle clusters, height $\sim 25 \mathrm{~nm}$; (b) single nanoparticle cluster, height $\sim 28 \mathrm{~nm}$, width $\sim 400 \mathrm{~nm}$. 

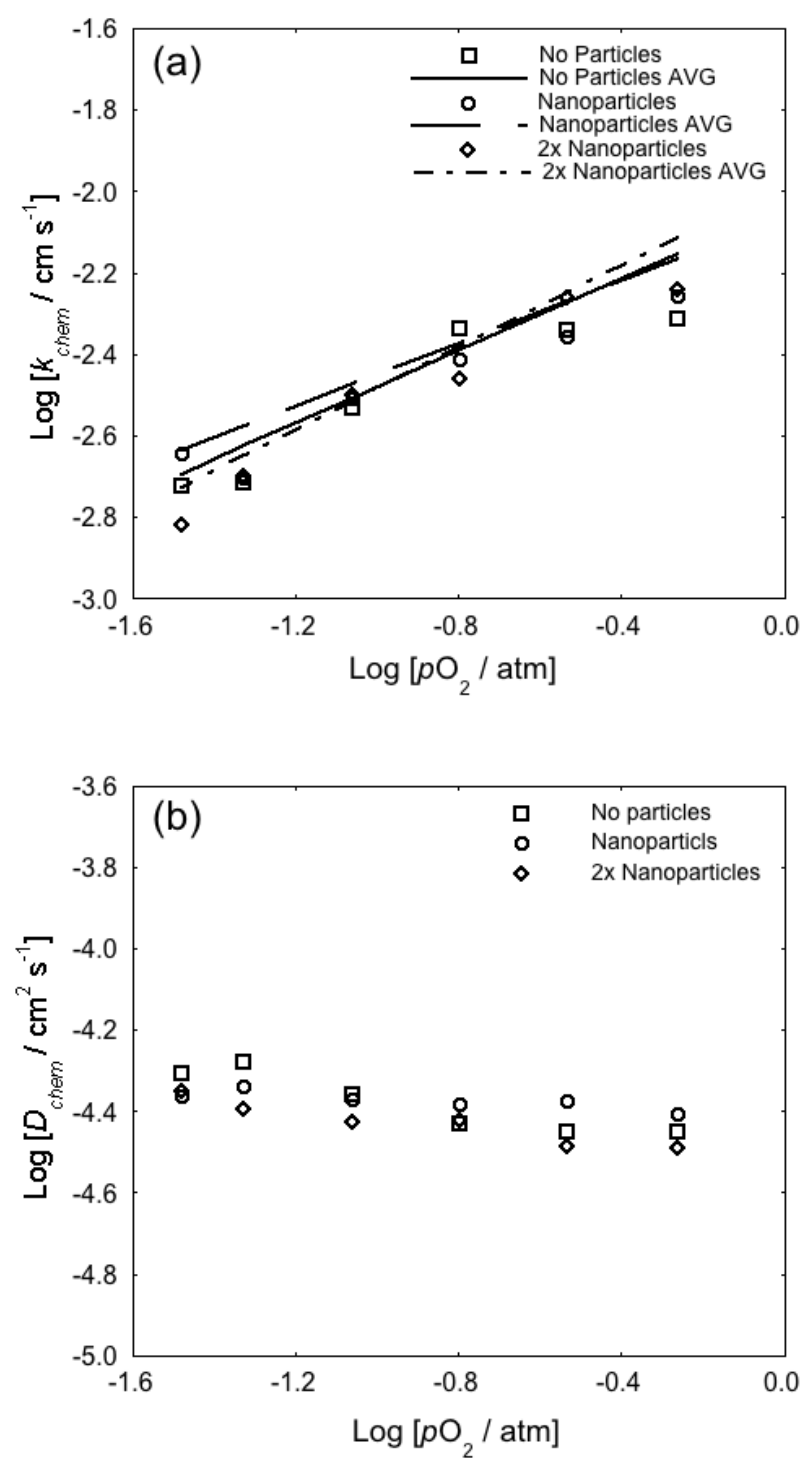

Figure 18. Three samples tested at $1073 \mathrm{~K}\left(800^{\circ} \mathrm{C}\right):(1)$ unmodified polished surface, $(2)$ nanoparticles added, and (3) double amount of nanoparticles added: (a) Log $\left[k_{\text {chem }} / \mathrm{cm}\right.$ $\mathrm{s}^{-1}$ ] for reduction switches with lines denoting the average between the oxidation and reduction switches; (b) $\log \left[D_{c h e m} / \mathrm{cm}^{2} \mathrm{~s}^{-1}\right]$. 
The $k_{\text {chem }}$ and $D_{\text {chem }}$ values extracted from the oxidation steps of both nanoparticle loadings are shown in Figure 18. There was almost no variation in $k_{\text {chem }}$ between the polished sample and the once-doped and twice-doped nanoparticle samples at each $\mathrm{pO}_{2}$ (Figure 18a), indicating that the nanoparticle-modified surface did not enhance $k_{\text {chem }}$. The particles were likely at too low a concentration ( 3 particle agglomerates per $5 \mu \mathrm{m}$ in Figure $16 \mathrm{a})$ to influence $k_{\text {chem }}$, which remained unchanged even after approximately doubling the amount of particles on the sample with the second addition. Sholklapper et al. report that LSM-YSZ cathodes must be doped with $\mathrm{Sm}_{0.5} \mathrm{Sr}_{0.5} \mathrm{CoO}_{3-\delta}$ nanoparticles more than 20 times via precipitation to achieve high loadings (tens of particles per $500 \mathrm{~nm}^{2}$ as determined by SEM) that increase the peak power density at $873 \mathrm{~K}\left(600^{\circ} \mathrm{C}\right)$ by nearly $100 \%$ with respect to an unmodified electrode [65]. Future work must include samples with well-controlled, densely populated microstructures to better characterize their effect on cathode performance.

\subsection{Conclusions}

Although reliable values of $k_{\text {chem }}$ and $D_{\text {chem }}$ cannot be extracted from a simultaneous fit of both variables, data trends can be studied for samples that are analyzed consistently. Trends in $k_{\text {chem }}$ for polished LSCF 6428 samples individually surface doped with La, Sr, Co, and Fe were investigated. Ultimately, La, Sr, and Co surface doping did not affect oxygen exchange kinetics, while Fe caused a decrease. Surface doping was also performed with LSCF 6428 nanoparticles, which were added twice to the same sample. Nanoparticle doping (at both particle densities) yielded no change in $k_{\text {chem }}$ compared with a non-doped sample most likely due to low particle density. In future, samples with well-controlled, densely populated microstructures must 
be manufactured to better characterize their effect on cathode performance, and specifically on the oxygen surface exchange coefficient. 


\section{Chapter 3 - Electrical Conductivity Relaxation of Layered}

\section{Perovskite Thin Films Deposited via Spray Pyrolysis}

\subsection{Introduction}

Layered perovskites of the series $\mathrm{LnBaCO}_{2} \mathrm{O}_{5+\delta}$ (where $\mathrm{Ln}=\mathrm{La}, \mathrm{Pr}, \mathrm{Nd}, \mathrm{Sm}, \mathrm{Gd}$ ) have long been investigated because of their magnetic properties [17, 77-81], but are more recently being studied as potential cathodes for SOFCs, because they have shown enhanced oxygen surface exchange kinetics and lower activation energies at reduced temperatures, compared with traditional $\mathrm{ABO}_{3}$ perovskites.[22-25] The improved activation energies at intermediate temperatures may be due to ordering of oxygen vacancies within the bulk structure to provide routes for facile oxygen transport [21, 23]. However, further study is necessary to understand the increased oxygen surface exchange reported for these materials, particularly as it relates to surface structure and composition of a sample. This information is essential for developing cathode materials that are better suited for operation in IT-SOFCs.

Electrical conductivity relaxation $(E C R)$ is a technique commonly used to determine the oxygen surface exchange coefficient, $k_{c h e m}$, and bulk diffusion coefficient, $D_{\text {chem }}$ of mixed oxygen anion and electronic conductors using bulk, rectangular samples [9, 11, 42-50]. However, Cox-Galhotra and Mclntosh [82] showed that simultaneous determination of $k_{\text {chem }}$ and $D_{\text {chem }}$ using electrical conductivity relaxation (ECR) yields unreliable values. Therefore, to obtain accurate values of $k_{\text {chem }}$, dense thin film samples must be used such that the bulk component negligible and $D_{c h e m}$ can be eliminated.

Perovskite thin films have been manufactured using techniques such as pulsed laser deposition, chemical vapor deposition, and spray pyrolysis [83-85]. However, spray pyrolysis is a comparatively low cost, scalable technique for depositing high quality 
polycrystalline films in a variety of morphologies and compositions [83, 86-89]. It involves spraying a metal nitrate precursor solution onto a heated substrate [88]. The stoichiometry of the metal nitrate solutions decomposes such that it is preserved in the resulting film [90].

Cubic perovskite thin films, especially of the form $\mathrm{La}_{1-x} \mathrm{Sr}_{x} \mathrm{Co}_{1-y} \mathrm{Fe}_{y} \mathrm{O}_{3-\delta}$ have been produced using spray pyrolysis $[83,90]$. However, to our knowledge, the production of dense polycrystalline double perovskite thin films with this technique has never been reported. Pulsed laser deposition (PLD) has been used to make epitaxial $\mathrm{PrBaCO}_{2} \mathrm{O}_{5+\delta}$ (PBCO) thin films on (001) $\mathrm{SrTiO}_{3}$ single crystal substrates, chosen due to the similar lattice constant $[15,91]$. Epitaxial $\mathrm{LaBaCO}_{2} \mathrm{O}_{5+\delta}(\mathrm{LBCO})$ films have similarly been made using PLD on $\mathrm{LaAlO}_{3}$ substrates, again due to a favorable lattice match [92], though $\mathrm{LaAlO}_{3}$ undergoes a structural transition from cubic to rhombohedral at $\sim 530{ }^{\circ} \mathrm{C}$ [93], which may result in cracking or delamination of the film at IT-SOFC conditions.

ECR has been performed on PBCO materials in the form of epitaxial thin films deposited onto single crystalline $\mathrm{SrTiO}_{3}$ [15] and polycrystalline bar samples [94] by Jacobson and co-workers; however, to our knowledge, ECR has not been performed on polycrystalline layered perovskite thin films. A two-parameter fit of the conductivity data was preformed for the epitaxial PBCO thin film $(\sim 195 \mathrm{~nm})$ to account for two distinct microstructural regions, resulting in two $k_{\text {chem }}$ values, $k_{1}$ and $k_{2}[15,34]$. At $477{ }^{\circ} \mathrm{C}(750$ K) between $10 \%$ and $2 \%$ oxygen, $k_{1}$ and $k_{2}$ were $\sim 5 \times 10^{-6}$ and $5 \times 10^{-7} \mathrm{~cm} / \mathrm{s}$, respectively [15]. The polycrystalline PBCO sample had a much higher reported $\mathrm{k}_{\text {chem }}$ value of $\sim 10^{-2} \mathrm{~cm} / \mathrm{s}$ at $477{ }^{\circ} \mathrm{C}$ (no $\mathrm{pO}_{2}$ range reported), obtained through a simultaneous fit with $D_{\text {chem }}$ [94]. The authors suggest that this discrepancy may be due to differences in crystallinity, surface contamination, and stoichiometry of the two samples [94]. 
In this study, polycrystalline PBCO thin films are deposited onto polished polycrystalline $\mathrm{SrTiO}_{3}$ substrates using spray pyrolysis. $k_{\text {chem }}$ is measured via ECR in the $650-850 \mathrm{~K}\left(377-577{ }^{\circ} \mathrm{C}\right)$ temperature range and the $100 \%$ to $0.05 \% \mathrm{pO}_{2}$ range.

\subsection{Experimental}

\section{a. Sample preparation}

Three grams of $\mathrm{SrTiO}_{3}$ (STO) powder [99.5\% purity, Sigma Aldrich, St. Louis, MO, USA] was uniaxially pressed into a 1-inch diameter disk, and was sintered in air at $1400{ }^{\circ} \mathrm{C}$ for $6 \mathrm{~h}$ with $2 \%$ min heating and cooling rates to obtain $>95 \%$ theoretical density, determined by measuring mass and volume. One side was progressively polished using P400 and P4000 silicon carbide polishing pads [Buehler, Lake Bluff, IL, USA] followed by a $0.05 \mu \mathrm{m}$ alumina suspension [MasterPrep Polishing Suspension, Buehler, Lake Bluff, IL, USA]. Rectangular bar substrates were cut from the polished disk to approximate dimensions of $1.0 \mathrm{~cm} \times 0.5 \mathrm{~cm} \times(0.05-0.1) \mathrm{cm}$ and were cleaned by sonication in ethanol prior to use.

A thin film of $\mathrm{PrBaCO}_{2} \mathrm{O}_{5+\delta}(\mathrm{PBCO})$ was deposited onto the polished STO substrate using a spray pyrolysis technique, shown in Figure 19. An aqueous nitrate solution equivalent to $0.033 \mathrm{M} \mathrm{PBCO}$ was prepared using $\operatorname{Pr}\left(\mathrm{NO}_{3}\right)_{3} \cdot 6 \mathrm{H}_{2} \mathrm{O}[99.9 \%$, Alfa Aesar, Ward Hill, MA, USA], $\operatorname{Sr}\left(\mathrm{NO}_{3}\right)_{2}$ [min 99\%, Alfa Aesar, Ward Hill, MA, USA], and $\mathrm{Co}\left(\mathrm{NO}_{3}\right)_{2} \cdot 6 \mathrm{H}_{2} \mathrm{O}$ [min 99\%, Acros Organics, Morris Plains, NJ, USA] precursors combined in the appropriate stoichiometric ratio in a solution of de-ionized water. The STO substrate was heated to $200{ }^{\circ} \mathrm{C}$ on a homemade resistive-heater plate and the PBCO solution was added to the surface via spray deposition [Air Brush Model 175-7, Badger Air-Brush Co., Franklin Park, IL, USA] with air at 0.5 barg as the carrier gas. The distance between the nozzle and the substrate was fixed at $20 \mathrm{~cm}$, and the volumetric 
flow rate was controlled at $3 \mathrm{~mL} / \mathrm{h}$ using a syringe pump [KDS100, KD Scientific, Holliston, MA, USA]. Two layers of PBCO were deposited: $0.5 \mathrm{~mL}$ of the $0.033 \mathrm{M} \mathrm{PBCO}$ solution (10 $\mathrm{min}$ ) was deposited per layer. The samples were heated and cooled at 3 $\% /$ min from $50-200{ }^{\circ} \mathrm{C}$ on the resistive heater before and after deposition of each layer to prevent cracking due to rapid thermal expansion. After each layer was deposited, the sample was sintered in air at $1100{ }^{\circ} \mathrm{C}$ for $10 \mathrm{~min}$ with $2 \% \mathrm{~min}$ heating and cooling rates.

A four-point configuration was utilized to collect DC conductivity data. Gold electrode wires [Alfa Aesar, Ward Hill, MA, USA] were attached to the film surface at each end of the bar sample using gold ink [Engelhard, Newark, NJ, USA]. Two additional contacts, placed $0.2-0.4 \mathrm{~cm}$ from each end of the bar, were made by again attaching gold wire to the surface of the film and applying gold ink to ensure good electrical contact. The sample was then heated to $150^{\circ} \mathrm{C}$ in air to allow the ink to dry.

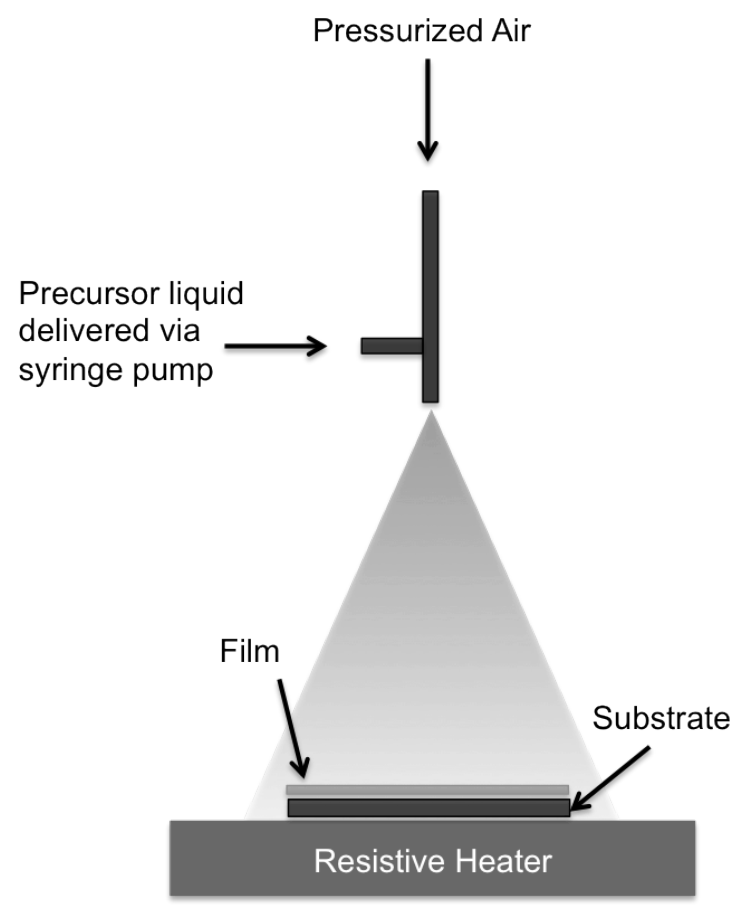

Figure 19. Experimental setup for spray pyrolysis thin film deposition. 


\section{b. Electrical conductivity relaxation (ECR)}

The sample was placed inside a quartz tube with oxygen [99.994\% purity, GTSWelco, Allentown, PA, USA] flowing at $200 \mathrm{~mL} / \mathrm{min}$. The gas $\mathrm{pO}_{2}$ was varied by diluting the oxygen stream with nitrogen [99.999\% purity, GTS- Welco, Allentown, PA USA]. Two gas pathways were included in the system, each with one oxygen stream and one nitrogen stream, such that two different $\mathrm{pO}_{2}$ values could be simultaneously achieved. Only one gas pathway was able to flow through the quartz tube at any time. A computercontrolled 4-way-valve [Swagelok, Dibert Valve \& Fitting Co, Inc., Richmond, VA, USA] was utilized to rapidly switch between gas pathways and achieve instantaneous step changes in $\mathrm{pO}_{2}$. The gas residence time above the sample is $0.01 \mathrm{~s}$ and the step change in $\mathrm{pO}_{2}$ occurs within $0.05 \mathrm{~s}$ as measured using a mass spectrometer [OmniStar, Pfeiffer Vacuum, Nashua, $\mathrm{NH}, \mathrm{USA}]$ at the quartz tube outlet. The gas flow rates for each $\mathrm{pO}_{2}$ stream were set with computerized mass flow controllers [Omega, Stamford, CT, USA]. The total flowrate was fixed at $200 \mathrm{~mL} / \mathrm{min}$ with $\mathrm{pO}_{2}$ ranging from $100 \%$ to $5.0 \%$ in steps that are equally spaced when viewed on a log-scale. A second gas mixture was available on the oxygen pathway that provided $1 \%$ UHP oxygen with balance UHP nitrogen [GTS-Welco, Allentown, PA, USA], making available a lower $\mathrm{pO}_{2}$ range of $1 \%$ to $0.05 \%$ when diluted with the nitrogen pathway. Each $\mathrm{pO}_{2}$ switch was measured twice, and two measurement schemes were used: (1) pO2 was decreased from $10 \%$ to $2 \%$, then increased to $10 \%$; (2) $\mathrm{pO}_{2}$ was decreased from $100 \%$ to $36.87 \%$ to $13.59 \%$ to $5.01 \%$ (three steps), then accessing the lower $\mathrm{pO}_{2}$ range, from $1.00 \%$ to $0.37 \%$ to $0.14 \%$ to $0.05 \%$ (three steps), and increased to $100 \%$ (six steps). Prior to changing the $\mathrm{pO}_{2}$, the sample was equilibrated in UHP oxygen at the measurement temperature, which ranged

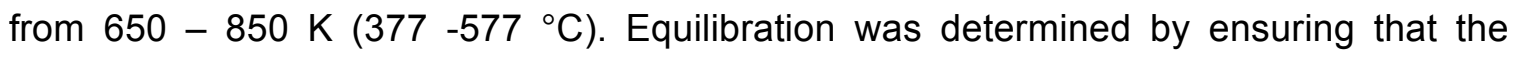
conductivity remained constant for approximately $1-2$ hours. 
Changes in conductivity resulting from the $\mathrm{pO}_{2}$ switches were measured using the four-point electrode arrangement described above with data recorded at a constant frequency of $100 \mathrm{~Hz}$ [Gamry Instruments Reference 600, Gamry Instruments, Malvern, PA, USA]. The conductivity was normalized for each $\mathrm{pO}_{2}$ switch according to Eqn. 15 and was fit to Eqn. 20, which is obtained from conservation of mass at the surface of the film (see Section 1.4 for derivation). The sole variable is the surface exchange coefficient, $k_{\text {chem }}$, measured in $\mathrm{cm} / \mathrm{s}$.

$\sigma_{n}=\frac{\sigma_{t}-\sigma_{0}}{\sigma_{\infty}-\sigma_{0}}$

$\left(\frac{\sigma_{t}-\sigma_{0}}{\sigma_{\infty}-\sigma_{0}}\right)=1-\exp \left(\frac{l t}{k_{c h e m}}\right)$

where $t$ is time in seconds; $\sigma_{n}$ is normalized conductivity, $\sigma_{t}$ is instantaneous conductivity at time $t, \sigma_{0}$ is initial conductivity and $\sigma_{\infty}$ is conductivity at equilibrium for a given $p \mathrm{O}_{2}$, and $I$ is the film thickness.

\section{c. Sample Characterization}

Powder X-ray diffraction patterns [X'Pert, PANalytical, USA] with $\mathrm{Cu}-\mathrm{Ka}$ radiation source and fixed slit width were collected on PBCO thin film samples. The patterns were obtained in the range of $15-85^{\circ}$ with a $0.008^{\circ}$ step size and a counting time of $10 \mathrm{~s} / \mathrm{step}$. The film thickness and surface structure prior to ECR testing was determined using a field emission scanning electron microscope (SEM) [JEOL JSM 6700, Tokyo, Japan]. 


\subsection{Results and Discussion}

The polycrystalline $\mathrm{PrBaCO}_{2} \mathrm{O}_{5+\delta}$ (PBCO) thin film deposited onto polished polycrystalline $\mathrm{SrTiO}_{3}$ (STO) shown in Figure 20a is dense and crack-free, though surface roughness is present. The grain size varies from approximately $0.3-1.0 \mu \mathrm{m}$. A cross-section of the film and substrate is in Figure 20b, showing that both layers are dense and that there are no gaps between the film and substrate. The average film thickness is approximately $1 \mu \mathrm{m}$.

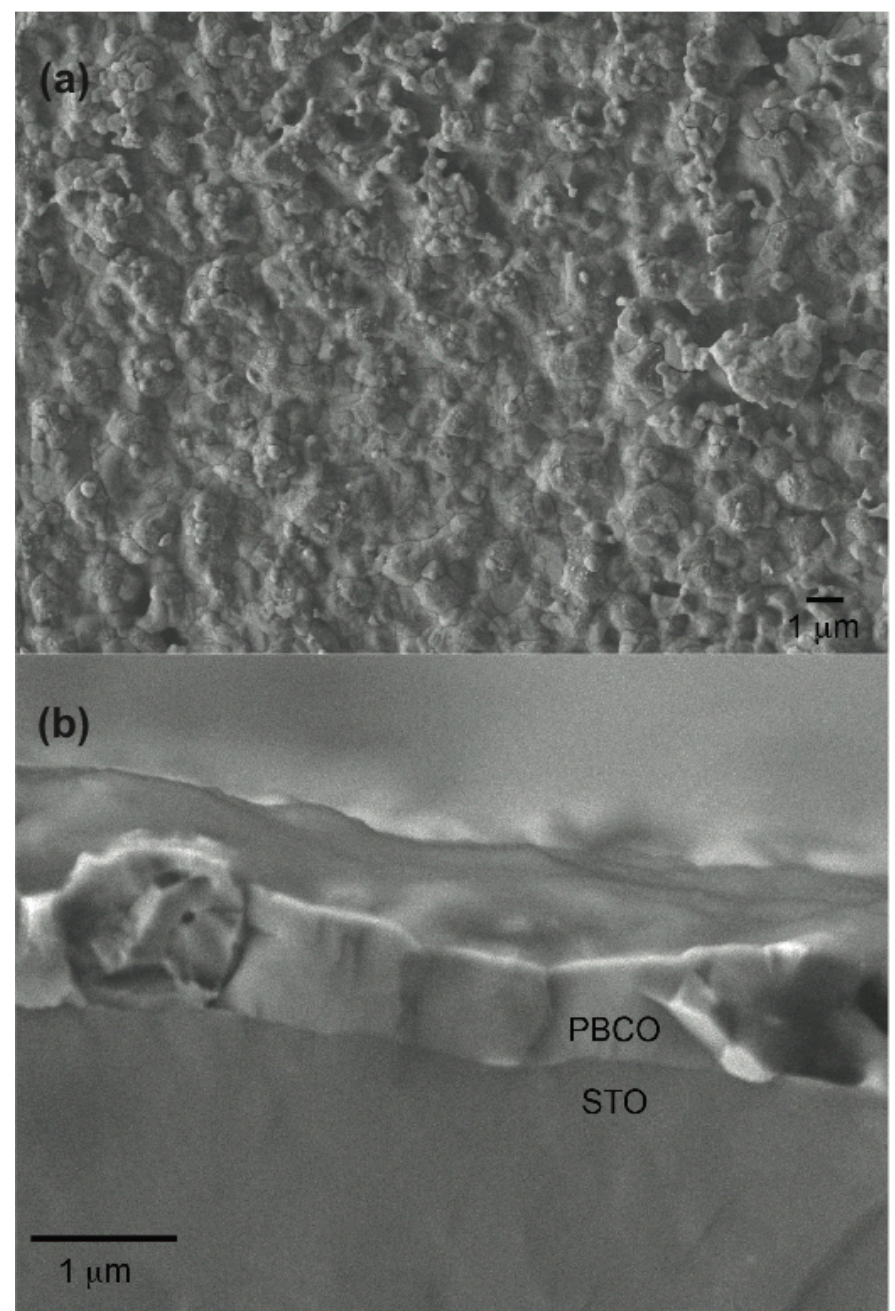

Figure 20. SEM images of as-synthesized PBCO thin films: (a) surface morphology; (b) cross-section with film and substrate labeled. 
X-ray diffraction of a PBCO film deposited on STO is shown in Figure 21. STO peaks overlap with many PBCO peaks due to their common perovskite structures. However, many layered perovskites, including PBCO, exhibit doublet peaks at the typical perovskite $2 \theta$ values. These doublets are present and marked in Figure 21, indicating that the PBCO double perovskite structure was formed. Four small-intensity impurity peaks are present and index to elemental $\mathrm{Pr}$ and Co, and are likely the result of incomplete conversion to the perovskite phase during the sintering step. Similar small impurity phases have been reported for thin films deposited with spray pyrolysis $[95,96]$.

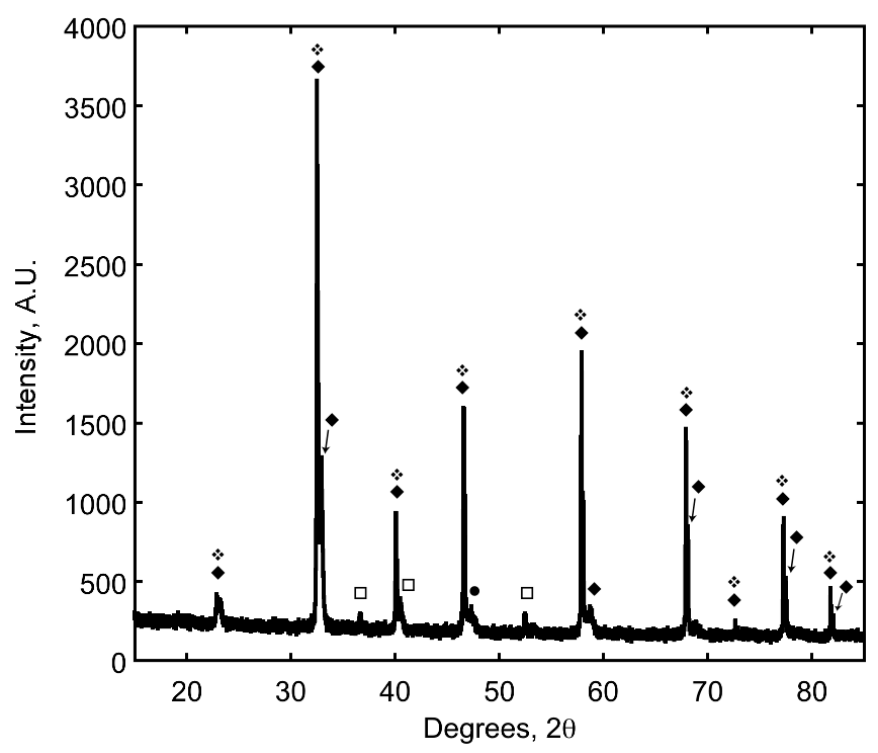

Figure 21. XRD of PBCO thin film. Peaks are indexed as marked: - PBCO; $\mathrm{SrTiO}_{3} ; \square-\mathrm{Pr} ; \bullet-\mathrm{Co}$.

Electrical conductivity relaxation (ECR) testing was performed on the PBCO film shown in Figure 20a. A representative model fit to the normalized conductivity data using Eqns. 15 and 20 is shown in Figure 22 for the $10 \%$ to $2 \% p \mathrm{O}_{2}$ switch at $427{ }^{\circ} \mathrm{C}(700 \mathrm{~K})$. The raw data exhibits more scattering compared with a typical bulk sample. The cause of this behavior is unknown, as the gold contacts were securely fastened to the film and 
no other sample or equipment issues that might affect data collection were apparent. This scattering was observed for each thin film sample tested. Published raw data could not be found for comparison, highlighting the importance of reporting such information. However, the model accurately predicts the average shape of the raw data curve in Figure 22.

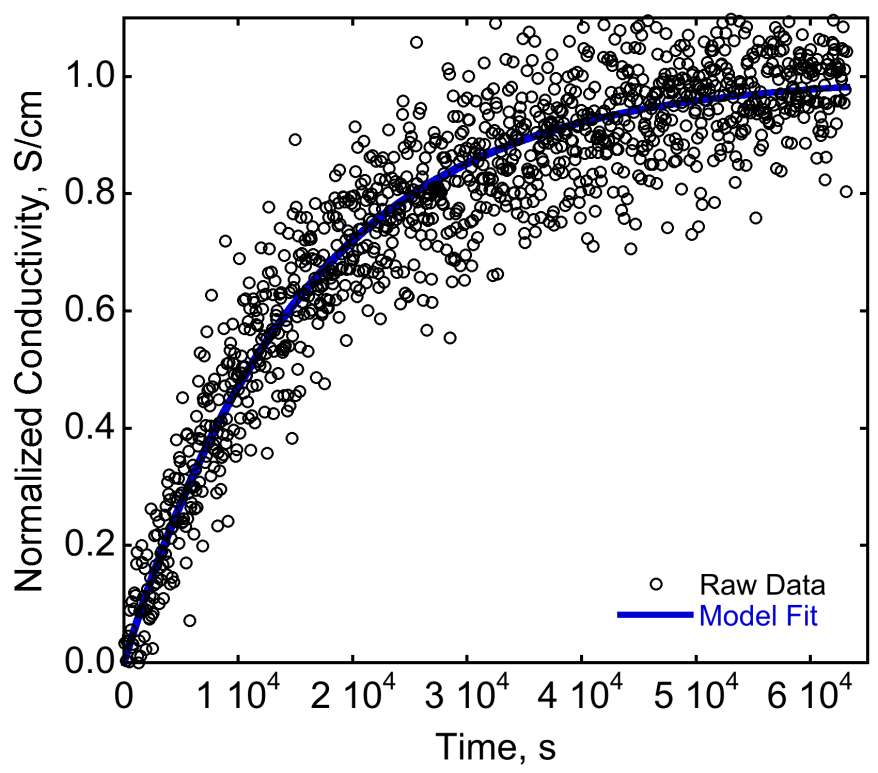

Figure 22. Normalized conductivity data and model fit for PBCO thin film at $427^{\circ} \mathrm{C}(700$ K) during the $\mathrm{pO}_{2}$ switch from $10 \%$ to $2 \%$ oxygen. For clarity, only a fraction of the collected raw data points are shown.

The resulting $k_{\text {chem }}$ values are plotted in Figure 23 and Figure 24 at various T-pO ranges. In Figure 23, $k_{\text {chem }}$ increases with temperature, which is due to a corresponding increase in oxygen vacancies within the material, leading to enhanced oxygen surface exchange at a given $\mathrm{pO}_{2}$ range. The values resulting from the low-to-high and high-tolow $\mathrm{pO}_{2}$ steps are in agreement, indicating that there are no mass transfer limitations. The change in $k_{\text {chem }}$ with $\mathrm{pO}_{2}$ at constant temperature is shown in Figure $24 . k_{\text {chem }}$ is a stronger function of temperature than $\mathrm{pO}_{2}$, as higher values correspond with higher 
temperature at all $\mathrm{pO}_{2}$. Across the $100 \%$ to $0.05 \% \mathrm{pO}_{2}$ range, $k_{\text {chem }}$ is approximately constant at each temperature. This behavior may be due to the relatively small amount of PBCO in the sample. For a bulk sample, $k_{\text {chem }}$ typically decreases with decreasing $\mathrm{pO}_{2}$ $[44,82,97]$, which is likely due to a local decrease in $\mathrm{pO}_{2}$ above the sample. A sufficiently thin sample would not have such mass transfer limitations, as evidenced by the results in Figure 24.

The $k_{\text {chem }}$ values in Figure 23 exhibit a trend consistent with the $k_{1}$ and $k_{2}$ values reported by Jacobson and co-workers [15] for epitaxial PBCO thin films. However, the values are approximately 1 order of magnitude lower than $k_{2}$ and two orders of magnitude lower than $k_{1}$, ranging from $8.6 \times 10^{-7} \mathrm{~S} / \mathrm{cm}$ at $577{ }^{\circ} \mathrm{C}(850 \mathrm{~K})$ to $3.4 \times 10^{-9}$ $\mathrm{S} / \mathrm{cm}$ at $377 \mathrm{C}(650 \mathrm{~K})$. It is unclear how the epitaxial and polycrystalline thin film values would compare if both utilized a one-parameter fit of the conductivity data. The difference in the $k_{\text {chem }}$ vs $k_{1}$ and $k_{2}$ values may also be attributed to the dissimilar microstructure of the two thin films - uniform polycrystalline with surface roughness and epitaxial with two distinct microstructures [34] - though the relationship between microstructure and oxygen transport behavior is not well understood for these materials. As with the epitaxial thin film, the $k_{\text {chem }}$ values in Figure 23 and Figure 24 are also several orders of magnitude lower than those reported for bulk PBCO [94]. 


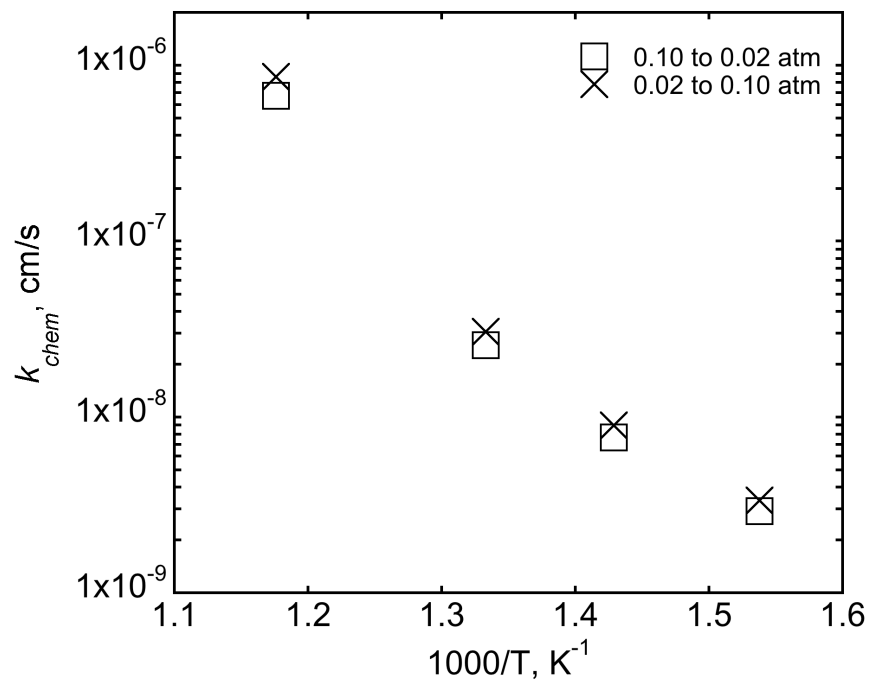

Figure 23. PBCO thin film: $k_{\text {chem }}$ as a function of temperature, $650-850 \mathrm{~K}(377-577$ $\left.{ }^{\circ} \mathrm{C}\right)$, for the step change from $10 \%$ to $2 \%$ oxygen.

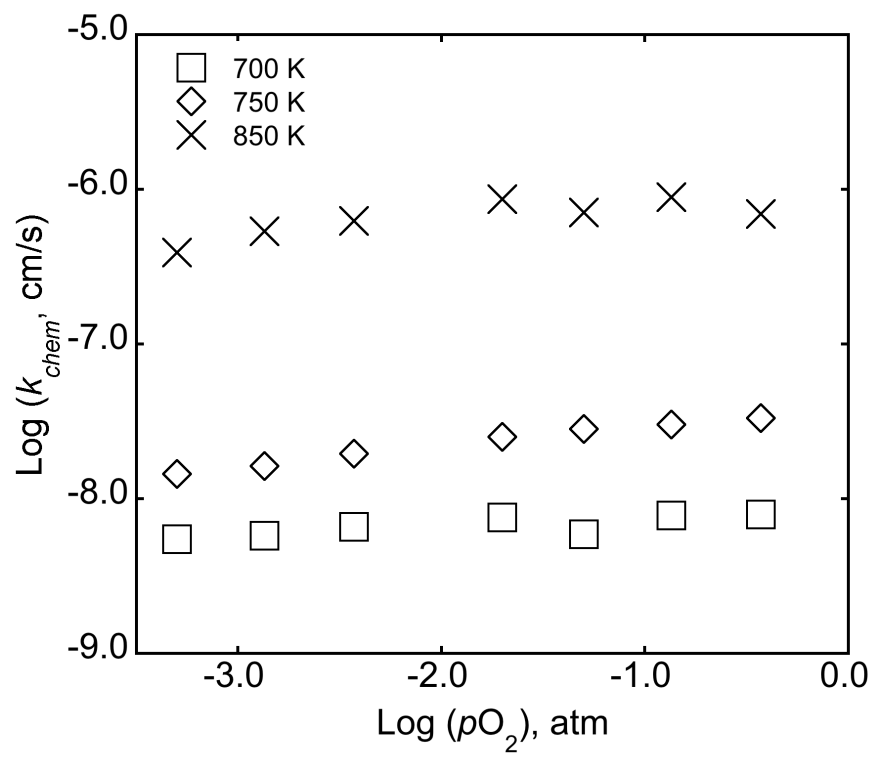

Figure 24. PBCO thin film: $\log k_{\text {chem }}$ as a function of $\log \mathrm{pO} 2$ (100\% to $0.05 \%$ oxygen) at $700-850 \mathrm{~K}\left(427-577^{\circ} \mathrm{C}\right)$. 
Despite discrepancies with PBCO epitaxial thin films and bulk PBCO, these oxygen surface exchange coefficient values compare favorably with those reported for traditional single perovskite SOFC cathode materials. For example, Søgaard et al.[98] performed ECR on $\left(\mathrm{La}_{0.6} \mathrm{Sr}_{0.4}\right)_{0.99} \mathrm{FeO}_{3-\delta}$ thin films deposited onto MgO single crystals, resulting in $k_{c h e m}$ values approximately equal to those in Figure 24 , but at a temperature range of $702{ }^{\circ} \mathrm{C}$ to $548{ }^{\circ} \mathrm{C}$, more than $100{ }^{\circ} \mathrm{C}$ higher than the conditions in this study. Thus, PBCO may be a suitable material for use in IT-SOFCs compared with some traditional perovskite materials, due to its enhanced oxygen transport properties at intermediate temperatures.

\subsection{Conclusions}

Polycrystalline $\mathrm{PrBaCO}_{2} \mathrm{O}_{5+\delta}$ (PBCO) thin films were deposited onto polished polycrystalline $\mathrm{SrTiO}_{3}$ (STO) using a spray pyrolysis technique, resulting in dense, crackfree films with surface roughness. Electrical conductivity relaxation was used to determine the oxygen surface exchange coefficient, $k_{\text {chem }}$, in the $650-850 \mathrm{~K}$ (377 -577 ${ }^{\circ} \mathrm{C}$ ) temperature range and the $100 \%$ to $0.05 \% \mathrm{pO}_{2}$ range. The resulting values range from $8.6 \times 10^{-7} \mathrm{~cm} / \mathrm{s}$ at $577{ }^{\circ} \mathrm{C}(850 \mathrm{~K})$ to $3.4 \times 10^{-9} \mathrm{~cm} / \mathrm{s}$ at $377 \mathrm{C}(650 \mathrm{~K}), 1-2$ orders of magnitude lower than the reported values for epitaxial PBCO thin films. Ultimately, PBCO may be a suitable candidate for use in IT-SOFCs due to its greater $k_{\text {chem }}$ values at intermediate temperature compared with some traditional single perovskite materials. 


\section{Chapter 4 - Neutron Diffraction of $\mathrm{NdBaCO}_{2} \mathrm{O}_{5+\delta}$ at in-situ SOFC Conditions}

\subsection{Introduction}

As discussed in Chapter 1, Perovskite-structured MIEC materials must operate at high temperatures $\left(>500^{\circ} \mathrm{C}\right)$ and in oxygen partial pressures ranging from 1 to $10^{-5} \mathrm{~atm}$ in SOFCs, as well as maintain structural, mechanical and chemical stability, while providing high mixed conductivity and catalytic activity under operating conditions. [23, 36, 99-101] The bulk conductivity of these materials is dictated by crystal structure, oxygen stoichiometry, and cation oxidation state. These parameters are a function of temperature and oxygen partial pressure, thus, in order to understand the structurefunction relationships in this material class, it is imperative to measure these properties under in-situ conditions.

Neutron powder diffraction (NPD) allows for precise, simultaneous determination of information such as crystal symmetry, lattice parameters, oxygen stoichiometry, and degree of cation and vacancy ordering. NPD has been performed on $\mathrm{PrBaCO}_{2} \mathrm{O}_{5+\delta}$ materials with an oxygen stoichiometry $(\delta)$ range of $\sim 0.2$ to $\sim 0.9$ from $-275{ }^{\circ} \mathrm{C}$ to 350 ${ }^{\circ} \mathrm{C}[18,80,102]$ and at $27-547{ }^{\circ} \mathrm{C} .[21,103]$ Similarly, NPD studies of $\mathrm{NdBaCo}_{2} \mathrm{O}_{5+\delta}$ (NBCO) materials with varying $\delta$ values have been performed at and below room temperature, all presumably in air.[20, 77, 104, 105] $\mathrm{NdBa}_{0.5} \mathrm{Sr}_{0.5} \mathrm{Co}_{2} \mathrm{O}_{5+\delta}$ has more recently been characterized using NPD in the range of $100-700{ }^{\circ} \mathrm{C},[106]$ but to our knowledge there have been no high temperature NPD studies of $\mathrm{NdBaCO}_{2} \mathrm{O}_{5+\delta}$. It would be highly advantageous to obtain further information at higher temperatures and in a 
range of $\mathrm{pO}_{2}$ environments, which more accurately reflect in-situ conditions during SOFC operation.

Layered perovskites of the series $\mathrm{LnBaCO}_{2} \mathrm{O}_{5+\delta}$ (where $\mathrm{Ln}=\mathrm{La}, \mathrm{Pr}, \mathrm{Nd}, \mathrm{Sm}, \mathrm{Gd}$ ) have long been investigated because of their magnetic properties,[17, 77-81] but are more recently being studied as potential cathodes for SOFC and oxygen separation applications.[23, 24, 29] These materials exhibit A-site ordering with alternating layers of Ln and $\mathrm{Ba}$ in the $\left(\begin{array}{lll}0 & 0 & 1\end{array}\right)$ direction.[17] Oxygen vacancies are primarily located in the $\mathrm{LnO}_{\delta}$ layers.[17] When all O-sites are fully occupied, the Co-sites are octahedrally coordinated as $\mathrm{CoO}_{6}$. Oxygen vacancies in the $\mathrm{LnO}_{\delta}$ layer result in square pyramidal Co-site coordination as $\mathrm{CoO}_{5}$. Therefore, $\mathrm{LnBaCO}_{2} \mathrm{O}_{5+\delta}$ materials contain a mixture of Co-sites in octahedral and square pyramidal configurations with varying degrees of ordering based on oxygen stoichiometry and temperature.[18-21] This ordering phenomenon is thought to account for observations of enhanced oxygen surface exchange kinetics and lower activation energies at reduced temperatures, compared with traditional $\mathrm{ABO}_{3}$ perovskites.[22-25] However, this hypothesis has not been structurally verified at cathode operating conditions (> $500{ }^{\circ} \mathrm{C}, \mathrm{pO}_{2} 1-10^{-5} \mathrm{~atm}$ ). These materials have been well characterized at low temperatures, and studies have been devoted to investigating their catalytic properties at cathode operating temperatures and at varying $\mathrm{pO}_{2}$ environments [18, 22, 23, 25-35], but few studies have investigated their structural properties in such conditions.

The crystal structure of $\mathrm{LnBaCO}_{2} \mathrm{O}_{5+\delta}$ compounds has primarily been described as tetragonal, $P 4 / \mathrm{mmm}$, or orthorhombic, $P m m m$. The tetragonal structure has been reported at intermediate oxygen stoichiometries $(0.75<\delta<0.5)[18,19,80]$ and at $\mathrm{T}>$ $500{ }^{\circ} \mathrm{C}$ for $\delta \sim 0.5$ materials.[21, 103, 106]. Otherwise, the orthorhombic structure prevails, especially at $\delta \sim 0.5$ and $T<500{ }^{\circ} \mathrm{C} .[17,19-21,77,105]$ Streule et al. [21, 103] 
have determined an orthorhombic to tetragonal transition temperature for $\mathrm{PrBaCo}_{2} \mathrm{O}_{5+\delta}$ at $503{ }^{\circ} \mathrm{C}$. Consistent with these results, Kim et al.[29] have used high temperature $\mathrm{x}$-ray diffraction to identify an $\mathrm{NdBaCO}_{2} \mathrm{O}_{5+\delta}$ orthorhombic to tetragonal transition at $500{ }^{\circ} \mathrm{C}$. Similarly, Azad et al.[106] have used NPD to determine that $\mathrm{NdBa}_{0.5} \mathrm{Sr}_{0.5} \mathrm{Co}_{2} \mathrm{O}_{5+\delta}$ has a $\mathrm{P} 4 / \mathrm{mmm}$ structure in the $100-700{ }^{\circ} \mathrm{C}$ range, but between $100{ }^{\circ} \mathrm{C}$ and $200{ }^{\circ} \mathrm{C}$ the unit cell changes from $\left(2 a_{p} \times 2 a_{p} \times 2 a_{p}\right)$ to $\left(a_{p} \times 2 a_{p} \times 2 a_{p}\right)$. There are a variety of unit cells reported within these space groups at various temperature and $\delta$ ranges for $\mathrm{LnBaCo}_{2} \mathrm{O}_{5+\delta}$ materials, though the most common are $P 4 / m m m\left(a_{p} \times a_{p} \times 2 a_{p} ; 2 a_{p} \times 2 a_{p}\right.$ $\left.\times 2 a_{p}\right)$ and Pmmm $\left(a_{p} \times 2 a_{p} \times 2 a_{p} ; 2 a_{p} \times 2 a_{p} \times 2 a_{p}\right)$, where $a_{p}$ is the lattice parameter of a simple cubic perovskite $\left(a_{p} \sim a\right)$.

This study provides structural information obtained via NPD for $\mathrm{NdBaCO}_{2} \mathrm{O}_{5+\delta}$ at in-situ SOFC conditions $\left(550-825^{\circ} \mathrm{C}, \mathrm{pO}_{2} 1-10^{-5} \mathrm{~atm}\right)$, including crystal symmetry, lattice parameters, oxygen stoichiometry, and degree of vacancy ordering.

\subsection{Experimental}

Phase pure $\mathrm{NdBaCO}_{2} \mathrm{O}_{5+\delta}(\mathrm{NBCO})$ layered perovskite oxide was synthesized by conventional solid-state reaction. Required amounts of $\mathrm{Nd}_{2} \mathrm{O}_{3}, \mathrm{BaCO}_{3}$, and $\mathrm{Co}_{3} \mathrm{O}_{4}$ [min 99.7\% purity, Alfa Aesar, Ward Hill, MA, USA] were thoroughly mixed using mortar and pestle and calcined at $1000{ }^{\circ} \mathrm{C}$ for $12 \mathrm{~h}$ in air. The calcined powders were then ground, pressed into pellets, and sintered at $1200{ }^{\circ} \mathrm{C}$ for $12 \mathrm{~h}$ in air, followed by cooling to room temperature at a rate of $4{ }^{\circ} \mathrm{C} / \mathrm{min}$.

Neutron diffraction patterns were collected at the POWGEN beamline, Spallation Neutron Source (SNS), Oak Ridge National Laboratory, Oak Ridge, TN, USA. 5.264 g of the NBCO powder sample was placed in a quartz basket with a $0.5 \mathrm{~cm}$ radius and $4 \mathrm{~cm}$ length. A vanadium tube furnace, with elements operating under vacuum conditions, was 
used to heat the sample. A long quartz tube was placed inside the furnace with its ends outside the hot zone. A quartz wire was used as a vertical hanger for the quartz sample basket; the basket was lowered into the larger quartz tube until the sample was in the path of the beam and in the furnace hot zone. The sample environment was sealed with Swagelok (Solon, Ohio, USA) ultra-torr fittings, to create a gas environment isolated from the vacuum of the furnace. Two thermocouples placed outside the neutron beam monitored the furnace temperature. A thermal gradient existed between the two probes, such that the sample temperature was approximately $15-30{ }^{\circ} \mathrm{C}$ higher than the furnace controller readings reported here. The experimental setup is shown schematically in Figure 25.

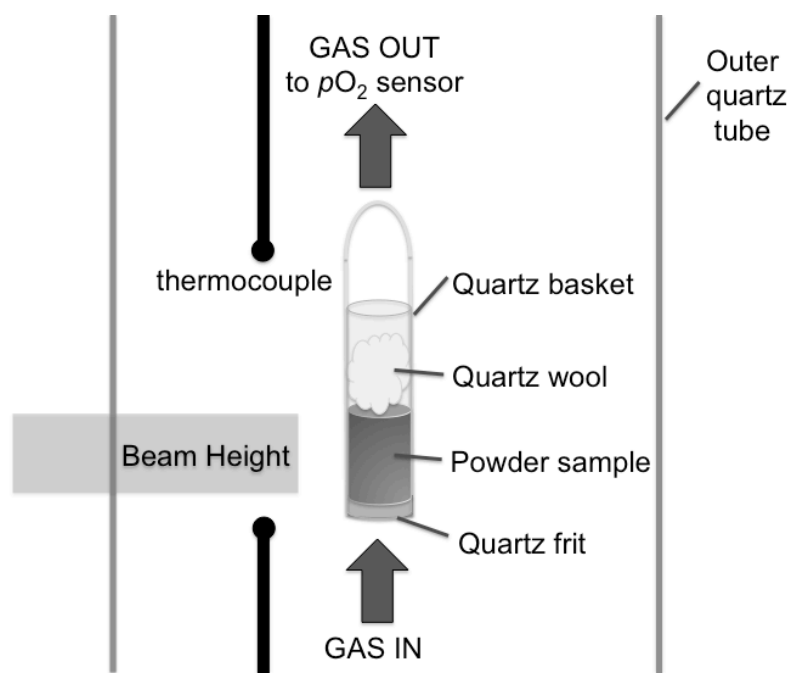

Figure 25. Schematic of neutron diffraction experimental setup. Note that the basket is hanging from the end of a sealed quartz tube of similar diameter (not depicted).

The powder sample was equilibrated in four $p \mathrm{O}_{2}$ environments: $10 \%, 1 \%, 0.1 \%$ and $0.01 \%$ ultra high purity (UHP) oxygen with the balance UHP nitrogen at the inlet. The chamber pressure was 1 atm, yielding oxygen partial pressures $\left(p \mathrm{O}_{2}\right)$ of $10^{-1}, 10^{-2}$, 
$10^{-3}$ and $10^{-4} \mathrm{~atm}$. Gas mixtures flowed continually at $400 \mathrm{sccm}$ through the large tube from bottom to top, entering the sample basket through a quartz frit located on the bottom. The outlet gas $\mathrm{pO}_{2}$ was continually recorded using a stabilized zirconia oxygen sensor [Imtech, Knoxville, TN, USA]. An initial diffraction pattern was collected at $10^{-1}$ atm oxygen while the sample cooled from $60-50{ }^{\circ} \mathrm{C}$. Diffraction patterns were then collected at four temperatures within each gas environment: $550{ }^{\circ} \mathrm{C}, 650{ }^{\circ} \mathrm{C}, 750{ }^{\circ} \mathrm{C}$, and $825{ }^{\circ} \mathrm{C}$, in that order, starting from the highest $\mathrm{pO}_{2}$ and moving lower. The sample temperature was decreased to $550{ }^{\circ} \mathrm{C}$ upon switching gases.

Diffraction patterns were collected in the $d$-spacing range of $0.45-3.6 \AA$. Several patterns with short collection durations (5-20 $\mathrm{min}$ ) were recorded during the equilibration period following changes in temperature and/or $\mathrm{pO}_{2}$. Equilibration was judged by no shift in the lattice parameter between short scans. This was typically achieved within 20 minutes - 1 hour. Once equilibrated, a pattern was recorded until a total proton charge of (5.0-7.0) x $10^{12} \mathrm{pC}$ was reached, which corresponded to approximately 1.5-2.0 hours per scan, depending on beam intensity. These were utilized for the refinements reported here. Background scans of the quartz tubes and basket were recorded at each temperature used in the study. These diffraction patterns were subtracted from the raw data prior to further analysis.

Rietveld [107] refinements were performed using the GSAS package.[108] The lattice parameter, fractional occupancy of all oxygen sites, thermal parameters (either isotropic or anisotropic) and positions of all sites were refined for each pattern, as well as the $\gamma_{1}$ and $\sigma_{2}^{2}$ profile parameters. A combined scale factor was refined for the $60-50{ }^{\circ} \mathrm{C}$ data set, the four $10^{-1}$ atm oxygen data sets, and the four $10^{-4}$ atm data sets. That fixed value was held constant in all data sets. Any additional constraints are noted when describing specific models. We present two separate tetragonal $(P 4 / \mathrm{mmm})$ refinement 
models in this work, defined as Models 1 and 2 in the following section. Model 1 includes one site each of $\mathrm{Nd}, \mathrm{Ba}$, and $\mathrm{Co}$, and three $\mathrm{O}$ sites $(\mathrm{O} 1, \mathrm{O} 2, \mathrm{O} 3)$, while Model 2 incorporates split $\mathrm{Nd}$ and $\mathrm{O} 2$ sites. Structural refinements were initially performed on each pattern using Model 1 with the same default starting point. Model 2 was refined using Model 1 as a starting point. The occupancies of oxygen sites were refined to determine the total oxygen vacancy concentration of the material. The standard deviation of these values is derived from the fit accuracy and is indicated by error bars on the relevant data points.

\subsection{Results and Discussion}

a. Sample Environment and Equilibration

Outlet $\mathrm{pO}_{2}$ data for the first two and last two patterns collected during this study, corresponding to $\mathrm{pO}_{2}=10^{-1}$ atm at 550 and $650{ }^{\circ} \mathrm{C}$, and $p \mathrm{O}_{2}=10^{-4}$ atm at 750 and 825 ${ }^{\circ} \mathrm{C}$, is shown in Figure 26. The sharp rises in $\mathrm{pO}_{2}$ in each section of the graph correspond to the points at which temperature was increased to measure the next data set. Figure 27 tracks the $P 4 / \mathrm{mmm}$ lattice parameter stabilization during the equilibration period for (a) $p \mathrm{O}_{2}=10^{-1} \mathrm{~atm}$ at $550{ }^{\circ} \mathrm{C}$ and (b) $10^{-4}$ atm at $825^{\circ} \mathrm{C}$. 


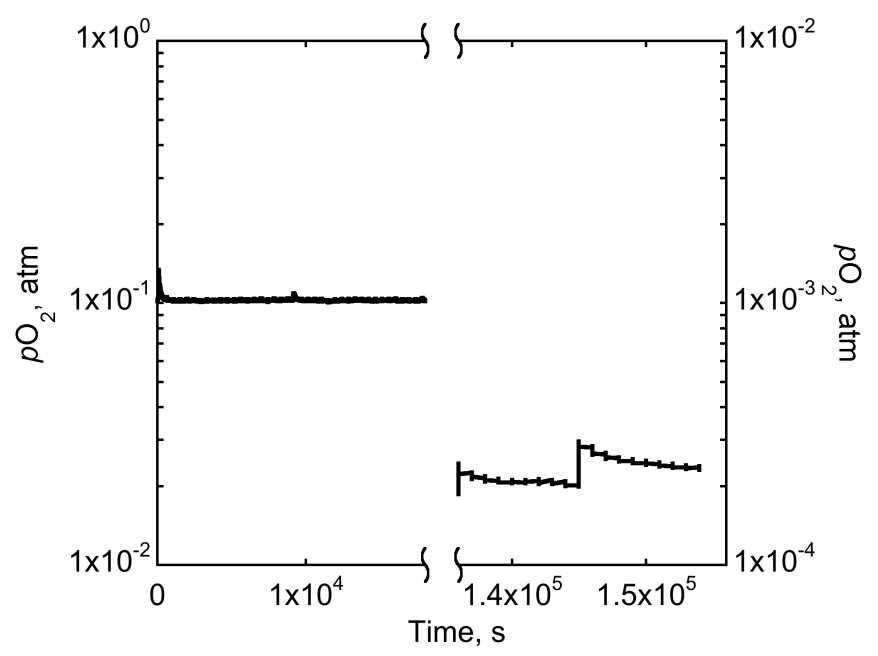

Figure 26. Semi-logarithmic plot of effluent gas oxygen content for inlet mixtures of $10^{-1}$ atm oxygen at $550{ }^{\circ} \mathrm{C}$ and $650{ }^{\circ} \mathrm{C}$ (left side), and $10^{-4}$ oxygen at $750{ }^{\circ} \mathrm{C}$ and $825^{\circ} \mathrm{C}$ (right side).

The temperature increase results in a rapid decrease in lattice oxygen stoichiometry, corresponding to an increase in measured outlet oxygen partial pressure. Note that the measured outlet $\mathrm{pO}_{2}$ for the $\mathrm{pO}_{2}=10^{-4}$ atm feed varies between $1.86 \times 10^{-4}-2.96 \times 10^{-4}$ atm, including stabilization periods. The oxygen released from the sample into this unbuffered, low $\mathrm{pO}_{2}$ gas leads to a measurable increase in $\mathrm{pO}_{2}$ and reduction in the driving forces for further sample equilibration. Limited beam time does not allow for complete equilibration, which may take several hours; however, this difference is small and does not vary significantly during measurement on the logarithmic scale that dictates the material response. Note that the higher $\mathrm{pO}_{2}$ does not show the same issue, as the oxygen released from the material is a small quantity when compared with the oxygen content of the surrounding gas. The equilibrium outlet $\mathrm{pO}_{2}$ values for each temperature and gas mixture are reported in Table 2. 

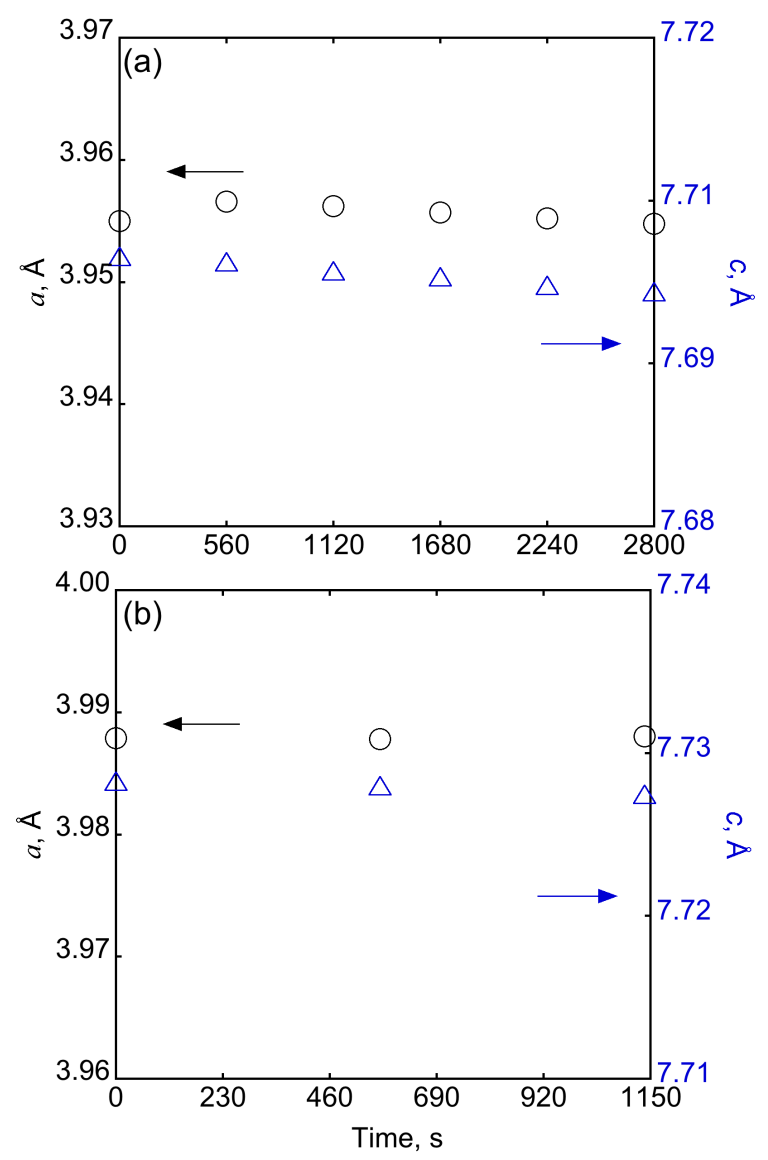

Figure 27. Lattice parameters $(P 4 / \mathrm{mmm})$ for $\mathrm{NBCO}$ at: (a) $10^{-1}$ atm oxygen at $550{ }^{\circ} \mathrm{C}$ and (b) $10^{-4} \mathrm{~atm}$ oxygen at $825^{\circ} \mathrm{C}$ during the equilibration prior to recording the neutron diffraction pattern at these conditions. Error bars are smaller than the data symbols.

Table 2. Average outlet $\mathrm{pO}_{2}$ (atm) at equilibrium for each temperature and inlet gas mixture.

\begin{tabular}{c|cccc}
\hline inlet $\mathrm{pO}_{2}$, atm & $550{ }^{\circ} \mathrm{C}$ & $650^{\circ} \mathrm{C}$ & $750{ }^{\circ} \mathrm{C}$ & $825^{\circ} \mathrm{C}$ \\
\hline \hline $10^{-1}$ & $1.02 \times 10^{-1}$ & $1.02 \times 10^{-1}$ & $1.02 \times 10^{-1}$ & $1.02 \times 10^{-1}$ \\
\hline $10^{-2}$ & $1.15 \times 10^{-2}$ & $1.17 \times 10^{-2}$ & $1.17 \times 10^{-2}$ & $1.17 \times 10^{-2}$ \\
\hline $10^{-3}$ & $1.36 \times 10^{-3}$ & $1.35 \times 10^{-3}$ & $1.40 \times 10^{-3}$ & $1.46 \times 10^{-3}$ \\
\hline $10^{-4}$ & $1.94 \times 10^{-4}$ & $1.90 \times 10^{-4}$ & $2.13 \times 10^{-4}$ & $2.46 \times 10^{-4}$ \\
\hline
\end{tabular}




\section{b. Space group determination}

When compared with a single perovskite unit cell, a doubling of the unit cell in the c-direction captures ordering of the A-site cations. The $\mathrm{Nd}$ and $\mathrm{Ba}$ site-ordering are then represented as alternating $\mathrm{Nd}$ and $\mathrm{Ba}$ layers in the $\mathrm{c}$-direction. Two structural models were fit to each data set: a vacancy-ordered orthorhombic $\left(P m m m, a_{p} \times 2 a_{p} \times 2 a_{p}\right)$ and a tetragonal $\left(P 4 / \mathrm{mmm}, a_{p} \times a_{p} \times 2 a_{p}\right)$. The orthorhombic model was chosen because it is often used to describe NBCO and similar materials with $\delta \sim 0.5,[21,77,103,105]$ and it would evaluate the existence of vacancy ordering in the crystal. This structure[21] differentiates between two different $\mathrm{O}$ sites in the $\mathrm{NdO}_{\delta}$ plane, creating a model where the vacancies may be ordered within this plane. Studies indicate that at lower temperatures and oxygen stoichiometry values $(\delta)$ of $\sim 0.5$, vacancy ordering in layered perovskites leads to alternating columns of $\mathrm{Co}$ in octahedral and square planar coordination.[18, 20, 21, 77, 105] These correspond to two distinct Co sites; Co1 sits above $\mathrm{O} 3$, and $\mathrm{Co} 2$ above $\mathrm{O} 4$. We refined all sites as isotropic, with the $\mathrm{O} 3$ and $\mathrm{O} 4$ site $U_{\text {ISO }}$ parameters constrained to be identical. In contrast with this orthorhombic model, the tetragonal model treats the oxygen atoms within each cation $a-b$ plane as equivalent. As such, the oxygen vacancies and resulting Co-centered octahedrons and square pyramids are disordered, and only one Co site is defined for the simplest approach. The tetragonal model was chosen because it is often used to describe materials at higher temperature and with $\delta<0.5 .[18,21,29,103,106]$ 
Table 3. Rietveld fit parameters for NBCO orthorhombic $(P m m m)$ model at $550^{\circ} \mathrm{C}$ and a $\mathrm{pO}_{2}$ of $10^{-1} \mathrm{~atm}$ with sites: $\mathrm{Nd} 2 p(0.5$ y 0.5$)$; $\mathrm{Ba} 20(0.5$ y 0$)$; Co1 $2 r(00.5 \mathrm{z})$; Co2 $2 q(0$

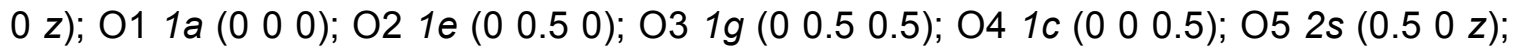
$062 t(0.50 .5 z) ; 074 u(0 y z)$

\begin{tabular}{|c|c|}
\hline$a(\AA)$ & $3.9536(2)$ \\
\hline$b(\AA)$ & $7.9081(3)$ \\
\hline$c(\AA)$ & 7.6985(1) \\
\hline $\mathrm{Nd}(y)$ & $0.251(1)$ \\
\hline $\mathrm{Ba}(y)$ & $0.248(2)$ \\
\hline Co1 (z) & $0.254(2)$ \\
\hline Co2 (z) & $0.251(2)$ \\
\hline $05(z)$ & $0.304(1)$ \\
\hline $\mathrm{O} 6(z)$ & $0.269(1)$ \\
\hline O7 (y) & $0.250(1)$ \\
\hline $07(z)$ & $0.287(1)$ \\
\hline Occ. O3 & $0.53(3)$ \\
\hline Occ. O4 & $0.53(3)$ \\
\hline Ox. Cont. & $5.53(6)$ \\
\hline$X^{2}$ & 1.797 \\
\hline$R_{P}$ & 0.0852 \\
\hline$w R_{P}$ & 0.0464 \\
\hline$V\left(\AA^{3}\right)$ & $240.703(3)$ \\
\hline$\rho_{c}\left(\mathrm{~g} / \mathrm{cm}^{3}\right)$ & 6.732 \\
\hline $\begin{array}{l}\text { Thermal } \\
\text { parameters } \\
\left(\AA^{2}\right)^{*} 100\end{array}$ & $U_{I S O}$ \\
\hline $\mathrm{Nd}$ & $2.6(1)$ \\
\hline $\mathrm{Ba}$ & $1.8(1)$ \\
\hline Co1 & $2.3(2)$ \\
\hline Co2 & $2.1(2)$ \\
\hline O1 & $3.0(2)$ \\
\hline $\mathrm{O} 2$ & $2.7(2)$ \\
\hline $\mathrm{O} 3$ & $3.0(2)$ \\
\hline O4 & $3.0(2)$ \\
\hline O5 & $3.4(2)$ \\
\hline O6 & $5.2(2)$ \\
\hline O7 & $2.7(1)$ \\
\hline
\end{tabular}


Table 3 and Table $4 \mathrm{a}$ are the resulting fit parameters for the Pmmm and $P 4 / \mathrm{mmm}$ models, respectively, for the $10^{-1}$ atm oxygen $550{ }^{\circ} \mathrm{C}$ diffraction pattern. The corresponding representative NPD pattern for the $P 4 / \mathrm{mmm}$ structure with fit and difference lines is shown in Figure 28a. No secondary phases were found at any temperature or $\mathrm{pO}_{2}$ in this study. In both models, the A-site cations ( $\mathrm{Nd}$ and $\mathrm{Ba}$ ) were constrained by position and occupancy to order alternating in the $\left(\begin{array}{lll}0 & 0 & 1\end{array}\right)$ direction. Relaxing these constraints did not lead to a change in position or occupancy (within error) of $\mathrm{Nd}$ and $\mathrm{Ba}$ at $10^{-1} \mathrm{~atm}$ oxygen $550^{\circ} \mathrm{C}$, indicating that intermixing between these cations is negligible. The Co occupancy was likewise fixed at a fractional occupancy of 1.0; when this constraint was eliminated, the occupancy remained at 1.0 (within error) for $10^{-1}$ atm oxygen $550{ }^{\circ} \mathrm{C}$. Oxygen vacancies in the $P 4 / \mathrm{mmm}$ model are primarily observed at the $\mathrm{O} 3$ site, which is in the Nd-layer, and may exist at the nearest-neighbor $\mathrm{O} 2$ site in the Co-layer, as well as the $\mathrm{O} 1$ site in the Ba-layer. In the Pmmm model, oxygen vacancies are located at the $\mathrm{O} 3$ and $\mathrm{O} 4$ sites, both of which are in the $\mathrm{Nd}$-layer.

We discounted the orthorhombic vacancy ordered structure, Model 1, based on three findings. First, there is no evidence of peak splitting to indicate significant orthorhombic distortion of the unit cell. This is illustrated in Figure 28b, which shows calculated peak positions for both structures in the $d$-spacing range 1.52 to $1.62 \AA$. Second, the results of the Pmmm space group refinements at all temperatures and oxygen partial pressures indicated that the $\mathrm{O} 3$ and $\mathrm{O} 4$ site occupancies were nearly identical, indicating random oxygen vacancy distribution in the $\mathrm{T}-\mathrm{pO}_{2}$ range studied. For example, refinement of the $550{ }^{\circ} \mathrm{C}$ and $10^{-1}$ atm $\mathrm{pO}_{2}$ pattern yields identical fractional $\mathrm{O} 3$ and $\mathrm{O} 4$ site occupancies of $0.53(3)$, shown in Table 3 . Third, the lattice parameters for the vacancy-ordered orthorhombic model are within $0.001 \AA$ of the corresponding tetragonal lattice parameters, and the orthorhombic $a$ and $b$ lattice parameters are also 
within $0.001 \AA$ of each other, further indicating the absence of an orthorhombic distortion. There is agreement among previous publications that NBCO, and indeed many $\mathrm{LnBaCO}_{2} \mathrm{O}_{5+\delta}$ compounds, are tetragonal $(P 4 / \mathrm{mmm})$ at $(0.75<\delta<0.5)[18,19,80]$ and at $\mathrm{T}>507{ }^{\circ} \mathrm{C}$ for $\delta \sim 0.5$ materials. $[21,103,106]$ The refined oxygen stoichiometry for the $550{ }^{\circ} \mathrm{C}$ and $10^{-1}$ atm $\mathrm{pO}_{2}$ pattern in Pmmm was 5.53(6); within ESD of 5.528(9), the value for the same data set refined using $P 4 / \mathrm{mmm}$. Both models only allow oxygen vacancies in the $\mathrm{Nd}$-layer. 
Table 4. Tetragonal $(P 4 / \mathrm{mmm})$ Rietveld fit parameters for $\mathrm{NBCO}$ at $550^{\circ} \mathrm{C}$ and $a \mathrm{O}_{2}$ of $10^{-1} \mathrm{~atm}$ refined using: (a) Model 1, with sites: $\mathrm{Nd} 1 \mathrm{c}(0.50 .5$ 0); Ba $1 d$ (0.5 0.5 0.5); Co

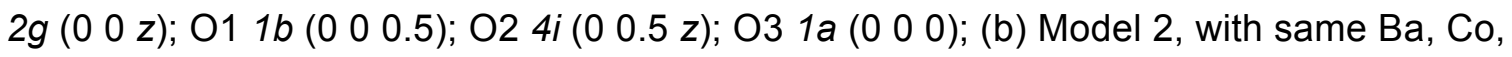
O1, O3 sites as Model 1, but $\mathrm{Nd} 4 j(x$ y 0$)$ and O2a/b $4 i\left(\begin{array}{lll}0 & 0.5 z)\end{array}\right.$

\begin{tabular}{|c|c|c|c|c|c|c|}
\hline \multicolumn{4}{|c|}{ (a) Model 1} & \multicolumn{3}{|c|}{ (b) Model 2} \\
\hline $\mathrm{a}(\AA)$ & \multicolumn{3}{|l|}{$3.95379(4)$} & $\mathrm{a}(\AA)$ & \multicolumn{2}{|l|}{$3.95380(4)$} \\
\hline$c(\AA)$ & \multicolumn{3}{|l|}{$7.6981(1)$} & $c(\AA)$ & \multicolumn{2}{|l|}{$\begin{array}{l}7.6981(1) \\
0.471(1)\end{array}$} \\
\hline Co $(z)$ & \multicolumn{3}{|l|}{$0.2490(4)$} & Co $(z)$ & \multicolumn{2}{|l|}{$0.2491(4)$} \\
\hline \multirow[t]{2}{*}{$\mathrm{O} 2(z)$} & \multirow{2}{*}{\multicolumn{3}{|c|}{$0.2127(1)$}} & $\mathrm{O} 2 \mathrm{a}(\mathrm{z})$ & \multicolumn{2}{|l|}{$0.1969(4)$} \\
\hline & & & & $\mathrm{O} 2 \mathrm{~b}(\mathrm{z})$ & \multicolumn{2}{|l|}{$0.2301(6)$} \\
\hline Occ. 01 & \multicolumn{3}{|l|}{$0.99(1)$} & Occ. 01 & \multicolumn{2}{|l|}{$1.00(1)$} \\
\hline \multirow[t]{2}{*}{ Occ. O2 } & \multirow{2}{*}{\multicolumn{3}{|c|}{$1.005(5)$}} & Occ. O2a & \multicolumn{2}{|l|}{$0.53(1)$} \\
\hline & & & & Occ. O2b & \multicolumn{2}{|l|}{$0.477(9)$} \\
\hline Occ. 03 & \multicolumn{3}{|l|}{$0.50(1)$} & Occ. O3 & \multicolumn{2}{|l|}{$0.48(1)$} \\
\hline Ox. Cont. & \multicolumn{3}{|l|}{$5.51(4)$} & Ox. Cont. & \multicolumn{2}{|l|}{$5.51(6)$} \\
\hline$X^{2}$ & \multicolumn{3}{|l|}{1.793} & $X^{2}$ & \multicolumn{2}{|l|}{1.844} \\
\hline$R_{P}$ & \multicolumn{3}{|l|}{0.0909} & $R_{P}$ & \multicolumn{2}{|l|}{0.0918} \\
\hline$w R_{P}$ & \multirow{2}{*}{\multicolumn{3}{|c|}{$\begin{array}{c}0.0467 \\
120.340(3)\end{array}$}} & $w R_{P}$ & \multicolumn{2}{|l|}{0.0474} \\
\hline$V\left(\AA^{3}\right)$ & & & & $V\left(\AA^{3}\right)$ & \multicolumn{2}{|l|}{$120.340(4)$} \\
\hline$\rho_{c}\left(\mathrm{~g} / \mathrm{cm}^{3}\right)$ & & \multicolumn{2}{|c|}{$\begin{array}{c}120.340(3) \\
6.728\end{array}$} & $\rho_{c}\left(\mathrm{~g} / \mathrm{cm}^{3}\right)$ & \multicolumn{2}{|l|}{6.722} \\
\hline $\begin{array}{l}\text { Thermal } \\
\text { parameters } \\
\left(\AA^{2}\right)^{*} 100\end{array}$ & $U_{11}$ & $U_{22}$ & $U_{33}$ & $\begin{array}{l}\text { Thermal } \\
\text { parameters } \\
\left(\AA^{2}\right)^{*} 100 \\
\end{array}$ & $\begin{array}{l}U_{\text {Iso or }} \\
U_{11}, U_{22} \\
\end{array}$ & $U_{33}$ \\
\hline $\mathrm{Nd}$ & $2.89(6)$ & $2.89(6)$ & $1.89(8)$ & $\mathrm{Nd}$ & $1.63(7)$ & \\
\hline $\mathrm{Ba}$ & $2.07(8)$ & $2.07(8)$ & $2.6(1)$ & $\mathrm{Ba}$ & $1.91(8)$ & $2.6(1)$ \\
\hline Co & $2.60(7)$ & $2.60(7)$ & $1.6(1)$ & Co & $2.57(7)$ & $1.7(1)$ \\
\hline 01 & $3.4(1)$ & $3.4(1)$ & $1.7(1)$ & O1 & $3.7(1)$ & $1.5(1)$ \\
\hline \multirow[t]{2}{*}{$\mathrm{O} 2$} & $3.32(7)$ & $2.92(7)$ & $5.03(7)$ & O2a & $3.20(4)$ & \\
\hline & & & & $\mathrm{O} 2 \mathrm{~b}$ & $3.20(4)$ & \\
\hline $\mathrm{O} 3$ & $4.8(3)$ & $4.8(3)$ & $1.4(3)$ & $\mathrm{O} 3$ & $3.1(2)$ & \\
\hline
\end{tabular}



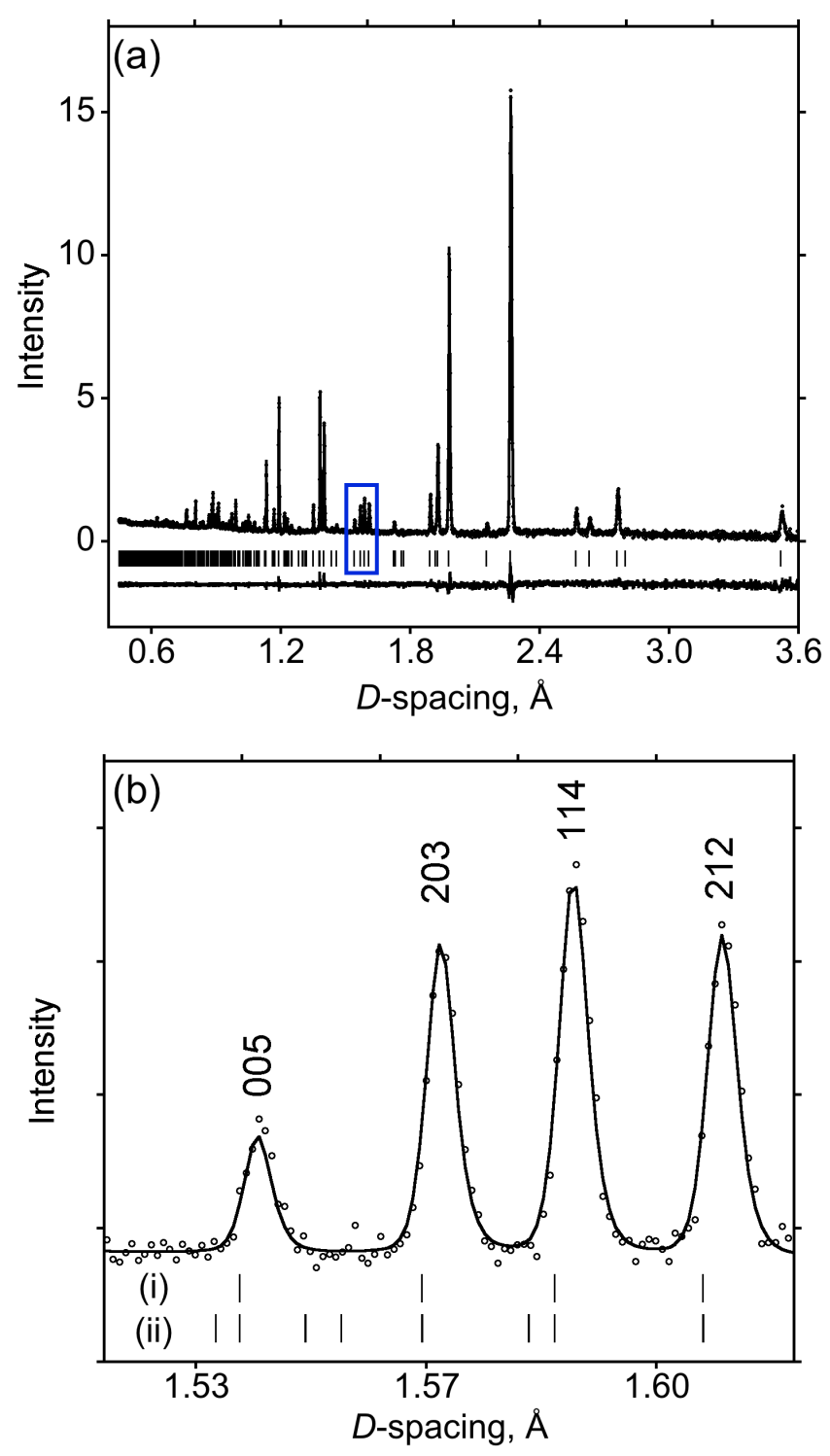

Figure 28. NBCO Model $1(P 4 / \mathrm{mmm}): 10^{-1}$ atm oxygen at $550{ }^{\circ} \mathrm{C}$. The entire pattern is shown in (a). Patterns consist of observed (circles), calculated (top line), and difference (bottom line) data. Theoretical Bragg reflection positions are marked with vertical lines. A detailed view of the boxed area indicated in the top figure is shown in (b) with Bragg reflections marked for (i) $P 4 / \mathrm{mmm}$ and (ii) $P m m m$ space groups. 
c. Tetragonal (P4/mmm) models \& oxygen motion

We now focus on the details of a $P 4 / \mathrm{mmm}$ space group model. Model 1 is shown in Figure 29a and has single $\mathrm{Nd}, \mathrm{Ba}$, and Co sites and three $\mathrm{O}$ sites, with each refined using anisotropic thermal parameters. We refined the occupancy of all three $\mathrm{O}$ sites, which resulted in the majority of vacancies at the $\mathrm{O} 3$ site, none at the $\mathrm{O} 2$ site, and a 0.5$3 \%$ vacancy concentration at the 01 site for all data sets. Note that the 01 site fractional vacancies of $550{ }^{\circ} \mathrm{C}$ at $10^{-1}$ and $10^{-3}$ atm oxygen are within a standard deviation of 1.0 . The oxygen stoichiometry calculated for Model 1 is shown in Figure 30. Other studies have developed models of this material that restricted oxygen vacancies to only the $\mathrm{Nd}$ layer $[20,104,105]$, but if we consider oxygen anion transport via vacancy hopping, restricting vacancies to the $\mathrm{O} 3$ site would require a pathway between adjacent $\mathrm{O} 3$ sites. The 03-O3 distance varies from $3.95-3.99 \AA$, which may be prohibitively large to allow for the reported facile ion transport reported for this material.[22-24] 
(a)

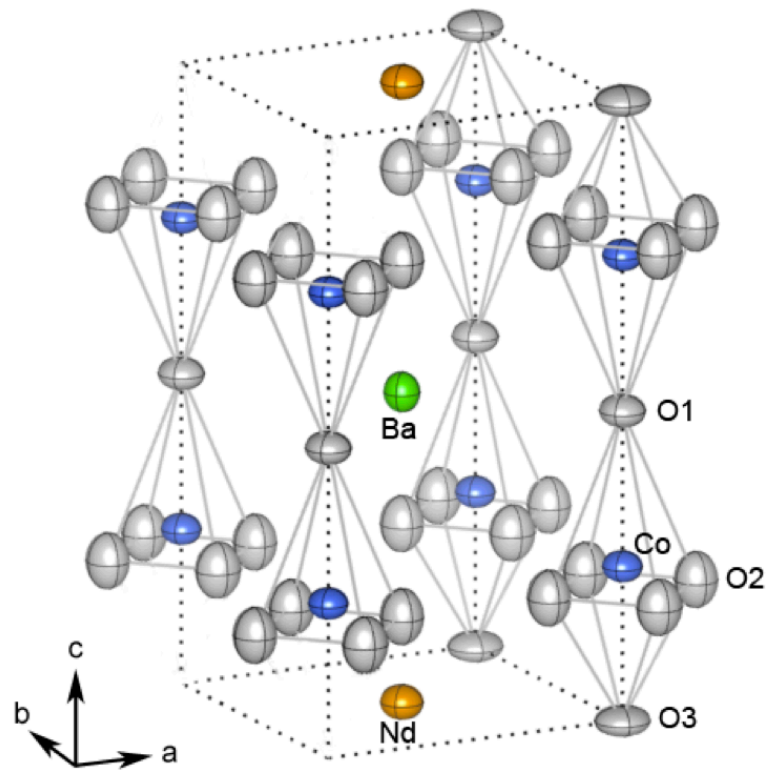

(b)

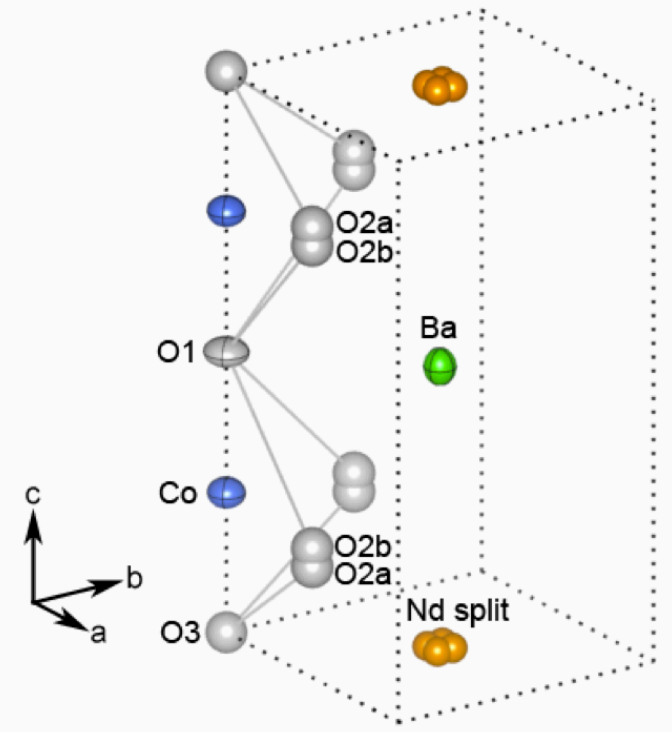

Figure 29. Crystal structure of $\mathrm{NdBaCo}_{2} \mathrm{O}_{5+\delta}$ in the $P 4 / \mathrm{mmm}$ space group: (a) Model 1 with $\mathrm{O} 3$ site vacancies shown; (b) Model 2, split $\mathrm{Nd}$ and $\mathrm{O} 2$ sites, with $1 / 4$ of the unit cell shown. $50 \%$ probability thermal ellipsoids are illustrated for all sites, but $\mathrm{Nd}, \mathrm{O} 3, \mathrm{O} 2 \mathrm{a}$, and $\mathrm{O} 2 \mathrm{~b}$ sites in (b) have isotropic thermal parameters and are thus spherical. 

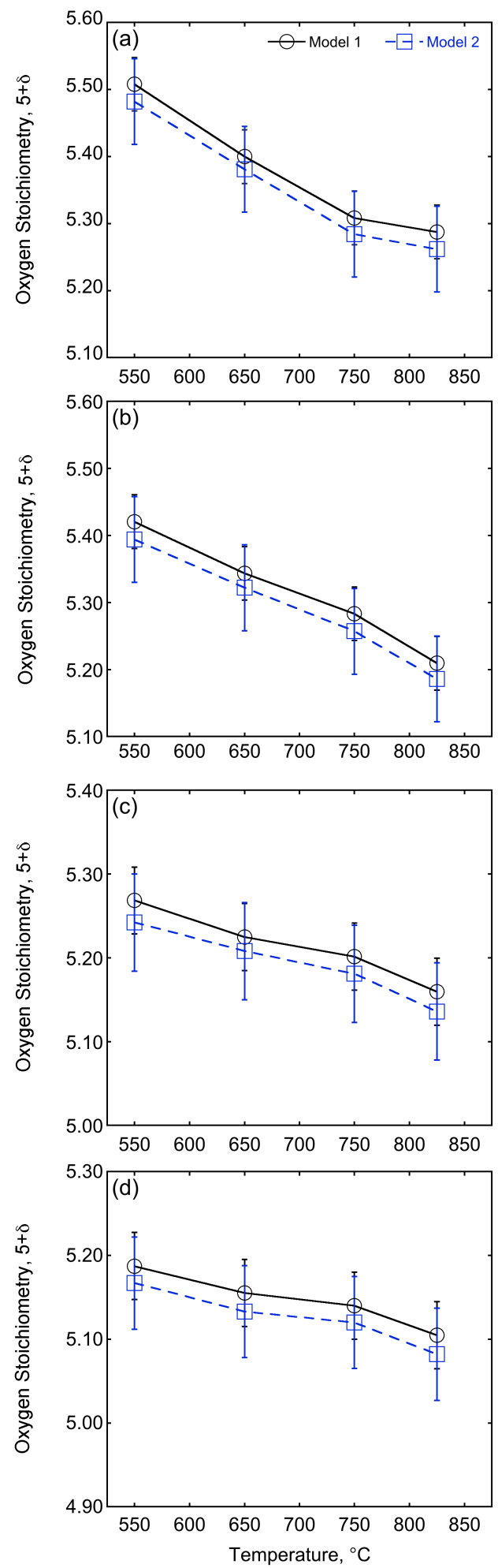

Figure 30 Oxygen stoichiometry with temperature for $\mathrm{P} 4 / \mathrm{mmm}$ Models 1 and 2 with $p \mathrm{O}_{2}$ values: (a) $10^{-1} \mathrm{~atm}$; (b) $10^{-2} \mathrm{~atm}$; (c) $10^{-3} \mathrm{~atm}$; (d) $10^{-4} \mathrm{~atm}$. Lines serve as a guide for the eye. 
The $02-03$ site distance is much shorter at $2.52-2.57 \AA$, making a case for allowing vacancies in the $\mathrm{O} 2$ site to facilitate the hopping mechanism. This would suggest an oxygen transport mechanism consisting of hopping from the vacancy-rich $\mathrm{NdO}_{\delta}$ plane to the nearest neighbor site in the more fully occupied $\mathrm{CoO}$ plane. Refining the occupancy of all $\mathrm{O}$ sites leads to fractional $\mathrm{O} 2$ site occupancies of 1.0 within a standard deviation, but an $0.5-3 \%$ vacancy concentration at the 01 site. These are time and structure average values and it is possible that oxygen vacancies can exist at the O2 site. The O2-O1 site distance ranges from 2.97 - $3.04 \AA$, a larger distance than $\mathrm{O} 2-$ O3. Thus, the most facile hopping mechanism route would be O3-O2-O3; however, the slight vacancy concentration at the 01 site indicates that a fraction of the oxygen motion may also occur via O3-02-01. The thermal ellipsoids defined by the anisotropic thermal parameters for Model 1 are listed in Table $4 a$ and show motion of the 03 and 01 sites primarily in the $x, y$-direction, while the $\mathrm{O} 2$ site motion is largely in the z-direction. These results indicate that these atoms move such that the $\mathrm{O} 2-\mathrm{O} 3$ site distance is further minimized, providing evidence for the proposed vacancy-hopping route.

The $\mathrm{O} 1-\mathrm{Co}-\mathrm{O} 2$ bond angle for Model 1 is plotted with $\mathrm{O} 3$ site occupancy in Figure 31 showing an increase in bond angle as the vacancy concentration at $\mathrm{O} 3$ increases. Note that the larger differences in $\mathrm{O} 3$ site occupancy with $\mathrm{pO}_{2}$ at lower temperatures lead to a large variation in bond angle. This variation decreases as the differences in occupancy decrease at higher temperature. Since the Co and $\mathrm{O} 1$ sites are fixed at fractional coordinates $(x, y)=0$, the increased in angle is due to a shift in the $\mathrm{O} 2$ site toward the increasingly oxygen deficient $\mathrm{Nd}-\mathrm{O} 3$ layer. The Co site also shifts towards this oxygen vacancy rich $\mathrm{Nd}-\mathrm{O} 3$ layer with increasing oxygen vacancy concentration. 


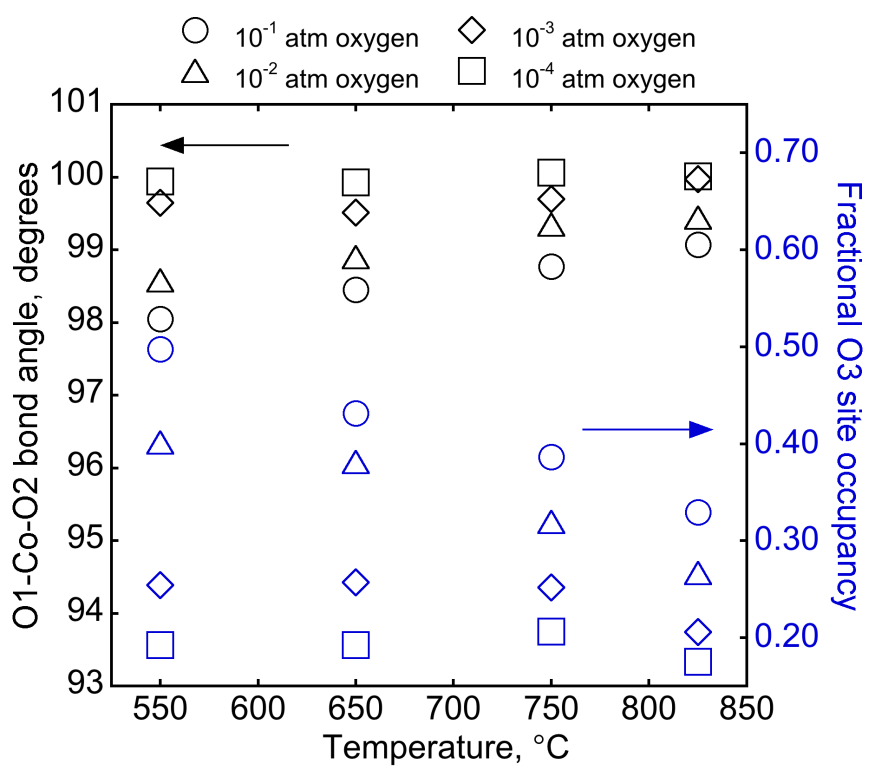

Figure 31. $\mathrm{P} 4 / \mathrm{mmm}$ Model 1 change in $\mathrm{O} 1-\mathrm{Co}-\mathrm{O} 2$ bond angle with fractional $\mathrm{O} 3$ site occupancy as a function of temperature and $\mathrm{pO}_{2}$. Error bars are smaller than the data symbols.

Figure 32 provides the $\mathrm{Co}-\mathrm{O} 1$ and $\mathrm{Co}-\mathrm{O} 3$ bond lengths plotted alongside $\mathrm{O} 3$ site occupancy. The Co-O1 bond length (Figure 32a) is not strongly dependent on $\mathrm{O} 3$ occupancy, but increases slightly with temperature; however, the overall change in length for the range studied is $0.020(4) \AA$. The Co-O3 bond length (Figure 32b) decreases and is a stronger function of $\mathrm{O} 3$ occupancy, but the total change is length is equivalent to Co-O1. This combination of changes in $\mathrm{Co}-\mathrm{O}$ bond length results an overall $0.039(8) \AA$ decrease in the $c$-axis length and (within error) accounts for the $0.0458(2) \AA$ reduction in the $c$ lattice parameter over the studied $\mathrm{T}-\mathrm{pO}_{2}$ range. The vertical shrinkage of the cation-oxygen layers brings the $\mathrm{Co}$ and $\mathrm{O}$ atoms toward the vacancy-rich $\mathrm{NdO}_{\delta}$ plane. The increased proximity of these planes also leads to a decrease in the $\mathrm{O} 2-\mathrm{O} 3$ bond length, further facilitating the vacancy hopping mechanism. 

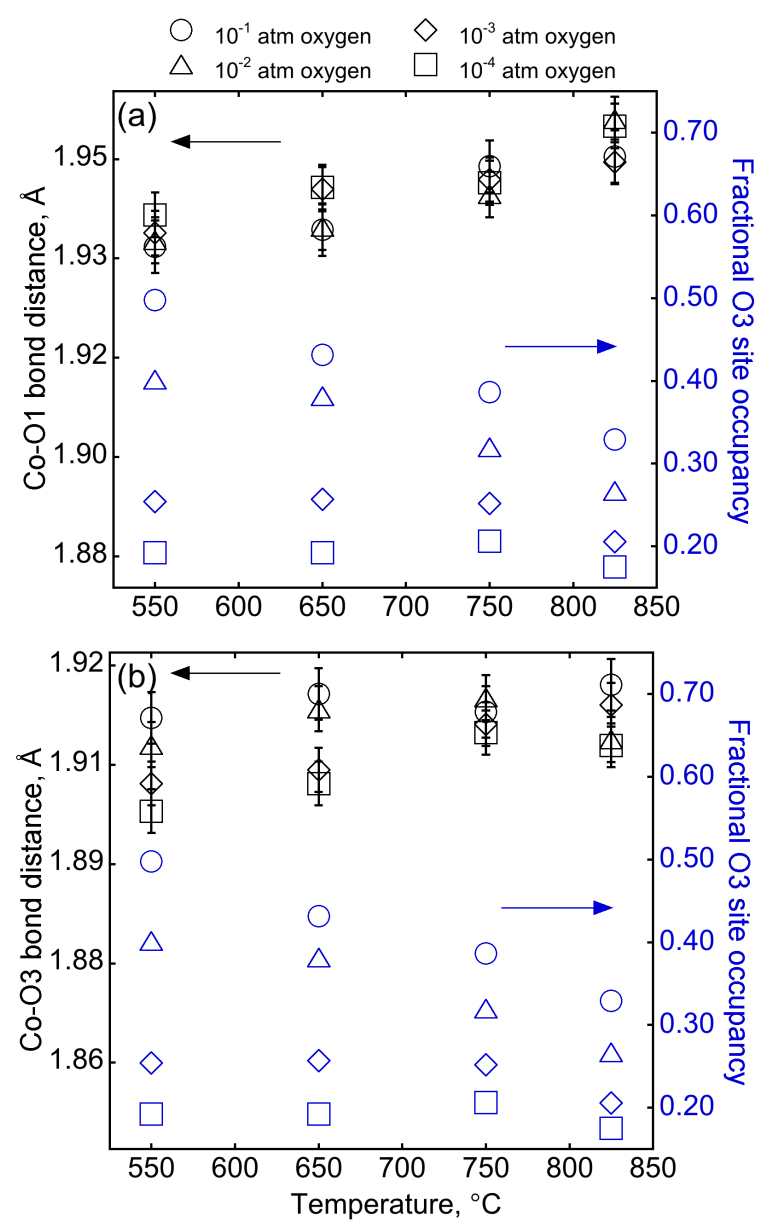

Figure 32. $\mathrm{P} 4 / \mathrm{mmm}$ Model 1: change in (a) Co-O1 bond length and (b) Co-O3 bond length with fractional $\mathrm{O} 3$ site occupancy as a function of temperature and $\mathrm{pO}_{2}$. Error bars for fractional $\mathrm{O} 3$ site occupancy are smaller than the data symbols.

The lattice parameters plotted in Figure 33 verify this decrease in the $c$-axis with decreasing $\mathrm{pO}_{2}$. All lattice parameters increase with temperature due to thermal expansion. In contrast to the $c$-axis, the $a, b$ axes both increase with decreasing $\mathrm{pO}_{2}$. This behavior is consistent with the typical influence of chemical expansion due to increasing average Co atomic radius as it is reduced, with the concomitant formation of 
oxygen vacancies, as we lower the $\mathrm{pO}_{2}$.[109] Thus we have two contrasting effects of increased oxygen vacancy formation in the $\mathrm{NdO}$ plane. The $a$ and $b$ axes show chemical expansion, while the c-axis shows contraction due to the shifts in $\mathrm{Co}$ and $\mathrm{O} 2$ positions due to the high degree of oxygen vacancy localization in the $\mathrm{NdO}$ layer. Note that the lattice parameters were identical to three decimal places for all tetragonal models considered in this work, and thus Model 1 values were plotted as representative.

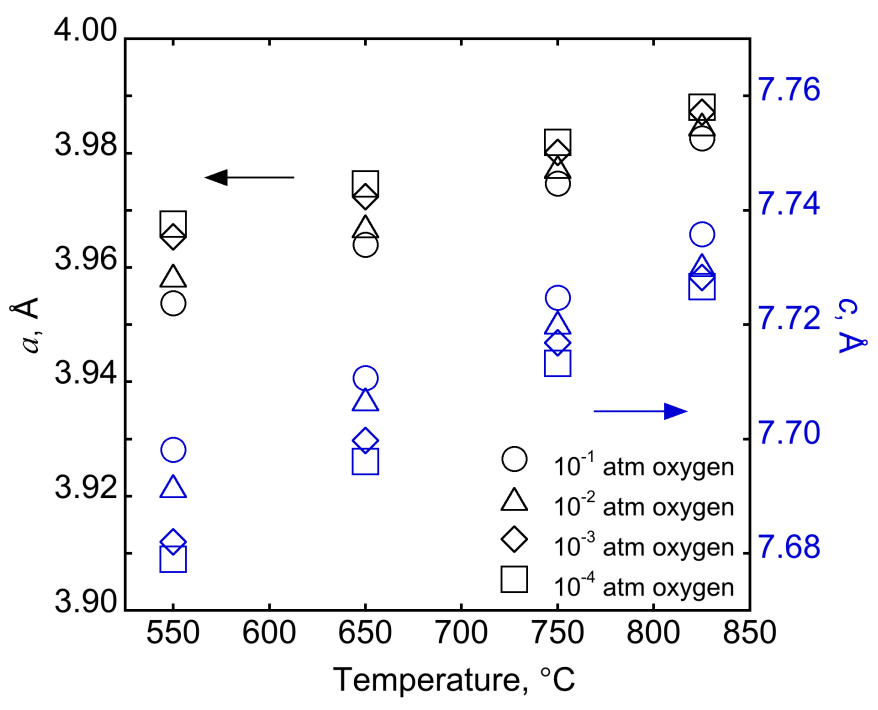

Figure 33. Tetragonal $(P 4 / \mathrm{mmm})$ lattice parameters for each $\mathrm{pO}_{2}$ range. Error bars are smaller than the symbols used in the figure. All tetragonal models yielded identical lattice parameters to within three decimal places.

The second major refinement option explored within the $P 4 / \mathrm{mmm}$ space group, Model 2, was the splitting of sites closest to the $\mathrm{O} 3$ site and is shown in Figure 29b. The highly vacant state of the $\mathrm{O} 3$ site gives rise to disorder in the $\mathrm{O} 3$ site occupancy, which may lead to positional disorder in the neighboring sites if positional constrains are eliminated. In Model 2, the $\mathrm{Nd}$ and $\mathrm{O} 2$ sites are split as near neighbors to the $\mathrm{O} 3$ site, 
where most oxygen vacancies reside. Splitting the $\mathrm{Nd}$ site creates a direct relationship between disorder in the $\mathrm{O} 3$ site occupancy and disorder in the $\mathrm{Nd}$ site position. The $\mathrm{O} 3$ site occupancy disorder is minimized when the site is entirely full or entirely empty, allowing the $\mathrm{Nd}$ site to reside at its minimum disorder position of $(0.5,0.5,0)$. Only the $\mathrm{Co}, \mathrm{Ba}$, and $\mathrm{O} 1$ sites are refined anisotropically, while the $U_{I S O}$ values of the $\mathrm{O} 2 \mathrm{a}$ and $\mathrm{O} 2 \mathrm{~b}$ sites are constrained to be identical. The fractional $\mathrm{O} 2 \mathrm{a}$ and $\mathrm{O} 3$ site occupancies are also constrained as $\mathrm{O} 3=1-\mathrm{O} 2 \mathrm{a}$, allowing for vacancies in the combined $\mathrm{O} 2$ site, but ensuring that either $\mathrm{O} 3$ or $\mathrm{O} 2 \mathrm{a}$ is constantly occupied such that a Co-O coordination number of 5 is maintained (square pyramid). The Model 2 refinement results of the 550 ${ }^{\circ} \mathrm{C}$ at $10^{-1} \mathrm{~atm}$ oxygen data set are detailed in Table $4 \mathrm{~b}$. The $z$ fractional coordinates of Co and $\mathrm{O} 2 \mathrm{~b}$ are close indicating that when the $\mathrm{O} 3$ site is occupied, the Co-site will be octahedrally coordinated to include the $\mathrm{O} 2 \mathrm{~b}$ site. The $\mathrm{O} 2 \mathrm{a}$ site is further away from the Co site and would lead to the formation of a square pyramid encompassing the Co site when the $\mathrm{O} 3$ site is vacant. Figure $34 \mathrm{a}$ shows that as the $\mathrm{O} 3$ site becomes more vacant, especially with decreasing $\mathrm{pO}_{2}$, the $\mathrm{Nd}(x, y)$ fractional position tends toward 0.5 , which is consistent with approaching its minimum disorder position. The distance between the $\mathrm{O} 2 \mathrm{a}$ and $\mathrm{O} 2 \mathrm{~b}$ sites is plotted with fractional $\mathrm{O} 3$ site occupancy in Figure $34 \mathrm{~b}$ and lengthens with increasing temperature, but shortens with decreasing $p \mathrm{O}_{2}$. At high temperature, and thus decreased $\mathrm{pO}_{2}$, the $\mathrm{O} 2 \mathrm{a}$ site shifts toward the vacant $\mathrm{O} 3$ site, while $\mathrm{O} 2 \mathrm{~b}$ site remains relatively stationary, resulting in greater site distance. In contrast, the $\mathrm{O} 2 \mathrm{a}$ site is more stationary at low temperature, while the $\mathrm{O} 2 \mathrm{~b}$ site shifts toward the vacant $\mathrm{O} 3$ site with decreasing $\mathrm{pO}_{2}$, bringing the $\mathrm{O} 2 \mathrm{a}$ and $\mathrm{O} 2 \mathrm{~b}$ sites closer. The occupancy of the $\mathrm{O} 1$ site was refined and resulted in a $0-4 \%$ vacancy concentration. The oxygen stoichiometry values resulting from Model 2 are plotted in Figure 30 and are identical to the values of Model 1 within uncertainty. 

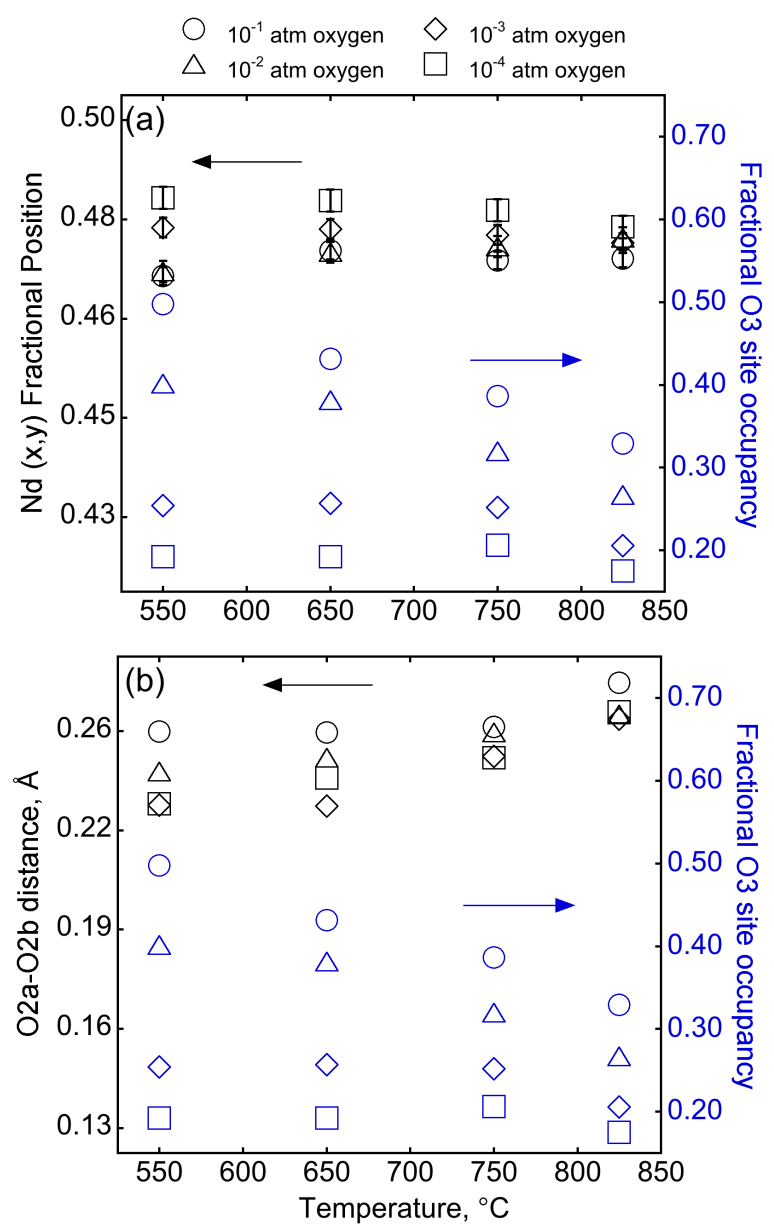

Figure 34. P4/mmm Model 2: (a) fractional position of $\mathrm{Nd}(x, y)$ and (b) O2a-O2b site distance, both plotted with fractional $\mathrm{O} 3$ site occupancy for the Temperature and $\mathrm{pO}_{2}$ range studied. Error bars for $\mathrm{O} 3$ occupancy and $\mathrm{O} 2 \mathrm{a}-\mathrm{O} 2 \mathrm{~b}$ distance are smaller than the data symbols.

\subsection{Conclusions}

Phase pure $\mathrm{NdBaCO}_{2} \mathrm{O}_{5+}$ ( $\mathrm{NBCO}$ ) was characterized using neutron powder diffraction under in-situ conditions: $550-825{ }^{\circ} \mathrm{C}$ and $10^{-1}-10^{-4}$ atm oxygen. The tetragonal $(P 4 / \mathrm{mmm})$ space group provided the best fit for the data, which did not exhibit vacancy ordering. Two variations were considered: Models 1 (no split sites) and Model 2 
(split $\mathrm{Nd}$ and $\mathrm{O} 2$ sites). Total oxygen stoichiometry values ranged from $5.51-5.11$. The lattice parameters for both tetragonal models were identical to within three decimal places and showed crystal expansion with temperature. However, the crystal shortened (c-direction) with decreasing $\mathrm{pO}_{2}$ at a given temperature due to all sites shifting toward the increasingly vacant $\mathrm{Nd}-\mathrm{O} 3$ layer. 


\section{Chapter 5 - Neutron Diffraction of $\mathrm{PrBaCO}_{2} \mathrm{O}_{5+\delta}$ at in-situ SOFC Conditions}

\subsection{Introduction}

MIEC materials with perovskite structure are under study as solid oxide fuel cell (SOFC) cathodes and ceramic oxygen separation membranes, as discussed in Chapter 1.[23, 36, 99-101] These materials must maintain structural, mechanical and chemical stability, while providing high mixed conductivity and catalytic activity at high temperatures $\left(>500^{\circ} \mathrm{C}\right)$ and in oxygen partial pressures ranging from 1 to $10^{-5} \mathrm{~atm}$. The bulk conductivity of these materials is dictated by crystal structure, oxygen stoichiometry, and cation oxidation state. Given that these parameters are a function of temperature and oxygen partial pressure, it is important to measure these properties under in-situ conditions to better understand the structure-property relationships in these materials.

As discussed in Chapter 4, neutron powder diffraction (NPD) allows for precise, simultaneous determination of lattice parameters, crystal symmetry, oxygen stoichiometry, and degree of ordering among cations and oxygen vacancies. NPD has been performed on $\mathrm{PrBaCO}_{2} \mathrm{O}_{5+\delta}$ materials with an oxygen stoichiometry $(\delta)$ range of $\sim 0.2$ to $\sim 0.9$ from $-275{ }^{\circ} \mathrm{C}$ to $350{ }^{\circ} \mathrm{C}[18,80,102]$ and at $27-547^{\circ} \mathrm{C}[21,103]$, but to our knowledge there have been no high temperature NPD studies of $\mathrm{PrBaCO}_{2} \mathrm{O}_{5+\delta}$. It would be highly advantageous to obtain further information in environments that more accurately reflect in-situ conditions during SOFC operation.

The $\mathrm{LnBaCO}_{2} \mathrm{O}_{5+\delta}$ (where $\mathrm{Ln}=\mathrm{La}, \mathrm{Pr}, \mathrm{Nd}, \mathrm{Sm}, \mathrm{Gd}$ ) series of layered perovskites are currently under study as potential cathodes for SOFC and oxygen separation applications due to reports of enhanced oxygen transport kinetics and decreased activation energies at intermediate temperatures $\left(500-700{ }^{\circ} \mathrm{C}\right)$, compared with 
traditional $\mathrm{ABO}_{3}$ perovskites.[22-25, 29] As discussed in Chapter 4, these materials exhibit A-site ordering with alternating layers of $\mathrm{Ln}$ and $\mathrm{Ba}$ in the $\left(\begin{array}{lll}0 & 0 & 1\end{array}\right)$ direction and oxygen vacancies are primarily located in the $\mathrm{LnO}_{\delta}$ layers.[17] The catalytic properties of these materials have been studied for a wide $\mathrm{T}-\mathrm{pO}_{2}$ range $[18,22,23,25-35]$, but structural characterization has been limited primarily to low temperatures $\left(<500^{\circ} \mathrm{C}\right)$.

In this work, structural information is provided for $\mathrm{PrBaCO}_{2} \mathrm{O}_{5+\delta}$ at in-situ SOFC conditions $\left(550-825^{\circ} \mathrm{C}, \mathrm{pO}_{2} 1-10^{-5} \mathrm{~atm}\right)$ using NPD. Specifically, lattice parameters, oxygen stoichiometry, and crystal symmetry are reported for the tetragonal $(P 4 / \mathrm{mmm})$ space group.

\subsection{Experimental}

The layered perovskite $\mathrm{PrBaCO}_{2} \mathrm{O}_{5+\delta}(\mathrm{PBCO})$ was synthesized using an EDTAcitrate complexing sol gel method.[22, 35, 110] The precursors were $\operatorname{Pr}\left(\mathrm{NO}_{3}\right)_{3} \cdot 6 \mathrm{H}_{2} \mathrm{O}$ [99.9\%, Alfa Aesar, Ward Hill, MA, USA], $\mathrm{Sr}\left(\mathrm{NO}_{3}\right)_{2}$ [min 99\%, Alfa Aesar, Ward Hill, MA, USA], and $\mathrm{Co}\left(\mathrm{NO}_{3}\right)_{2} \cdot 6 \mathrm{H}_{2} \mathrm{O}$ [min 99\%, Acros Organics, Morris Plains, NJ, USA]. Nitrate solutions were prepared by dissolving the salts in de-ionized water. The final metal concentrations were determined using complexometric titrations with ethylenediaminetetraacetic acid (EDTA).[111] These solutions were mixed in the appropriate ratios to form the desired composition, then complexed with EDTA and citric acid monohydrate [min 99\%, Acros Organics, Morris Plains, NJ, USA] in the presence of ammonium hydroxide ( $\mathrm{pH}$ adjusted to $\sim 6$ ). These compounds were added using a ratio of $1 \mathrm{~mol}$ metal ions: 1 mol EDTA: 2 mol citric acid. The resulting mixture was evaporated to a gel-like state and pyrolized in an oven at $300{ }^{\circ} \mathrm{C}$ in air for a minimum of $12 \mathrm{~h}$. The combustion product was ground and heated to $600{ }^{\circ} \mathrm{C}$ for $12 \mathrm{~h}$ in air, and then calcined at $900{ }^{\circ} \mathrm{C}$ for $5 \mathrm{~h}$ in air $\left(3^{\circ} \mathrm{C} / \mathrm{min}\right.$ heating and cooling rates). The resulting powder was sieved through $212 \mu \mathrm{m}$ mesh prior to uniaxial pressing at 8000 psi to form 1 -inch 
diameter disks, which were sintered in air at $1100{ }^{\circ} \mathrm{C}$ for $24 \mathrm{~h}(2 \% / \mathrm{min}$ heating and cooling rates). The sintered pellets were ground to a powder and re-sieved through 212 $\mu \mathrm{m}$ mesh.

Neutron diffraction patterns were collected at the POWGEN beamline, Spallation Neutron Source (SNS), Oak Ridge National Laboratory, Oak Ridge, TN, USA. 6.027 g of the PBCO powder sample was placed in a quartz basket with a $0.5 \mathrm{~cm}$ radius and $4 \mathrm{~cm}$ length. A vanadium tube furnace was used to heat the sample. Two thermocouples placed outside the neutron beam monitored the furnace temperature. A thermal gradient existed between the probes, such that the sample temperature was approximately 15 $30{ }^{\circ} \mathrm{C}$ higher than the furnace controller readings reported here. Further details regarding the experimental setup are available in Figure 25 (Section 4.2).

The powder sample was initially equilibrated in ultra high purity (UHP) nitrogen at $25{ }^{\circ} \mathrm{C}$ and a room temperature diffraction pattern was collected. The sample was then equilibrated in four $\mathrm{pO}_{2}$ environments: $10 \%, 1 \%, 0.1 \%$ and $0.01 \%$ UHP oxygen with the balance UHP nitrogen at the inlet. The chamber pressure was $1 \mathrm{~atm}$, yielding oxygen partial pressures $\left(\mathrm{pO}_{2}\right)$ of $10^{-1}, 10^{-2}, 10^{-3}$ and $10^{-4}$ atm. Gas mixtures flowed continually at $400 \mathrm{sccm}$ and the outlet gas $\mathrm{pO}_{2}$ was continually recorded using a stabilized zirconia oxygen sensor [Imtech, Knoxville, TN, USA]. Diffraction patterns were collected starting from the highest $\mathrm{pO}_{2}$ and moving lower at four temperatures within each gas environment: $550{ }^{\circ} \mathrm{C}, 650{ }^{\circ} \mathrm{C}, 750{ }^{\circ} \mathrm{C}$, and $825{ }^{\circ} \mathrm{C}$, in that order. The sample temperature was decreased to $550^{\circ} \mathrm{C}$ upon switching gases.

Diffraction patterns were collected in the $d$-spacing range of $0.45-3.6 \AA$. Several patterns with short collection durations (5-20 $\mathrm{min}$ ) were recorded during the equilibration period following changes in temperature and/or $\mathrm{pO}_{2}$. Equilibration was typically achieved within 20 minutes -1 hour, and was judged by no shift in the lattice parameter between 
short scans. After equilibration, a pattern was recorded until a total proton charge of 6.0 x $10^{12} \mathrm{pC}$ was reached, which corresponded to approximately 2.0 hours per scan, depending on beam intensity. These patterns were utilized for the refinements reported here. Background scans of the quartz tubes and basket were recorded at each temperature used in the study, and were subtracted from the raw data prior to further analysis.

Rietveld[107] refinements were performed using the GSAS package.[108] The lattice parameters, fractional occupancy of all oxygen sites, anisotropic thermal parameters and positions of all sites were refined for each pattern, as well as the $\mathrm{V}_{1}$ and $\sigma_{2}^{2}$ profile parameters. A combined scale factor was refined for the $25^{\circ} \mathrm{C}$ data set, the four $10^{-1}$ atm oxygen data sets, and the four $10^{-4}$ atm data sets. That fixed value was held constant in all data sets. Any additional constraints are noted when describing specific models. One tetragonal $(P 4 / \mathrm{mmm})$ refinement model was used in this work, which contains single $\mathrm{Pr}, \mathrm{Ba}$, and $\mathrm{Co}$ sites and three $\mathrm{O}$ sites $(\mathrm{O} 1, \mathrm{O} 2, \mathrm{O} 3)$. The same default starting point was used in refining each pattern. The occupancies of all oxygen sites were refined, unless otherwise noted, to determine the total oxygen vacancy concentration of the material. The standard deviation of these values is derived from the fit accuracy and is indicated by error bars on the relevant data points.

\subsection{Results and Discussion}

Table 5 reports the average equilibrium outlet $\mathrm{pO}_{2}$ values at each temperature and $p \mathrm{O}_{2}$, while Figure 35 traces the stabilization in $P 4 / \mathrm{mmm}$ lattice parameter during the equilibration period for a $\mathrm{pO}_{2}$ of $10^{-1}$ atm oxygen at $550{ }^{\circ} \mathrm{C}$. The outlet $p \mathrm{O}_{2}$ measured for the $10^{-4}$ atm oxygen feed varies between $1.68 \times 10^{-4}-2.80 \times 10^{-4} \mathrm{~atm}$, which includes the equilibration period after each temperature change. As noted in Chapter 4, complete 
equilibration at this low $\mathrm{pO}_{2}$ may take several hours and is not possible to due beam time limitations. However, the difference between the observed and desired $p \mathrm{O}_{2}$ is small and does not vary significantly during measurement on the logarithmic scale in which the material response may be observed.

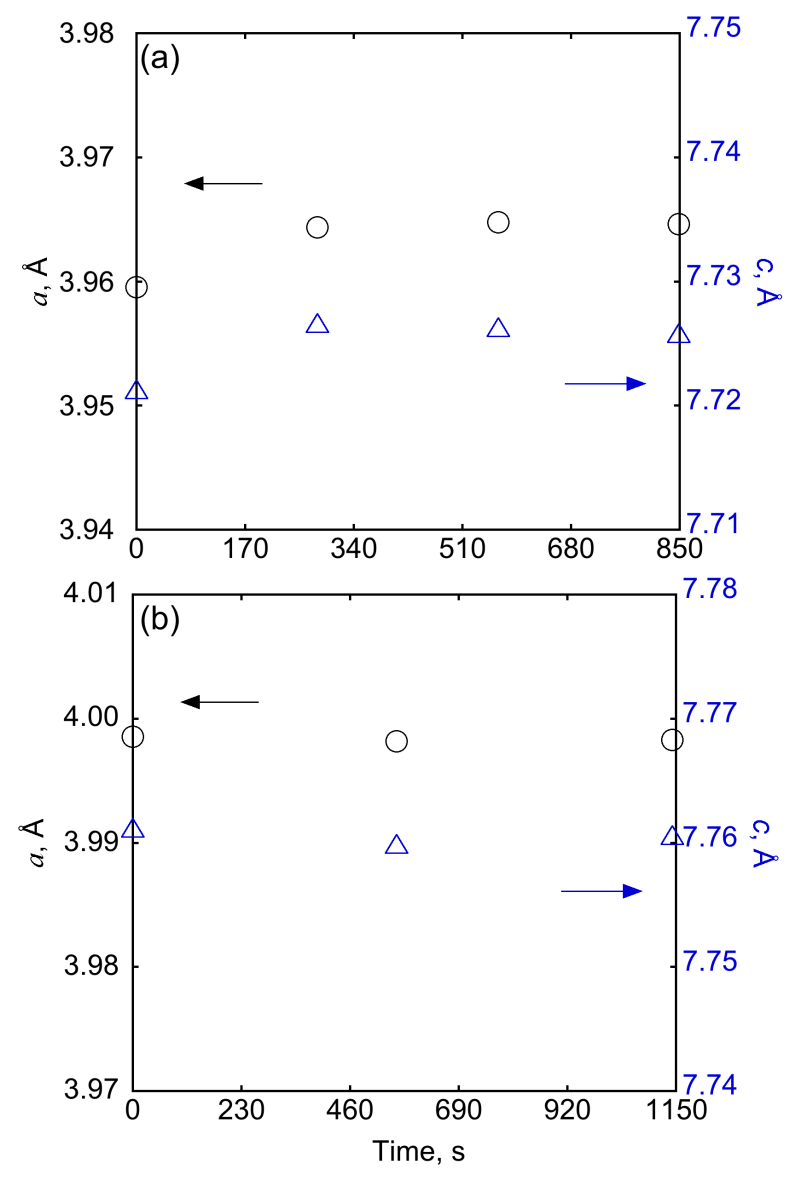

Figure 35. Lattice parameters for PBCO during equilibration prior to recording the neutron diffraction pattern at (a)10-1 atm oxygen at $550{ }^{\circ} \mathrm{C}$ and (b) $10^{-4}$ atm oxygen at $825^{\circ} \mathrm{C}$. Error bars are smaller than the data symbols. 
Table 5. Average outlet $\mathrm{pO}_{2}$ (atm) at equilibrium for each temperature and inlet gas mixture.

\begin{tabular}{c||cccc}
\hline inlet $\mathrm{pO}_{2}, \mathrm{~atm}$ & $550{ }^{\circ} \mathrm{C}$ & $650^{\circ} \mathrm{C}$ & $750^{\circ} \mathrm{C}$ & $825^{\circ} \mathrm{C}$ \\
\hline \hline $10^{-1}$ & $1.02 \times 10^{-1}$ & $1.02 \times 10^{-1}$ & $1.03 \times 10^{-1}$ & $1.03 \times 10^{-1}$ \\
\hline $10^{-2}$ & $1.10 \times 10^{-2}$ & $1.12 \times 10^{-2}$ & $1.12 \times 10^{-2}$ & $1.13 \times 10^{-2}$ \\
\hline $10^{-3}$ & $1.25 \times 10^{-3}$ & $1.25 \times 10^{-3}$ & $1.29 \times 10^{-3}$ & $1.34 \times 10^{-3}$ \\
\hline $10^{-4}$ & $1.75 \times 10^{-4}$ & $1.73 \times 10^{-4}$ & $1.87 \times 10^{-4}$ & $2.19 \times 10^{-4}$ \\
\hline
\end{tabular}

A tetragonal $\left(P 4 / \mathrm{mmm}, a_{p} \times a_{p} \times 2 a_{p}\right)$ model was fit to each data set after discounting other options, which are detailed for the example of $\mathrm{NdBaCO}_{2} \mathrm{O}_{5+\delta}$ in Section 4.3. This model was chosen because it is often used to describe materials at higher temperature and with $\delta<0.5 .[18,21,29,103,106]$ The A-site cations, Pr and $\mathrm{Ba}$, are ordered as alternating $\mathrm{Pr}$ and $\mathrm{Ba}$ layers in the $\mathrm{c}$-direction, which leads to a doubling of the unit cell in the c-direction when compared with a typical perovskite cubic unit cell. The model is shown structurally in Figure 36 and has single $\mathrm{Pr}, \mathrm{Ba}$, and $\mathrm{Co}$ sites and three $O$ sites, which were refined using anisotropic thermal parameters. The oxygen sites are distributed as one per cation $a-b$ plane, and each oxygen atom within its plane is treated as equivalent. Oxygen vacancies in the PrO layer, corresponding to the $\mathrm{O} 3$ site, result in Co-centered square pyramids; occupied $\mathrm{O} 3$ sites result in Co-centered octahedrons. This model allows for random dispersion of oxygen vacancies and resulting Co-centered octahedrons and square pyramids. 


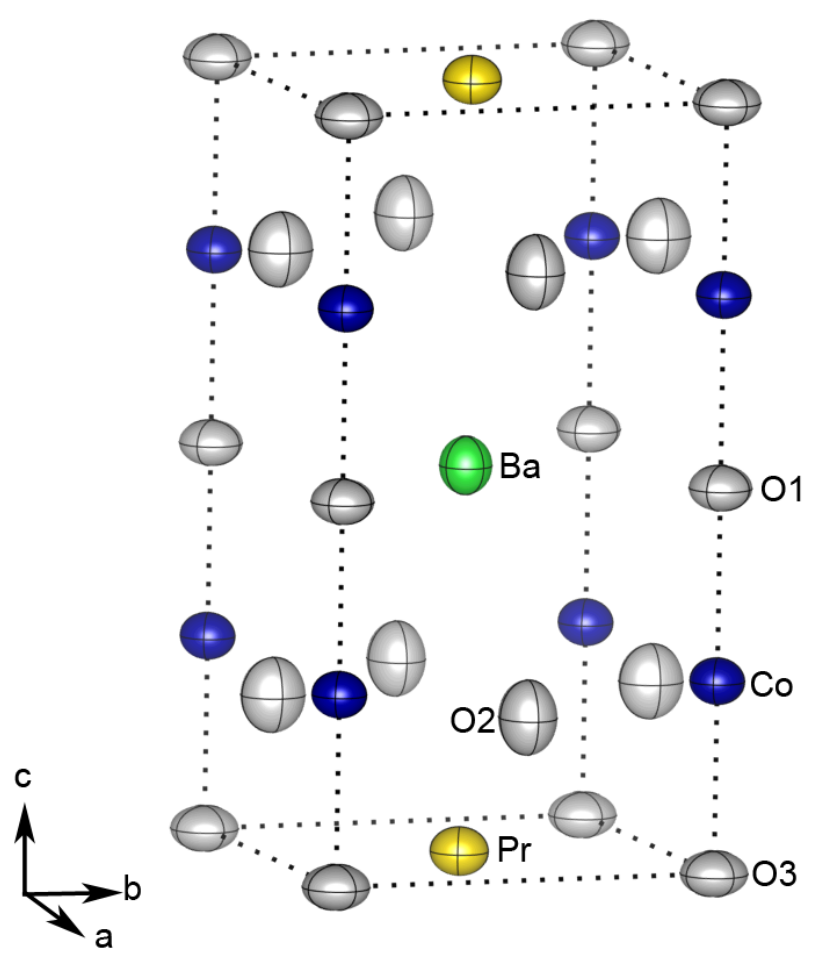

Figure 36. Crystal structure of $\mathrm{PrBaCO}_{2} \mathrm{O}_{5+\delta}$ in the $P 4 / \mathrm{mmm}$ space group with thermal ellipsoids (50\% probability) for the $10^{-1}$ atm oxygen at $825^{\circ} \mathrm{C}$ data set.

The resulting fit parameters for the $P 4 / \mathrm{mmm}$ model for the $10^{-1}$ atm oxygen 825 ${ }^{\circ} \mathrm{C}$ diffraction pattern are provided in Table 6 . The corresponding representative NPD pattern with fit and difference lines is shown in Figure 37a. The A-site cations ( $\operatorname{Pr}$ and $\mathrm{Ba})$ were constrained by position and occupancy to order alternating in the $\left(\begin{array}{lll}0 & 0 & 1\end{array}\right)$ direction. Relaxing the positional constraint lead to no change in position of $\mathrm{Pr}$ and $\mathrm{Ba}$. Refining the occupancies lead to a slight decrease to $0.948(18)$ for $\operatorname{Pr}$ and no change for $\mathrm{Ba}$ at $10^{-1} \mathrm{~atm}$ oxygen $825^{\circ} \mathrm{C}$. The lack of positional change and approximately $1: 1$ cation ratio justify the decision to maintain these positional and occupancy constraints. The Co occupancy was likewise fixed at a fractional occupancy of 1.0 , which did not result in vacancies when this constraint was eliminated for $10^{-1} \mathrm{~atm}$ oxygen $550{ }^{\circ} \mathrm{C}$. Thus the Co site was constrained as fully occupied. We refined the occupancy of all three $O$ 
sites, which resulted in the majority of vacancies at the 03 site, a $1.0-2.5 \%$ vacancy concentration for 750 and $825{ }^{\circ} \mathrm{C}$ patterns $\left(\right.$ all $\left.p \mathrm{O}_{2}\right)$ at the $\mathrm{O} 2$ site, and none at the $\mathrm{O} 1$ site. Four data sets initially refined to have $\mathrm{O} 1$ and/or $\mathrm{O} 2$ site occupancies greater than 1.0 (more than a standard deviation) and were constrained to have occupancies of 1.0. The affected data sets were all at low temperature: $550^{\circ} \mathrm{C}$ at $10^{-1}$ atm oxygen $(\mathrm{O} 1), 10^{-2}$ atm $(\mathrm{O} 1, \mathrm{O} 2), 10^{-3} \mathrm{~atm}(\mathrm{O} 1, \mathrm{O} 2)$, and $650{ }^{\circ} \mathrm{C}$ at $10^{-1}$ atm $(\mathrm{O} 1)$. The total oxygen stoichiometry is shown in Figure 38.

Oxygen vacancies have been restricted to the Pr-layer only in models developed in other studies[18, 19, 21], but constraing vacancies to the $\mathrm{O} 3$ site would require a pathway between adjacent $\mathrm{O} 3$ sites for oxygen anion transport via vacancy hopping. The 03-O3 distance, which varies from $3.96-4.00 \AA$, may be prohibitively large for the facile ion transport reported for this material [22-24] to be attributed to successive O3-O3 site hops, as noted in Chapter 4 with NBCO. The shorter O2-O3 site distance of $2.55-$ $2.59 \AA$ supports the notion that vacancies in the $\mathrm{O} 2$ site facilitate the hopping mechanism. This would suggest an oxygen transport mechanism consisting of hopping from the $\mathrm{O} 3$ site in the vacancy-rich $\mathrm{PrO}_{\delta}$ plane to the nearest neighbor $\mathrm{O} 2$ site in the more fully occupied $\mathrm{CoO}$ plane, which agrees with the findings for NBCO in Chapter 4. Our refinements indicate that fractional $\mathrm{O} 2$ site occupancies include a $1.0-2.5 \%$ vacancy concentration at 750 and $825^{\circ} \mathrm{C}\left(\right.$ all $\left.p \mathrm{O}_{2}\right)$. However, it is possible that oxygen vacancies can exist at the $\mathrm{O} 2$ site at lower temperatures $\left(550\right.$ and $\left.650{ }^{\circ} \mathrm{C}\right)$, as these are time and structure averaged values. Given the lack of 01 site vacancies and that the O2-O1 site distance is larger than the $\mathrm{O} 2$ - $\mathrm{O} 3$ distance, the most facile hopping mechanism route would be $\mathrm{O} 3-\mathrm{O} 2-\mathrm{O} 3$, avoiding the $\mathrm{O} 1$ site. The thermal ellipsoids defined by the anisotropic thermal parameters are listed in Table 6 and show motion of the $\mathrm{O} 3$ and $\mathrm{O} 1$ sites primarily in the $x, y$-direction, while the $\mathrm{O} 2$ site motion is largely in 
the z-direction, which agree with the findings for NBCO in Chapter 4 . These results provide evidence for the proposed vacancy hopping mechanism by indicating that thermal motion of the $\mathrm{O}$ sites occurs such at the $\mathrm{O} 2-\mathrm{O} 3$ site distance is minimized.

Table 6. Rietveld fit parameters for $\mathrm{PBCO}$ at $825^{\circ} \mathrm{C}$ and $p \mathrm{O}_{2}$ of $10^{-1} \mathrm{~atm}$ refined using a tetragonal $(P 4 / \mathrm{mmm})$ model, with sites: $\operatorname{Pr} 1 c(0.50 .50)$; Ba $1 d(0.50 .50 .5)$; Co $2 g(00$

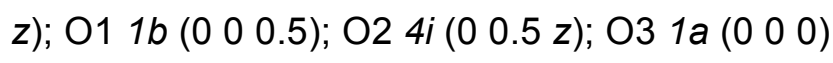

\begin{tabular}{|c|c|c|c|}
\hline a $(\AA)$ & $3.99175(6)$ & & \\
\hline$c(\AA)$ & $7.7660(1)$ & & \\
\hline Co $(z)$ & $0.2497(5)$ & & \\
\hline $\mathrm{O} 2(z)$ & $0.2112(1)$ & & \\
\hline Occ. 01 & $0.998(12)$ & & \\
\hline Occ. O2 & $0.975(6)$ & & \\
\hline Occ. 03 & $0.374(12)$ & & \\
\hline Ox. Cont. & $5.27(5)$ & & \\
\hline$X^{2}$ & 1.515 & & \\
\hline$R_{P}$ & 0.0908 & & \\
\hline$w R_{P}$ & 0.0494 & & \\
\hline$V\left(\AA^{3}\right)$ & $123.744(5)$ & & \\
\hline$\rho_{c}\left(\mathrm{~g} / \mathrm{cm}^{3}\right)$ & 6.447 & & \\
\hline $\begin{array}{l}\text { Thermal } \\
\text { parameters } \\
\left(\AA^{2}\right)^{*} 100\end{array}$ & $U_{11}$ & $U_{22}$ & $U_{33}$ \\
\hline $\mathrm{Pr}$ & $3.6(2)$ & $3.6(2)$ & $2.5(2)$ \\
\hline $\mathrm{Ba}$ & $3.0(2)$ & $3.0(2)$ & $3.6(2)$ \\
\hline Co & $3.19(9)$ & $3.19(9)$ & $2.3(2)$ \\
\hline 01 & $4.2(2)$ & $4.2(2)$ & $2.2(2)$ \\
\hline $\mathrm{O} 2$ & $4.5(1)$ & $3.6(1)$ & $6.0(1)$ \\
\hline $\mathrm{O} 3$ & $4.9(5)$ & $4.9(5)$ & $2.2(5)$ \\
\hline
\end{tabular}



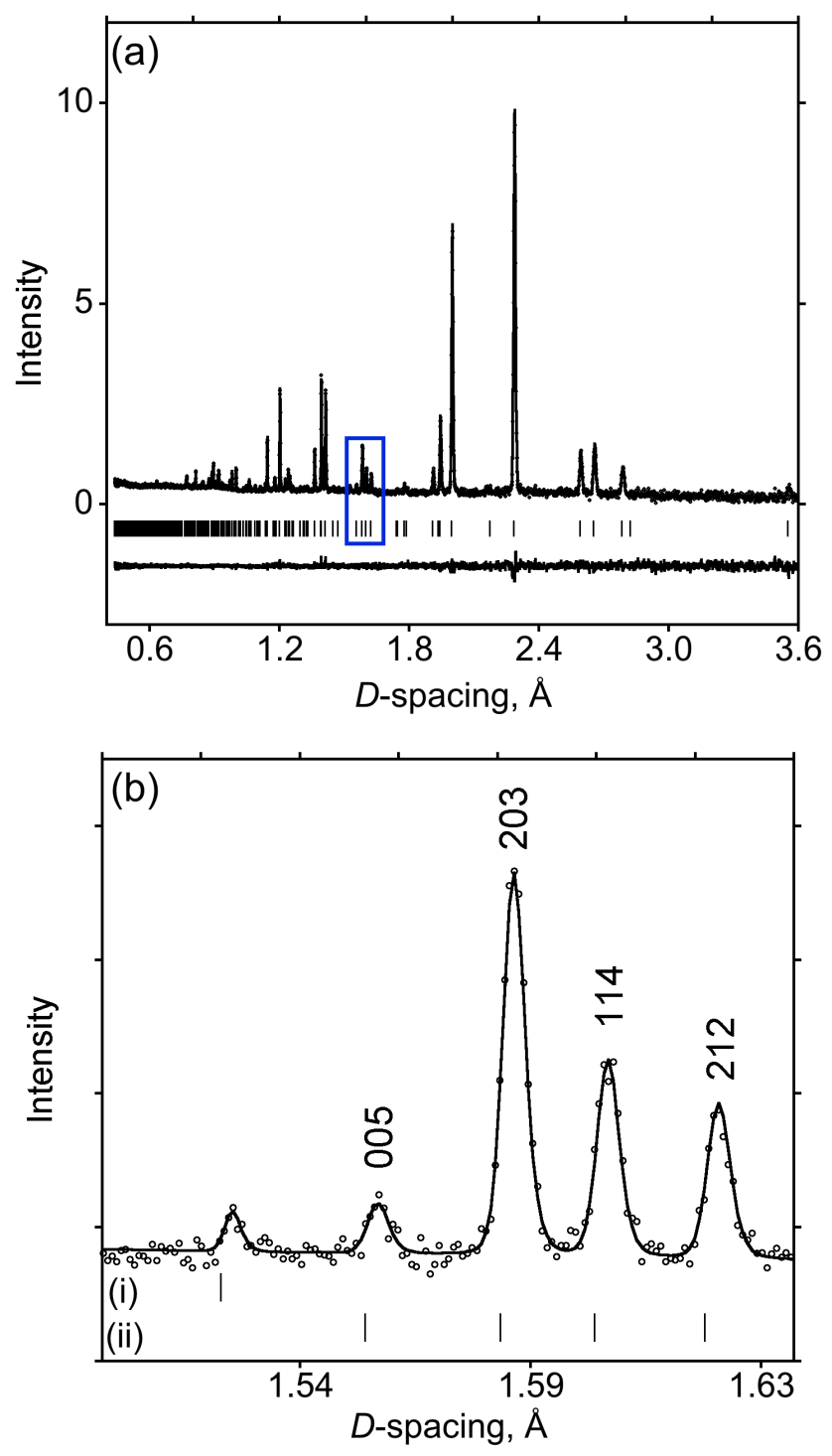

Figure 37. Rietveld fit of neutron diffraction pattern for PBCO $(P 4 / \mathrm{mmm}) 10^{-1} \mathrm{~atm}$ oxygen at $825^{\circ} \mathrm{C}$. The entire pattern is shown in (a) and consist of observed (circles), calculated (top line), and difference (bottom line) data. Theoretical Bragg reflection positions are marked with vertical lines. A detailed view of the boxed area indicated in the top figure is shown in (b) with Bragg reflections marked for (i) $\mathrm{CoO}(F m \overline{3} m)$ secondary phase, and (ii) PBCO $(P 4 / m m m)$ phase. 


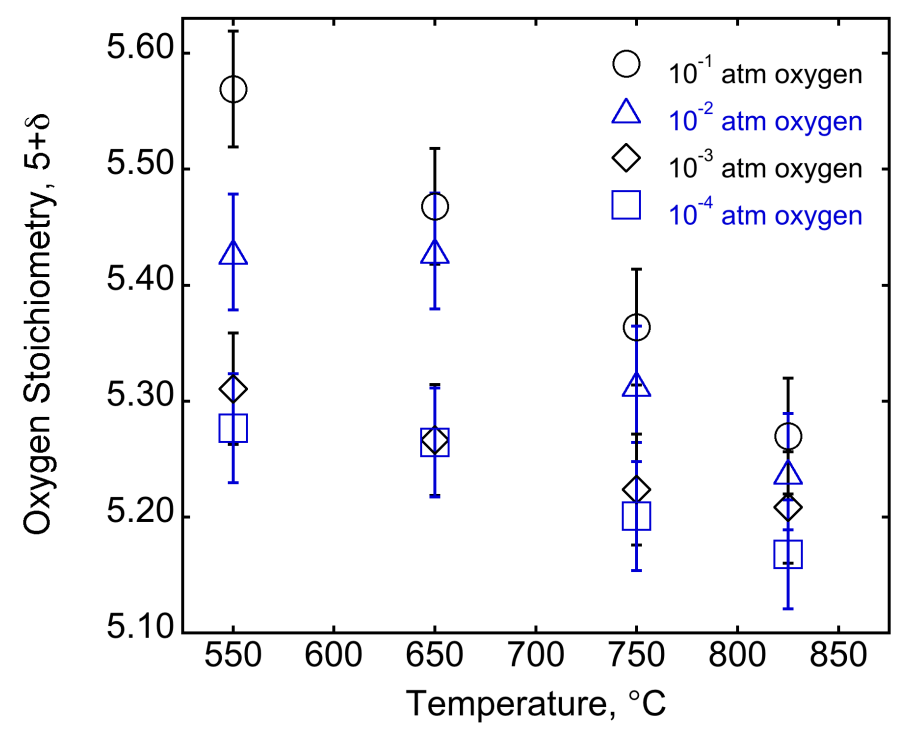

Figure 38. Oxygen stoichiometry of PBCO with temperature and $\mathrm{pO}_{2}$.

Figure 39 gives the $\mathrm{O} 1-\mathrm{Co}-\mathrm{O} 2$ bond angle plotted with $\mathrm{O} 3$ site occupancy. The bond angle increases as the $\mathrm{O} 3$ site vacancy concentration increases, which is due to a shift in the $\mathrm{O} 2$ site toward the increasingly oxygen deficient $\mathrm{Pr}-\mathrm{O} 3$ layer, since the Co and 01 sites are fixed at $(x, y)$ fractional coordinates of $(0,0)$. The Co site also shifts towards the Pr-O3 layer with increasing oxygen vacancy concentration. The Co-O1 and Co-O3 bond lengths shown in Figure 40 are not strongly dependent on temperature or $\mathrm{pO}_{2}$, though the Co-O3 bond length is a stronger function of $\mathrm{O} 3$ site occupancy. The changes in both $\mathrm{Co}-\mathrm{O} 1, \mathrm{O} 3$ bond lengths across the $\mathrm{T}-\mathrm{pO}_{2}$ range studied are approximately equivalent, resulting in an overall $0.039(8) \AA$ decrease in the $c$-axis length, which accounting for, within error, the $0.0458(2) \AA$ reduction in the $c$ lattice parameter that is observed as the $\mathrm{O} 3$ site becomes increasingly vacant. These trends in O1-Co-O2 bond angle, Co-O bond lengths, as well as the vertical shrinkage of the unit cell are consistent with the behavior of NBCO discussed in Chapter 4. It must be noted that the reduction in the $c$ lattice parameter brings the $\mathrm{Co}$ and $\mathrm{O} 2$ atoms toward the 
increasingly vacant $\mathrm{Pr}-\mathrm{O} 3$ plane, which causes a reduction of the $\mathrm{O} 2$ - $\mathrm{O} 3$ site bond length, aiding the proposed vacancy hopping mechanism.

The lattice parameters shown in Figure 41 confirm the reduction in length of the $c$-axis with decreasing $\mathrm{pO}_{2}$. Both lattice parameters increase with temperature due to thermal expansion, while the a lattice parameter increases with decreasing $\mathrm{pO}_{2}$, in contrast to the $c$ lattice parameter. This behavior is consistent with NBCO in Chapter 4 and corresponds with chemical expansion as a result of the increasing average atomic radius of Co as it is reduced.[109] The reduction of this cation is concomitant with formation of oxygen vacancies as $\mathrm{pO}_{2}$ is decreased. Thus, as oxygen vacancies form and are localized in the PrO plane, chemical expansion occurs in the $a$ and $b$ axes, while the $c$-axis contracts as the $\mathrm{Co}$ and $\mathrm{O} 2$ sites shift toward the increasingly vacant $\mathrm{O} 3$ site in the PrO layer.

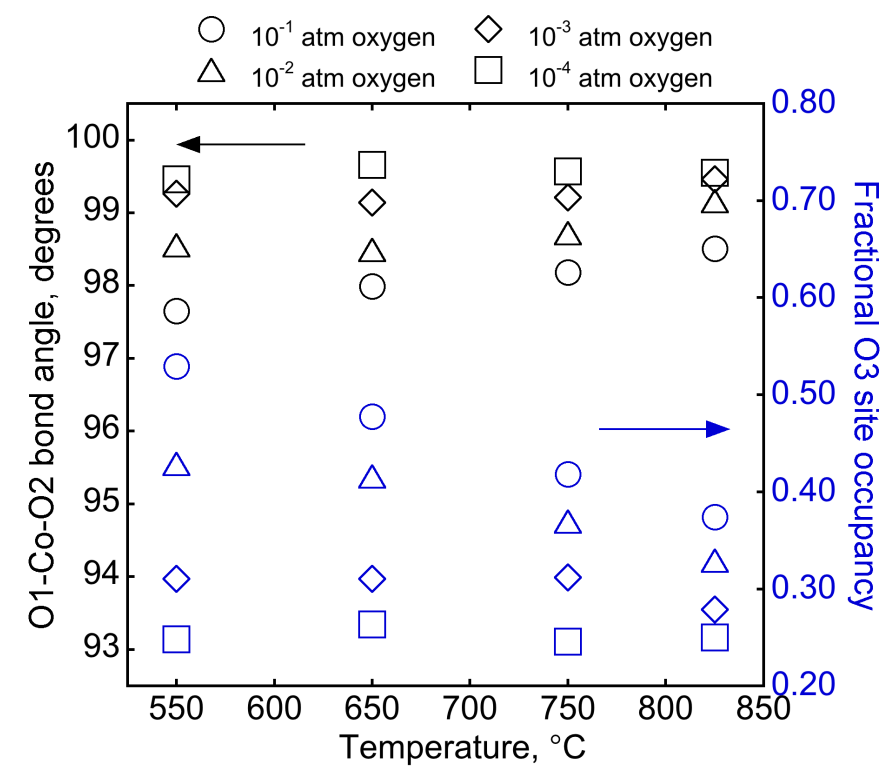

Figure 39. Change in $\mathrm{O} 1-\mathrm{Co}-\mathrm{O} 2$ bond angle with fractional $\mathrm{O} 3$ site occupancy as a function of temperature and $\mathrm{pO}_{2}$. Error bars are smaller than the data symbols. 

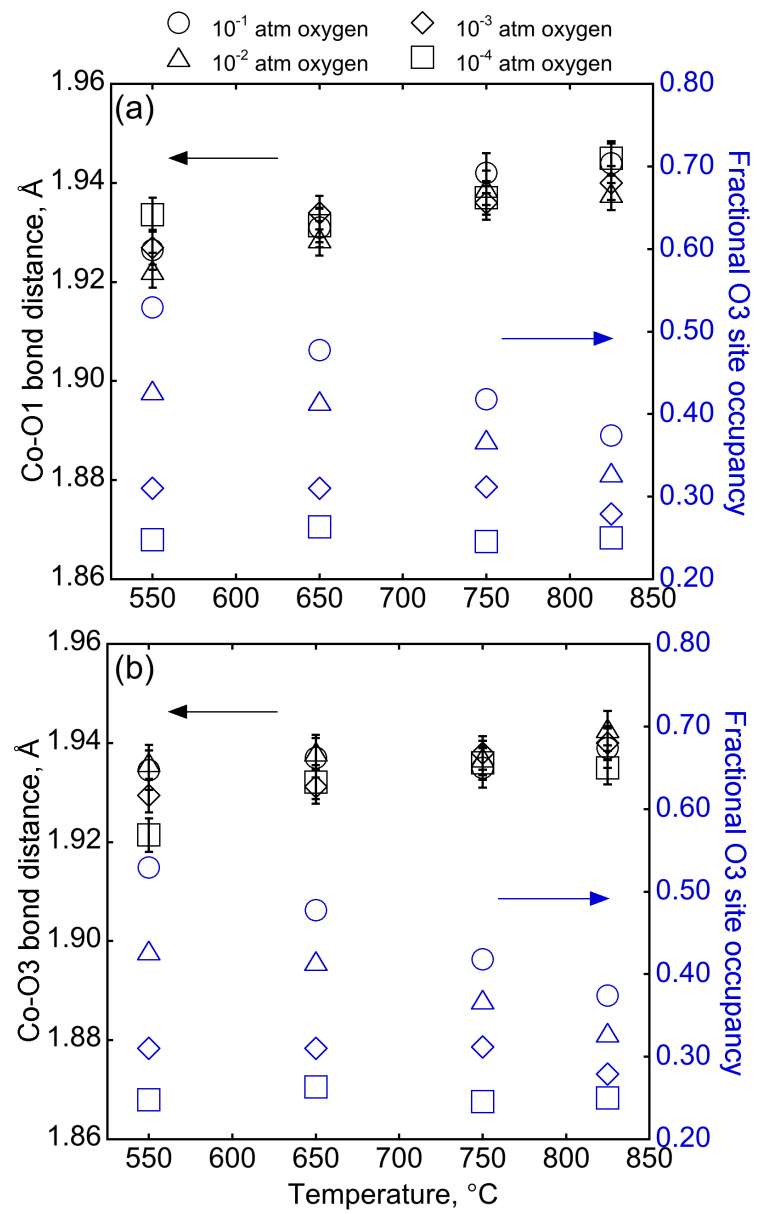

Figure 40. (a) Co-O1 bond length and (b) $\mathrm{Co}-\mathrm{O} 3$ bond length with fractional $\mathrm{O} 3$ site occupancy as a function of temperature and $\mathrm{pO}_{2}$. Error bars for $\mathrm{O} 3$ site occupancy are smaller than the data symbols and are not plotted. 


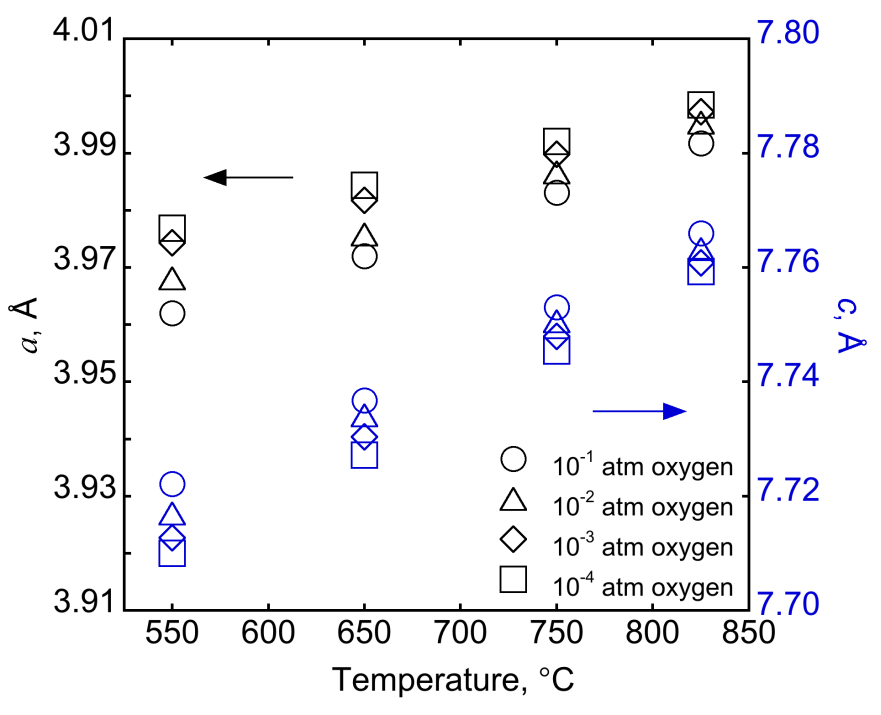

Figure 41. Tetragonal $(P 4 / \mathrm{mmm})$ lattice parameters for each $\mathrm{pO}_{2}$ range. Error bars are smaller than the symbols used in the figure.

A small secondary phase $(<2 \%$ of the total moles of PBCO) that refined as $\mathrm{CoO}$ $(F m \overline{3} \mathrm{~m})$ was observed in the following data sets: $10^{-1}$ atm oxygen at $825^{\circ} \mathrm{C}, 10^{-2}$ atm at 550 and $825^{\circ} \mathrm{C}$, and $10^{-3}$ and $10^{-4}$ atm at all temperatures. This is illustrated in Figure 37b, which shows calculated peak positions for both $\mathrm{CoO}$ and PBCO structures in the $d$ spacing range of 1.50 to $1.64 \AA$. The $\mathrm{CoO}$ phase first appears at $10^{-1} \mathrm{~atm}$ oxygen $825^{\circ} \mathrm{C}$ after $\sim 7$ hours in the neutron beam, so it is likely the result of sample decomposition rather than a pre-existing impurity phase. The phase was present in the next chronological diffraction pattern, which was $10^{-2}$ atm oxygen at $550{ }^{\circ} \mathrm{C}$, but does not appear again until $825^{\circ} \mathrm{C}$ is reached. This indicates that an equilibrium exists between $\mathrm{PBCO}$ and $\mathrm{CoO}$ at low temperature and higher $\mathrm{pO}$. Once low $\mathrm{pO}_{2}$ was reached, corresponding with a higher number of oxygen vacancies, the $\mathrm{CoO}$ phase remained and increased in mole fraction. This decomposition behavior has been observed at temperatures of $650-750{ }^{\circ} \mathrm{C}$ and $10^{-4}-10^{-10}$ atm oxygen for $\mathrm{NdBaCo}_{2} \mathrm{O}_{5+\delta}$ [33] and for 
$\mathrm{NdBaCO}_{2-x} \mathrm{Fe}_{\mathrm{x}} \mathrm{O}_{5+\delta}-\mathrm{YSZ}(\mathrm{x}=0,1)$ composites [112] using coulometric titration. Higher temperatures lead to a higher $\mathrm{pO}_{2}$ at which decomposition was observed, which is consistent with our findings. These diffraction patterns were recorded over the course of approximately $2-3$ hours per pattern, so it is unclear if the decomposition process had reached equilibrium when the temperature and/or $\mathrm{pO}_{2}$ was changed for the next diffraction pattern.

\subsection{Conclusions}

$\mathrm{PrBaCO}_{2} \mathrm{O}_{5+\delta}(\mathrm{PBCO})$ was characterized using neutron powder diffraction at 550 - $825{ }^{\circ} \mathrm{C}$ and $10^{-1}-10^{-4}$ atm oxygen in order to study the material at in-situ SOFC conditions. The diffraction patterns were fit to a tetragonal $(P 4 / \mathrm{mmm})$ space group and resulted in total oxygen stoichiometry values ranging from $5.17-5.57$. The lattice parameters indicated crystal expansion with increasing temperature, but contraction of the c-axis with decreasing $\mathrm{pO}_{2}$ as the $\mathrm{Co}$ and $\mathrm{O} 2$ sites shifted toward the increasingly vacant $\mathrm{Pr}-\mathrm{O} 3$ layer. These results are consistent with $\mathrm{NdBaCO}_{2} \mathrm{O}_{5+\delta}(\mathrm{NBCO})$ discussed in Chapter 4. However, in contrast with NBCO, a small secondary phase identified as $\mathrm{CoO}$ was observed for $\mathrm{PBCO}$ at high temperature and at low $\mathrm{pO}_{2}$. 


\section{Chapter 6 - Attempts to Synthesize Perovskite Nanorods}

\subsection{Introduction}

$\mathrm{La}_{1-\mathrm{x}} \mathrm{Sr}_{\mathrm{x}} \mathrm{CoO}_{3-\delta}$ (LSC) oxides with perovskite structure are mixed oxygen ionelectron conductors frequently used as SOFC cathode materials $[46,49,60,67,75$, 113-115]. LSC exhibits oxygen-ion conductivity at elevated temperatures and is a good electrocatalyst for oxygen reduction [1].

Studies have shown that nanostructured electrodes provide enhanced performance over bulk materials, specifically in the case of nanoparticles applied at high loading densities to porous cathodes $[65,66]$. However, it is unclear whether this improvement is due to an increase in active surface area or due to changes in material properties upon nanostructuring. The production of uniform, phase pure nanostructured cathode materials would allow for fundamental studies on the nanomaterials, themselves, as well as support further investigation of nanostructured cathodes for ITSOFC applications.

Hydrothermal synthesis is a facile, low temperature, scalable method of producing a variety of nanostructured materials. This technique has been used to synthesize nanoparticles, nanorods, nanocubes, and other geometries [116-128], as well as to grow epitaxial arrays of nanorods onto single crystalline substrates [128-131]. Growth of nanostructures is thought to occur through a dissolution / precipitation mechanism during which precursor materials continually dissolve in solution and are precipitated such that the total surface energy of the crystalline product is minimized $[131,132]$. Anisotropic growth occurs in crystals with differing surface energies among its crystal faces and is more readily observed in crystals with anisotropic unit cells [131]. Nanorods (high aspect ratio nanocrystals) exhibit rapid anisotropic growth at one high 
surface energy crystal face and are preserved in solution by favorable, generally nonequilibrium, growth kinetics $[131,133]$. The chemical potential of the solution (based on $\mathrm{pH}$ and precursor concentration) relative to the solid precipitate also provides a driving force for the rapid assembly of 1-D structures $[132,133]$. This one-dimensional growth has been readily observed with lanthanide precipitates, where precursor materials are consumed by formation of surfaces mainly perpendicular to the c-axis $[133,134]$.

Published accounts indicate that $\mathrm{La}_{1-x} \mathrm{Sr}_{x} \mathrm{CoO}_{3-\delta}$ nanorods may be produced via hydrothermal synthesis. Wang and Fan [135] reported the formation of $\mathrm{La}_{0.1} \mathrm{Sr}_{0.9} \mathrm{CoO}_{3}$ nanorods by combining $\mathrm{La}, \mathrm{Sr}$ and Co nitrate precursors adjusting the solution $\mathrm{pH}$ to 13 with $\mathrm{KOH}$, and hydrothermal treatment at 200,230 and $250{ }^{\circ} \mathrm{C}$ for $48 \mathrm{~h}$. The sole synthesis product was phase-pure $\mathrm{La}_{0.1} \mathrm{Sr}_{0.9} \mathrm{CoO}_{3}$ nanorods. Additionally, Deng et al. [136] reported formation of $\mathrm{La}_{0.6} \mathrm{Sr}_{0.4} \mathrm{CoO}_{3}$ (LSC64) nanorods by calcining hydrothermal synthesis products at 650,800 and $900{ }^{\circ} \mathrm{C}$. The rod nano-structure was preserved postcalcination, though the material calcined at $650{ }^{\circ} \mathrm{C}$ retained the smallest diameter. An alternative nanorod synthesis method involves converting non-perovskite templates into perovskites through a soft chemical reaction, while maintaining the template structure. Such topochemical conversions have been used successfully to transform anisotropic materials [137-141]. For example, Madero et al. [140] converted $\mathrm{K}_{4} \mathrm{Nb}_{6} \mathrm{O}_{17}$ and $\mathrm{KNb}_{3} \mathrm{O}_{8}$ (plate structures) and $\mathrm{K}_{2} \mathrm{Nb}_{4} \mathrm{O}_{11}$ (needle structure) non-perovskite templates into $\mathrm{KNbO}_{3}$ and $\mathrm{K}_{x} \mathrm{Na}_{1-\mathrm{x}} \mathrm{NbO}_{3-\delta}$ perovskites, while preserving the respective template morphology.

The work presented here attempts to produce $\mathrm{La}_{0.6} \mathrm{Sr}_{0.4} \mathrm{CoO}_{3-\delta}(\mathrm{LSC64})$ nanorods via hydrothermal synthesis, post-synthesis calcination, and topochemical conversion of non-perovskite $\mathrm{La}(\mathrm{OH})_{3}$ nanorods into LSC64. We discuss the products resulting from these techniques, as well as the inability to produce phase-pure LSC64 nanorods. 


\subsection{Experimental}

a. Hydrothermal synthesis

Stoichiometric amounts of solid nitrate precursors, $\mathrm{La}\left(\mathrm{NO}_{3}\right)_{3} \cdot 6 \mathrm{H}_{2} \mathrm{O}$ [min $99 \%$, Metall Rare Earth Limited, Shenzhen, China], $\operatorname{Sr}\left(\mathrm{NO}_{3}\right)_{2}$ [min 99\%, Sigma-Aldrich, St. Louis, MO, USA], and $\mathrm{Co}\left(\mathrm{NO}_{3}\right)_{2} \cdot 6 \mathrm{H}_{2} \mathrm{O}$ [min 98\%, Sigma-Aldrich, St. Louis, MO, USA], were dissolved in $10 \mathrm{~mL}$ of distilled water. A $10 \mathrm{M}$ solution of potassium hydroxide $(\mathrm{KOH})[90 \%$, Sigma-Aldrich, St. Louis, MO, USA] was prepared as a mineralizing agent. Once the nitrates were fully dissolved, $10 \mathrm{~mL}$ of the $\mathrm{KOH}$ solution $(100 \mathrm{mmol} \mathrm{KOH})$ was added to the nitrates (unless otherwise noted) and the total solution level was adjusted to $50 \mathrm{~mL}$ by adding distilled water. The solution was magnetically stirred for a minimum of 30 minutes before transferring to a $125 \mathrm{~mL}$ Teflon-lined stainless steel vessel [Parr Instruments, Moline, IL, USA]. The vessel was heated to $200{ }^{\circ} \mathrm{C}$ or $250{ }^{\circ} \mathrm{C}$ under autogenous pressure for $46 \mathrm{~h}$ (unless otherwise noted). Once the vessel returned to room temperature, the supernatant liquid $(\mathrm{pH}>13)$ was removed via centrifugation and the product was washed with distilled water until a neutral $\mathrm{pH}$ was reached. After a final rinse with ethanol, the product was dried at ambient conditions.

\section{b. Conversion of non-perovskite templates}

i. Production of $\mathrm{La}(\mathrm{OH})_{3}$ nanorods via mild hydrothermal synthesis

$25 \mathrm{~mL}$ of a $1.0 \mathrm{M} \mathrm{La}\left(\mathrm{NO}_{3}\right)_{3}$ solution $\left[\mathrm{La}\left(\mathrm{NO}_{3}\right)_{3} \cdot 6 \mathrm{H}_{2} \mathrm{O}\right.$, min $99 \%$, Alfa Aesar, Ward Hill, MA, USA] was combined with $25 \mathrm{~mL}$ of a $10 \mathrm{M} \mathrm{KOH}$ solution [90\%, Fisher Scientific, Fair Lawn, NJ, USA]. A thick white precipitate formed immediately; rapid magnetic stirring decreased the viscosity over time. The solution was stirred for a minimum of 30 minutes before transferring to a homemade $100 \mathrm{~mL}$ Teflon-aluminum vessel, which was heated to $140{ }^{\circ} \mathrm{C}$ under autogenous pressure for $46 \mathrm{~h}$. Once the vessel returned to room 
temperature, the supernatant liquid $(\mathrm{pH}>13)$ was removed via centrifugation and the product was washed with distilled water. After a final rinse with ethanol, the white product was dried overnight at $80{ }^{\circ} \mathrm{C}$ and subsequently crushed to a fine powder.

ii. Evaporation deposition of nitrates onto nanorods and calcination

The $\mathrm{La}(\mathrm{OH})_{3}$ nanorods produced via mild hydrothermal synthesis were coated with $\mathrm{Sr}$ and Co precursors via evaporation deposition. Stoichiometric amounts of a $\mathrm{Sr}\left(\mathrm{NO}_{3}\right)_{2}$ solution [min 99\%, Alfa Aesar, Ward Hill, MA, USA] and a $\mathrm{Co}\left(\mathrm{NO}_{3}\right)_{2}$ solution $\left[\mathrm{Co}\left(\mathrm{NO}_{3}\right)_{2} \cdot 6 \mathrm{H}_{2} \mathrm{O}\right.$ min $99 \%$, Acros Organics, Morris Plains, NJ, USA], $3.51 \mathrm{~mL}$ and 8.77 $\mathrm{mL}$, respectively, were combined in a beaker. The concentration of both nitrate solutions was 0.25 M. Ammonium hydroxide [27\%(w/w), Mallinckrodt Chemicals, Phillipsburg, NJ, USA] was added drop-wise until the solution reached $\mathrm{pH}$ 7. It was ultrasonically stirred [Omni-Ruptor 250, Omni International, Inc., Kennesaw, GA, USA] at 10\% power, 30\% pulse for $3 \mathrm{~min}$ before $0.25 \mathrm{~g}$ of the washed, as-synthesized $\mathrm{La}(\mathrm{OH})_{3}$ nanorod powder was added. The solution was ultrasonically mixed for an additional $10 \mathrm{~min}$, and then heated to $70{ }^{\circ} \mathrm{C}$ while being magnetically stirred. After approximately $1 \mathrm{~h}$ at $70{ }^{\circ} \mathrm{C}$, the solution had dried to a green solid and was scraped from the beaker and then crushed to a fine powder. The powder was calcined at 500, $(400+650)$, or $800{ }^{\circ} \mathrm{C}$ with heating and cooling rates of $1^{\circ} \mathrm{C} / \mathrm{min}$ and durations of either 2 or $8 \mathrm{~h}$.

\section{c. Treatment of $\mathrm{La}_{0.6} \mathrm{Sr}_{0.4} \mathrm{CoO}_{3-\delta}$ powder in mild hydrothermal conditions}

Phase pure LSC64 powder was manufactured using a spray pyrolysis technique with metal nitrate precursors: $\mathrm{La}\left(\mathrm{NO}_{3}\right)_{3} \cdot 6 \mathrm{H}_{2} \mathrm{O}, \mathrm{Sr}\left(\mathrm{NO}_{3}\right)_{2}$, and $\mathrm{Co}\left(\mathrm{NO}_{3}\right)_{2} \cdot 6 \mathrm{H}_{2} \mathrm{O}$ (purity and source listed in section 'a'). After synthesis, the LSC64 powder was calcined in air at 800 ${ }^{\circ} \mathrm{C}$ for $2 \mathrm{~h}$. In a beaker, $0.56 \mathrm{~g}(2.5 \mathrm{mmol})$ of this material was combined with $1.25 \mathrm{~mL}$ of a $10 \mathrm{M} \mathrm{KOH}$ solution $(12.5 \mathrm{mmol} \mathrm{KOH})$ [90\%, Fisher Scientific, Fair Lawn, NJ, USA]. 
The total solution level was adjusted to $40 \mathrm{~mL}$, magnetically stirred for approximately 15 minutes, and then transferred to a homemade $100 \mathrm{~mL}$ Teflon-aluminum vessel. This vessel was heated to $150{ }^{\circ} \mathrm{C}$ under autogenous pressure for $46 \mathrm{~h}$. Once the vessel returned to room temperature, the supernatant liquid $(\mathrm{pH}>13)$ was removed and the product was washed with distilled water until a neutral $\mathrm{pH}$ was reached. After a final rinse with ethanol, the product was dried at ambient conditions. This process was repeated using LSC64 powder that was further annealed in ultra high purity (UHP) nitrogen gas. Annealing was performed in a sealed alumina tube with a $25 \mathrm{~mL} / \mathrm{min}$ gas flowrate at $500{ }^{\circ} \mathrm{C}$ for $12 \mathrm{~h}$ with $2 \% / \mathrm{min}$ heating and cooling rates. Upon returning to room temperature, the powder (0.56 $\mathrm{g}$ initial mass) was removed from its gas environment and immediately combined with the appropriate amount of $\mathrm{KOH}$ in preparation for mild hydrothermal synthesis.

\section{d. Sample characterization}

\section{iii. Hydrothermal synthesis products}

Powder X-ray diffraction patterns [Siemens X-Ray Diffractometer B, D5005, Karlsrhue, Germany] with $\mathrm{Cu}-\mathrm{Ka}$ radiation source, fixed slit width, and secondary graphite monochromator were collected on hydrothermal synthesis products to determine their phase composition. The washed samples were dispersed in ethanol via sonication and applied to a low-background silicon specimen holder. The patterns were obtained in the range of $15-45^{\circ}$ with a $0.01^{\circ}$ step size and scan rate of 1.0 s/step.

Morphology was determined using a field emission gun scanning electron microscope (FEG-SEM) [Zeiss Ultra 55 Limited Edition, Germany]. The samples were prepared by applying a droplet of the earlier described suspension in ethanol to the SEM sample holder and coating with carbon. Transmission electron microscopy (TEM) [JEOL 
JEM-2010, Tokyo, Japan] was used to further examine the product morphology. Samples were prepared by placing a droplet of the product in an ethanol suspension onto a 300 mesh copper grid coated with holey amorphous carbon [Agar Scientific, Essex, England]. Energy dispersive x-ray spectroscopy (EDS) was used in the TEM to probe the element composition of selected samples. The average length and width was determined from SEM and TEM images using the ImageJ software [National Institutes of Health, Bethesda, MD, USA] [142].

Thermogravimetric analysis (TG) and differential scanning calorimetry (DSC) [Netzsch STA 449C, Germany] were simultaneously performed using $27.2 \mathrm{mg}$ of material in an alumina crucible with a continuous $30 \mathrm{~mL} / \mathrm{min}$ flow of synthetic air. The sample was heated from $30-1000{ }^{\circ} \mathrm{C}$ at a rate of $2{ }^{\circ} \mathrm{C} / \mathrm{min}$.

iv. Topochemical conversion products

Powder X-ray diffraction patterns [Scintag X-Ray Diffraction, XDS 2000, Cupertino, CA, USA] with $\mathrm{Cu}-\mathrm{Ka}$ radiation source and fixed slit width were also collected on samples prepared as above and then crushed to a powder. The patterns were obtained in the range of $15-45^{\circ}$ with a step size of $0.02^{\circ}$ and a scan rate of 2.0 s/step. Peak analysis was performed using the JADE 9 software package [MDI, Livermore, CA, USA]. Product morphology was determined using a field emission scanning electron microscope (SEM) [JEOL JSM 6700, Tokyo, Japan].

v. Mild hydrothermal treatment products

Powder X-ray diffraction patterns [PANalytical, X'Pert, Westborough, MA 01581] with $\mathrm{Cu}-\mathrm{Ka}$ radiation source and fixed slit width were collected on the resulting powders. Patterns were obtained in the range of $15-85^{\circ}$ with a step size of $0.008^{\circ}$ and a scan rate of 26.0 s/step. Peak analysis was performed using the JADE 9 software package [MDI, Livermore, CA, USA]. 


\subsection{Results}

a. Attempts to produce $\mathrm{La}_{0.6} \mathrm{Sr}_{0.4} \mathrm{CoO}_{3}$ nanorods during hydrothermal synthesis In a typical example, a solution containing $20 \mathrm{mmol}$ of $\mathrm{La}, \mathrm{Sr}$, and Co nitrate precursor and $94 \mathrm{mmol}$ of potassium hydroxide was held at $250{ }^{\circ} \mathrm{C}$ for $46 \mathrm{~h}$ in a Teflonlined vessel. The XRD pattern of the washed and dried product is shown in Figure 42a. The major phases in the product are $\mathrm{La}(\mathrm{OH})_{3}, \mathrm{Co}_{3} \mathrm{O}_{4}$, and $\mathrm{CoO}$; there is no perovskite phase present. Figure 42b provides a FEG-SEM image of the product. By qualitative inspection, greater than $95 \%$ of the material is composed of nanorod structures interspersed with smaller, often isometric structures. TEM images of the nanorods are shown in Figure 43. They are $25 \mathrm{~nm}$ wide on average (Figure 43a,b), highly crystalline (Figure 43c,d) and in selected areas contain 1-2 $\mathrm{nm}$ circular spots with material that appears unrelated to the underlying crystal structure. EDS was used to probe the composition of the synthesis products. EDS analysis of Figure 44a showed that the nanorod surface primarily contains La with smaller amounts of $\mathrm{Sr}$ and trace quantities of Co, while the cube-like particles are primarily composed of Co. EDS analysis of Figure 44b adds that the surface of the oval particles primarily contains Sr and Co with trace amounts of La. 

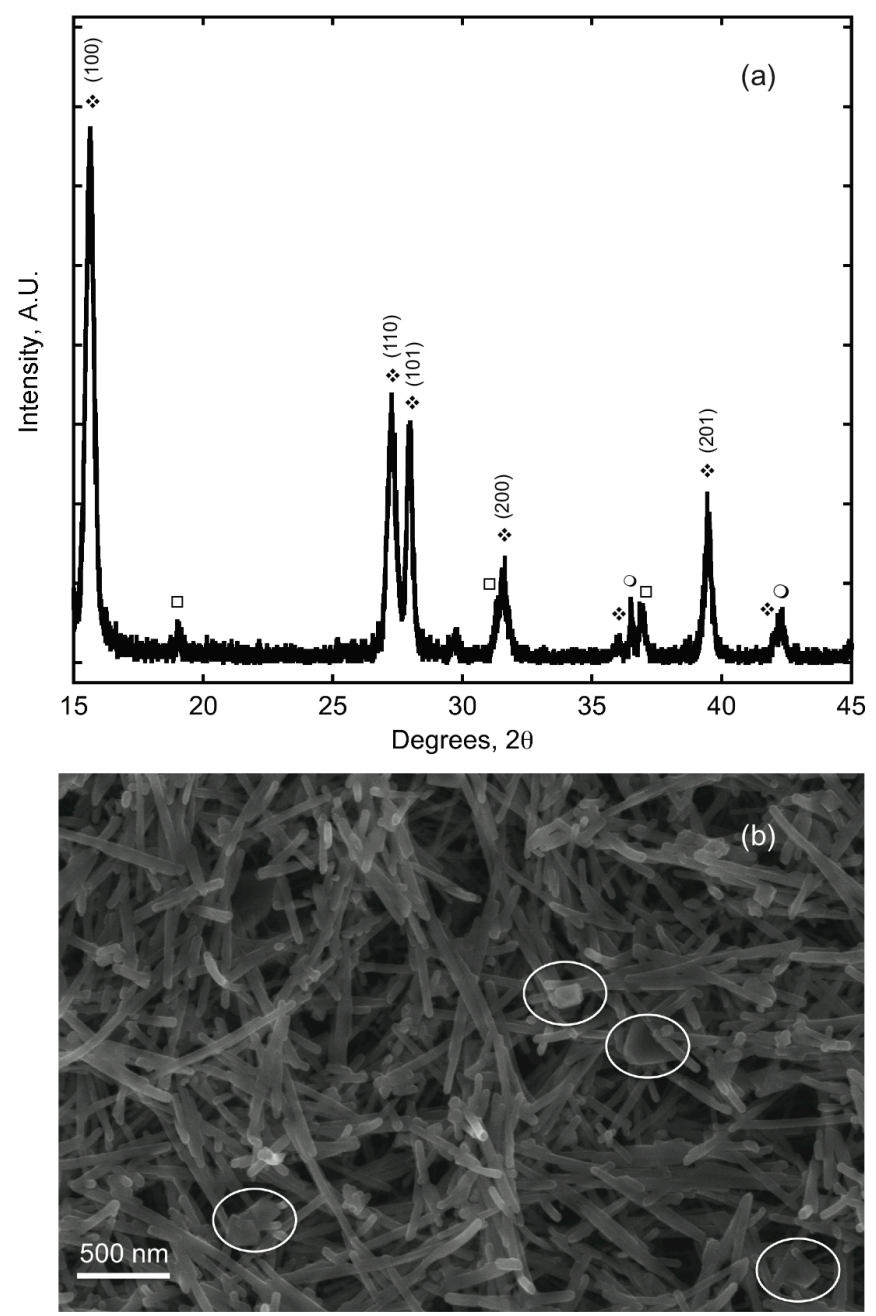

Figure 42. (a) XRD of washed hydrothermal synthesis product. Phases are labeled as: *-La(OH) $)_{3}\left(\right.$ ICDD PDF\# 01-083-2034) $\square-\mathrm{Co}_{3} \mathrm{O}_{4}$ (PDF\# 01-076-1802), O-CoO (PDF\# 01-078-0431). Miller indices are added for the largest $\mathrm{La}(\mathrm{OH})_{3}$ peaks. (b) FEG-SEM image of same material. Examples of structures other than nanorods are circled. 

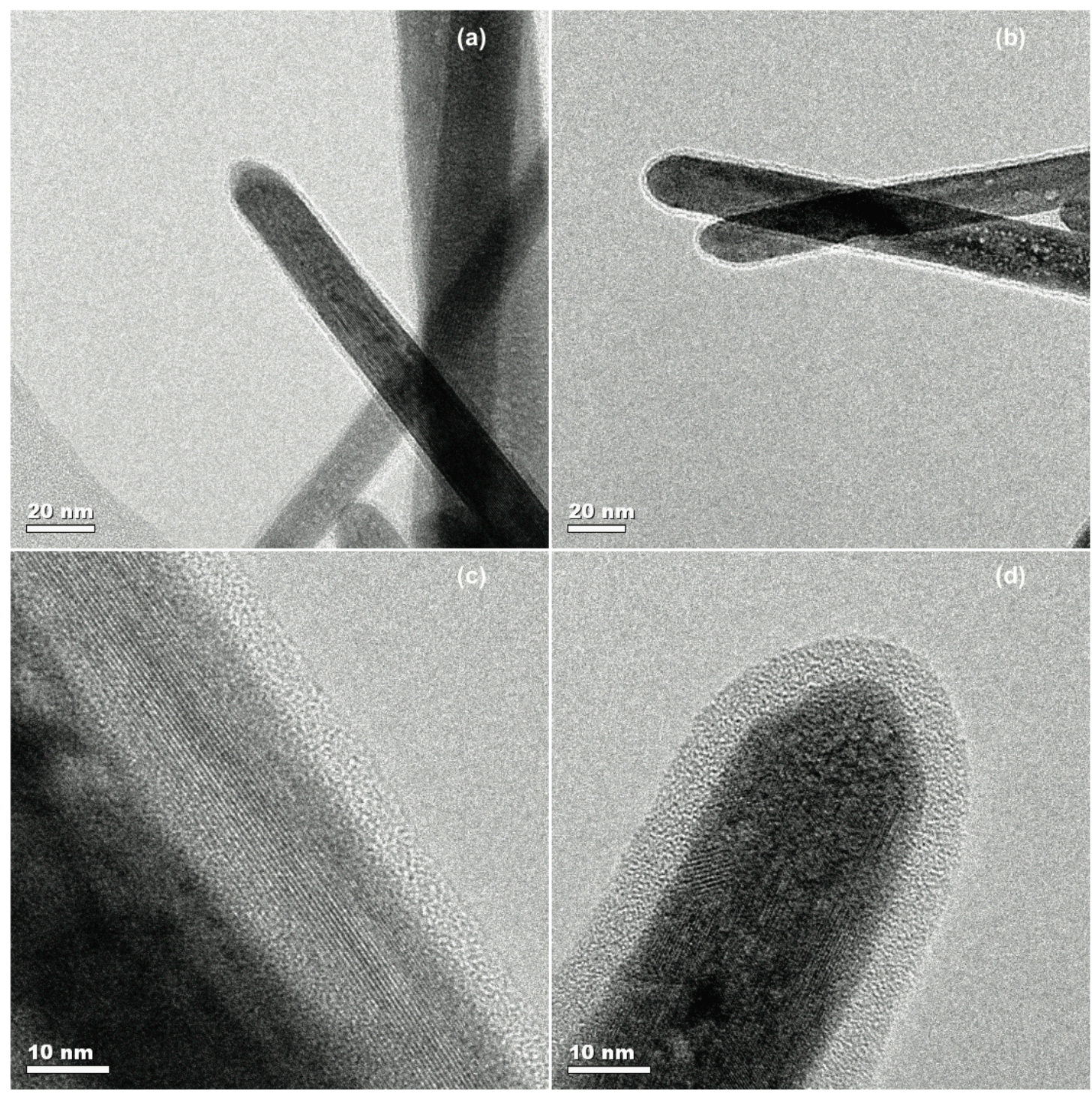

Figure 43. TEM images of nanorods present in washed synthesis product. 

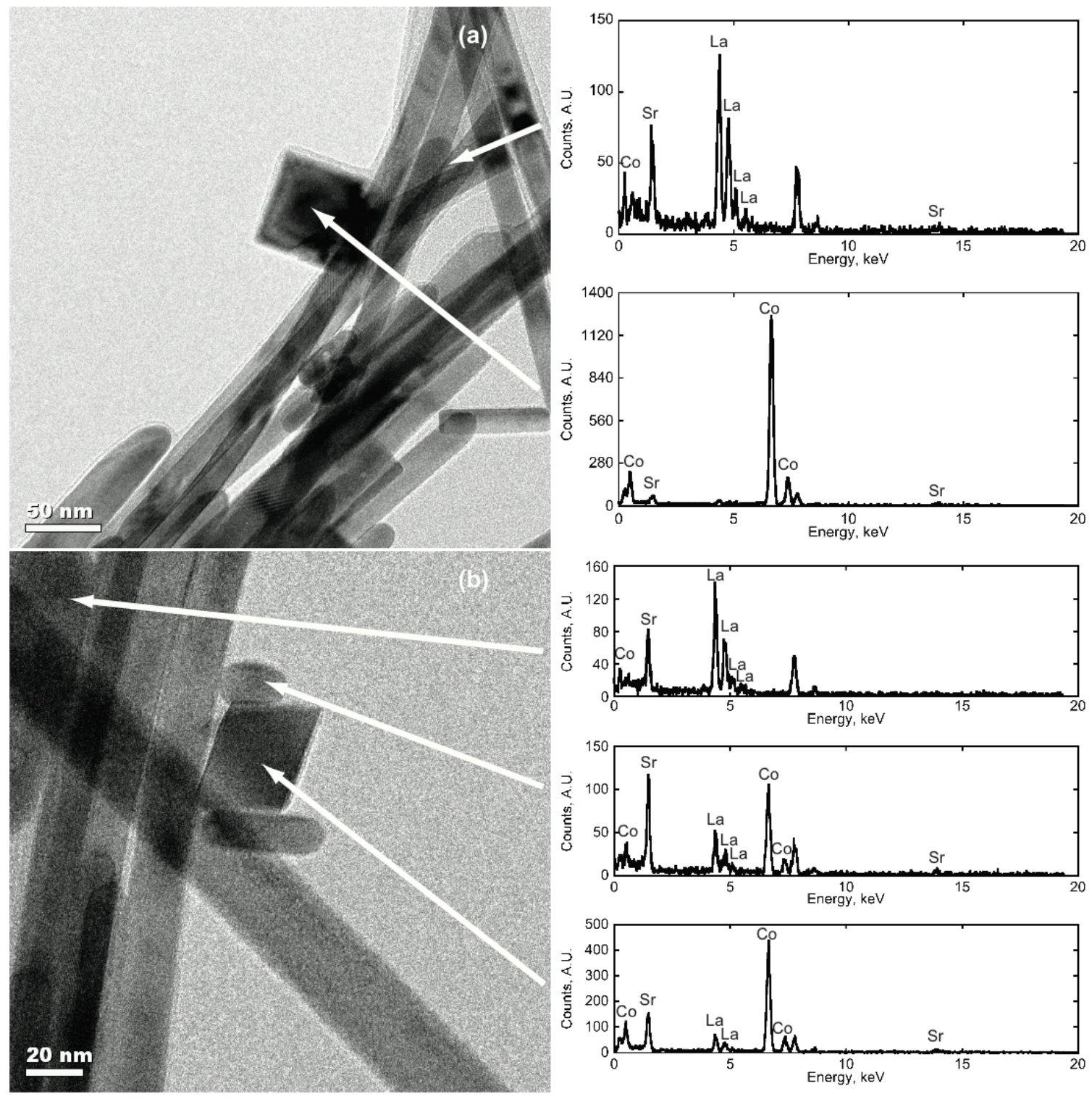

Figure 44. TEM images of nanorods and other hydrothermal synthesis product structures. EDS analysis is provided for the indicated areas.

Three major variables were examined during attempts to directly synthesize $\mathrm{La}_{0.6} \mathrm{Sr}_{0.4} \mathrm{CoO}_{3}$ (LSC64) nanorods via the hydrothermal method: reaction temperature, $\mathrm{KOH}$ concentration, and reaction duration. Table 7 provides a comprehensive overview of the synthesis conditions investigated and the major phases identified in the washed products by XRD. No perovskite phase could be detected in any of the washed products, 
but all products contained substantial amount of nanorods. SEM and TEM images of the products in Table 7 were analyzed to determine average nanorod dimensions.

Table 7. Conditions and phases observed in washed hydrothermal synthesis products. Average width, length and aspect ratio of nanorods present are included.

\begin{tabular}{|c|c|c|c|c|c|c|c|c|}
\hline $\begin{array}{l}\text { Major } \\
\text { Variable }\end{array}$ & $\begin{array}{c}\text { Temperature } \\
{[\mathrm{C}]}\end{array}$ & $\begin{array}{c}\text { Duration } \\
{[\mathrm{h}]}\end{array}$ & $\begin{array}{l}\text { Precursor } \\
\text { Concentration } \\
{[\mathrm{mmol}]}\end{array}$ & $\begin{array}{l}\mathrm{KOH} \\
\text { Concentration } \\
\quad[\mathrm{mmol}]\end{array}$ & $\begin{array}{l}\text { Observed } \\
\text { Phases } \\
\text { XRD* }\end{array}$ & $\begin{array}{l}\text { Average } \\
\text { Nanorod } \\
\text { Length [nm] }\end{array}$ & $\begin{array}{l}\text { Average } \\
\text { Nanorod } \\
\text { Width [nm] } \\
\end{array}$ & $\begin{array}{c}\text { Aspect } \\
\text { Ratio }\end{array}$ \\
\hline \multirow[t]{2}{*}{$\begin{array}{l}\text { Precursor } \\
\text { Concentration }\end{array}$} & 200 & 46 & 20 & 111 & $\begin{array}{l}\mathrm{Co}(\mathrm{OH})_{2} \\
\mathrm{La}(\mathrm{OH})_{3}\end{array}$ & $5900^{* *}$ & $3248^{* *}$ & 2 \\
\hline & 200 & 46 & 2.5 & 19 & $\begin{array}{l}\mathrm{Co}_{3} \mathrm{O}_{4} \\
\mathrm{Co}(\mathrm{OH})_{2} \\
\mathrm{La}(\mathrm{OH})_{3}\end{array}$ & 297 & 29 & 10 \\
\hline \multirow[t]{2}{*}{$\begin{array}{l}\text { Reaction } \\
\text { Temperature }\end{array}$} & 250 & 46 & 20 & 94 & $\begin{array}{l}\mathrm{La}(\mathrm{OH})_{3} \\
\mathrm{Co}_{3} \mathrm{O}_{4} \\
\mathrm{CoO}\end{array}$ & 392 & 25 & 16 \\
\hline & 250 & 46 & 2.5 & 14 & $\begin{array}{l}\mathrm{La}(\mathrm{OH})_{3} \\
\mathrm{La}_{2} \mathrm{O}_{3} \\
\mathrm{Co}_{3} \mathrm{O}_{4} \\
\mathrm{CoO}\end{array}$ & 672 & 21 & 32 \\
\hline \multirow[t]{4}{*}{$\begin{array}{l}\mathrm{KOH} \\
\text { Concentration }\end{array}$} & 250 & 46 & 20 & 100 & $\begin{array}{l}\mathrm{La}(\mathrm{OH})_{3} \\
\mathrm{Co}_{3} \mathrm{O}_{4} \\
\mathrm{SrCO}_{3}\end{array}$ & 663 & 40 & 17 \\
\hline & 250 & 46 & 20 & 200 & $\begin{array}{l}\mathrm{La}(\mathrm{OH})_{3} \\
\mathrm{Co}(\mathrm{OH})_{2} \\
\mathrm{SrCO}_{3}\end{array}$ & 1140 & 35 & 33 \\
\hline & 250 & 46 & 20 & 300 & $\begin{array}{l}\mathrm{La}(\mathrm{OH})_{3} \\
\mathrm{Co}(\mathrm{OH})_{2} \\
\mathrm{SrCO}_{3}\end{array}$ & 2742 & 49 & 56 \\
\hline & 250 & 46 & 20 & 400 & $\begin{array}{l}\mathrm{La}(\mathrm{OH})_{3} \\
\mathrm{Co}(\mathrm{OH})_{2} \\
\mathrm{SrCO}_{3}\end{array}$ & 2873 & 118 & 24 \\
\hline \multirow[t]{3}{*}{$\begin{array}{l}\text { Reaction } \\
\text { Duration }\end{array}$} & 250 & 1 & 20 & 100 & $\begin{array}{l}\mathrm{Co}_{3} \mathrm{O}_{4} \\
\mathrm{Co}(\mathrm{OH})_{2} \\
\mathrm{La}(\mathrm{OH})_{3}\end{array}$ & 131 & 17 & 8 \\
\hline & 250 & 10 & 20 & 100 & $\begin{array}{l}\mathrm{Co}(\mathrm{OH})_{2} \\
\mathrm{CoO} \\
\mathrm{La}(\mathrm{OH})_{3}\end{array}$ & 609 & 19 & 32 \\
\hline & 250 & 72 & 20 & 100 & $\begin{array}{l}\mathrm{Co}_{3} \mathrm{O}_{4} \\
\mathrm{Co}(\mathrm{OH})_{2} \\
\mathrm{La}(\mathrm{OH})_{3}\end{array}$ & 1253 & 32 & 39 \\
\hline
\end{tabular}

The nanorods were confirmed to be $\mathrm{La}(\mathrm{OH})_{3}$ by TEM/EDS and XRD. The width varied from 17 to $118 \mathrm{~nm}$, while the length varied from approximately 130 to $2900 \mathrm{~nm}$. The width and length of the nanorods increased with increasing $\mathrm{KOH}$ concentration and with 
increasing reaction duration. At low precursor concentrations $(2.5 \mathrm{mmol})$, an increase in the reaction temperature lead to an increase in nanorod length; however, the opposite effect was observed with higher precursor concentrations $(20 \mathrm{mmol})$. The result of changes in precursor concentration at constant temperature and reaction duration could not be assessed because the amount of $\mathrm{KOH}$ was also changed. It must be noted that addition of $\mathrm{KOH}$ in quantities above $400 \mathrm{mmol}$ resulted in precipitation of macroscopic $\mathrm{KOH}$ crystals during the synthesis. In such cases, the product mixture was identical in color and texture to the reactant mixture indicating that the synthesis reaction may have been inhibited.

b. Attempts to produce $\mathrm{La}_{0.6} \mathrm{Sr}_{0.4} \mathrm{CoO}_{3}$ nanorods by calcining hydrothermal synthesis products

The typical hydrothermal synthesis product shown in Figure 42 - Figure 44 was calcined at temperatures in the range of $400-900^{\circ} \mathrm{C}$ for $2-12 \mathrm{~h}$. The calcination conditions and phases identified in the XRD diffractograms for these samples are summarized in Table 8 . Several new diffraction peaks, which can be indexed to a perovskite structure, began to appear at $650{ }^{\circ} \mathrm{C}$ and higher. At $900{ }^{\circ} \mathrm{C}$ the $\mathrm{La}_{1-\mathrm{x}} \mathrm{Sr}_{\mathrm{x}} \mathrm{CoO}_{3-\delta}$ perovskite is dominant with only traces of the two principle oxides remaining. FEG-SEM images (Figure 45) reveal that the nanorod structure is lost upon heating to $650{ }^{\circ} \mathrm{C}$ and above. 
Table 8. Calcination of washed hydrothermal synthesis product: conditions and observed phases.

\begin{tabular}{|c|c|c|}
\hline $\begin{array}{l}\text { Calcination Temperature } \\
{\left[{ }^{\circ} \mathrm{C}\right]}\end{array}$ & $\begin{array}{l}\text { Duration } \\
{[\mathrm{h}]}\end{array}$ & $\begin{array}{c}\text { Observed Phases } \\
\text { XRD }\end{array}$ \\
\hline 0 & 0 & $\begin{array}{l}\mathrm{La}(\mathrm{OH})_{3} \\
\mathrm{Co}_{3} \mathrm{O}_{4} \\
\mathrm{CoO}\end{array}$ \\
\hline 400 & 12 & $\begin{array}{l}\mathrm{La}_{2} \mathrm{O}_{2} \mathrm{CO}_{3} \\
\mathrm{Sr}(\mathrm{CO})_{3} \\
\mathrm{Co}_{3} \mathrm{O}_{4} \\
\mathrm{CoO}\end{array}$ \\
\hline 500 & 8 & $\begin{array}{l}\mathrm{La}_{2}\left(\mathrm{CO}_{3}\right) \mathrm{O}_{2} \\
\mathrm{Sr}(\mathrm{CO})_{3} \\
\mathrm{Co}_{3} \mathrm{O}_{4}\end{array}$ \\
\hline $\begin{array}{l}400 \\
650\end{array}$ & $\begin{array}{l}2 \\
2\end{array}$ & $\begin{array}{l}\mathrm{La}_{2} \mathrm{O}_{3} \\
\text { Perovskite* }^{*}\end{array}$ \\
\hline 650 & 12 & $\begin{array}{l}\mathrm{La}_{2} \mathrm{O}_{3} \\
\text { Perovskite**} \\
\mathrm{Co}_{3} \mathrm{O}_{4} \\
\mathrm{CoO}\end{array}$ \\
\hline 800 & 2 & $\begin{array}{l}\text { Perovskite } \\
\mathrm{La}_{2} \mathrm{O}_{3}\end{array}$ \\
\hline 900 & 2 & $\begin{array}{l}\text { Perovskite } \\
\mathrm{Co}_{3} \mathrm{O}_{4} \\
\mathrm{La}_{2} \mathrm{O}_{3}\end{array}$ \\
\hline $\begin{array}{l}{ }^{*} \text { Perovskite options: } \mathrm{La}(\mathrm{C} \\
{ }^{* *} \text { Perovskite options: LaC } \\
{ }^{* * *} \text { Perovskite options: } \mathrm{La}(( \\
{ }^{* * * *} \text { Perovskite options: like }\end{array}$ & $\begin{array}{l}2.94), \mathrm{SrCc} \\
{ }_{3}^{2}, \mathrm{SrCoO} \\
\left.\mathrm{O}_{3}\right), \mathrm{SrCc} \\
-\mathrm{aCoO}_{3}\end{array}$ & $\begin{array}{l}\text { 2.87, } \mathrm{La}_{0.8} \mathrm{Sr}_{0.2} \mathrm{CoO}_{3-\delta} \\
\text { 0, } \mathrm{La}_{0.5} \mathrm{Sr}_{0.5} \mathrm{CoO}_{2.91} \\
\text { 2..87 }_{2}\left(\mathrm{La}_{0.7} \mathrm{Sr}_{0.3}\right) \mathrm{CoO}_{3}\end{array}$ \\
\hline
\end{tabular}



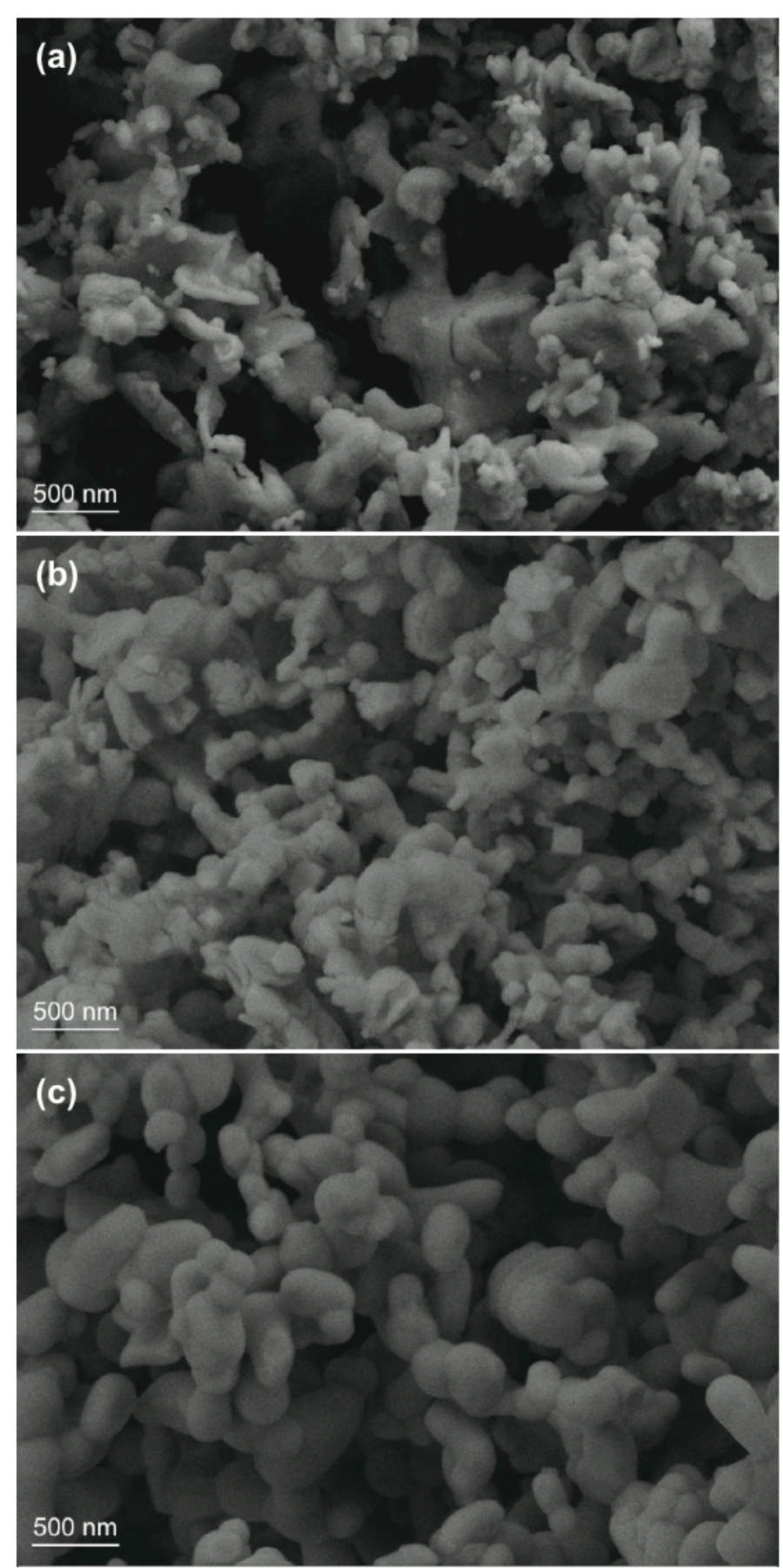

Figure 45. FEG-SEM images of washed synthesis products calcined at (a) $400{ }^{\circ} \mathrm{C}$ for $2 \mathrm{~h}$ $+650{ }^{\circ} \mathrm{C}$ for $2 \mathrm{~h}$, (b) $800{ }^{\circ} \mathrm{C}$ for $2 \mathrm{~h}$, and (c) $900{ }^{\circ} \mathrm{C}$ for $2 \mathrm{~h}$. 
TG and DSC were performed on the washed, uncalcined sample referenced in Figure 42-Figure 45 to better understand the chemical reaction and phase transformations occurring between $180^{\circ} \mathrm{C}$ and $1000^{\circ} \mathrm{C}$. Those data are shown in Figure 46 and indicate that the material continues to lose mass throughout the temperature range studied. The sharp mass loss ending at approximately $350{ }^{\circ} \mathrm{C}$ is attributed to the conversion of hydroxides to oxide hydroxides (e.g. $\mathrm{La}(\mathrm{OH})_{3}$ to $\mathrm{LaOOH}$ ), and the slight decrease at approximately $500{ }^{\circ} \mathrm{C}$ marks the conversion to oxides [143]. The gradual mass loss ending at approximately $750{ }^{\circ} \mathrm{C}$ is due to the conversion of residual surface carbonates to oxides [143]. DSC data show increases in heat flow coincident with the sharp mass losses below $900{ }^{\circ} \mathrm{C}$.

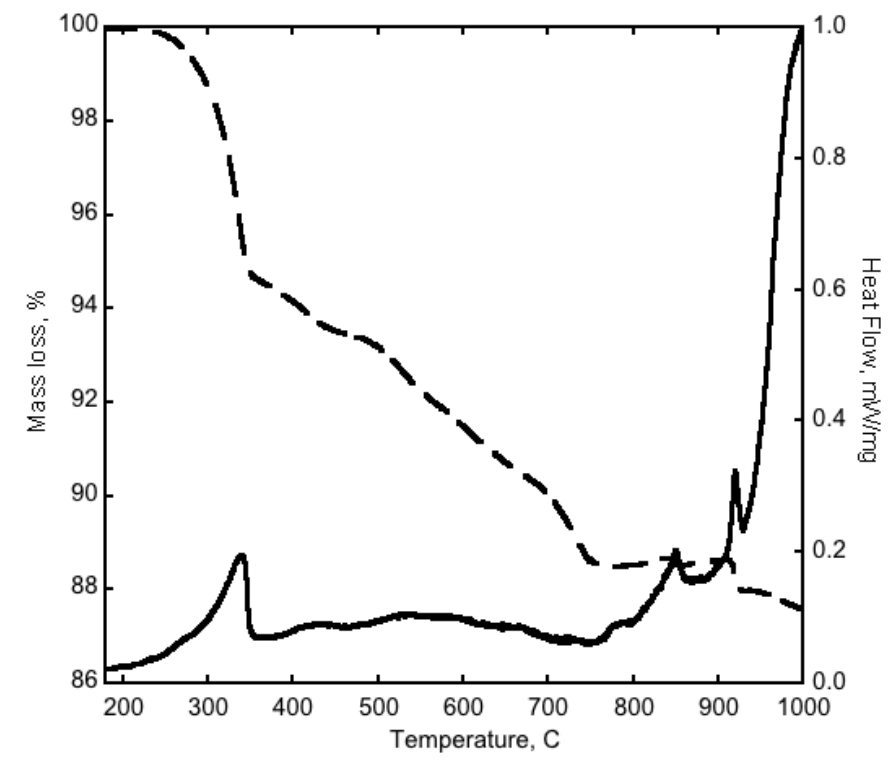

Figure 46. TG / DSC of washed, uncalcined hydrothermal synthesis product during heating from $180{ }^{\circ} \mathrm{C}$ to $1000{ }^{\circ} \mathrm{C}$. Dashed line refers to TG; solid line refers to DSC. 
c. Attempt to convert non-perovskite $\mathrm{La}(\mathrm{OH})_{3}$ to $\mathrm{La}_{0.6} \mathrm{Sr}_{0.4} \mathrm{CoO}_{3}$ via two-step process

Fabrication of LSC64 nanorods was attempted through a two-step topochemical conversion process. First, template rods were fabricated via mild hydrothermal synthesis. Figure $47(\mathrm{i})$ is an XRD diffractogram of the product; all peaks index as $\mathrm{La}(\mathrm{OH})_{3}$. The SEM image (Figure 48a) of the material shows uniform rods with an average length of $95 \mathrm{~nm}$ and width of $13 \mathrm{~nm}$ as the sole structure present.

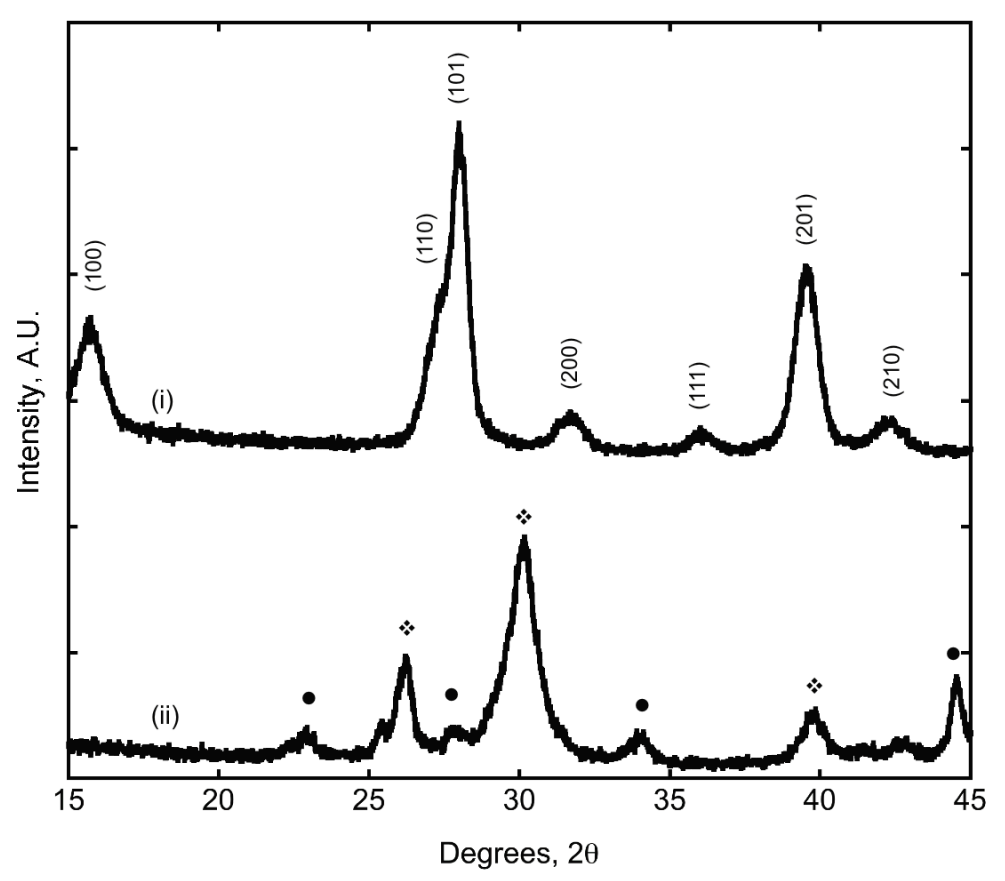

Figure 47. XRD spectrum of (i) phase pure $\mathrm{La}(\mathrm{OH})_{3}$ (IDCC PDF\# 04-005-8587) via mild hydrothermal synthesis, and (ii) this material after calcination at $400{ }^{\circ} \mathrm{C} 2 \mathrm{~h}+650{ }^{\circ} \mathrm{C} 2 \mathrm{~h}$. Labeled phases: - $\mathrm{La}_{2} \mathrm{O}_{3}$ (PDF\# 00-005-0602), •- $\mathrm{La}_{2} \mathrm{CO}_{5}$ (PDF\# 00-023-0320) 


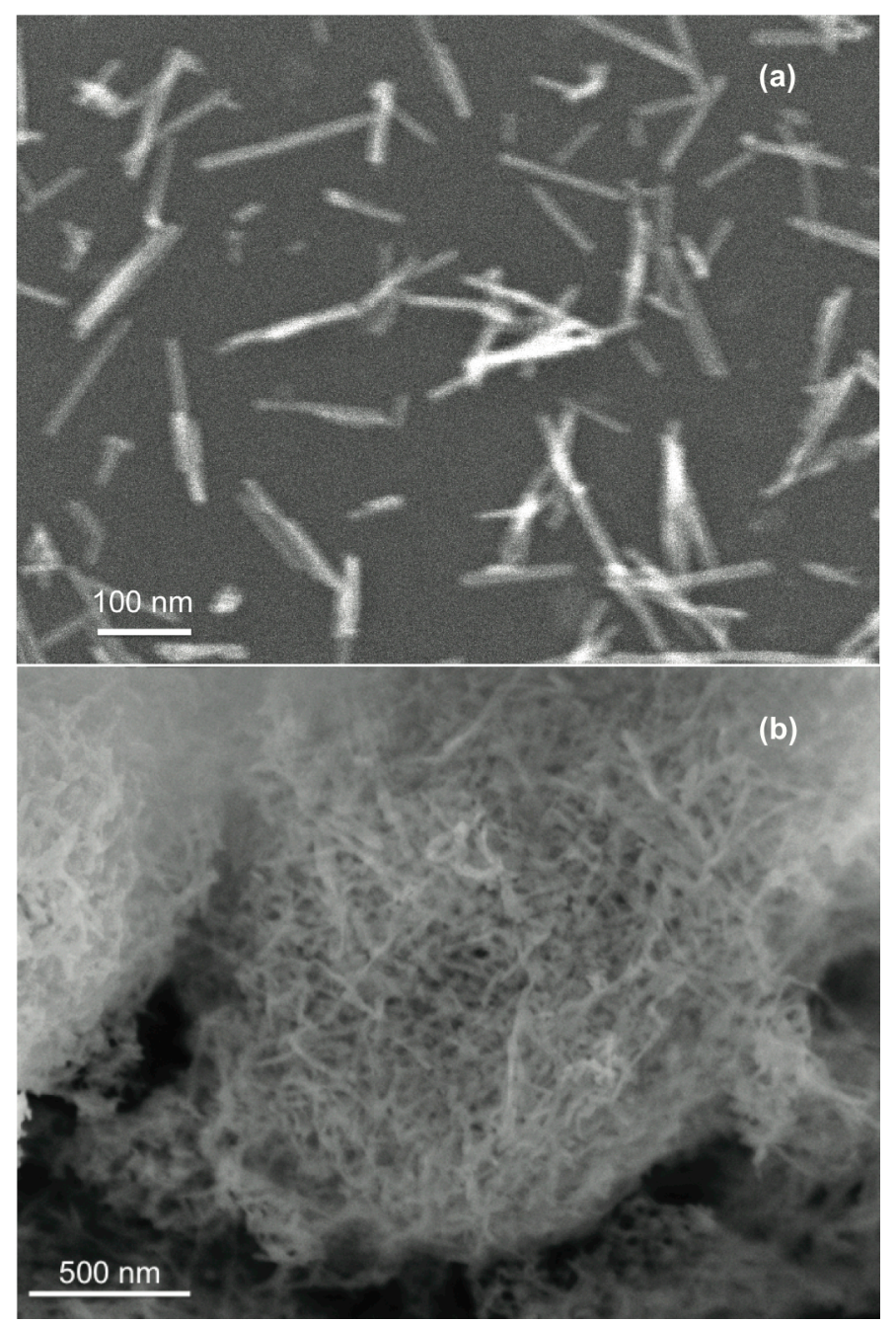

Figure 48 SEM images of $\mathrm{La}(\mathrm{OH})_{3}$ nanorods (a) as synthesized, and (b) after calcination at $400{ }^{\circ} \mathrm{C} 2 \mathrm{~h}+650{ }^{\circ} \mathrm{C} 2 \mathrm{~h}$.

The washed as-synthesized nanorodes were coated with a combined $\operatorname{Sr}\left(\mathrm{NO}_{3}\right)_{2}$ and $\mathrm{Co}\left(\mathrm{NO}_{3}\right)_{2}$ solution, and the material was calcined at $500{ }^{\circ} \mathrm{C}$ for $8 \mathrm{~h}, 400{ }^{\circ} \mathrm{C}$ for $2 \mathrm{~h}+$ $650{ }^{\circ} \mathrm{C}$ for $2 \mathrm{~h}$, or $800{ }^{\circ} \mathrm{C}$ for $2 \mathrm{~h}$. XRD spectra of the products are shown in Figure 49. The diffraction patterns clearly evidence the formation of a new phase, which becomes more pronounced with increasing temperature, and can be indexed to a perovskite structure. The materials calcined at $500{ }^{\circ} \mathrm{C}$ and $650{ }^{\circ} \mathrm{C}$ (Figure $49 \mathrm{ii}-\mathrm{iii}$ ) also include a 
$\mathrm{SrCO}_{3}$ phase, which decreases in intensity with increased temperature. This phase is not observed in the $800{ }^{\circ} \mathrm{C}$ material. SEM images of the calcined materials (Figure 50a-c) show that the rod structure is lost upon heating at all temperatures. The materials have similar morphology despite the variations in calcination temperature, indicating that the loss of the desired rod morphology occurred quickly and at temperatures below $500{ }^{\circ} \mathrm{C}$.

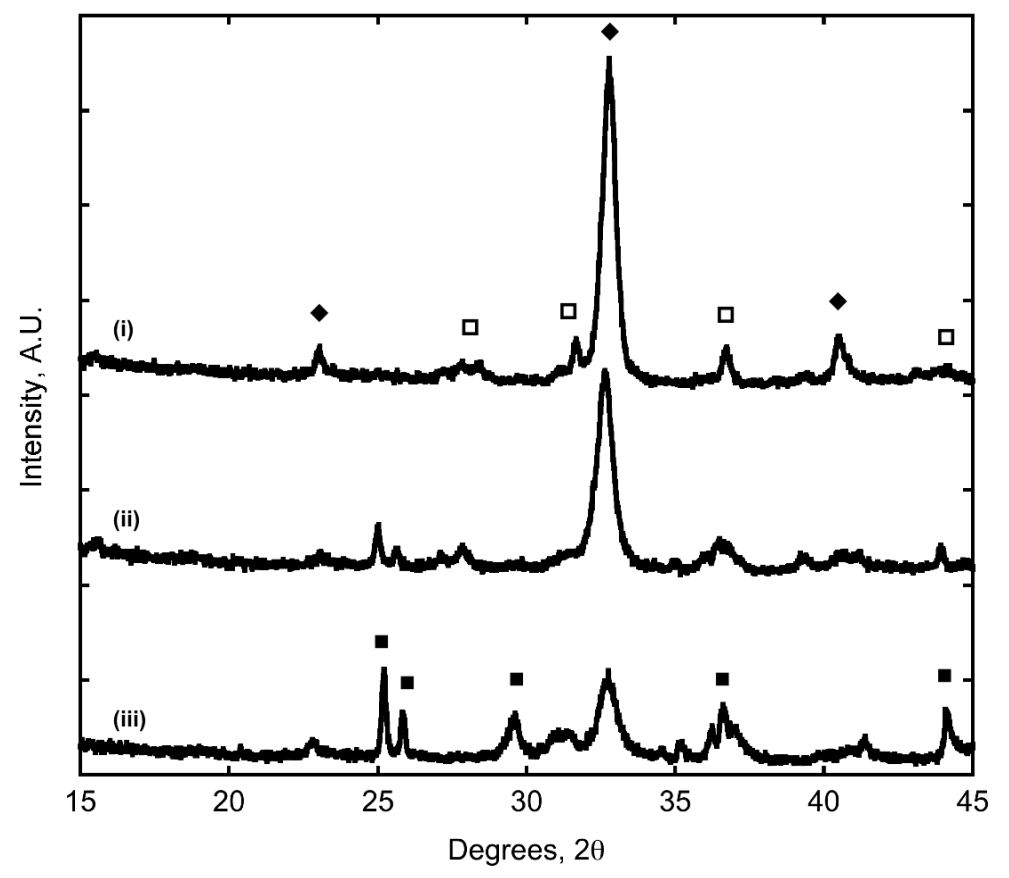

Figure 49. XRD spectra of two-step synthesis products after calcination at (i) $800^{\circ} \mathrm{C}, 2 \mathrm{~h}$, (ii) $400{ }^{\circ} \mathrm{C} 2 \mathrm{~h}+, 650{ }^{\circ} \mathrm{C} 2 \mathrm{~h}$, (iii) $500^{\circ} \mathrm{C}$, 8h. Labeled phases: $\bullet-\mathrm{La}_{1-\mathrm{x}} \mathrm{Sr}_{\mathrm{x}} \mathrm{CoO}_{3}, \square-$-unknown, - $-\mathrm{SrCO}_{3}($ ICDD PDF\# 00-005-0418).

Undoped $\mathrm{La}(\mathrm{OH})_{3}$ nanorods were calcined at $400{ }^{\circ} \mathrm{C}$ for $2 \mathrm{~h}+650{ }^{\circ} \mathrm{C}$ for $2 \mathrm{~h}$ to determine the effect of heating on the rod structure alone. The XRD diffractogram for the material is shown in Figure 47(ii), and the phases present are $\mathrm{La}_{2} \mathrm{O}_{3}$ and $\mathrm{La}_{2} \mathrm{CO}_{5}$. SEM images of the calcined rods (Figure 48b) show that the rod structure remains intact, 
though the average length decreased to $50 \mathrm{~nm}$ and width increased to $19 \mathrm{~nm}$. Agglomeration is also apparent.

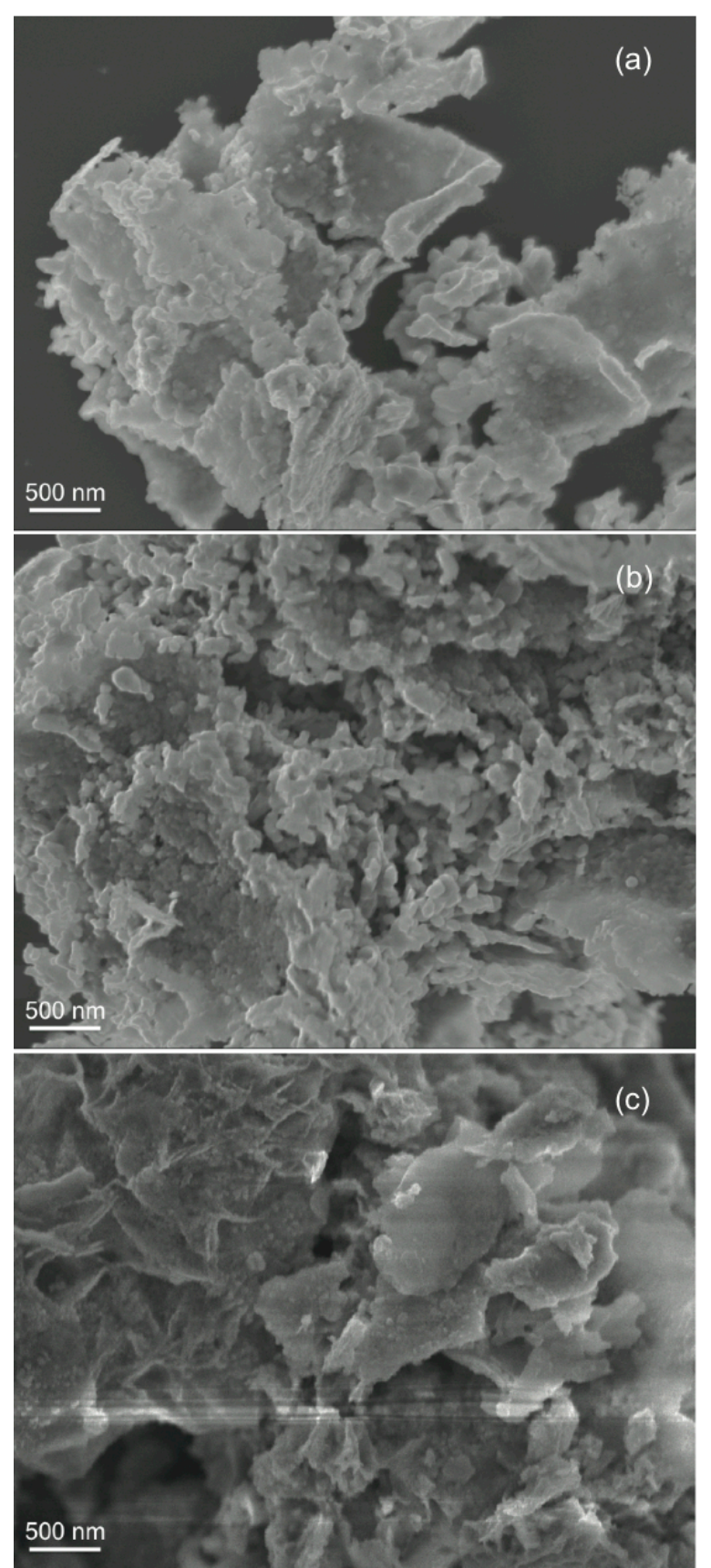

Figure 50. SEM images of two-step synthesis products after calcination at (a) $800{ }^{\circ} \mathrm{C}$, $2 \mathrm{~h},(\mathrm{~b}) 400{ }^{\circ} \mathrm{C} 2 \mathrm{~h}+, 650^{\circ} \mathrm{C} 2 \mathrm{~h},(\mathrm{c}) 500^{\circ} \mathrm{C}, 8 \mathrm{~h}$. 


\section{d. $\mathrm{La}_{0.6} \mathrm{Sr}_{0.4} \mathrm{CoO}_{3-\delta}$ subjected to mild hydrothermal conditions}

The diffractogram shown in Figure 51(i) indicates that the LSC64 was phase pure prior to treatment in mild hydrothermal conditions $\left(150^{\circ} \mathrm{C}, 46 \mathrm{~h}, \mathrm{KOH}\right.$ added). Following treatment, the un-annealed powder was largely intact as a LSC64, but contained small impurity phases that index as $\mathrm{SrCO}_{3}$ and $\mathrm{La}(\mathrm{OH})_{3}$, shown in Figure 51(ii). However, annealing LSC64 in $\mathrm{N}_{2}$ prior to hydrothermal treatment resulted in the decomposition of the perovskite structure, shown in Figure 51(iii). The major phases in the annealed sample index as $\mathrm{La}(\mathrm{OH})_{3}$ and $\mathrm{SrCO}_{3}$; the Co-species may have been eliminated during post-synthesis rinsing.

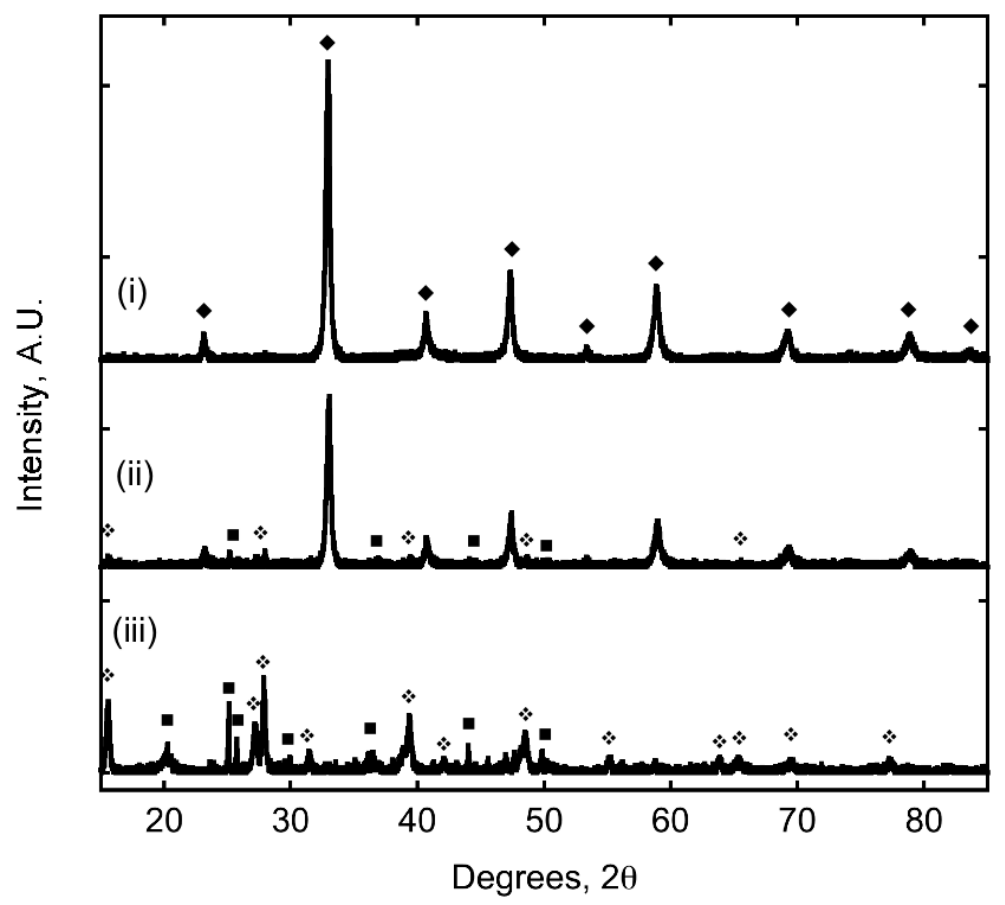

Figure 51. XRD spectra of (i) Phase pure untreated $\mathrm{La}_{0.6} \mathrm{Sr}_{0.4} \mathrm{CoO}_{3}$ powder (ii) product after LSC64 powder was subjected to mild hydrothermal conditions, (iii) product after LSC64 powder was annealed in $\mathrm{N}_{2}$ and then subjected to mild hydrothermal conditions. Labeled phases: $\bullet-\mathrm{La}_{0.6} \mathrm{Sr}_{0.4} \mathrm{CoO}_{3}\left(\mathrm{ICDD}\right.$ PDF\# 00-048-0121), $-\mathrm{La}(\mathrm{OH})_{3}(\mathrm{ICCD}$ PDF\# 00-036-1481), $\mathbf{-}-\mathrm{SrCO}_{3}$ (ICDD PDF\# 01-017-0213). 


\subsection{Discussion}

a. Inability to produce $\mathrm{La}_{0.6} \mathrm{Sr}_{0.4} \mathrm{CoO}_{3}$ nanorods

Efforts to synthesize $\mathrm{La}_{0.6} \mathrm{Sr}_{0.4} \mathrm{CoO}_{3}$ (LSC64) nanorods via the hydrothermal method were initially focused on replicating experimental conditions described in previous accounts $[135,136]$. It is important to note that the direct synthesis of $\mathrm{La}_{1}$ ${ }_{x} \mathrm{Sr}_{\mathrm{x}} \mathrm{CoO}_{3-\delta}$ nanorods (or any perovskite structures) reported by Wang and Fan [135] could not be replicated. The experimental parameter space was subsequently expanded to include additional variables. All of these syntheses resulted in $\mathrm{La}(\mathrm{OH})_{3}$ nanorod structures, but none were successful in producing perovskite materials (Table 7).

Dai and co-workers [136] report formation of $\mathrm{La}_{0.6} \mathrm{Sr}_{0.4} \mathrm{CoO}_{3-\delta}$ nanorods by calcining washed hydrothermal synthesis products at 650,800 , and $900{ }^{\circ} \mathrm{C}$ in air. Calcination of a typical synthesis product led to a perovskite phase at and above $650{ }^{\circ} \mathrm{C}$ (Table 8), but the nanorod structure was not preserved (Figure 45). Similarly, a two-step topochemical conversion was attempted by doping $\mathrm{La}(\mathrm{OH})_{3}$ nanorods with $\mathrm{Sr}$ and $\mathrm{Co}$. A perovskite phase began to form at $500{ }^{\circ} \mathrm{C}$, though the rod structure was lost upon heating.

The inability to form LSC64 nanorods with these methods is likely due to kinetic and thermodynamic limitations. Kinetic limitations likely prevented direct synthesis due to poor solubility of $\mathrm{La}(\mathrm{OH})_{3}$ in solution. Lanthanide cations are known to rapidly react to form anisotropic trivalent hydroxide hexagonal crystals in strongly alkaline solutions $[119,133,144]$. Accordingly, preferential formation of $\mathrm{La}(\mathrm{OH})_{3}$ nanorods from $\mathrm{La}^{3+}$ precursors during hydrothermal syntheses in hydroxide solutions has been well documented [118, 120, 126]. Solubility data in Supporting Information, Section 6.6 (Table A) indicates that $\mathrm{La}\left(\mathrm{NO}_{3}\right)_{3}$ readily dissociates into pure water (Eqn. i), but dissolution of the $\mathrm{La}(\mathrm{OH})_{3}$ precipitate (Eqn. ii), is limited by low solubility in the alkaline 
solution, even at elevated temperatures. Poor solubility of the rapidly formed $\mathrm{La}(\mathrm{OH})_{3}$ crystallites prevents reaction of La with the Sr and Co species in solution. This may be overcome by increasing the synthesis temperature to $\sim 360{ }^{\circ} \mathrm{C}$, which is above the temperature at which $\mathrm{La}(\mathrm{OH})_{3}$ dehydrates to become $\mathrm{LaO}(\mathrm{OH})\left(340^{\circ} \mathrm{C}\right)$, a more reactive species [119]. Poeppelmeier and co-workers suggest that hydrothermal reactions which include rare-earth trihydroxides and are performed below their dehydration temperature of $340{ }^{\circ} \mathrm{C}$ [143] will result in no reaction [119]. Further investigation is necessary to determine whether a significant increase in synthesis temperature would result in direct formation of perovskite nanorods.

The production of nanorods via calcination of solid-state precursors is limited by the high temperatures necessary to form phase pure LSC64. Cherepanov et al. have determined that solid state formation of phase pure $\mathrm{La}_{1-\mathrm{x}} \mathrm{Sr}_{\mathrm{x}} \mathrm{CoO}_{3-\delta}$ is accomplished at $1100^{\circ} \mathrm{C}$, with $\mathrm{LaCoO}_{3}$ and $\mathrm{Sr}_{2} \mathrm{Co}_{2} \mathrm{O}_{5}$ as intermediate products [145]. This temperature far exceeds the point at which $\mathrm{La}(\mathrm{OH})_{3}$ nanorods convert to $\mathrm{La}_{2} \mathrm{O}_{3}\left(500{ }^{\circ} \mathrm{C}\right)[119]$ and would lead to the decreased aspect ratio and agglomeration evidenced in Figure 48b. Furthermore, the addition of $\mathrm{Sr}$ and $\mathrm{Co}$ species to $\mathrm{La}(\mathrm{OH})_{3}$ leads to total loss of rod morphology upon heating above $500{ }^{\circ} \mathrm{C}$, thus eliminating the possibility retaining the nanorod structure in the phase pure LSC64 product. Ultimately, LSC64 nanorods could not be synthesized using hydrothermal synthesis, post-synthesis calcination, or topochemical conversion.

\section{b. Thermodynamic Considerations}

The stability of LSC64 can be understood from the thermodynamic stability of $\mathrm{LaCoO}_{3}$ under hydrothermal conditions. If we consider the reaction to form $\mathrm{LaCoO}_{3}$ from 
two common solid products found after hydrothermal synthesis, we obtain the following reaction:

$\mathrm{La}(\mathrm{OH})_{3(s)}+\frac{1}{3} \mathrm{Co}_{3} \mathrm{O}_{4(s)}+\frac{1}{12} \mathrm{O}_{2(g)} \rightarrow \mathrm{LaCoO}_{3(s)}+\frac{3}{2} \mathrm{H}_{2} \mathrm{O}_{(l)}$

The Gibbs energy of this equation is calculated using the following equations [146], which include a correction for the reaction temperature:

$\Delta_{r} G\left(T, a_{w}\right)=\Delta_{r} G^{0}(T)+\frac{3}{2} R T \ln \left(a_{w}\right)$

$$
\Delta_{r} G^{0}(T)=\left(\Delta_{r} H_{298 K}^{0}+\int_{298 K}^{523 K} \Delta_{r} C_{P, 298 K}^{0} d T\right)-T\left(\Delta_{r} S_{298 K}^{0}+\int_{298 K}^{523 K} \frac{\Delta_{r} C_{P, 298 K}^{0}}{T} d T\right)
$$

where $\mathrm{G}$ is Gibbs energy $(\mathrm{kJ} / \mathrm{mol}), \mathrm{H}$ is enthalpy $(\mathrm{kJ} / \mathrm{mol}), \mathrm{C}_{P}$ is heat capacity $(\mathrm{J} / \mathrm{mol}-\mathrm{K})$, $\mathrm{T}$ is temperature $(K)$ and $\mathrm{a}_{w}$ is activity of water. Addition of $\mathrm{KOH}$ affects the value of $\mathrm{a}_{\mathrm{w}}$ according to the following equation from Balej [147]:

$$
\log a_{w(K O H)}=-0.02255 m+0.001434 m^{2}+\frac{1.38 m-0.9254 m^{2}}{T}
$$

where $m$ is molality $\left(\mathrm{mol} / \mathrm{kg} \mathrm{H}_{2} \mathrm{O}\right)$ of $\mathrm{KOH}$, and was set to $2 \mathrm{~mol} / \mathrm{kg} \mathrm{H}_{2} \mathrm{O}$ in all calculations, which corresponds to $100 \mathrm{mmol} \mathrm{KOH} / 50 \mathrm{~mL}$ solution. At a reaction temperature of $250{ }^{\circ} \mathrm{C}(523 \mathrm{~K})$, the value of $\Delta_{r} G(523 \mathrm{~K})$ for Eqn. 22 was $14.2 \mathrm{~kJ} / \mathrm{mol}$, which indicates that formation of LSC64 is unlikely to occur at the hydrothermal 
synthesis conditions used in this work. $\mathrm{LaCoO}_{3}$ would become stable at $424{ }^{\circ} \mathrm{C}$, corresponding to $\Delta_{r} G=0$. Table 9 lists the values of the thermodynamic quantities used in this calculation.

Table 9. Thermodynamic properties of species involved in the formation of $\mathrm{LaCoO}_{3}$. Citation numbers are in brackets next to each value.

\begin{tabular}{|l|l|l|l|}
\hline Compound & $\begin{array}{l}\Delta_{r} H_{298 K}^{0} \\
(\mathbf{k J} / \mathbf{m o l})\end{array}$ & $\Delta_{r} S_{298 K}^{0} \mathbf{( J / m o l - K )}$ & $\Delta_{r} C_{P, 298 K}^{0} \mathbf{( J / m o l - K )}$ \\
\hline $\mathrm{La}(\mathrm{OH})_{3}$ & $-1416.7[148]$ & $117.8[148]$ & $117.38[149]$ \\
\hline $\mathrm{Co}_{3} \mathrm{O}_{4}$ & $-891.0[150]$ & $102.5[150]$ & $123.40[150]$ \\
\hline $\mathrm{O}_{2}$ & $0[150]$ & $205.15[150]$ & $29.38[150]$ \\
\hline $\mathrm{LaCoO}_{3}$ & $-1241.34[151]$ & $111.3[51]$ & $107.51[152]$ \\
\hline $\mathrm{H}_{2} \mathrm{O}_{(I)}$ & $-2858.3[150]$ & $69.95[150]$ & $75.35[150]$ \\
\hline
\end{tabular}

A corresponding analysis of the formation of LSC64 is not possible due to lack of thermodynamic data for that compound; however, the addition of $\mathrm{Sr}$ to $\mathrm{LaCoO}_{3}$ is expected to reduce the stability of the material [145]. Furthermore, LSC64 powder subjected to mild hydrothermal conditions $\left(150{ }^{\circ} \mathrm{C}\right.$ vs. $250{ }^{\circ} \mathrm{C}$ for the hydrothermal synthesis reactions) slightly decomposed to form $\mathrm{La}(\mathrm{OH})_{3}$ and $\mathrm{SrCO}_{3}$ (Figure 51), supporting the notion that LSC64 is likely thermodynamically unstable at these conditions.

\section{c. Availability of oxygen during hydrothermal synthesis}

It is important to note that according to Eqn. 22 the formation of $\mathrm{LaCoO}_{3}$ implies oxidation of $\mathrm{Co}$, requiring an oxygen source. In the case of $\mathrm{LSC}$, oxidation of $\mathrm{Co}^{2+}$ to $\mathrm{Co}^{3+} / \mathrm{Co}^{4+}$ will give the most stable products, as LSC will decompose at low partial pressure (corresponding to a lower oxidation state of Co). It is therefore proposed that 
control of the partial pressure of oxygen is a key element to obtain LSC by hydrothermal synthesis.

For the simplified case of $\mathrm{LaCoO}_{3}$, conversion of $\mathrm{Co}^{2+}$ from the $\mathrm{Co}\left(\mathrm{NO}_{3}\right)_{2}$ precursor into $\mathrm{Co}^{3+}$ occurs via:

$$
2 \mathrm{Co}^{2+}+2 \mathrm{O}^{-} \rightarrow 2 \mathrm{Co}^{3+}+\mathrm{O}_{2(g)}
$$

The amount of oxygen needed to convert $20 \mathrm{mmol} \mathrm{Co}^{2+}$, a typical precursor concentration used in this work, is $0.01 \mathrm{~mol} \mathrm{O}_{2}$. This amount would increase for LSC64, where cobalt is further oxidized to $\mathrm{Co}^{3+} / \mathrm{Co}^{4+}$. Oxygen from air trapped inside the vessel when sealed may provide a source for oxidation of $\mathrm{Co}^{2+}[119]$, though it corresponds to only $0.00064 \mathrm{~mol} \mathrm{O}_{2}$ at standard temperature and pressure, an insufficient amount to form the perovskite according to Eqn. 22. However, partial oxidation of $\mathrm{Co}^{2+}$ to form $\mathrm{Co}_{3} \mathrm{O}_{4}$ is possible. The presence of $\mathrm{Co}_{3} \mathrm{O}_{4}$ and lack of LSC in the hydrothermal synthesis products indicates that partial oxidation occurred. $\mathrm{NO}_{3}{ }^{-}$species from the metal nitrate precursors may also provide an oxygen source, though nitrate decomposition typically occurs at temperatures far greater than $250{ }^{\circ} \mathrm{C}$ [153]. Thus, a sufficient amount of available oxygen is required for complete oxidation of $\mathrm{Co}^{2+}$. The amount and source of such oxygen is not reported by Wang and Fan [135] in their direct preparation of LSC91 via hydrothermal synthesis.

The necessity of available oxygen is further supported by the total decomposition of the LSC64 sample annealed in $\mathrm{N}_{2}$ and then subjected to mild hydrothermal conditions. After annealing in $\mathrm{N}_{2}$, the oxygen non-stoichiometry, $\delta$, of LSC64 would have been approximately 0.14 , compared with a value of $\sim 0.09$ in air $[154,155]$. This oxygen deficiency combined with an insufficient amount of oxygen from alternate sources explains the decomposition of the perovskite into $\mathrm{La}(\mathrm{OH})_{3}$ and $\mathrm{SrCO}_{3}$ (Figure 51). 


\section{d. Composition and structure of the hydrothermal synthesis products}

A mixture of compositions and morphologies could be observed in the observed hydrothermal synthesis products, though every synthesis yielded nanorod structures. No perovskite phases were detected in any of the washed products. The typical product examined in Figure 42 - Figure 46 had a high percentage of nanorods, which, when correlated with the strong XRD peaks indexed as $\mathrm{La}(\mathrm{OH})_{3}$ (Figure 42a) and the La-rich EDS measurements from Figure 44, supports the conclusion that the nanorod species were composed of $\mathrm{La}(\mathrm{OH})_{3}$. The EDS measurements in Figure 44 also indicated the presence of $\mathrm{Sr}$ and $\mathrm{Co}$ in small quantities when rod structures were scanned. Thus, the small round spots seen on individual nanorods, especially in Figure 43b, are likely composed of excess Sr-based and Co-based materials.

According to EDS measurements in Figure 44, the isometric structures both in SEM (Figure 42b) and TEM (Figure 44) images were comprised primarily of Co. In correlation with the diffractogram in Figure 42a, these Co-based particles likely consist of $\mathrm{Co}_{3} \mathrm{O}_{4}$. Formation of $\mathrm{Co}_{3} \mathrm{O}_{4}$ nanocubes during hydrothermal synthesis has been reported by Lester, et al. [127].

\section{e. Composition and structure of calcination products}

Calcination of hydrothermal synthesis products in the $500{ }^{\circ} \mathrm{C}$ to $900{ }^{\circ} \mathrm{C}$ range resulted in the XRD phases identified in Table 8. A phase pure perovskite was never formed, though a small perovskite phase $\left(2 \theta=32.8^{\circ}\right)$ was produced after calcination at $400{ }^{\circ} \mathrm{C} 2 \mathrm{~h}+650{ }^{\circ} \mathrm{C} 2 \mathrm{~h}$. Similarly, the $\mathrm{Sr}\left(\mathrm{NO}_{3}\right)_{2}$ and $\mathrm{Co}\left(\mathrm{NO}_{3}\right)_{2}$ doped $\mathrm{La}(\mathrm{OH})_{3}$ nanorods (two-step synthesis) were calcined in the $500{ }^{\circ} \mathrm{C}$ to $800{ }^{\circ} \mathrm{C}$ range resulting in the XRD spectra shown in Figure 49. A small perovskite peak $\left(2 \theta=32.6^{\circ}\right)$ was observed after calcination at $500{ }^{\circ} \mathrm{C}$ for $2 \mathrm{~h}$, increasing in intensity with calcination temperature. Phase 
pure LSC64 was not observed at higher calcination temperatures, despite reports indicating this is possible [136].

During calcination of both the hydrothermal synthesis products and the Sr and Codoped $\mathrm{La}(\mathrm{OH})_{3}$, the rod structure of the material was not preserved upon heating, as shown in Figure 45 and Figure 50, respectively. Calcination of the phase pure $\mathrm{La}(\mathrm{OH})_{3}$ rods at $400{ }^{\circ} \mathrm{C}+650^{\circ} \mathrm{C}$ caused a decrease in length and width, from an aspect ratio of 7.3 to 2.6 (Figure $48 \mathrm{~b}$ ), indicating coarsening and possible agglomeration. XRD of the material, shown in Figure 47(ii), indicates that all peaks index as either $\mathrm{La}_{2} \mathrm{O}_{3}$ or $\mathrm{La}_{2} \mathrm{CO}_{5}$, which is consistent with reported composition changes upon heating for this material [143].

One explanation for the observed coarsening is related to such compositional changes upon heating. $\mathrm{La}(\mathrm{OH})_{3}$ decomposes to form $\mathrm{La}_{2} \mathrm{O}_{3}$ via:

$$
\begin{aligned}
& \mathrm{La}(\mathrm{OH})_{3} \rightarrow \mathrm{LaO}(\mathrm{OH})+\mathrm{H}_{2} \mathrm{O}_{(\mathrm{g})} \\
& 2 \mathrm{LaO}(\mathrm{OH}) \rightarrow \mathrm{La}_{2} \mathrm{O}_{3}+\mathrm{H}_{2} \mathrm{O}_{(\mathrm{g})}
\end{aligned}
$$

These reactions occur at $340^{\circ} \mathrm{C}$ and $500{ }^{\circ} \mathrm{C}$, respectively, [143] which is in agreement with mass losses detected in the hydrothermal synthesis product TG study (Figure 46). Morris and co-workers [156] cycled $\mathrm{La}(\mathrm{OH})_{3}$ through dehydroxylation to obtain $\mathrm{La}_{2} \mathrm{O}_{3}$ and re-hydroxylation to obtain $\mathrm{La}(\mathrm{OH})_{3}$, the latter of which occurs spontaneously in air. After cycling, the material exhibited increased crystallite size and decreased surface area. They believe this behavior is due to the condensation of two $\mathrm{LaO}(\mathrm{OH})$ molecules into one $\mathrm{La}_{2} \mathrm{O}_{3}$ molecule (Eqn. 28), which would lead to a decrease in aspect ratio and/or aggregation [156]. This explanation correlates well the decrease in aspect ratio observed 
for $\mathrm{La}(\mathrm{OH})_{3}$ rods calcined at $650{ }^{\circ} \mathrm{C}$. However, heating $\mathrm{La}(\mathrm{OH})_{3}$ nanorods doped with $\mathrm{Sr}$ and Co nitrates and hydrothermal synthesis products to this temperature resulted in a complete loss of rod structure. In both cases, $\mathrm{Sr}$ and Co species are in close contact with the $\mathrm{La}(\mathrm{OH})_{3}$ rods, so an additional process may be causing enhanced or accelerated loss of structure. Further study is necessary to determine the mechanism for this coarsening upon calcination.

\subsection{Conclusions}

Production of $\mathrm{La}_{0.6} \mathrm{Sr}_{0.4} \mathrm{CoO}_{3}$ (LSC64) nanorods was attempted via hydrothermal synthesis, post-synthesis calcination, and topochemical conversion of non-perovskite $\mathrm{La}(\mathrm{OH})_{3}$ nanorods into perovskite LSC64. Nanorod structures were produced during all hydrothermal syntheses, but were identified as $\mathrm{La}(\mathrm{OH})_{3}$, and no perovskite phases were directly formed. Calcination of hydrothermal synthesis products and pure $\mathrm{La}(\mathrm{OH})_{3}$ nanorods doped with $\mathrm{Sr}\left(\mathrm{NO}_{3}\right)_{2}$ and $\mathrm{Co}\left(\mathrm{NO}_{3}\right)_{2}$ led to the eventual formation of perovskite phases; however, the rod morphology was lost through a coarsening process at temperatures as low as $500{ }^{\circ} \mathrm{C}$. Likewise, efforts to calcine these products and to perform topochemical conversions to obtain a perovskite product were hampered by complete loss of rod structure upon heating.

Thermodynamic and kinetic limitations likely prevented the formation of LSC64 nanorods using the techniques investigated in this work. Analysis of the simplified compound, $\mathrm{LaCoO}_{3}$, indicated that formation of the perovskite is not thermodynamically favored under the conditions tested; stability is not reached until a reaction temperature of $424{ }^{\circ} \mathrm{C}$. The thermodynamic stability of LSC64 could not be directly determined, but it is expected to be less stable than $\mathrm{LaCoO}_{3}$. It is also likely that there are insufficient oxygen sources to support complete oxidation of $\mathrm{Co}^{2+}$ into $\mathrm{Co}^{3+} / \mathrm{Co}^{4+}$, which is necessary 
for formation of LSC64. Kinetic limitations may also exist due to the poor solubility of the rapidly formed $\mathrm{La}(\mathrm{OH})_{3}$ crystallite, precluding reaction of $\mathrm{La}$ with the $\mathrm{Sr}$ and Co species. Increasing the temperature of the reaction to $\sim 360{ }^{\circ} \mathrm{C}$ may lead to formation of a perovskite product, because it is above the temperature at which $\mathrm{La}(\mathrm{OH})_{3}$ dehydrates to form $\mathrm{LaO}(\mathrm{OH})$, a more reactive species. However, further study is necessary to investigate this possibility. Additionally, the high temperatures $\left(\sim 1100{ }^{\circ} \mathrm{C}\right)$ necessary to achieve a phase pure LSC64 via post-synthesis calcination or topochemical conversion eliminate the possibility of preserving the rod morphology due to the observed loss of structure upon heating. Ultimately, LSC64 could not be synthesized using the investigated methods.

\subsection{Supporting Information}

\section{Estimated solubility of $\mathrm{Sr}^{2+}, \mathrm{Co}^{2+}$, and $\mathrm{La}^{3+}$}

The solubility of $\mathrm{Sr}^{2+}, \mathrm{Co}^{2+}$, and $\mathrm{La}^{3+}$ was approximated based on published data for three solution environments, which are similar to those encountered while preparing for and during hydrothermal synthesis. First, the dissolution of nitrate precursors in distilled water at $25^{\circ} \mathrm{C}$ and 1 bar via the equilibrium:

$\mathrm{M}\left(\mathrm{NO}_{3}\right)_{y} \leftrightarrow \mathrm{M}^{y+}+y \mathrm{NO}_{3}^{-}$

where $\mathrm{M}^{\mathrm{y+}}=\mathrm{Sr}^{2+}, \mathrm{Co}^{2+}, \mathrm{La}^{3+}$. Second, solid crystalline hydroxides are in equilibrium with the solution at $25^{\circ} \mathrm{C}$ and 1 bar after the addition of $\mathrm{KOH}$ via the equilibrium:

$\mathrm{M}(\mathrm{OH})_{y} \leftrightarrow M^{y^{+}}+y \mathrm{OH}^{-}$ 
Third, the cation-containing $\mathrm{KOH}$ solution is heated in a closed vessel to $100{ }^{\circ} \mathrm{C}$ at 1 bar, causing a shift in equilibrium of Eqn. (ii).

The unavailability of published data, especially in the case of $\mathrm{Sr}^{2+}$, at increased pressure and temperature precludes determining exact solubility of the cations during hydrothermal synthesis; however, the third condition serves as a guide to illustrate solubility trends with increased temperature for $\mathrm{Co}^{2+}$ and $\mathrm{La}^{3+}$. In the second and third cases, the solution is assumed to initially contain $100 \mathrm{mmol} \mathrm{KOH}$ in a total volume of 50 $\mathrm{mL}$ of water $(2 \mathrm{M})$ with initial $\mathrm{pH} \sim 14.3$. The equilibrium constants, $\mathrm{K}_{\mathrm{sp}}$, and concentration of cation in solution, $\mathrm{c}_{\mathrm{s}}$, are assembled in Table 10.

The relationship between cation concentration and $\mathrm{K}_{\mathrm{sp}}$ for the equilibrium

$M_{x} A_{y(s)} \leftrightarrow x M_{(a q)}^{y+}+y A_{(a q)}^{x-}$

is given by the equations (solved simultaneously):

$K_{s p}=\left[M^{y+}\right]^{x}\left[A^{x-}\right]^{y}$

$y\left[M^{y+}\right]=x\left[A^{x-}\right]$

Note that the initial presence of $\left.\mathrm{CH}^{-}\right]$in solution due to $\mathrm{KOH}$ is taken into account when applicable in calculating the cation concentration.

All of the nitrate precursors readily dissolve in pure water. In contrast, the hydroxide compounds are significantly less soluble in the alkaline solution. At $25^{\circ} \mathrm{C}$ and 1 bar, $\operatorname{Sr}(\mathrm{OH})_{2}$ is mostly likely to dissolve at room temperature with an equilibrium cation concentration of $1.31 \times 10^{-5} \mathrm{M}$, while the equilibrium concentrations of dissolved $\mathrm{Co}(\mathrm{OH})_{2}$ 
and $\mathrm{La}(\mathrm{OH})_{3}$ are vanishingly small at $3.94 \times 10^{-16} \mathrm{M}$ and $1.16 \times 10^{-22} \mathrm{M}$, respectively. Increasing temperature to $150{ }^{\circ} \mathrm{C}$ at 1 bar lead to an increase in equilibrium cation concentration by 6 orders of magnitude for both $\mathrm{Co}^{2+}$ and $\mathrm{La}^{3+}$, though the new values continue to be vanishingly small. No data are available for $\mathrm{Sr}^{2+}$ at high temperature, but it is reasonable to assume it will behave similarly, leading to a significant increase in cation concentration and an overall solubility greater than $\mathrm{La}^{3+}$ and $\mathrm{Co}^{2+}$. It must also be noted that the calculation of $\left[\mathrm{La}^{2+}\right]$ in the alkaline solution via Eqn. (v) does not account for the formation of other La-containing ions, such as $\mathrm{La}(\mathrm{OH})^{2+}, \mathrm{La}(\mathrm{OH})^{+}$, or $\mathrm{La}(\mathrm{OH})_{4}^{-}$, which may be present in solution [144].

Table 10. Solubility product constant and concentration of cation in solution for $\mathrm{Sr}^{2+}$, $\mathrm{Co}^{2+}$, and $\mathrm{La}^{3+}$ in three different solution environments.

\begin{tabular}{cccc}
\hline & $\mathrm{K}_{\mathrm{sp}}$ & $\begin{array}{c}\text { Cation Concentration } \\
{[\mathrm{mol} / \mathrm{L}]}\end{array}$ & Reference \\
\hline \multicolumn{3}{c}{ Nitrate dissolution (eqn 1) at $25 \mathrm{C}, 1$ bar, pure water } \\
$\mathrm{Sr}^{2+}$ & 37.20 & 2.10 & {$[150]^{*}$} \\
$\mathrm{Co}^{2+}$ & 85.02 & 2.77 & {$[150]^{*}$} \\
$\mathrm{La}^{3+}$ & 314.01 & 1.85 & {$[150]^{*}$} \\
\hline Hydroxide dissolution (eqn 2) at $25 \mathrm{C}, 1$ bar, $2 \mathrm{M} \mathrm{KOH}$ solution \\
$\mathrm{Sr}^{2+}$ & $2.09 \times 10^{-4}$ & $1.31 \times 10^{-5}$ & {$[157]$} \\
$\mathrm{Co}^{2+}$ & $6.31 \times 10^{-15}$ & $3.94 \times 10^{-16}$ & {$[144]$} \\
$\mathrm{La}^{3+}$ & $2.51 \times 10^{-20}$ & $1.16 \times 10^{-22}$ & {$[158]$} \\
\hline
\end{tabular}

Hydroxide dissolution (eqn 2) at $150 \mathrm{C}, 1$ bar, $2 \mathrm{M} \mathrm{KOH}$ solution $\mathrm{Sr}^{2+}$ used to calculate cation concentration. 


\section{Summary and Recommendations for Future Work}

The work presented in this dissertation focused on synthesis and characterization of novel solid oxide fuel cell (SOFC) cathode materials. Accurate determination of the bulk and surface properties of these materials is critical for development of next-generation SOFCs that are tailored for efficient operation at intermediate temperatures. These properties were characterized using pure materials at simulated operating conditions to isolate the processes occurring in the cathode, particularly concerning oxygen incorporation at the surface and transport within the bulk. The synthesis methods used to produce novel cathode materials, as well as their limitations, were also discussed in this dissertation.

Oxygen transport properties were characterized using electrical conductivity relaxation (ECR) in Chapters 2 and 3. This technique was applied to a bulk perovskite material in Chapter 2 to determine the oxygen surface exchange coefficient, $k_{\text {chem }}$, and the bulk oxygen diffusion coefficient, $D_{\text {chem, }}$ of $\mathrm{La}_{0.6} \mathrm{Sr}_{0.4} \mathrm{Co}_{0.2} \mathrm{Fe}_{0.8} \mathrm{O}_{3-\delta}$ (LSCF 6428), a common cathode material. However, the simultaneous determination of $k_{\text {chem }}$ and $D_{\text {chem }}$ yielded unreliable values. Therefore, in Chapter 3, layered perovskite $\mathrm{PrBaCO}_{2} \mathrm{O}_{5+\delta}$ (PBCO) polycrystalline thin films were utilized, so that $D_{c h e m}$ was eliminated and a precise determination of $k_{\text {chem }}$ was accomplished.

Bulk structural properties were obtained for $\mathrm{PBCO}$ and $\mathrm{NdBaCo}_{2} \mathrm{O}_{5+\delta}(\mathrm{NBCO})$ using neutron diffraction at in-situ SOFC conditions in Chapters 4 and 5, respectively. These novel measurements yielded information regarding space groups, lattice parameters, atomic positions within the lattice, and oxygen stoichiometry. The primarily location of oxygen vacancies, as well as the likely oxygen transport route within the crystal were also elucidated. Many of these properties differ significantly with those 
previously reported at lower temperature and higher $\mathrm{pO}_{2}$, which are not reflective of SOFC operating conditions.

Synthesis of the materials studied in this dissertation was achieved using several methods. The bulk materials in Chapters 2 (LSCF 6428) and 5 (PBCO) were produced using a sol-gel combustion technique, resulting in uniform, phase-pure powders. Spray pyrolysis was utilized in Chapter 3 to deposit dense, polycrystalline PBCO thin films onto polycrystalline $\mathrm{SrTiO}_{3}$ substrates. Spray pyrolysis was also used in Chapter 2 to add surface dopants to LSCF 6428 to determine their effect on $k_{\text {chem }}$. Finally, formation of $\mathrm{La}_{0.6} \mathrm{Sr}_{0.4} \mathrm{CoO}_{3}$ (LSC64) nanorods was attempted via direct hydrothermal synthesis, calcination of hydrothermal synthesis products and topochemical conversion of $\mathrm{La}(\mathrm{OH})_{3}$ nanorod templates in Chapter 6. LSC64 nanorods were not formed during hydrothermal synthesis as reported previously, nor were the indirect formation methods successful in producing perovskite nanorods. Ultimately, kinetic and thermodynamic barriers existed to the formation of LSC64 at the synthesis conditions studied.

Recommended future work would involve additional neutron diffraction experiments with PBCO and NBCO. This dissertation has focused on obtaining structural information across a broad $\mathrm{T}-\mathrm{pO}_{2}$ range, which, due to time constraints at the neutron source, necessitates short dwelling times of 2-4 hours at each set of conditions. This is helpful for a broad understanding of the material's behavior at in-situ SOFC conditions; however, time is also a critical factor in determining the performance of a material. SOFCs must operate continuously without decomposing, interacting with adjacent materials to from secondary phases, or otherwise changing their structure or properties. Therefore, it is recommended that PBCO and NBCO be subjected to neutron diffraction at a fixed temperature and $\mathrm{pO}_{2}$ (for example, $800{ }^{\circ} \mathrm{C}$ and $10^{-4}$ atm $\mathrm{O}_{2}$ ) for at least 1-2 days with patterns collected continuously. Changes in structure and 
composition of the material would be monitored in continuously. This measurement would be particularly interesting for $\mathrm{PBCO}$, as a small secondary phase identified as $\mathrm{CoO}$ was found at high temperature and low $\mathrm{pO}_{2}$ (Chapter 5). It is unclear if the formation of this phase is anomalous, or a sign of early decomposition, and in the latter case, it is unclear how far the decomposition would progress. Answering these questions is crucial for understanding the long-term viability of layered perovskite SOFC cathode materials. 


\section{References}

1. Adler, S.B., Factors Governing Oxygen Reduction in Solid Oxide Fuel Cell Cathodes. Chemical Reviews, 2004. 104(10): p. 4791-4844.

2. McIntosh, S. and R.J. Gorte, Direct Hydrocarbon Solid Oxide Fuel Cells. Chemical Reviews, 2004. 104(10): p. 4845-4866.

3. Fleig, J., Solid oxide Fuel Cell Cathodes: Polarization Mechanisms and Modeling of the Electrochemical Performance. Annual Review of Materials Research, 2003. 33(1): p. 361-382.

4. Perovskite oxide for solid oxide fuel cells. Fuel Cells and Hydrogen Energy, ed. T. Ishihara, 2009, New York, NY: Springer. 302.

5. Mizusaki, J., Nonstoichiometry, diffusion, and electrical properties of perovskitetype oxide electrode materials. Solid State Ionics, 1992. 52(1-3): p. 79-91.

6. Solid oxide fuel cells materials properties and performance, ed. J.W. Fergus, 2009, Boca Raton: CRC Press.

7. Kilner, J.A., Optimisation of oxygen ion transport in materials for ceramic membrane devices. Faraday Discussions, 2007. 134: p. 9-15.

8. Kröger, F.A., The Chemistry of Imperfect Crystals. Vol. 1-3. 1974, Amsterdam: North-Holland.

9. Lane, J.A., et al., Oxygen transport in $\mathrm{La}_{0.6} \mathrm{Sr}_{0.4} \mathrm{Co}_{0.2} \mathrm{Fe}_{0.8} \mathrm{O}_{3-\delta}$, Solid State Ionics, 1999. 121(1-4): p. 201-208.

10. Boukamp, B.A., M.W. Otter, and H.J.M. Bouwmeester, Oxygen transport in $\mathrm{La}_{0.6} \mathrm{Sr}_{0.4} \mathrm{Co}_{1-y} \mathrm{Fe}_{y} \mathrm{O}_{3-\delta}$, Journal of Solid State Electrochemistry, 2004. 8(9).

11. Bouwmeester, H.J.M., M.W. Den Otter, and B.A. Boukamp, Oxygen transport in $\mathrm{La}_{0.6} \mathrm{Sr}_{0.4} \mathrm{Co}_{1-y} \mathrm{Fe}_{y} \mathrm{O}_{3-\delta}$, Journal of Solid State Electrochemistry, 2004. 8(9): p. 599605. 
12. Tai, L.W., et al., Structure and electrical properties of $\mathrm{La}_{1-x} \mathrm{Sr}_{x} \mathrm{Co}_{1-y} \mathrm{Fe}_{y} \mathrm{O}_{3}$. Part 2. The system $\mathrm{La}_{1-\mathrm{x}} \mathrm{Sr}_{x} \mathrm{Co}_{0.2} \mathrm{Fe}_{0.8} \mathrm{O}_{3}$. Solid State Ionics, 1995. 76(3-4): p. 273-283.

13. De Souza, R.A., A universal empirical expression for the isotope surface exchange coefficients $\left(k^{*}\right)$ of acceptor-doped perovskite and fluorite oxides. Physical Chemistry Chemical Physics, 2006. 8(7): p. 890-897.

14. Jacobson, A.J., Materials for Solid Oxide Fuel Cells. Chemistry of Materials, 2010. 22(3): p. 660-674.

15. Kim, G., et al., Oxygen exchange kinetics of epitaxial PrBaCo2O $\mathrm{O}_{5+\delta}$ thin films. Applied Physics Letters, 2006. 88(2): p. 024103.

16. Frontera, C., et al., Tailoring Oxygen Content on $\mathrm{PrBaCO}_{2} \mathrm{O}_{5+\delta}$ Layered Cobaltites. Chemistry of Materials, 2005. 17(22): p. 5439-5445.

17. Maignan, A., et al., Structural and Magnetic Studies of Ordered Oxygen-Deficient Perovskites $\mathrm{LnBaCO}_{2} \mathrm{O}_{5+\delta}$, Closely Related to the "112” Structure. J. Solid State Chem., 1999. 142(2): p. 247-260.

18. Frontera, C., et al., Tailoring Oxygen Content on $\mathrm{PrBaCO}_{2} \mathrm{O}_{5+\delta}$ Layered Cobaltites. Chem. Mater., 2005. 17(22): p. 5439-5445.

19. Frontera, C., et al., Structural and magnetic study of $\mathrm{PrBaCO}_{2} \mathrm{O}_{5+\delta}(\delta \sim 0.75)$ cobaltite. Phys. Rev. B, 2004. 70(18).

20. Khalyavin, D., et al., Crystal and magnetic structures of $\mathrm{NdBaCO}_{2} \mathrm{O}_{5+\delta}(\delta \sim 0.75): A$ neutron diffraction study. Phys. Rev. B, 2008. 77(17).

21. Streule, S., et al., High-temperature order-disorder transition and polaronic conductivity in $\mathrm{PrBaCO}_{2} \mathrm{O}_{5.48}$. Phys. Rev. B, 2006. 73(9).

22. Kim, G., et al., Rapid oxygen ion diffusion and surface exchange kinetics in $\mathrm{PrBaCO}_{2} \mathrm{O}_{5+\delta}$ with a perovskite related structure and ordered A cations. J. Mater. Chem., 2007. 17(24): p. 2500. 
23. Tarancón, A., et al., Advances in layered oxide cathodes for intermediate temperature solid oxide fuel cells. J. Mater. Chem., 2010. 20(19): p. 3799.

24. Taskin, A.A., A.N. Lavrov, and Y. Ando, Achieving fast oxygen diffusion in perovskites by cation ordering. Appl. Phys. Lett., 2005. 86(9): p. 091910.

25. Kim, J.H. and A. Manthiram, $\mathrm{LnBaCO}_{2} \mathrm{O}_{5+\delta}$ Oxides as Cathodes for IntermediateTemperature Solid Oxide Fuel Cells. J. Electrochem. Soc., 2008. 155(4): p. B385.

26. Jacobson, A.J., Materials for Solid Oxide Fuel Cells. Chem. Mater., 2010. 22(3): p. 660-674.

27. Kim, G., et al., Oxygen exchange kinetics of epitaxial $\mathrm{PrBaCO}_{2} \mathrm{O}_{5+\delta}$ thin films. Appl. Phys. Lett., 2006. 88(2): p. 024103.

28. Kim, J.H., et al., Structural, thermal and electrochemical properties of layered perovskite $\mathrm{SmBaCO}_{2} \mathrm{O}_{5+\delta}$, a potential cathode material for intermediatetemperature solid oxide fuel cells. J. Power Sources, 2009. 194(2): p. 704-711.

29. Kim, J.H., et al., High Temperature Crystal Chemistry and Oxygen Permeation Properties of the Mixed Ionic-Electronic Conductors $\mathrm{LnBaCO}_{2} \mathrm{O}_{5+\delta} \quad(\mathrm{Ln}=$ Lanthanide). J. Electrochem. Soc., 2009. 156(12): p. B1376.

30. Leonidov, I.A., et al., Thermodynamic and Structural Properties of $\mathrm{PrBaCO}_{2} \mathrm{O}_{5+\delta}$. Inorg. Mater., 2006. 42(2): p. 196-201.

31. Liu, J., et al., Epitaxial Nature and Transport Properties in (LaBa) $\mathrm{Co}_{2} \mathrm{O}_{5+\delta}$ Thin Films. Chem.Mater., 2010. 22(3): p. 799-802.

32. Rautama, E.L., et al., New Member of the "112" Family, $\mathrm{LaBaCO}_{2} \mathrm{O}_{5.5}$ : Synthesis, Structure, and Magnetism. Chem. Mater., 2009. 21(1): p. 102-109.

33. Yoo, S., J.Y. Shin, and G. Kim, Thermodynamic and electrical characteristics of $\mathrm{NdBaCO}_{2} \mathrm{O}_{5+\delta}$ at various oxidation and reduction states. J. Mater. Chem., 2011. 21(2): p. 439. 
34. Yuan, Z., et al., Epitaxial behavior and transport properties of $\mathrm{PrBaCO}_{2} \mathrm{O}_{5}$ thin films on (001) SrTiO3. Appl. Phys. Lett., 2007. 90(21): p. 212111.

35. Zhang, K., et al., Synthesis, characterization and evaluation of cation-ordered

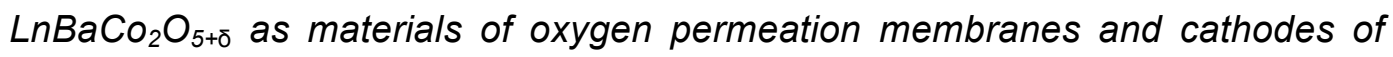
SOFCs. Acta Mater., 2008. 56(17): p. 4876-4889.

36. Bouwmeester, H.J.M. and A.J. Burggraaf, Chapter 10 Dense ceramic membranes for oxygen separation, in Membrane Science and Technology, A.J. Burggraaf and L. Cot, Editors. 1996, Elsevier. p. 435-528.

37. Tarancón, A., et al., Advances in layered oxide cathodes for intermediate temperature solid oxide fuel cells. Journal of Materials Chemistry, 2010. 20(19): p. 3799.

38. Mineshige, A., et al., Introduction of A-site deficiency into $\mathrm{La}_{0.6} \mathrm{Sr}_{0.4} \mathrm{Co}_{0.2} \mathrm{Fe}_{0.8} \mathrm{O}_{3-\delta}$ and its effect on structure and conductivity. Solid State Ionics, 2005. 176(11-12): p. $1145-1149$.

39. Wang, L., et al., Oxygen tracer diffusion in dense $\mathrm{Ba}_{0.5} \mathrm{Sr}_{0.5} \mathrm{Co}_{0.8} \mathrm{Fe}_{0.2} \mathrm{O}_{3-\delta}$ films. Applied Physics Letters, 2009. 94(7): p. 071908.

40. Peña-Martínez, J., et al., Evaluation of $\mathrm{GdBaCo}_{2} \mathrm{O}_{5+\delta}$ as Cathode Material for Doped Lanthanum Gallate Electrolyte IT-SOFCs. Fuel Cells, 2008. 8(5): p. 351359.

41. Zhang, K., et al., Synthesis, characterization and evaluation of cation-ordered

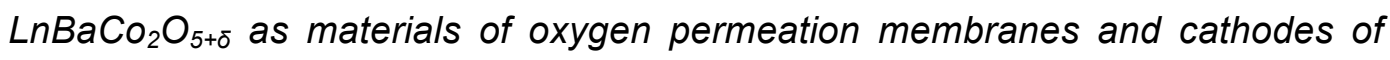
SOFCs. Acta Materialia, 2008. 56(17): p. 4876-4889.

42. Yasuda, I. and T. Hikita, Precise determination of the chemical diffusion coefficient of calcium-doped lanthanum chromites by means of electrical conductivity relaxation. Journal of The Electrochemical Society, 1994. 141(5): p. 1268-1273. 
43. Chen, L., C.L. Chen, and A.J. Jacobson, Electrical conductivity relaxation studies of oxygen transport in epitaxial $\mathrm{YBa}_{2} \mathrm{Cu}_{3} \mathrm{O}_{7-\delta}$ thin films. leee Transactions on Applied Superconductivity, 2003. 13(2): p. 2882-2885.

44. Lane, J.A. and J.A. Kilner, Measuring oxygen diffusion and oxygen surface exchange by conductivity relaxation. Solid State lonics, 2000. 136-137: p. 9971001.

45. Yasuda, I. and M. Hishinuma, Electrical Conductivity and Chemical Diffusion Coefficient of Strontium-Doped Lanthanum Manganites. Journal of Solid State Chemistry, 1996. 123(2): p. 382-390.

46. van der Haar, L.M., et al., Chemical Diffusion and Oxygen Surface Transfer of $\mathrm{La}_{1-\mathrm{x}} \mathrm{Sr}_{\mathrm{x}} \mathrm{CoO}_{3-\delta}$ Studied with Electrical Conductivity Relaxation. Journal of The Electrochemical Society, 2002. 149(3): p. J41-J46.

47. ten Elshof, J.E., M.H.R. Lankhorst, and H.J.M. Bouwmeester, Chemical diffusion and oxygen exchange of $\mathrm{La}_{0.6} \mathrm{Sr}_{0.4} \mathrm{Co}_{0.6} \mathrm{Fe}_{0.4} \mathrm{O}_{3-\delta}$. Solid State Ionics, 1997. 99(12): p. $15-22$.

48. Yoo, J., et al., Oxygen transport kinetics in $\mathrm{SrFeO}_{3-\delta}, \mathrm{La}_{0.5} \mathrm{Sr}_{0.5} \mathrm{FeO}_{3-\delta}$, and $\mathrm{La}_{0.2} \mathrm{Sr}_{0.8} \mathrm{Cr}_{0.2} \mathrm{Fe}_{0.8} \mathrm{O}_{3-\delta}$ measured by electrical conductivity relaxation. Journal of The Electrochemical Society, 2005. 152(3): p. A497-A505.

49. Søgaard, M., et al., Oxygen nonstoichiometry and transport properties of strontium substituted lanthanum cobaltite. Solid State Ionics, 2006. 177(37-38): p. 3285-3296.

50. Preis, W., E. Bucher, and W. Sitte, Oxygen exchange kinetics of $\mathrm{La}_{0.4} \mathrm{Sr}_{0.6} \mathrm{FeO}_{3-\delta}$ by simultaneous application of conductivity relaxation and carrier gas coulometry. Solid State Ionics, 2004. 175(1-4): p. 393-397.

51. Steele, B.C.H., Oxygen ion conductors and their technological applications. Materials Science and Engineering, 1992. B13: p. 79-87. 
52. den Otter, M.W., et al., Reactor Flush Time Correction in Relaxation Experiments. Journal of The Electrochemical Society, 2001. 148(2): p. J1-J6.

53. den Otter, M.W., L.M. van der Haar, and H.J.M. Bouwmeester, Numerical evaluation of eigenvalues of the sheet diffusion problem in the surface/diffusion mixed regime. Solid State lonics, 2000. 134(3-4): p. 259-264.

54. Crank, J., The Mathematics of Diffusion, 2nd ed. 2nd ed. ed 1975, New York: Oxford Univ. Press.

55. Kim, G., et al., Measurement of oxygen transport kinetics in epitaxial $\mathrm{La}_{2} \mathrm{NiO}_{4+\delta}$ thin films by electrical conductivity relaxation. Solid State lonics, 2006. 177(1718): p. $1461-1467$.

56. Bacon, G.E., Neutron diffraction. 2d. ed., 1962, Oxford: Clarendon Press.

57. Massa, W., Crystal Structure Determination. 2nd ed 2002, Berlin, Germany: Springer.

58. Bae, J.-M. and B.C.H. Steele, Properties of $\mathrm{La}_{0.6} \mathrm{Sr}_{0.4} \mathrm{Co}_{0.2} \mathrm{Fe}_{0.8} \mathrm{O}_{3-\delta}(L S C F)$ double layer cathodes on gadolinium-doped cerium oxide (CGO) electrolytes: I. Role of SiO2. Solid State Ionics, 1998. 106(3-4): p. 247-253.

59. Liu, J., et al., Oxygen reduction at sol-gel derived $\mathrm{La}_{0.8} \mathrm{Sr}_{0.2} \mathrm{Co}_{0.8} \mathrm{Fe}_{0.2} \mathrm{O}_{3}$ cathodes. Solid State Ionics, 2006. 177(3-4): p. 377-387.

60. Skinner, S.J., Recent advances in Perovskite-type materials for solid oxide fuel cell cathodes. International Journal of Inorganic Materials, 2001. 3(2): p. 113121.

61. la O, G.J., R.F. Savinell, and Y. Shao-Horn, Activity Enhancement of Dense Strontium-Doped Lanthanum Manganite Thin Films under Cathodic Polarization: A Combined AES and XPS Study. Journal of The Electrochemical Society, 2009. 156(6): p. B771-B781. 
62. Vance, A.A. and S. Mclntosh, Performance and Activation Behavior of SurfaceDoped Thin-Film $\mathrm{La}_{0.8} \mathrm{Sr}_{0.2} \mathrm{MnO}_{3-\delta}$ Cathodes. Journal of The Electrochemical Society, 2008. 155(1): p. B1-B7.

63. Haider, M.A. and S. Mclntosh, Evidence for Two Activation Mechanisms in LSM SOFC Cathodes. Journal of The Electrochemical Society, 2009. 156(12): p. B1369-B1375.

64. Baumann, F.S., et al., Strong Performance Improvement of $\mathrm{La}_{0.6} \mathrm{Sr}_{0.4} \mathrm{Co}_{0.8} \mathrm{Fe}_{0.2} \mathrm{O}_{3-}$ ¿ SOFC Cathodes by Electrochemical Activation. Journal of The Electrochemical Society, 2005. 152(10): p. A2074-A2079.

65. Sholklapper, T.Z., et al., Synthesis of Dispersed and Contiguous Nanoparticles in Solid Oxide Fuel Cell Electrodes. Fuel Cells, 2008. 8(5): p. 303-312.

66. Sholklapper, T.Z., et al., Nanostructured Solid Oxide Fuel Cell Electrodes. Nano Letters, 2007. 7(7): p. 2136-2141.

67. van Doorn, R.H.E., et al., Preparation of $\mathrm{La}_{0.3} \mathrm{Sr}_{0.7} \mathrm{CoO}_{3-\delta}$ perovskite by thermal decomposition of metal-EDTA complexes. Journal of Materials Chemistry, 1998. 8(9): p. 2109-2112.

68. Vogel, A.I., Textbook of Quantitative Inorganic Analysis 1986, Harlow, UK: Longman Scientific \& Technical.

69. Haider, M.A., et al., Reverse micelle synthesis of perovskite oxide nanoparticles. Solid State Ionics, 2011. 196(1): p. 65-72.

70. Merkle, R. and J. Maier, How Is Oxygen Incorporated into Oxides? A Comprehensive Kinetic Study of a Simple Solid-State Reaction with $\mathrm{SrTiO}_{3}$ as a Model Material. Angewandte Chemie International Edition, 2008. 47(21): p. 38743894.

71. Hansen, K.V., K. Norrman, and M. Mogensen, TOF-SIMS studies of yttriastabilised zirconia. Surface and Interface Analysis, 2006. 38(5): p. 911-916. 
72. Yuasa, M., et al., Reverse Micelle-Based Preparation of Carbon-Supported La ${ }_{x} \mathrm{Sr}_{x} \mathrm{Mn}_{1-y} \mathrm{Fe}_{y} \mathrm{O}_{3+\delta}$ for Oxygen Reduction Electrode. Journal of The Electrochemical Society, 2004. 151(10): p. A1690-A1695.

73. Pang, G., et al., Preparation of $\mathrm{La}_{1-x} \mathrm{Sr}_{x} \mathrm{MnO}_{3}$ nanoparticles by sonication-assisted coprecipitation. Materials Research Bulletin, 2003. 38(1): p. 11-16.

74. Beckel, D., et al., Solid-state dewetting of $\mathrm{La}_{0.6} \mathrm{Sr}_{0.4} \mathrm{Co}_{0.2} \mathrm{Fe}_{0.8} \mathrm{O}_{3-\delta}$ thin films during annealing. Journal of the European Ceramic Society, 2008. 28(1): p. 49-60.

75. Bhatt, H.D., et al., $\mathrm{La}_{(1-x)} \mathrm{Sr}_{x} \mathrm{CoO}_{3}$ for thin film thermocouple applications. Thin Solid Films, 1999. 350(1-2): p. 249-257.

76. Lee, J.-W., et al., Preparation of dense and uniform $\mathrm{La}_{0.6} \mathrm{Sr}_{0.4} \mathrm{Co}_{0.2} \mathrm{Fe}_{0.8} \mathrm{O}_{3-\delta}$ (LSCF) films for fundamental studies of SOFC cathodes. Journal of Power Sources, 2009. 190(2): p. 307-310.

77. Burley, J.C., et al., Structural and Magnetic Chemistry of $\mathrm{NdBaCO}_{2} \mathrm{O}_{5+\delta}$. J. Solid State Chem., 2003. 170(2): p. 339-350.

78. Akahoshi, D. and Y. Ueda, Oxygen Nonstoichiometry, Structures, and Physical Properties of $\mathrm{YBaCO}_{2} \mathrm{O}_{5+x}(0.00 \leq x \leq 0.52)$. J. Solid State Chem., 2001. 156(2): p. 355-363.

79. Fauth, F., E. Suard, and V. Caignaert, Intermediate spin state of $\mathrm{Co}^{3+}$ and $\mathrm{Co}^{4+}$ ions in $\mathrm{La}_{0.5} \mathrm{Ba}_{0.5} \mathrm{CoO}_{3}$ evidenced by Jahn-Teller distortions. Phys. Rev. B, 2001. 65(6).

80. Garcia-Munoz, J.L., et al., Magnetic and electronic properties of the oxygendeficient $\mathrm{PrBaCO}_{2} \mathrm{O}_{5+\delta}(\delta>0.50)$. J. Magn. Magn. Mater., 2004. 272-276: p. 17621763. 
81. Conder, K., et al., Oxygen isotope effect on metal-insulator transition in layered cobaltites $\mathrm{RBaCO}_{2} \mathrm{O}_{5.5}(\mathrm{R}=\mathrm{Pr}, \mathrm{Dy}, \mathrm{Ho}$ and Y). J. Phys.: Condens. Matter, 2005. 17(37): p. 5813-5820.

82. Cox-Galhotra, R.A. and S. McIntosh, Unreliability of simultaneously determining kchem and Dchem via conductivity relaxation for surface-modified $\mathrm{La}_{0.6} \mathrm{Sr}_{0.4} \mathrm{Co}_{0.2} \mathrm{Fe}_{0.8} \mathrm{O}_{3-\delta}$. Solid State Ionics, 2010. 181(31-32): p. 1429-1436.

83. Beckel, D., et al., Spray pyrolysis of $\mathrm{La}_{0.6} \mathrm{Sr}_{0.4} \mathrm{Co}_{0.2} \mathrm{Fe}_{0.8} \mathrm{O}_{3-\delta}$ thin film cathodes. Journal of Electroceramics, 2006. 16(3): p. 221-228.

84. Pederson, L., P. Singh, and X. Zhou, Application of vacuum deposition methods to solid oxide fuel cells. Vacuum, 2006. 80(10): p. 1066-1083.

85. Burriel, M.n., et al., Enhanced High-Temperature Electronic Transport Properties in Nanostructured Epitaxial Thin Films of the $\mathrm{La}_{n+1} \mathrm{Ni}_{n} \mathrm{O}_{3 n+1}$ Ruddlesden-Popper Series $(n=1,2,3, \ldots)$. Chemistry of Materials, $2007.19(16)$ : p. 4056-4062.

86. Beckel, D., et al., Electrochemical performance of LSCF based thin film cathodes prepared by spray pyrolysis. Solid State Ionics, 2007. 178(5-6): p. 407-415.

87. Muecke, U.P., et al., Initial stages of deposition and film formation during spray pyrolysis -- Nickel oxide, cerium gadolinium oxide and mixtures thereof. Thin Solid Films, 2009. 517(5): p. 1522-1529.

88. Muecke, U.P., G.L. Messing, and L.J. Gauckler, The Leidenfrost effect during spray pyrolysis of nickel oxide-gadolinia doped ceria composite thin films. Thin Solid Films, 2009. 517(5): p. 1515-1521.

89. Rupp, J.L.M., et al., Crystallization and Grain Growth Kinetics for PrecipitationBased Ceramics: A Case Study on Amorphous Ceria Thin Films from Spray Pyrolysis. Advanced Functional Materials, 2009. 19(17): p. 2790-2799.

90. Beckel, D., et al., Electrochemical performance of LSCF based thin film cathodes prepared by spray pyrolysis. Solid State lonics, 2007. 178(5-6): p. 407-415. 
91. Yuan, Z., et al., Epitaxial behavior and transport properties of $\mathrm{PrBaCO}_{2} \mathrm{O}_{5}$ thin films on (001) $\mathrm{SrTiO}_{3}$. Applied Physics Letters, 2007. 90(21): p. 212111.

92. Liu, J., et al., Epitaxial Nature and Transport Properties in (LaBa) $\mathrm{Co}_{2} \mathrm{O}_{5+\delta}$ Thin Films. Chemistry of Materials, 2010. 22(3): p. 799-802.

93. Obryan, H.M., et al., THERMAL-ANALYSIS OF RARE-EARTH GALLATES AND ALUMINATES. Journal of Materials Research, 1990. 5(1): p. 183-189.

94. Kim, G., et al., Rapid oxygen ion diffusion and surface exchange kinetics in $\mathrm{PrBaCO}_{2} \mathrm{O}_{5+x}$ with a perovskite related structure and ordered A cations. Journal of Materials Chemistry, 2007. 17(24): p. 2500.

95. Haider, M.A. and S. Mclntosh, The Influence of Grain Size on $\mathrm{La}_{0.6} \mathrm{Sr}_{0.4} \mathrm{Co}_{0.2} \mathrm{Fe}_{0.8} \mathrm{O}_{3-\delta}$ Thin Film Electrode Impedance. Journal of The Electrochemical Society, 2011. 158(9): p. B1128-B1136.

96. Siwach, P.K., et al., Anomalous ferromagnetism in spray pyrolysis deposited multiferroic $\mathrm{BiFeO}_{3}$ films. Applied Physics Letters, 2007. 91(12): p. 122503-3.

97. Bouwmeester, H.J.M., M.W. Otter, and B.A. Boukamp, Oxygen transport in $\mathrm{La}_{0.6} \mathrm{Sr}_{0.4} \mathrm{Co}_{1-y} \mathrm{Fe}_{y} \mathrm{O}_{3-\delta}$. Journal of Solid State Electrochemistry, 2004. 8(9).

98. Søgaard, M., et al., Oxygen incorporation in porous thin films of strontium doped lanthanum ferrite. Journal of Electroceramics, 2011. 27(3): p. 134-142.

99. Skinner, S.J., Recent advances in Perovskite-type materials for solid oxide fuel cell cathodes. Int. J. Inorg. Mater., 2001. 3(2): p. 113-121.

100. Sunarso, J., et al., Mixed ionic-electronic conducting (MIEC) ceramic-based membranes for oxygen separation. J. Membr. Sci., 2008. 320(1-2): p. 13-41.

101. Adler, S.B., Factors Governing Oxygen Reduction in Solid Oxide Fuel Cell Cathodes. Chem. Rev., 2004. 104(10): p. 4791-4844.

102. Garcia-Munoz, J.L., et al., Study of the oxygen-deficient double perovskite $\mathrm{PrBaCO}_{2} \mathrm{O}_{5.75}$. Physica B, 2004. 350(1-3): p. E277-E279. 
103. Streule, S., et al., Oxygen order-disorder phase transition in $\mathrm{PrBaCO}_{2} \mathrm{O}_{5.48}$ at high temperature. Physica B, 2006. 378-380: p. 539-540.

104. Mitchell, J.F., J. Burley, and S. Short, Crystal and magnetic structure of $\mathrm{NdBaCO}{ }_{2} \mathrm{O}_{5+\delta}:$ Spin states in a perovskite-derived, mixed-valent cobaltite. Journal of Applied Physics, 2003. 93(10): p. 7364.

105. Lobanovsky, L.S., et al., Structure and Physical Properties of Layered Double Perovskite $\mathrm{NdBaCo}_{2} \mathrm{O}_{5.50+\delta}(\delta \approx 0.25)$. J. Exp. Theor. Phys., 2006. 103(5): p. 740746.

106. Azad, A.K., J.H. Kim, and J.T.S. Irvine, Structure-property relationship in layered perovskite cathode $\mathrm{LnBa}_{0.5} \mathrm{Sr}_{0.5} \mathrm{Co}_{2} \mathrm{O}_{5+\delta}(\mathrm{Ln}=\mathrm{Pr}, \mathrm{Nd})$ for solid oxide fuel cells. J. Power Sources, 2011. 196(17): p. 7333-7337.

107. Rietveld, H.M., A Profile Refinement Method for Nuclear and Magnetic Structures. J. Appl. Cryst., 1969. 2: p. 65-71.

108. Larson, A.C. and R.B. von Dreele, General Structure Analysis System (GSAS), in LAUR2004, Los Alamos National Laboratory: Los Alamos, New Mexico.

109. Mclntosh, S., et al., Oxygen Stoichiometry and Chemical Expansion of $\mathrm{Ba}_{0.5} \mathrm{Sr}_{0.5} \mathrm{Co}_{0.8} \mathrm{Fe}_{0.2} \mathrm{O}_{3-\delta}$ Measured by in Situ Neutron Diffraction. Chem. Mater., 2006. 18: p. 2178-2193.

110. van Doorn, R.H.E., et al., Preparation of $\mathrm{La}_{0.3} \mathrm{Sr}_{0.7} \mathrm{CoO}_{3-\delta}$ perovskite by thermal decomposition of metal-EDTA complexes. Journal of Mater. Chem., 1998. 8(9): p. $2109-2112$.

111. Vogel, A.I., Textbook of Quantitative Inorganic Analysis1986, Harlow, UK: Longman Scientific \& Technical.

112. Yoo, S., J.Y. Shin, and G. Kim, Thermodynamic and Electrical Properties of Layered Perovskite $\mathrm{NdBaCO}_{2-x} \mathrm{Fe}_{x} \mathrm{O}_{5+\delta}-\mathrm{YSZ}(x=0,1)$ Composites for 
Intermediate Temperature SOFC Cathodes. J. Electrochem. Soc., 2011. 158(6): p. B632.

113. Maric, R., et al., Solid Oxide Fuel Cells with Doped Lanthanum Gallate Electrolyte and $\mathrm{LaSrCoO}_{3}$ Cathode, and Ni-Samaria-Doped Ceria Cermet Anode. Journal of The Electrochemical Society, 1999. 146(6): p. 2006-2010.

114. Peters, C., A. Weber, and E. Ivers-Tiffee, Nanoscaled $\left(\mathrm{La}_{0.5} \mathrm{Sr}_{0.5}\right) \mathrm{CoO}_{3-\delta}$ thin film cathodes for SOFC application at 500 degrees $C<T<700$ degrees $C$. Journal of The Electrochemical Society, 2008. 155(7): p. B730-B737.

115. Yashima, M. and T. Tsuji, Structural investigation of the cubic perovskite-type doped lanthanum cobaltite $\mathrm{La}_{0.6} \mathrm{Sr}_{0.4} \mathrm{CoO}_{3-\delta}$ at $1531 \mathrm{~K}$ : possible diffusion path of oxygen ions in an electrode material. Journal of Applied Crystallography, 2007. 40(6): p. 1166-1168.

116. Rørvik, P.M., et al., Influence of Volatile Chlorides on the Molten Salt Synthesis of Ternary Oxide Nanorods and Nanoparticles. Inorganic Chemistry, 2008. 47(8): p. 3173-3181.

117. Sardar, K., et al., Direct Hydrothermal Synthesis and Physical Properties of RareEarth and Yttrium Orthochromite Perovskites. Chemistry of Materials, 2010. 23(1): p. 48-56.

118. Spooren, J., R.I. Walton, and F. Millange, A study of the manganites $\mathrm{La}_{0.5} \mathrm{M}_{0.5} \mathrm{MnO}_{3}(\mathrm{M}=\mathrm{Ca}, \mathrm{Sr}, \mathrm{Ba})$ prepared by hydrothermal synthesis. Journal of Materials Chemistry, 2005. 15(15): p. 1542-1551.

119. Stampler, E.S., et al., Hydrothermal synthesis of $\mathrm{LnMnO}_{3}(\mathrm{Ln}=\mathrm{Ho}-\mathrm{Lu}$ and $\mathrm{Y})$ : exploiting amphoterism in late rare-earth oxides. Journal of Materials Chemistry, 2009. 19(25): p. 4375.

120. Teng, F., Hydrothermal synthesis and their catalytic properties of manganite nanowires. Solid State Sciences, 2009. 11(9): p. 1643-1648. 
121. Urban, J.J., et al., Synthesis of Single-Crystalline $\mathrm{La}_{1-x} \mathrm{Ba}_{x} \mathrm{MnO}_{3}$ Nanocubes with Adjustable Doping Levels. Nano Letters, 2004. 4(8): p. 1547-1550.

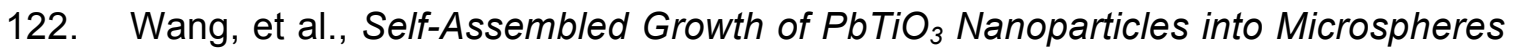
and Bur-like Structures. Chemistry of Materials, 2007. 19(9): p. 2213-2221.

123. Wang, G., et al., Hydrothermal synthesis and characterization of $\mathrm{KNbO}_{3}$ nanorods. CrystEngComm, 2009. 11(9): p. 1958.

124. Zhang, L., et al., Hydrothermal synthesis and catalytic performance of singlecrystalline $\mathrm{La}_{2-\mathrm{x}} \mathrm{Sr}_{x} \mathrm{CuO}_{4}$ for methane oxidation. Catalysis Today, 2010. 153(3-4): p. $143-149$.

125. Zhao, D., et al., Study on supercritical hydrothermal synthesis of $\mathrm{CoFe}_{2} \mathrm{O}_{4}$ nanoparticles. The Journal of Supercritical Fluids, 2007. 42(2): p. 226-233.

126. Chen, Y., et al., Crystal growth and magnetic property of orthorhombic $\mathrm{RMnO}_{3}$ $(R=S m-H o)$ perovskites by mild hydrothermal synthesis. Journal of Crystal Growth, 2007. 305(1): p. 242-248.

127. Lester, E., et al., Controlled continuous hydrothermal synthesis of cobalt oxide $\left(\mathrm{CO}_{3} \mathrm{O}_{4}\right)$ nanoparticles. Progress in Crystal Growth and Characterization of Materials, 2012. 58(1): p. 3-13.

128. Modeshia, D.R. and R.I. Walton, Solvothermal synthesis of perovskites and pyrochlores: crystallisation of functional oxides under mild conditions. Chemical Society Reviews, 2010. 39(11): p. 4303-4325.

129. Rørvik, P.M., et al., $\mathrm{PbTiO}_{3}$ nanorod arrays grown by self-assembly of nanocrystals. Nanotechnology, 2008. 19(22): p. 225605.

130. Rørvik, P.M., T. Grande, and M.-A. Einarsrud, Hierarchical $\mathrm{PbTiO}_{3}$ Nanostructures Grown on $\mathrm{SrTiO}_{3}$ Substrates. Crystal Growth \& Design, 2009. 9(4): p. 1979-1984. 
131. Rørvik, P.M., T. Grande, and M.-A. Einarsrud, One-Dimensional Nanostructures of Ferroelectric Perovskites. Advanced Materials, 2011. 23(35): p. 4007-4034.

132. Peng, Z.A. and X. Peng, Mechanisms of the Shape Evolution of CdSe Nanocrystals. Journal of the American Chemical Society, 2001. 123(7): p. 13891395.

133. Wang, X. and Y. Li, Synthesis and Characterization of Lanthanide Hydroxide Single-Crystal Nanowires. Angewandte Chemie International Edition, 2002. 41(24): p. 4790-4793.

134. Zhang, N., et al., Lanthanide hydroxide nanorods and their thermal decomposition to lanthanide oxide nanorods. Materials Chemistry and Physics, 2009. 114(1): p. 160-167.

135. Wang, Y. and H.J. Fan, Improved Thermoelectric Properties of $\mathrm{La}_{1-\mathrm{x}} \mathrm{Sr}_{\mathrm{x}} \mathrm{CoO}_{3}$ Nanowires. The Journal of Physical Chemistry C, 2010. 114(32): p. 1394713953.

136. Deng, J.G., et al., Single-crystalline $\mathrm{La}_{0.6} \mathrm{Sr}_{0.4} \mathrm{CoO}_{3-\delta}$ nanowires/nanorods derived hydrothermally without the use of a template: Catalysts highly active for toluene complete oxidation. Catalysis Letters, 2008. 123(3-4): p. 294-300.

137. Kang, S.O., B.H. Park, and Y.I. Kim, Growth mechanism of shape-controlled barium titanate nanostructures through soft chemical reaction. Crystal Growth \& Design, 2008. 8(9): p. 3180-3186.

138. Li, L., et al., Topochemical Synthesis of Micron-Platelet $\left(\mathrm{Na}_{0.5} \mathrm{~K}_{0.5}\right) \mathrm{NbO}_{3}$ Particles. European Journal of Inorganic Chemistry, 2008. 2008(13): p. 2186-2190.

139. Li, L., et al., Wire Structure and Morphology Transformation of Niobium Oxide and Niobates by Molten Salt Synthesis. Chemistry of Materials, 2009. 21(7): p. 1207-1213. 
140. Madaro, F., et al., Synthesis of anisometric $\mathrm{KNbO}_{3}$ and $\mathrm{K}_{0.5} \mathrm{Na}_{0.5} \mathrm{NbO}_{3}$ single crystals by chemical conversion of non-perovskite templates. CrystEngComm, 2011.

141. Saito, Y. and $\mathrm{H}$. Takao, Synthesis of polycrystalline platelike $\mathrm{KNbO}_{3}$ particles by the topochemical micro-crystal conversion method and fabrication of grainoriented $\left(\mathrm{K}_{0.5} \mathrm{Na}_{0.5}\right) \mathrm{NbO}_{3}$ ceramics. Journal of the European Ceramic Society, 2007. 27(13-15): p. 4085-4092.

142. Abramoff, M.D., P.J. Magelhaes, and S.J. Ram, Image Processing with ImageJ. Biophotonics International, 2004. 11(7): p. 36-42.

143. Ozawa, M., R. Onoe, and H. Kato, Formation and decomposition of some rare earth (RE=La, Ce, Pr) hydroxides and oxides by homogeneous precipitation. Journal of Alloys and Compounds, 2006. 408-412: p. 556-559.

144. Baes, C.F., The hydrolysis of cations, ed. R.E. Mesmer1976, New York :: Wiley.

145. Cherepanov, V., et al., Phase equilibria in the La-Me-Co-O (Me=Ca, Sr, Ba) systems. lonics, 1998. 4(3): p. 309-315.

146. Reksten, A., Hydrothermal Synthesis of $\mathrm{LaFeO}_{3}$, in Materials Science and Engineering, 2011, Norwegian University of Science and Technology (NTNU): Trondheim, Norway.

147. Balej, J., Determination of the oxygen and hydrogen overvoltage in concentrated alkali hydroxide solutions. International Journal of Hydrogen Energy, 1985. 10(6): p. 365-374.

148. Merli, L., B. Lambert, and J. Fuger, Thermochemistry of lanthanum, neodymium, samarium and americium trihydroxides and their relation to the corresponding hydroxycarbonates. Journal of Nuclear Materials, 1997. 247: p. 172-176.

149. Chirico, R.D. and E.F. Westrum Jr, Thermophysics of the lanthanide hydroxides I. Heat capacities of $\mathrm{La}(\mathrm{OH})_{3}, \mathrm{Gd}(\mathrm{OH})_{3}$, and $\mathrm{Eu}(\mathrm{OH})_{3}$ from near 5 to $350 \mathrm{~K}$. 
Lattice and Schottky contributions. The Journal of Chemical Thermodynamics, 1980. 12(1): p. 71-85.

150. Nakatsuka, A., et al., Cubic phase of single-crystal $\mathrm{LaAlO}_{3}$ perovskite synthesized at $4.5 \mathrm{GPa}$ and $1273 \mathrm{~K}$. Acta Crystallographica Section E Structure Reports Online, 2005. 61(8): p. i148-i150.

151. Cheng, J., et al., Enthalpies of Formation of $\mathrm{LaMO}_{3}$ Perovskites ( $\mathrm{M}=\mathrm{Cr}, \mathrm{Fe}, \mathrm{Co}$, and Ni). Journal of Materials Research, 2011. 20(01): p. 191-200.

152. Stølen, S., et al., Heat Capacity and thermodynamic properties of $\mathrm{LaFeO}_{3}$ and $\mathrm{LaCoO}_{3}$ from $T=13 \mathrm{~K}$ to $T=1000 \mathrm{~K}$. Journal of Chemical Thermodynamics, 1998. 30: p. 365-377.

153. Stern, K.H., High Temperature Properties and Decomposition of Inorganic Salts Part 3, Nitrates and Nitrites. Journal of Physical and Chemical Reference Data, 1972. 1(3): p. 747-772.

154. Mastin, J., M.-A. Einarsrud, and T. Grande, Structural and Thermal Properties of $\mathrm{La}_{1-\mathrm{x}} \mathrm{Sr}_{x} \mathrm{CoO}_{3-\delta}$. Chemistry of Materials, 2006. 18(25): p. 6047-6053.

155. Lein, H.L., K. Wiik, and T. Grande, Thermal and chemical expansion of mixed conducting $\mathrm{La}_{0.5} \mathrm{Sr}_{0.5} \mathrm{Fe}_{1-x} \mathrm{Co}_{x} \mathrm{O}_{3-\delta}$ materials. Solid State Ionics, 2006. 177(19,Äì25): p. 1795-1798.

156. Fleming, P., et al., The Rapid Formation of $\mathrm{La}(\mathrm{OH})_{3}$ from $\mathrm{La}_{2} \mathrm{O}_{3}$ Powders on Exposureto Water Vapor. Journal of the American Ceramic Society, 2010. 93(4): p. $1187-1194$.

157. Felmy, A.R., et al., The hydrolysis and carbonate complexation of strontium and calcium in aqueous solution. Use of molecular modeling calculations in the development of aqueous thermodynamic models. Journal of Chemical Thermodynamics, 1998. 30(9): p. 1103-1120. 
158. Deberdt, S., et al., Experimental study of $\mathrm{La}(\mathrm{OH})_{3}$ and $\mathrm{Gd}(\mathrm{OH})_{3}$ solubilities (25 to 150 degrees $\mathrm{C}$ ), and La-acetate complexing (25 to 80 degrees C). Chemical Geology, 1998. 151(1-4): p. 349-372.

159. Ziemniak, S.E., M.A. Goyette, and K.E.S. Combs, Cobalt(II) Oxide Solubility and Phase Stability in Alkaline Media at Elevated Temperatures. Journal of Solution Chemistry, 1999. 28(7): p. 809-836. 